KLÉBER DE OLIVEIRA ANDRADE

\title{
Sistema Neural Reativo para o Estacionamento Paralelo com uma Única manobra em Veículos de Passeio
}

Dissertação apresentada à Escola de Engenharia de São Carlos da Universidade de São Paulo, para obtenção do título de Mestre em Engenharia Mecânica.

Área de Concentração: Dinâmica de Sistemas e Controles Orientador: Prof. Dr. Marcelo Becker 
AUTORIZO A REPRODUÇÃO E DIVULGAÇÃO TOTAL OU PARCIAL DESTE TRABALHO, POR QUALQUER MEIO CONVENCIONAL OU ELETRÔNICO, PARA FINS DE ESTUDO E PESQUISA, DESDE QUE CITADA A FONTE.

Ficha catalográfica preparada pela Seção de Tratamento da Informação do Serviço de Biblioteca - EESC/USP

\footnotetext{
Andrade, Kléber de Oliveira

Sistema neural reativo para o estacionamento paralelo com uma única manobra em veículos de passeio. / Kléber de Oliveira Andrade; orientador Marcelo Becker. São Carlos, 2011 .

Dissertação (Mestrado - Programa de Pós-Graduação em Engenharia Mecânica e Área de Concentração em Dinâmica de Sistemas e Controles)-- Escola de Engenharia de São Carlos da Universidade de São Paulo, 2011.

1. Robôs móveis inteligentes. 2. Veículos autônomos. 3. Redes neurais artificias. 4. Perceptron multi-camadas. 5. Aprendizado supervisionado. 6. Estacionamento paralelo. I. Título.
} 
FOLHA DE JULGAMENTO

Candidato: Bacharel KLÉBER DE OLIVEIRA ANDRADE

Título da dissertação: Sistema neural reativo para o estacionamento paralelo com uma única manobra em veículos de passeio.

Data da defesa: 29/08/2011:

Comissão Julgadora:

\section{Resultado:}

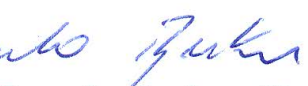

Prof. Associado Marcelo Becker (Orientador)

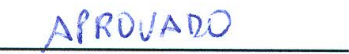

(Escola de Engenharia de São Carlos/EESC)

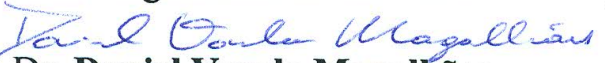

Prof. Dr. Daniel Varela Magalhães

(Escola de Engenharia de São Carlos/EESC)

Prof. Dr. Denis Hernando Wolf

(Instituto de Ciências Matemáticas e de Computação/ICMC/USP)

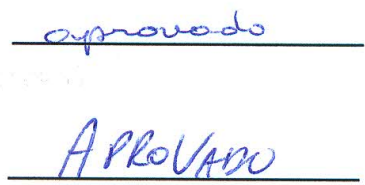

Coordenador do Programa de Pós-Graduação em Engenharia Mecânica:

Prof. Associado Marcelo Areias Trindade

Presidente da Comissão de Pós-Graduação:

Prof. Associado Paulo Cesar Lima Segantine 

Dedico este trabalho à minha família, por tornar possível mais esta fundamental conquista e à minha namorada Claudia, pela compreensão e paciência. 

Inicialmente gostaria de agradecer ao Instituto Nacional de Ciência e Tecnologia em Óptica e Fotônica (INCT-INOF) parceiro do projeto SENA pela concessão da bolsa CAPES (Coordenação de Aperfeiçoamento de Pessoal de Nível Superior), na qual, sem ela eu não conseguiria focar em meus estudos.

A presente dissertação resultou de uma vontade muito forte de concretizar o objetivo a que me foi proposto. Muitas foram as dificuldades com que me deparei e os obstáculos que tive que ultrapassar, mas tudo isso tornou ainda mais gratificante a conclusão desta tarefa. No entanto, não posso esquecer daqueles que de uma forma ou de outra contribuíram para esta realização.

No início do mestrado fui apresentado ao orientador Prof. Doutor Marcelo Becker, que durante dois anos e meio pude contar com a orientação, seu vasto conhecimento e conselhos que me ajudaram a chegar ao fim deste trabalho. Meu muito obrigado pela sua amizade e ensinamentos.

Muitos foram os docentes e os colegas que me motivaram e incentivaram. Por isso não vou os referir, pois correria o risco de esquecer algum. De todos eu guardo uma boa recordação.

Há, no entanto, alguns nomes que não posso deixar de lembrar, pela boa impressão que me deixaram e pelos ensinamentos transmitidos. São eles o Prof. Dr. Adriano Almeida Gonçalves Siqueira, o Prof. Dr. Glauco Augusto de Paula Caurin, Prof. Dr. Daniel Varela Magalhães, Prof. Dr. Fernando Santos Osório, Prof. Dr. Denis Fernando Wolf, Prof. Dr. Luís Henrique Sacchi, Prof. Dr. Luiz Camolesi Jr. e Prof. Dr. José Martins Jr. tendo todos enriquecendo-me um pouco com os seus conhecimentos.

A realização da presente dissertação não seria, no entanto, possível sem a ajuda e o apoio de algumas pessoas. Aos amigos da Pós-Graduação, que contribuíram de todas as maneiras para a realização desta pesquisa: André Carmona Hernandes, Jorge Pablo Moraga Galdames, Kelen Cristiane Teixeira Vivaldini, Poliane Torres Megda e Rafael Coronel Bueno Sampaio. Não posso deixar de lembrar também os amigos da República Pira Sushi que convivi: Edson Takashi Matsubara, Fernando Ruiz Rosário, Mauro Miazaki, Luis Fassis e Sidney Seiji Sato. A amizade, apoio e convivência dessas pessoas foram essenciais em minha formação.

Para aqueles que mais de perto acompanharam esta jornada. À minha família, pela simples existência em minha vida. Nenhuma palavra é capaz de expressar toda minha gratidão à minha mãe e aos meus irmãos, que estiveram sempre me apoiando. Agradeço especialmente à minha namorada Claudia Trevisan, pelo suporte, paciência, companhia e compreensão transmitida durante esta tarefa. Foram eles, sem dúvida, os grandes responsáveis pela conclusão desta dissertação. Sem esse apoio não seria possível investir longas horas de trabalho, privando-os da atenção merecida. Ofereço todo o meu sucesso a vocês! 
Por fim, a todos aqueles que leram este trabalho e deixaram suas valiosas contribuições, e também aos que sempre perguntaram sobre o andamento deste projeto: obrigado! O interesse demonstrado por vocês foi responsável pela qualidade que pude atingir neste trabalho. Espero que gostem do resultado final.

Muito obrigado a todos vocês! 
"It's clearly useful to have machines doing jobs that are insufficient for the human brain and thus leave human beings the possibility of devoting themselves to more creative labors that will stretch and expand their minds"

Isaac Asimov, 1920-1992 

ANDRADE, K. O. Sistema Neural Reativo para o Estacionamento Paralelo com uma Única Manobra em Veículos de Passeio. 2011. Dissertação (Mestrado) - Escola de Engenharia de São Carlos, Universidade de São Paulo, São Carlos, 2011.

Graças aos avanços tecnológicos nas áreas da computação, eletrônica embarcada e mecatrônica a robótica está cada vez mais presente no cotidiano da pessoas. Nessas últimas décadas, uma infinidade de ferramentas e métodos foram desenvolvidos no campo da Robótica Móvel. Um exemplo disso são os sistemas inteligentes embarcados nos veículos de passeio. Tais sistemas auxiliam na condução através de sensores que recebem informações do ambiente e algoritmos que analisam os dados e tomam decisões para realizar uma determinada tarefa, como por exemplo estacionar um carro. Este trabalho tem por objetivo apresentar estudos realizados no desenvolvimento de um controlador inteligente capaz de estacionar um veículo simulado em vagas paralelas, na qual seja possível entrar com uma única manobra. Para isso, foi necessário realizar estudos envolvendo a modelagem de ambientes, cinemática veicular e sensores, os quais foram implementados em um ambiente de simulação desenvolvido em C\# com o Visual Studio 2008. Em seguida é realizado um estudo sobre as três etapas do estacionamento, que consistem em procurar uma vaga, posicionar o veículo e manobrá-lo. Para realizar a manobra foi adotada a trajetória em $\mathrm{S}$ desenvolvida e muito utilizada em outros trabalhos encontrados na literatura da área. A manobra consiste em posicionar corretamente duas circunferências com um raio de esterçamento do veículo. Sendo assim, foi utilizado um controlador robusto baseado em aprendizado supervisionado utilizando Redes Neurais Artificiais (RNA), pois esta abordagem apresenta grande robustez com relação à presença de ruídos no sistema. Este controlador recebe dados de dois sensores laser (um fixado na frente do veículo e o outro na parte traseira), da odometria e de orientação de um sensor inercial. Os dados adquiridos desses sensores e a etapa da manobra em que o veículo está, servem de entrada para o controlador. Este é capaz de interpretar tais dados e responder a esses estímulos de forma correta em aproximadamente 99\% dos casos. Os resultados de treinamento e de simulação se mostraram muito satisfatórios, permitindo que o carro controlador pela RNA pudesse estacionar corretamente em uma vaga paralela.

Palavras-chave: Robôs móveis inteligentes. Veículos autônomos. Redes neurais artificias. Perceptron multi-camadas. Aprendizado supervisionado. Estacionamento paralelo. 


in Passenger Vehicles. 2011. Thesis (Master) - Sao Carlos School of Engineering, Sao Paulo University, Sao Carlos, 2011.

Thanks to technological advances in the fields of computer science, embedded electronics and mechatronics, robotics is increasingly more present in people's lives. On the past few decades a great variety of tools and methods were developed in the Mobile Robotics field, e.g. the passenger vehicles with smart embedded systems. Such systems help drivers through sensors that acquire information from the surrounding environment and algorithms which process this data and make decisions to perform a task, like parking a car. This work aims to present the studies performed on the development of a smart controller able to park a simulated vehicle in parallel parking spaces, where a single maneuver is enough to enter. To accomplish this, studies involving the modeling of environments, vehicle kinematics and sensors were conducted, which were implemented in a simulated environment developed in C\# with Visual Studio 2008. Next, a study about the three stages of parking was carried out, which consists in looking for a slot, positioning the vehicle and maneuvering it. The " $\mathrm{S}$ " trajectory was adopted and developed to maneuver the vehicle, since it is well known and highly used in related works found in the literature of this field. The maneuver consists in the correct positioning of two circumferences with the possible steering radius of the vehicle. For this task, a robust controller based on supervised learning using Artificial Neural Networks (ANN) was employed, since this approach has great robustness regarding the presence of noise in the system. This controller receives data from two laser sensors (one attached on the front of the vehicle and the other on the rear), from the odometry and from the inertial orientation sensor. The data acquired from these sensors and the current maneuver stage of the vehicle are the inputs of the controller, which interprets these data and responds to these stimuli in a correct way in approximately $99 \%$ of the cases. The results of the training and simulation were satisfactory, allowing the car controlled by the ANN to correctly park in a parallel slot.

Palavras-chave: Intelligent mobile robots. Autonomous vehicles. Artificial neural networks. Multi-layer Perceptron. Machine learning. Parallel parking. 

1. HERNANDES, A. C.; MENDONCA, A. S. B.; ANDRADE, K. O.; BECKER, M.; Redes neurais artificiais aplicadas à baliza paralela de veículo de passeio em ambiente simulado - In: VI Congresso Nacional de Engenharia Mecânica, CONEM 2010, Campina Grande, Paraíba, Ago. 2010.

2. ANDRADE, K. O.; HERNANDES, A. C.; BECKER, M.; A Rule-Based Controller Simulation for an Autonomous Parallel Parking of a Car-Like Robot Using Laser Sensors -In: 21 International Congress of Mechanical Engineering, COBEM 2011, Natal, Rio Grande do Norte, Out. 2011. (Aguardando publicação) 

1.1 Exemplos de robôs reais: (a) Asimo (Honda, 2011); (b) Robomower (Sahin e Guvenc, 2007); (c) Aibo (Sony, 2011); (d) IRobot Scooba (iRobot, 2011); (e) MIT-Manus (Krebs et al., 2008); (f) Robô NAO (NAO, 2011) . . . . . . . . . .

1.2 Competição do DARPA: (a) vencedor de 2005 (Stanley - Volkswagen Tuareg) da Universidade de Stanford (Thrun et al., 2006); (b) vencedor de 2007 (Tartan - Chevrolet) da Universidade de Changie Mellon (Baker e Dolan, 2009) . . . . 3

1.3 Protótipos do projeto SENA: (a) Navalha - quadriciclo elétrico infantil; (b) Gisa - Fiat Stilo 1.8 Dualogic . . . . . . . . . . . . . . . . . . 4

2.1 Etapas do estacionamento paralelo . . . . . . . . . . . . . . . 8

2.2 A tela do painel do Toyota Britânico com o Intelligent Parking Assist System (Retiradode http: //wapedia.mobi/en/Advanced_Parking_Guidance_

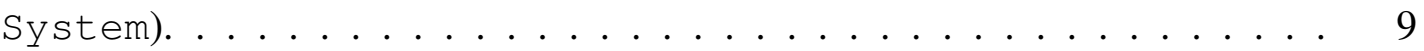

2.3 Exemplo de funcionamento do sistema da Bosch para medir o tamanho do espaço de estacionamento (Bosch, 2011). . . . . . . . . . . . . . 10

2.4 Sistema Park4U (Valeo, 2010) (a) e (b) procurando a vaga, em (c) entrando na vaga do tipo garagem e em (d) numa vaga paralela. . . . . . . . . . . . . . 11

3.1 Tipos de mapas utilizados na robótica: (a) representação métrica baseado em grades; (b) representação topológica; (c) representação geométrica. . . . . . . . . 16

3.2 Modelo cinemático do veículo. . . . . . . . . . . . . . . . . . 18

3.3 Mini-veículo HELVIS (Sampaio et al., 2011). . . . . . . . . . . . . . . . . 19

3.4 Princípios de funcionamento do encoder óptico (adaptado de Electronics (2009)). 21

3.5 Alguns sensores laser: (a) Modelo de sensor laser SICK LMS 291; (b) Modelo do sensor laser Hokuyo URG-04LX. . . . . . . . . . . . . . . . . . . . . 22

3.6 Diagrama de blocos simplificado do sensor IMU IG-500N (adaptado de (SBG Systems, 2011)). . . . . . . . . . . . . . . . . . . . 23

3.7 Imagem do sensor IMU IG-500N entre os dedos de uma pessoa para mostrar seu tamanho. . . . . . . . . . . . . . . . . . .

3.8 Simulador de Estacionamento de Veículos Autônomos (SEVA): (a) versão bidimensional do simulador (Heinen et al., 2001); (b) versão tridimensional do simulador (Heinen et al., 2007) . . . . . . . . . . . . . . . . 25

3.9 Diagrama de classes do simulador desenvolvido. . . . . . . . . . . . 26

3.10 Interface do simulador . . . . . . . . . . . . . . . 27 
4.1 Neurônio: (a) Representação do neurônio biológico (retirado de http: // www.sogab.com.br/anatomia/neuronio.jpg); (b) Representação do neurônio artificial segundo McCulloch e Pitts (adaptado de (Silva et al., 2010).

4.2 Funções de ativação parcialmente diferenciáveis: (a) degrau; (b) degrau bipolar; (c) rampa simétrica; e funções de ativação totalmente diferenciáveis: (d) logística; (e) tangente hiperbólica; (f) linear. . . . . . . . . . . . . . . . . . . 31

4.3 Exemplo de rede com arquitetura do tipo feedforward de camada simples. . . . 33

4.4 Exemplo de rede com arquitetura do tipo feedforward de camada múltiplas. . . 33

4.5 Exemplo de rede com arquitetura do tipo recorrente ou realimentada. . . . . . . 34

4.6 Exemplo de rede com arquitetura do tipo reticulada. . . . . . . . . . . . . 35

4.7 Esquema para o método 5-fold cross-validation. . . . . . . . . . . . . . 35

4.8 Situações envolvendo underfitting e overfitting usando parada antecipada. . . . 36

4.9 Diagrama simplificado do funcionamento do aprendizado supervisionado em uma RNA. . . . . . . . . . . . . . . . . . . . . . .

5.1 Passos para se encontrar uma vaga paralela: (a) início da procura por uma vaga; (b) detecta um possível espaço e começa a contar; (c) termina a contagem e armazena o tamanho da vaga encontrado. . . . . . . . . . . . . . . .

5.2 Posicionado na vaga: (a) o veículo acaba de mudar para o estado posicionando e em (b) o veículo chegou na posição desejada.

5.3 Tragetória de Estacionamento Paralelo .

5.4 Manobrando o veículo para dentro da vaga encontrada: (a) entrando na vaga; (b) esterçando inversamente para posicionar o veículo na vaga; (c) aproximando-se do veículo, tomando cuidado para não bater a traseira; (d) ajustando o carro à vaga e parando-o. . . . . . . . . . . . . . . . .

6.1 Descrição da Rede Neuralutilizada para controlar o veículo. . . . . . . . . . . . . .

6.2 Detalhes da análise realizada para descobrir as configurações iniciais aceitáveis, na qual foram variados os parâmetros $\Delta y$ e $P$, onde quatro trajetórias limitantes são representadas. . . . . . . . . . . . . . . . . . . . . . . . . .

6.3 Área de estacionamento paralelo: a área branca indica que é impossível estacionar em uma única manobra, enquanto a cor vermelha mais escura indica o ponto máximo de esterçamento e a cor amarela indica um ângulo menor de esterçamento.

6.4 Amostra da base de exemplos usada para o aprendizado supervisionado da rede neural. . . . . . . . . . . . . . . . . . .

6.5 Autômato Finito que representa o conhecimento humano para realizar o estacionamento paralelo em seis etapas. . . . . . . . . . . . . . . 53

6.6 Topologia da rede neural para a primeira estratégia de estacionamento paralelo.

6.7 Topologia da rede neural especialista para a segunda estratégia de estacionamento paralelo. . . . . . . . . . . . . . . . . . .

6.8 Manobras realizadas com o controlador III no simulador e analisadas visualmente: (a) $P=830,00 \mathrm{~mm}$ e $\Delta y=43,00 \mathrm{~mm}$; (b) $P=908,00 \mathrm{~mm}$ e $\Delta y=65,00$.

...........

6.9 Manobras realizadas com o controlador VII no simulador e analisadas visualmente: (a) $P=830,00 \mathrm{~mm}$ e $\Delta y=43,00 \mathrm{~mm}$; (b) $P 908,00=\mathrm{mm}$ e $\Delta y=65,00 \ldots \ldots \ldots \ldots \ldots \ldots \ldots$

6.10 Representação da área de estacionamento e da área posição final desejada do veículo dentro da área de estacionamento. 
6.11 Exemplo da medida de similaridade: (a) mostra como o veículo ficou posicionado na região de estacionamento desejada; (b) imagem binária da área de estacionamento desejada; (c) posição obtida do veículo dentro da área desejada; (d) área final de similaridade deste exemplo com 81,4\% . . . . . . . . . . . . 63

A.1 Mapa global do projeto SENA . . . . . . . . . . . . . . . . . . 79

A.2 Mapa do problema de veículos semi-autônomos . . . . . . . . . . . . . 80

A.3 Mapa do problema de veículos autônomos . . . . . . . . . . . . . 81

A.4 Mapa dos desafios do projeto SENA . . . . . . . . . . . . . . . . . . 82 

3.1 Descrições dos parâmetros da cinemática do carro. . . . . . . . . . . . . 18

3.2 Parâmetros do mini-veículo HELVIS utilizado na simulação. . . . . . . . . . . . 19

3.3 Comparação das especificações do sensor SICK e Hokuyo URG-04LX (Lee e Ehsani, 2008). . . . . . . . . . . . . . . . . . 22

6.1 Resultado das três melhores topologias candidatas para a primeira estratégia (sem ruídos no sensores e sem a presença de parede) usando o algoritmo de aprendizado Resilient Propagation e o algoritmo de aprendizado LevenbergMarquardt para o controlador neural I. . . . . . . . . . . . . . . . . .

6.2 Resultado das três melhores topologias candidatas para a primeira estratégia (sem ruídos no sensores e com a presença de parede) usando o algoritmo de aprendizado Resilient Propagation e o algoritmo de aprendizado LevenbergMarquardt para o controlador neural II.

6.3 Resultado das três melhores topologias candidatas para a primeira estratégia (sensores com ruídos e sem a presença de parede) usando o algoritmo de aprendizado Resilient Propagation e o algoritmo de aprendizado Levenberg-Marquardt para o controlador neural III.

6.4 Resultado das três melhores topologias candidatas para a primeira estratégia (sensores com ruídos e com a presença de parede) usando o algoritmo de aprendizado Resilient Propagation e o algoritmo de aprendizado Levenberg-Marquardt para o controlador neural IV. . . . . . . . . . . . . . . . . . . . . .

6.5 Resultado das três melhores topologias candidatas para cada rede da segunda estratégia, usando o algoritmo de aprendizado Resilient Propagation e o algoritmo de aprendizado Levenberg-Marquardt para o controlador neural V. . . . .

6.6 Resultado das três melhores topologias candidatas para cada rede da segunda estratégia usando o algoritmo de aprendizado Resilient Propagation e o algoritmo de aprendizado Levenberg-Marquardt para o controlador neural VI. . . . .

6.7 Resultado das três melhores topologias candidatas para cada rede da segunda estratégia usando o algoritmo de aprendizado Resilient Propagation e o algoritmo de aprendizado Levenberg-Marquardt para o controlador neural VII. . . .

6.8 Resultado das três melhores topologias candidatas para cada rede da segunda estratégia usando o algoritmo de aprendizado Resilient Propagation e o algoritmo de aprendizado Levenberg-Marquardt para o controlador neural VIII. . . 
C.1 Resultados do Treinamento e validação das topologias candidatas para o primeiro sistema neural (dados sem ruídos e sem parede), usando o algoritmo $R e$ silient Propagation. . . . . . . . . . . . . . . . . . . . . . .

C.2 Resultados do Treinamento e validação das topologias candidatas para o primeiro sistema neural (dados sem ruídos e sem parede), usando o algoritmo Levenberg-Marquardt. . . . . . . . . . . . . . . . .

C.3 Resultados do Treinamento e validação das topologias candidatas para o segundo sistema neural (dados sem ruídos e com parede), usando o algoritmo Resilient Propagation.

C.4 Resultados do Treinamento e validação das topologias candidatas para o segundo sistema neural(dados sem ruídos e com parede), usando o algoritmo Levenberg-Marquardt.

C.5 Resultados do Treinamento e validação das topologias candidatas para o terceiro sistema neural (dados com ruídos e sem parede), usando o algoritmo $R e$ silient Propagation. . . . . . . . . . . . . . . . . . .

C.6 Resultados do Treinamento e validação das topologias candidatas para o terceiro sistema neural (dados com ruídos e sem parede), usando o algoritmo Levenberg-Marquardt. . . . . . . . . . . . . . . . . .

C.7 Resultados do Treinamento e validação das topologias candidatas para o quarto sistema neural (dados com ruídos e com parede), usando o algoritmo Resilient Propagation. . . . . . . . . . . . . . . . .

C.8 Resultados do Treinamento e validação das topologias candidatas para o quarto sistema neural (dados com ruídos e com parede), usando o algoritmo LevenbergMarquardt. . . . . . . . . . . . . . . . .

C.9 Resultados do Treinamento e validação das topologias especialistas candidatas (12 entradas e uma saída com esterçamento do veículo) para o quinto sistema neural (dados sem ruídos e sem parede), usando o algoritmo Resilient Propagation . . . . . . . . . . . . . . . . . . . . .

C.10 Resultados do Treinamento e validação das topologias especialistas candidatas (12 entradas e uma saída com esterçamento do veículo) para o quinto sistema neural (dados sem ruídos e sem parede), usando o algoritmo LevenbergMarquardt.

C.11 Resultados do Treinamento e validação das topologias especialistas candidatas (12 entradas e uma saída com a velocidade do veículo) para o quinto sistema neural (dados sem ruídos e sem parede), usando o algoritmo Resilient Propagation. . . . . . . . . . . . . . . . . . . . . .

C.12 Resultados do Treinamento e validação das topologias especialistas candidatas (12 entradas e uma saída com a velocidade do veículo) para o quinto sistema neural (dados sem ruídos e sem parede), usando o algoritmo LevenbergMarquardt. . . . . . . . . . . . . . . . . .

C.13 Resultados do Treinamento e validação das topologias especialistas candidatas (12 entradas e três saídas com os próximos estados da manobra) para o quinto sistema neural (dados sem ruídos e sem parede), usando o algoritmo Resilient Propagation.

C.14 Resultados do Treinamento e validação das topologias especialistas candidatas (12 entradas e três saídas com os próximos estados da manobra) para o quinto sistema neural (dados sem ruídos e sem parede), usando o algoritmo LevenbergMarquardt. 
C.15 Resultados do Treinamento e validação das topologias especialistas candidatas (12 entradas e uma saída com esterçamento do veículo) para o quinto sistema neural (dados sem ruídos e com parede), usando o algoritmo Resilient Propa-

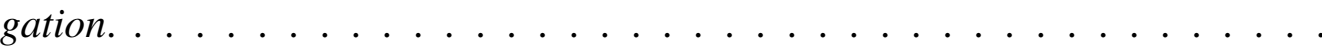

C.16 Resultados do Treinamento e validação das topologias especialistas candidatas (12 entradas e uma saída com esterçamento do veículo) para o quinto sistema neural (dados sem ruídos e com parede), usando o algoritmo LevenbergMarquardt.

C.17 Resultados do Treinamento e validação das topologias especialistas candidatas (12 entradas e uma saída com a velocidade do veículo) para o quinto sistema neural (dados sem ruídos e com parede), usando o algoritmo Resilient Propagation. . . . . . . . . . . . . . . . . . . .

C.18 Resultados do Treinamento e validação das topologias especialistas candidatas (12 entradas e uma saída com a velocidade do veículo) para o quinto sistema neural (dados sem ruídos e com parede), usando o algoritmo Levenberg-

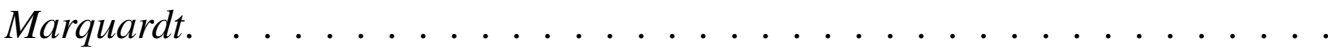

C.19 Resultados do Treinamento e validação das topologias especialistas candidatas (12 entradas e três saídas com os próximos estados da manobra) para o quinto sistema neural (dados sem ruídos e com parede), usando o algoritmo Resilient Propagation.

C.20 Resultados do Treinamento e validação das topologias especialistas candidatas (12 entradas e três saídas com os próximos estados da manobra) para o quinto sistema neural (dados sem ruídos e com parede), usando o algoritmo LevenberdMarquardt.

C.21 Resultado do treinamento e validação das topologias especialistas candidatas (12 entradas e uma saída com o esterçamento do veículo) para o sétimo sistema neural (dados com ruídos e sem parede), usando o algoritmo Resilient Propagation. . . . . . . . . . . . . . . . . . . .

C.22 Resultado do treinamento e validação das topologias especialistas candidatas (12 entradas e uma saída com o esterçamento do veículo) para o sétimo sistema neural (dados com ruídos e sem parede), usando o algoritmo LevenbergMarquardt.

C.23 Resultado do treinamento e validação das topologias especialistas candidatas (12 entradas e uma saída com a velocidade do veículo) para o sétimo sistema neural (dados com ruídos e sem parede), usando o algoritmo Resilient Propagation. . . . . . . . . . . . . . . . . . . .

C.24 Resultado do treinamento e validação das topologias especialistas candidatas (12 entradas e uma saída com a velocidade do veículo) para o sétimo sistema neural (dados com ruídos e sem parede), usando o algoritmo LevenbergMarquardt.

C.25 Resultado do treinamento e validação das topologias especialistas candidatas (12 entradas e 4 saídas com o próximo estado da manobra) para o sétimo sistema neural (dados com ruídos e sem parede), usando o algoritmo Resilient Propagation.

C.26 Resultado do treinamento e validação das topologias especialistas candidatas (12 entradas e 4 saídas com o próximo estado da manobra) para o sétimo sistema neural (dados com ruídos e sem parede), usando o algoritmo LevenbergMarquardt. 
C.27 Resultados do Treinamento e validação das topologias especialistas candidatas (12 entradas e uma saída com esterçamento do veículo) para o quinto sistema neural (dados com ruídos e com parede), usando o algoritmo Resilient Propagation. . . . . . . . . . . . . . . . . . . .

C.28 Resultados do Treinamento e validação das topologias especialistas candidatas (12 entradas e uma saída com esterçamento do veículo) para o quinto sistema neural (dados com ruídos e com parede), usando o algoritmo LevenbergMarquardt. . . . . . . . . . . . . . . . .

C.29 Resultados do Treinamento e validação das topologias especialistas candidatas (12 entradas e uma saída com a velocidade do veículo) para o quinto sistema neural (dados com ruídos e com parede), usando o algoritmo Resilient Propagation. . . . . . . . . . . . . . . . . . . . .

C.30 Resultados do Treinamento e validação das topologias especialistas candidatas (12 entradas e uma saída com a velocidade do veículo) para o quinto sistema neural (dados com ruídos e com parede), usando o algoritmo LevenbergMarquardt. . . . . . . . . . . . . . . . .

C.31 Resultados do Treinamento e validação das topologias especialistas candidatas (12 entradas e três saídas com os próximos estados da manobra) para o quinto sistema neural (dados com ruídos e com parede), usando o algoritmo Resilient Propagation. . . . . . . . . . . . . . . . . . 100

C.32 Resultados do Treinamento e validação das topologias especialistas candidatas (12 entradas e três saídas com os próximos estados da manobra) para o quinto sistema neural (dados com ruídos e com parede), usando o algoritmo Levenberg-Marquardt. . . . . . . . . . . . . . . . . . . . . . 101 


\section{Lista de Abreviaturas e Siglas}

2D

3D

AM

ABS

$\mathrm{AF}$

AG

API

CCD

CLMR

DARPA

DLL

EESC

ELROB

GPS

HELVIS

IA

IDE

IMU

IPAS

IRVW

LabRoM

LADAR

LIDAR

LM

LSP

MAE

MAPE

MEMS

MFC
Bidimensional

Tridimensional

Aprendizado de Máquina (Machine Learning - ML)

Anti-lock Braking System

Autômato Finito

Algoritmo Genético

Application Programming Interface

Charge-Coupled Device

Car-Like Mobile Robot

Agência de Pesquisa de Projetos Avançados de Defesa (Defense Advanced Research Projects Agency)

Dynamic Load Library

Escola de Engenharia de São Carlos

The European robot Trial

Global Positioning System

Hybrid Electric Vehicle In Low Scale

Inteligencia Artificial (AI - Artificial Intelligence)

Ambiente de Desenvolvimento Integrado (Integrated Development Environment)

Inertial Meaasurement Unit

Intelligent Parking Assist System

Integrated Research VolksWagen

Laboratório de Robótica Móvel (EESC/USP)

Laser Detection and Ranging

Light Detection and Ranging

Levenberg-Marquardt

Light Strip Projection

Erro Absoluto Médio (Mean Absolute Error)

Mean Absolute Percentage Error

Microelectromechanical Systems

Microsoft Foundation Classes 
Perceptron Multi-Camadas (Multi Layer Perceptron)

MSE

Erro Quadrático Médio (Mean Squared Error)

PAS

Parking Assistant System

PSD

Position Sensing Detector

$\mathrm{RBF}$

Rede Neural de Base Radial (Radial Basis Function)

RNA

Rede Neural Artificial (ANN - Artificial Neural Network)

RMSE

Raiz do Erro Quadrático Médio (Root Mean Square Error)

RPROP

Resilient Backpropagation

SENA

Sistema Embarcado de Navegação Autônoma

SEVA

Simulador de Estacionamento de Veículos Autônomos

SimRob

Simulador de Robôs Móveis

UML

Unified Modeling Language

USP

Universidade de São Paulo 
Distância entre rodas

$\mathrm{mm}$

Distância entre o eixo traseiro e a traseira do carro $\mathrm{mm}$

Distância entre o veículo e uma possível calçada

$\mathrm{mm}$

Distância entre eixos

$\mathrm{mm}$

Tamanho da vaga

$\mathrm{mm}$

Distância de segurança

$\mathrm{mm}$

Velocidade linear do veículo no eixo $\mathrm{Y}$

Velocidade linear do veículo no eixo $\mathrm{X}$

$C_{1}$

Matriz com as condições de contorno impostas pela hipótese simplificadora 2 (Rodas sem deslizamento)

$D_{I F} \quad$ Distância euclidiana entre o ponto $I$ e $F$

$\mathrm{mm}$

F

Ponto final da curva em $\mathrm{S}$ para realizar a manobra de estacionamento

Ponto inicial da curva em S para realizar a manobra de estacionamento

$I C R$

Centro instantâneo de rotação do veículo

$J_{1}$

Matriz com as condições de contorno impostas pela hipótese simplificadora 1 (Rodas sem escorregamento)

$J_{2}$

Matriz diagonal $N$ X $N$ com os raios das rodas do veículo

$L \quad$ Comprimento do carro

$\mathrm{mm}$

$M$

Ponto de virada do veículo

$O_{F}$

Centro da circunferência que passa pelo ponto $F$ e $M$

$O_{I}$

$P$

Centro da circunferência que passa pelo ponto $I$ e $M$

$R$

Tamanho da vaga de estacionamento

$\mathrm{mm}$

Raio descrito pela roda do carro

$\mathrm{mm}$

$R_{F}$

Raio da circunferência que passa por $F$ e $M$

$\mathrm{mm}$

$R_{I}$

Raio da circunferência que passa por $I$ e $M$

$\mathrm{mm}$

$R_{\text {min }}$

Raio mínimo que pode ser descrito pela roda do carro

$\mathrm{mm}$

$S F 1$

Feixe 1 do sensor na frente do veículo

$\mathrm{mm}$

$S F 2$

Feixe 2 do sensor na frente do veículo

$\mathrm{mm}$

$S F 3$

Feixe 3 do sensor na frente do veículo

$\mathrm{mm}$

$S R 1$

Feixe 1 do sensor de trás do veículo

$\mathrm{mm}$ 
Feixe 2 do sensor de trás do veículo

$\mathrm{mm}$

Feixe 3 do sensor de trás do veículo

$\mathrm{mm}$

V

Velocidade longitudinal do carro

$\mathrm{m} / \mathrm{s}$

W

Largura do carro

$\mathrm{mm}$

$Y$

Referência inercial em $X$ do veículo

$\mathrm{mm}$

Referência inercial em Y do veículo

$\mathrm{mm}$

$X$

Ângulo entre o ponto $F$ e o ponto $M$

$\mathrm{rad}$

Ângulo entre o ponto $I$ e o ponto $M$

$\mathrm{rad}$

$\alpha_{I}$ ângulo entre o ponto $I$ e $F$

$\mathrm{rad}$

Ângulo de esterçamento do carro

$\mathrm{rad}$

$\theta$

Ângulo de esterçamento da roda esquerda

$\mathrm{rad}$

$\theta_{r}$

Ângulo de esterçamento da roda direita

$\mathrm{rad}$

$\phi$

Orientação do carro

$\mathrm{rad}$

$\dot{\epsilon}_{I}$

Vetor de velocidades $[\dot{x} \dot{y} \text { theta }]^{T}$

$\dot{\varphi}$

Velocidade anguar da roda

$\phi$

Velocidade angular veículo

$\Delta t$

Intervalo de tempo

$\Delta y$

Distância entre a traseira do veículo e o veículo estacionado

$\mathrm{mm}$

$\Delta x$

Distância entre a lateral do veículo e o veículo estacionado

$\mathrm{mm}$ 
Resumo

xi

Abstract

xiii

Publicações

XV

Lista de Figuras

xix

Lista de Tabelas

xxiv

Lista de Abreviaturas e Siglas

xxvi

Lista de Símbolos

Xxviii

Sumário

xxxi

1 Introdução 1

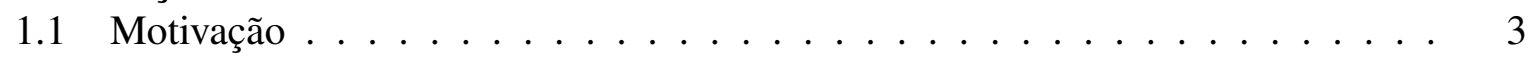

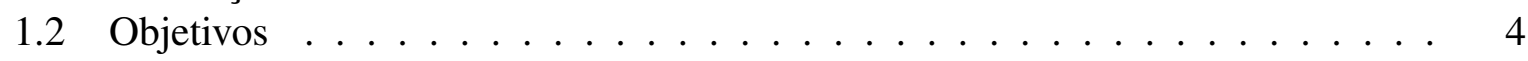

1.3 Estrutura da Dissertação . . . . . . . . . . . . . . 5

2 Estado da Arte $\quad 7$

2.1 O Problema do Estacionamento Paralelo . . . . . . . . . . . . . . . . . 7

2.2 Sistemas Automotivos para Estacionamento . . . . . . . . . . . . . . 9

2.3 Trabalhos Acadêmicos . . . . . . . . . . . . . . . . . . . 11

2.4 Considerações Finais . . . . . . . . . . . . . . . . . . . . 13

3 Modelagem e Simulação 15

3.1 Modelos . . . . . . . . . . . . . . . . . . . . 15

3.1.1 Modelo do Ambiente . . . . . . . . . . . . . . . . . . . 15

3.1 .2 Modelo do Veículo . . . . . . . . . . . . . . . . . . . . 16

3.1 .3 Sensores . . . . . . . . . . . . . . . . . . . . . . . . . . . . . . . . .

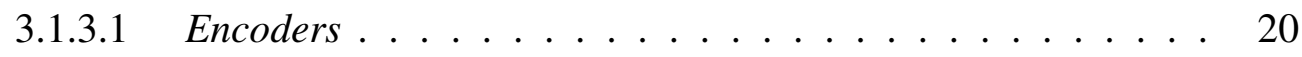

3.1.3.2 Sensor Laser . . . . . . . . . . . . . . . . . . . . 21

3.1.3.3 Sensor Inercial . . . . . . . . . . . . . . . . . 22

3.2 Simulação . . . . . . . . . . . . . . . . . . 23 
3.2.1 Simuladores de Robôs Móveis . . . . . . . . . . . . . . . . . . . . . . 24

3.2.2 Simulador Desenvolvido . . . . . . . . . . . . . . . . . 24

3.2.2.1 Implementação do Simulador . . . . . . . . . . . . . . . . . 25

3.2.2.2 Interface do Simulador . . . . . . . . . . . . . 26

3.3 Considerações Finais . . . . . . . . . . . . . . . . . . . . . . . 28

4 Aprendizado Supervisionado e Redes Neurais 29

4.1 Redes Neurais Artificiais - RNAs . . . . . . . . . . . . . . . . . . . . 30

4.1.1 Arquiteturas de RNAs . . . . . . . . . . . . . . . . . . . 32

4.1.1.1 Redes feedforward de Camada Simples . . . . . . . . . . . . . . 33

4.1.1.2 Redes feedforward de Camadas Múltiplas . . . . . . . . . 33

4.1.1.3 Redes Recorrentes . . . . . . . . . . . . . . . . . . 34

4.1.1.4 Redes Reticuladas . . . . . . . . . . . . . . . . . . . 34

4.2 Aspectos Topológicos da RNA . . . . . . . . . . . . . . . . . . . . . . . . . . . . . . . . . .

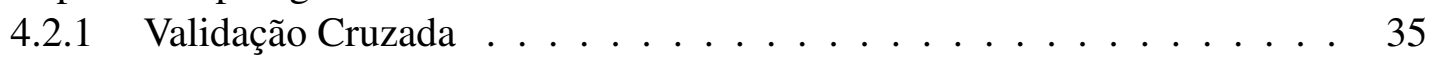

4.2.2 Overfitting e Underfitting . . . . . . . . . . . . . . . . . . . . . . . . . . . . . . . . 36

4.2 .3 Parada Antecipada . . . . . . . . . . . . . . . . 36

4.3 Algoritmo de Aprendizado de RNAs . . . . . . . . . . . . . . . . . . . . 37

4.3.1 Resilient Backpropagation . . . . . . . . . . . . . . . . . 38

4.3.2 Levenberg-Marquardt . . . . . . . . . . . . . . . . . . . . . 38

4.4 Considerações Finais . . . . . . . . . . . . . . . . . . . . . . . . 39

5 Abordagem do Estacionamento Paralelo 4

5.1 Deteç̧ão do Espaço . . . . . . . . . . . . . . . . . . . . . . . 41

5.2 Posicionando o Veículo . . . . . . . . . . . . . . . . . . . . 42

5.3 Trajetória de Referência . . . . . . . . . . . . . . . . . . . . . . . . 43

5.4 Realizando a Manobra . . . . . . . . . . . . . . . . . . . 46

5.5 Considerações Finais . . . . . . . . . . . . . . . . . . . 48

6 Sistema Neural Desenvolvido 49

6.1 O Controlador Neural . . . . . . . . . . . . . . . . . . . . . . . . . . 49

6.1.1 Geração da Base de Exemplos . . . . . . . . . . . . . . . . . . . 50

6.1.1.1 Controlador Baseado em Regras - Autômato Finito . . . . . 52

6.1.2 Pré-processamento dos dados ..................... 53

6.1.3 Definição das Topologias Candidatas . . . . . . . . . . . . . . . . . 54

6.2 Resultados de Aprendizado dos Controladores . . . . . . . . . . . . . . . . 55

6.2 .1 Controlador Neural I . . . . . . . . . . . . . . . . . 56

6.2 .2 Controlador Neural II . . . . . . . . . . . . . . . . . . . . 57

6.2 .3 Controlador Neural III . . . . . . . . . . . . . . . . . . . . . . . . 57

6.2 .4 Controlador Neural IV . . . . . . . . . . . . . . . . . . . 58

6.2 .5 Controlador Neural V . . . . . . . . . . . . . . . . . 58

6.2 .6 Controlador Neural VI . . . . . . . . . . . . . . . . . . . 58

6.2 .7 Controlador Neural VII . . . . . . . . . . . . . . . . . . . 59

6.2 .8 Controlador Neural VIII . . . . . . . . . . . . . . . . . . . 60

6.3 Resultados Simulados e Discussão . . . . . . . . . . . . . . . . . . . . 60

6.4 Considerações Finais . . . . . . . . . . . . . . . . . . . . . 64

7 Conclusões e Perspectivas Futuras $\quad 65$

7.1 Trabalhos Futuros . . . . . . . . . . . . . . . . . . 66 
A Mapa conceitual do projeto SENA

B Pseudo-Algoritmo do Autômato Finito $\quad 83$

C Resultados das Topologias das Redes Neurais $\quad 85$ 



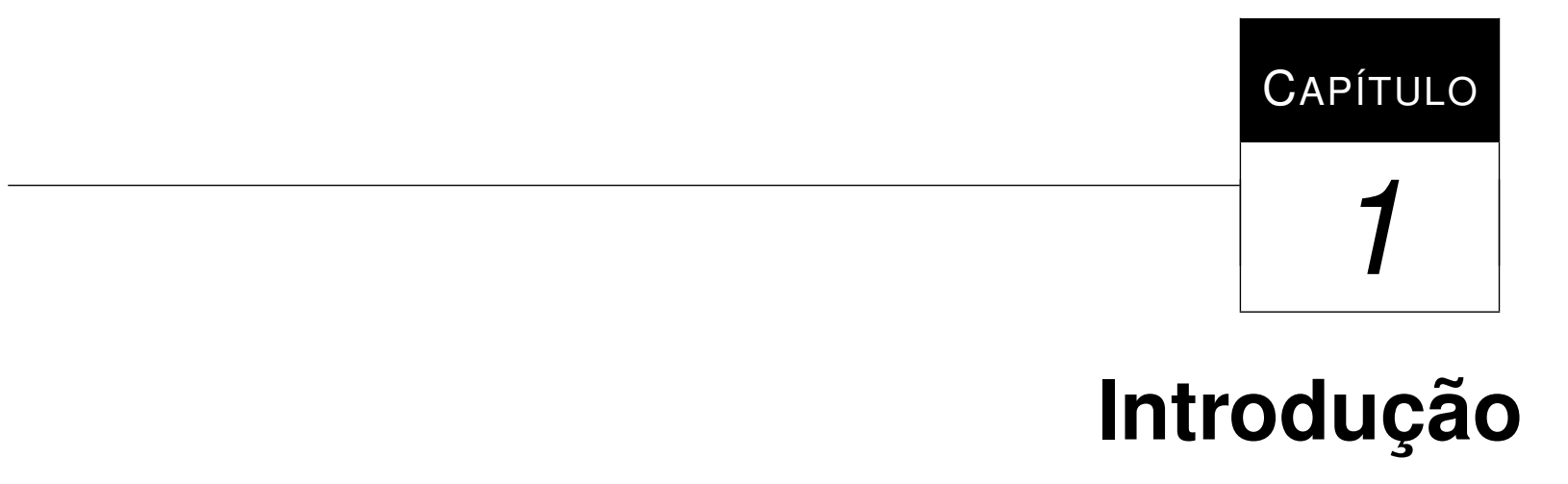

Desde o início da década passada é comum encontrar artigos e reportagens que abordam o uso da robótica (Siciliano e Khatib, 2008) em locais que há poucos anos eram somente sonhados pelos pesquisadores e amantes da ficção. Isto pode ser observado nas diferentes pesquisas que são desenvolvidas para aplicações militares e de exploração aérea e espacial (Chu et al., 2005), serviços domésticos (Sahin e Guvenc, 2007; Husqvarna, 2011; iRobot, 2011), educação e entretenimento (Sony, 2011; Honda, 2011), na área de saúde (Krebs et al., 2008; Rossi e Rosati, 2007; Andrade et al., 2011) e no setor automobilístico (Thrun et al., 2006; Hernandes et al., 2010). Alguns exemplos de robôs podem ser vistos da Figura 1.1(a) à Figura 1.1(f).

A robótica móvel (Dudek e Jenkin, 2000; Siegwart et al., 2011) é uma das áreas da robótica que tem se desenvolvido gradativamente há muitos anos. Seu principal objetivo é desenvolver dispositivos (robôs) com a capacidade de atuar autonomamente e interagir com os seres humanos e seu ambiente. Os ambientes em que esses robôs geralmente operam são complexos e se modificam dinamicamente, sendo compostos tanto de objetos estáticos como de objetos móveis. Segundo Siegwart et al. (2011), para que esses robôs possam operar neste tipo ambiente, eles devem resolver os problemas fundamentais da robótica móvel que são: perceber o ambiente, localizar-se no ambiente e mover-se pelo ambiente.

Graças aos avanços tecnológicos das últimas décadas em áreas como a computação, eletrônica embarcada e a mecatrônica, a robótica está cada vez mais presente no cotidiano das pessoas. Um exemplo disso é o emprego de sistemas inteligentes embarcados em veículos. Segundo Vlacic et al. (2001) esse tipo de tecnologia tem sido desenvolvido sobre duas abordagens distintas, como os sistemas assistivos, que possibilitam ao motorista recursos de auxílio na condução do veículo, e os veículos autônomos inteligentes, que devem tomar decisões sem 
a intervenção humana e determinar mudanças de comportamento para realizarem uma função. Ambas abordagens devem ser capazes de receber estímulos do ambiente através de sensores (infravermelho, sonar, lasers, câmeras de vídeo, etc.) e planejar assim suas ações conforme um objetivo proposto. Porém, existe um grande desafio nesta área que é dotar esses sistemas com capacidade de aprenderem e de se adaptarem a novas situações para interagir com o meio em que estão inseridos (Medeiros, 1998).

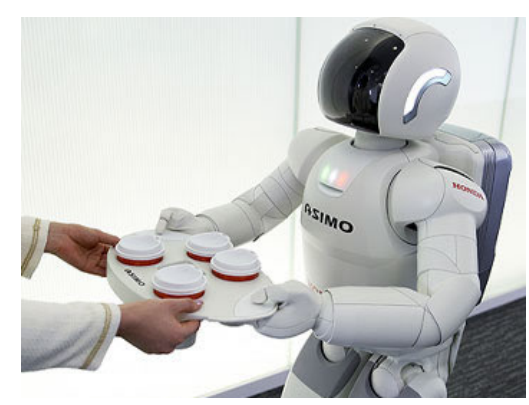

(a)

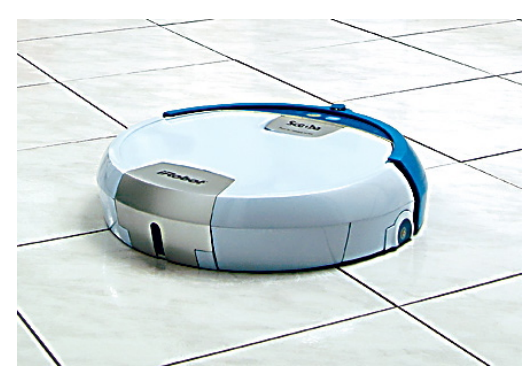

(d)

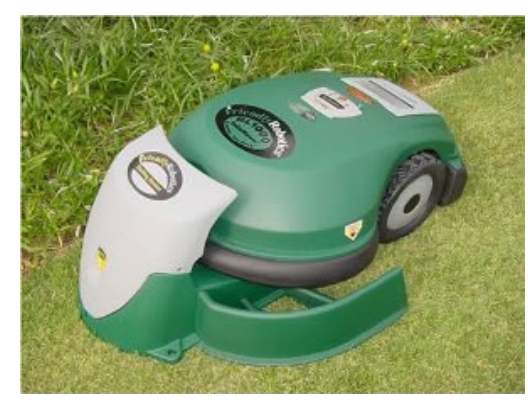

(b)

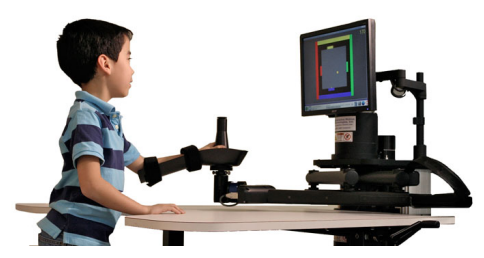

(e)

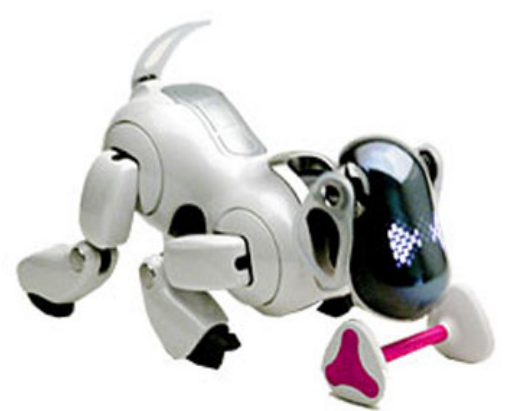

(c)

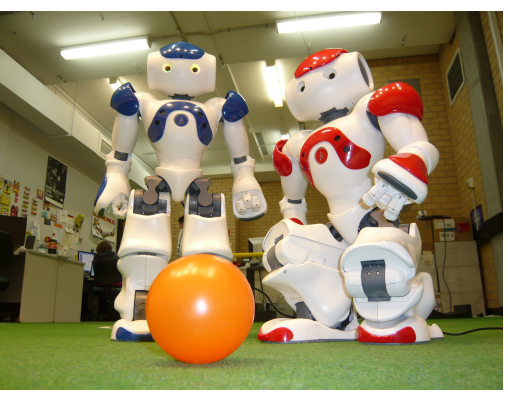

(f)

Figura 1.1: Exemplos de robôs reais: (a) Asimo (Honda, 2011); (b) Robomower (Sahin e Guvenc, 2007); (c) Aibo (Sony, 2011); (d) IRobot Scooba (iRobot, 2011); (e) MIT-Manus (Krebs et al., 2008); (f) Robô NAO (NAO, 2011)

Iniciativas civis e militares têm tido papel fundamental para incentivar o desenvolvimento de veículos autônomos. Pode-se citar, como exemplo, o Darpa Grand Challenge (Thrun et al., 2006), competição organizada pela agência de defesa norte-americana (DARPA ${ }^{1}$ ) que em 2004 ofereceu um prêmio de um milhão de dólares para o primeiro colocado que conseguisse atravessar um trecho de $240 \mathrm{~km}$ de extensão do deserto de Mojave (EUA) utilizando um carro autônomo não tripulado. Mesmo com várias equipes inscritas, somente no segundo ano da competição, em 2005, os robôs foram capazes de cumprir as tarefas propostas, o que demonstra o grande desafio existente na construção de veículos autônomos.

Como resultado, após o $1^{\text {nd }}$ Darpa Grand Challenge um grande interesse foi despertado na comunidade científica, o que incentivou o surgimento de muitas publicações sobre o assunto (Bajracharya et al., 2008) e com o passar dos anos diversas outras competições foram criadas nos Estados Unidos ( $2^{\text {nd }}$ Grand Challenge e Urban Challenge respectivamente em 2005 e 2007,

\footnotetext{
${ }^{1}$ The Defence Advanced Research Projects Agency - http://www.darpa.mil/
} 
ambas realizadas pelo DARPA) e o ELROB ${ }^{2}$ na Europa (C-ELROB que acontece em anos ímpares a partir de 2007, M-ELROB em anos pares a partir de 2006). Com o propósito maior que uma simples competição, elas foram concebidas para avaliar e desenvolver novas tecnologias, para tentar resolver os problemas da robótica móvel, criando e aperfeiçoando sistemas robustos que poderão ser embarcados nas futuras gerações dos veículos de passeio e militares. Os veículos campeões do DARPA 2005 e 2007 podem ser vistos respectivamente na Figura 1.2(a) e na Figura 1.2(b).

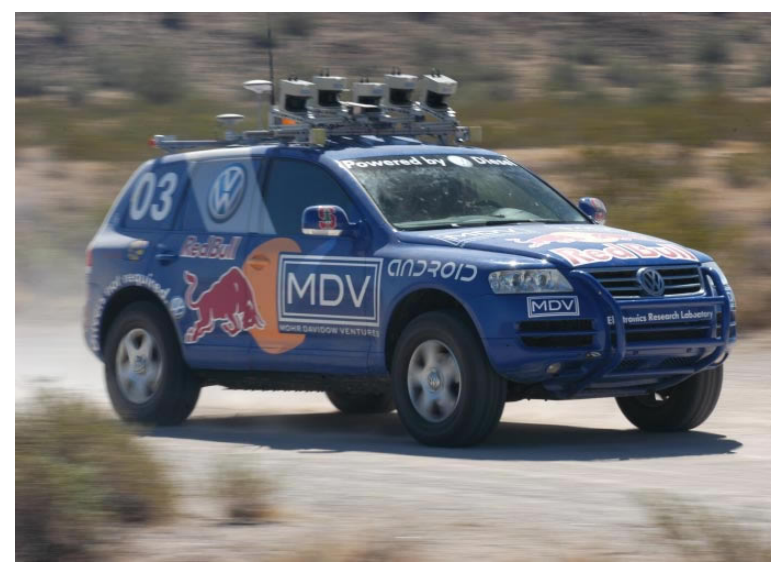

(a)

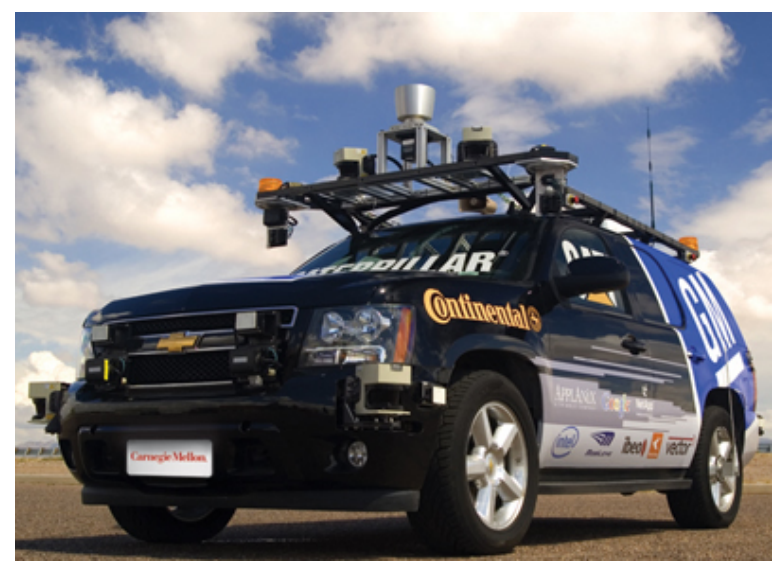

(b)

Figura 1.2: Competição do DARPA: (a) vencedor de 2005 (Stanley - Volkswagen Tuareg) da Universidade de Stanford (Thrun et al., 2006); (b) vencedor de 2007 (Tartan - Chevrolet) da Universidade de Changie Mellon (Baker e Dolan, 2009)

\subsection{Motivação}

A indústria automobilística tem apostado muito nas novas tecnologias, projetando e instalando componentes eletrônicos nos veículos para tentar promover um maior conforto e segurança para os motoristas. Porém, mesmo com tantas tecnologias existentes embarcadas hoje em dia, elas não são suficientes para reduzir os número de acidentes fatais nas estradas. É nesse contexto que o desenvolvimento de carros autônomos entra, visando a diminuição do número de acidentes e uma consequente diminuição nos gastos a eles relacionados, melhorando também a segurança e conforto dos motoristas.

Com o intuito de aprimorar as pesquisas nesta área, foi criado pelo grupo de Mecatrônica da Escola de Engenharia de São Carlos (EESC/USP), no Laboratório de Robótica Móvel (LabRoM), o projeto do carro do futuro, chamado SENA ${ }^{3}$ (Fig. 1.3). Este projeto tem por finalidade desenvolver tecnologias assistivas a serem embarcadas e testadas em um veículo de passeio que sejam capazes de evitar acidentes, provendo assistência ao motorista em situações

\footnotetext{
${ }^{2}$ The European Robot Trial - http://www.elrob.org/

${ }^{3}$ Sistema Embarcado de Navegação Autônoma - http://www.eesc.usp.br/sena
} 
de risco iminente, melhorando a dirigibilidade do motorista através de assistência cooperativa e, em casos extremos, atuando autonomamente em ambientes urbanos (Apêndice A).

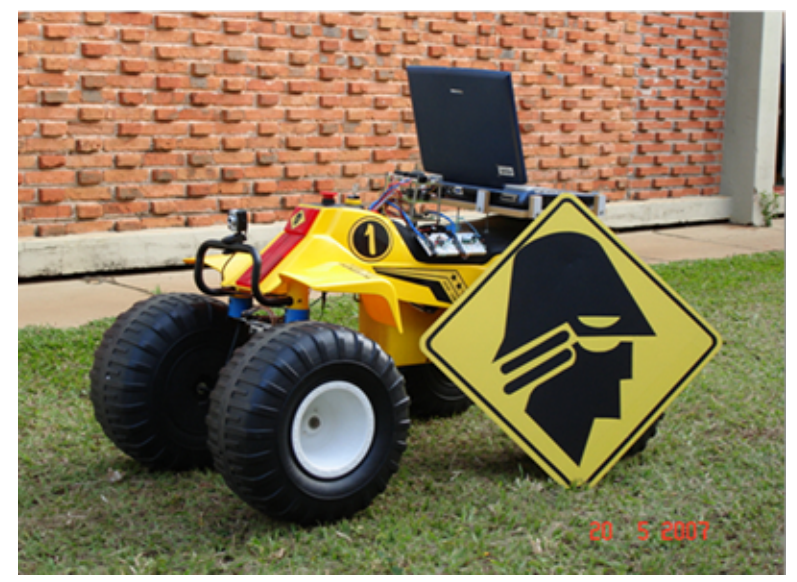

(a)

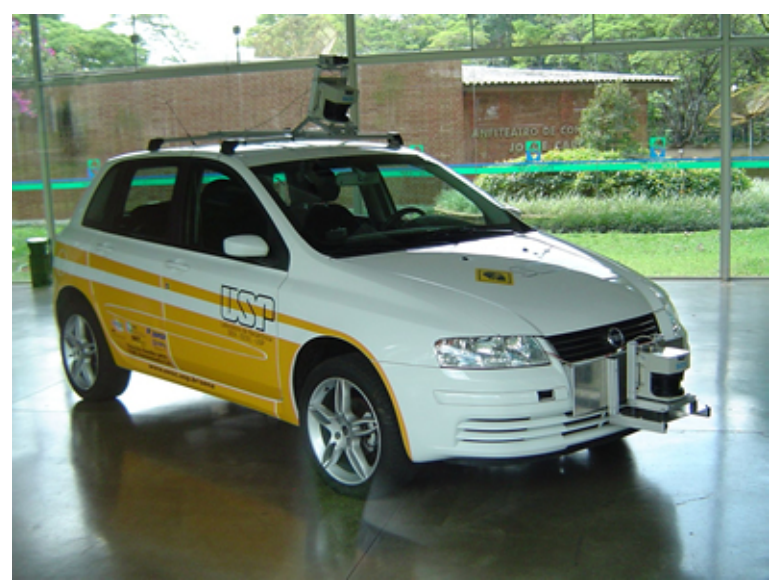

(b)

Figura 1.3: Protótipos do projeto SENA: (a) Navalha - quadriciclo elétrico infantil; (b) Gisa - Fiat Stilo 1.8 Dualogic

Uma das áreas de estudo do projeto SENA é o desenvolvimento de um sistema capaz de estacionar o veículo em vagas paralelas de forma autônoma, funcionalidade esta já encontrada em veículos no mercado consumidor, porém de forma semi-autônoma como exemplo o sistema Park4U da Valeo 4 (Valeo, 2010). Esta funcionalidade agregada ao projeto SENA pode ajudar os jovens condutores e até mesmo pessoas idosas que têm dificuldades em realizar esta manobra, seja por inexperiência, limitações visuais e motoras ou até mesmo nervosismo. Além disso, todos os países tiveram sua frota de veículos duplicada no período de uma década (IBGE, 2011), exigindo que as pessoas, principalmente nas grandes cidades, realizem a baliza o mais rápido possível, de modo a se desobstruir a via ocupada para que não haja congestionamentos ou até mesmo acidentes.

\subsection{Objetivos}

Este trabalho tem como objetivo o estudo e desenvolvimento de um sistema neural que seja capaz de fazer com que um veículo, em um ambiente simulado bidimensional, realize a manobra de estacionamento paralelo de forma autônoma entrando na vaga com uma única manobra. Estacionar o veículo com uma única manobra significa entrar realizar somente as seis etapas que serão mencionadas no início do Capítulo 2.

Para viabilizar o desenvolvimento do trabalho proposto o objetivo geral pode ser subdividido em objetivos específicos:

\footnotetext{
${ }^{4}$ Valeo Sistemas Automotivos - http: //www. valeo.com
} 
1. Estudar o estado da arte do problema de estacionamento para veículos do tipo carro de passeio;

2. Estudar e analisar a trajetória do veículo ao estacionar com uma única manobra;

3. Estudar técnicas de Aprendizado Supervisionado com Redes Neurais para criar um sistema autônomo e adaptável;

4. Simular diversos estacionamentos para validar o sistema proposto;

Ressalta-se que este trabalho realizou uma modelagem parametrizada podendo aplicar os resulatdos no veículo do projeto SENA e em qualquer outro veículo. Por isso, utilizou-se os parâmetros de um mini-veículo (Kyosho DRT) para tentar realizar os experimentos há tempo, porém o mesmo não ficou pronto até o término deste trabalho. Então, no final somente foi realizado testes no ambiente simulado desenvolvido.

\subsection{Estrutura da Dissertação}

O restante deste trabalho está disposto em seis capítulos organizados da seguinte forma:

Capítulo 2 - Estado da Arte: descreve o problema do estacionamento paralelo, principalmente para os motoristas recém habilitados. Além disso são apresentados os principais sistemas de estacionamento assistivos existentes no mercado e, logo na sequência, destacados alguns trabalhos acadêmicos relacionados a esta pesquisa.

Capítulo 3 - Modelagem e Simulação: este capítulo apresenta sucintamente os modelos do ambiente do veículo, modelo dos sensores para reconher o ambiente e o modelo cinemático do veículo. Por fim é apresentado também o simulador bidimensional desenvolvido para que seja possível realizar testes e validar o controle neural.

Capítulo 4 - Aprendizado Supervisionado e Redes Neurais: destaca-se neste capítulo os tipos de aprendizagem existentes na literatura e faz-se uso do aprendizado supervisionado usando redes neurais. Para finalizar é exibida uma breve revisão das características principais de funcionamento das redes neurais, assim como suas principais arquiteturas, métodos de avaliação e algoritmos de aprendizado supervisionado.

Capítulo 5 - Abordagem do Estacionamento Paralelo: este capítulo aborda como será realizado o estacionamento paralelo do veículo neste trabalho, que é dividido em três etapas. Além disso, na etapa de manobra do veículo é utilizada a curva em $S$, que se baseia em duas circunferências.

Capítulo 6 - Sistema Neural Desenvolvido: neste capítulo é abordado o funcionamento do sistema, a coleta de dados e as estratégias adotadas para escolha da melhor topologia de rede neural. Logo na sequência são apresentados os melhores resultados de topologias para oito casos de estudos, e algumas simulações são realizadas e discutidas. 
Capítulo 7 - Conclusão e Trabalhos Futuros: é discutida a proposta e apontadas perspectivas de desenvolvimento. 


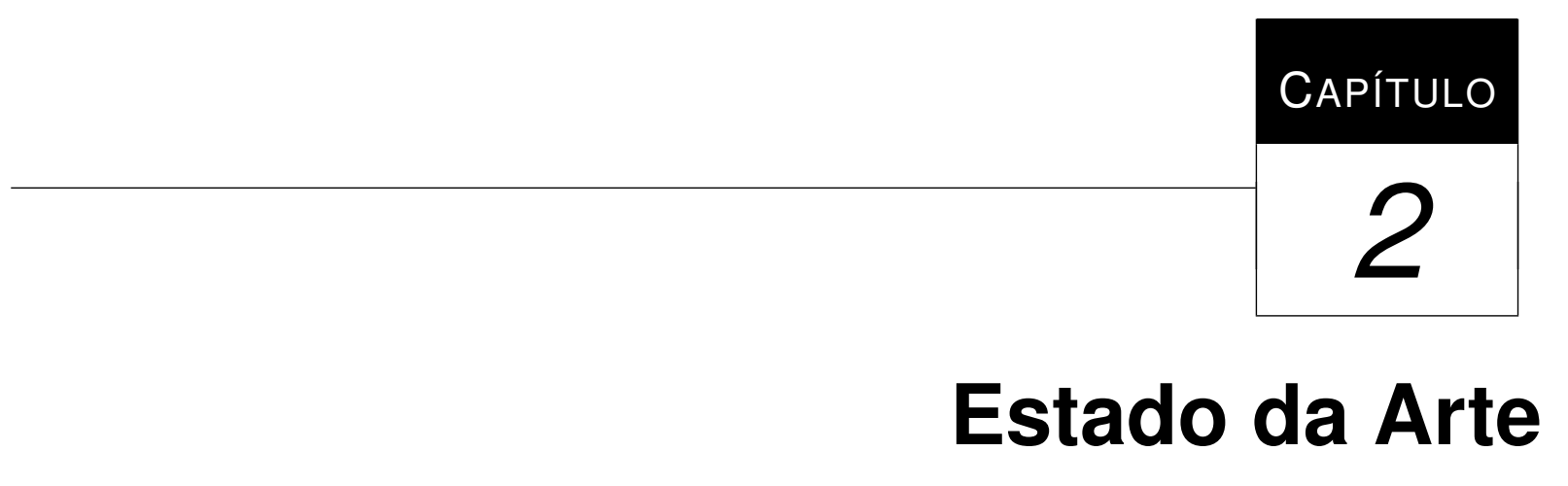

O problema de estacionamento pode ser classificado em três categorias: estacionamento do tipo garagem, estacionamento diagonal e estacionamento paralelo. Este projeto em particular somente estuda o problema do estacionamento paralelo (também conhecida como baliza), por se tratar da manobra mais difícil entre as três mencionadas para os motoristas com pouca experiência. Este capítulo tem como objetivo apresentar a baliza, assim como fazer um levantamento dos sistemas existentes no mercado que auxiliam a realização da manobra, como também das pesquisas acadêmicas realizadas nas duas últimas décadas.

\subsection{O Problema do Estacionamento Paralelo}

Estacionar o carro não é uma tarefa fácil, até mesmo para a maioria das pessoas que a realizam diariamente e, por vezes, acabam se frustando ao não conseguir realizá-la. A baliza consiste em colocar o veículo em linha entre outros dois veículos, formando uma linha paralela ao meio-fio. Apesar da grande dificuldade encontrada, principalmente pelos jovens condutores, a baliza pode ser realizada em passos muito bem definidos. Tais passos, que a partir de agora nomear-se-ão de etapas (Figura 2.1), seguidos de forma sequêncial sem nenhuma alteração, faz com que o veículo entre com uma única manobra na vaga (objetivo deste trabalho). Esses passos são descritos a seguir:

1. Procurar por um espaço para estacionar que seja no mínimo $\frac{1}{4}$ maior do que o comprimento do carro. Este valor do tamanho da vaga é questionável, pois depende de alguns fatores que serão apresentados na Equação 5.1 do Capítulo 6; 
2. Avançar paralelamente ao veículo em frente à vaga localizada, na qual será realizada a manobra. Usar como pontos de referência os para-choques traseiros dos dois carros, que devem estar emparelhados;

3. Engatar a marcha a ré e, assim que o carro começar a se mover, girar o volante para o lado do meio-fio. Entrar devagar com o carro no espaço encontrado;

4. Quando o para-choque traseiro do veículo estacionado adiante se encontrar na linha da metade da porta dianteira do carro, parar e virar todo o volante para o lado contrário ao meio-fio. Com a manobra anterior, o carro deve ficar aproximadamente em um ângulo de $45^{\circ}$ em relação ao meio-fio. Continuar em marcha a ré, devagar, até o carro ficar paralelo ao meio-fio. Quando o para-choque traseiro do carro se aproximar do veículo estacionado atrás, frenar para não bater e girar o volante até as rodas ficarem alinhadas;

5. Desloque o carro entre os dois estacionados até deixá-lo no centro da vaga para que, ao sair dela, possa manobrar mais facilmente;

6. Quando o carro estiver no centro da vaga, o motorisa deve parer e desliguar.

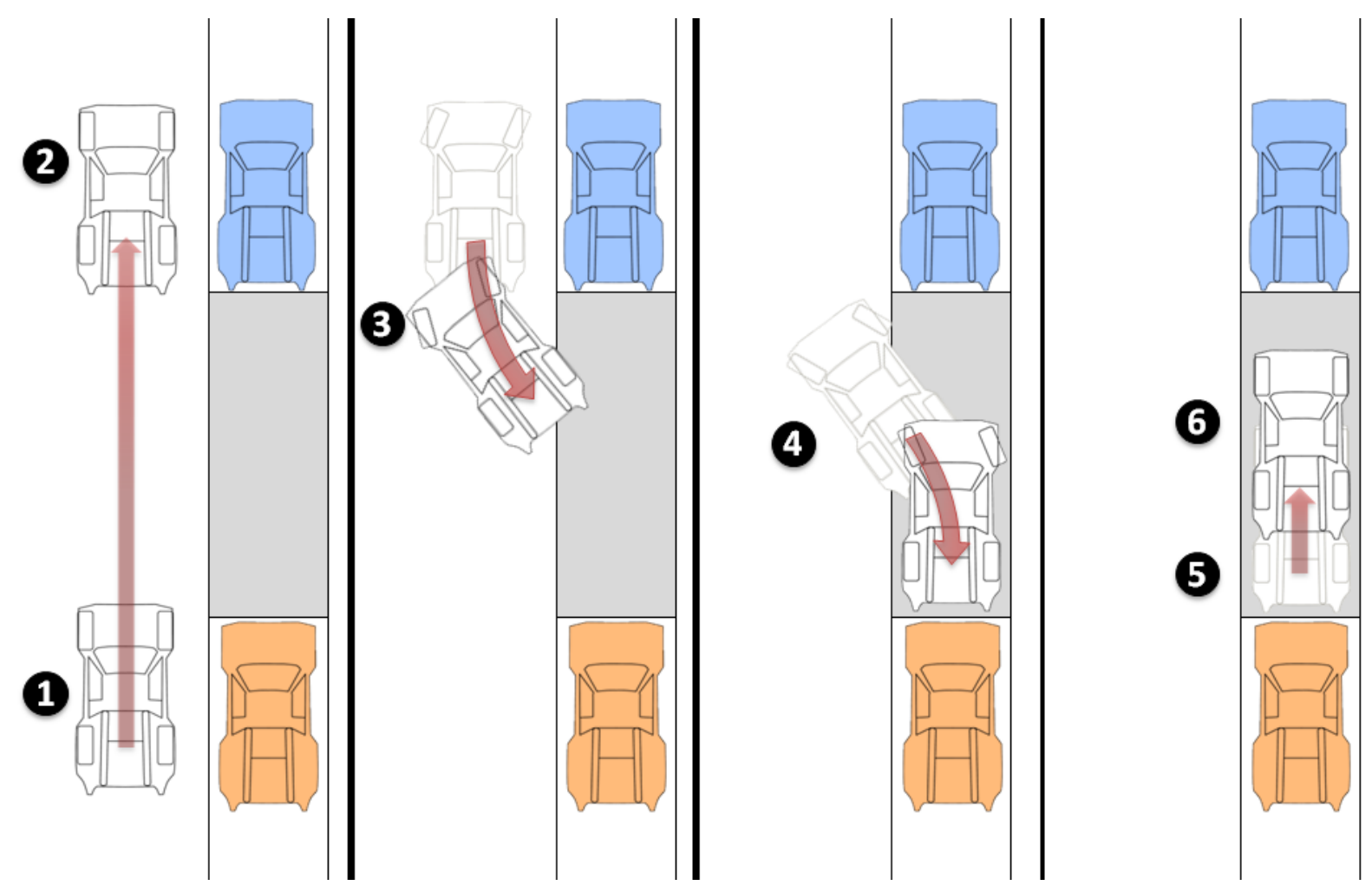

Figura 2.1: Etapas do estacionamento paralelo 


\subsection{Sistemas Automotivos para Estacionamento}

A indústria automobilistica e a comunidade acadêmica nestas últimas duas décadas, tem apostado no Parking Assistant System (PAS), sistema que auxilia o estacionamento (Lo et al., 2003; Huang e Lin, 2010). Em geral, o PAS pode fornecer informações ao motorista, como: distância até o carro da frente ou de trás, tamanho da vaga, quanto do volante deve ser girado e para qual lado, etc. Essas informações do ambiente externo (área ao redor do veículo) podem ser percebidas por diversos tipos de sensores, como por exemplo, sensores ultra-sônicos, câmeras do tipo CCD (do inglês, Charge-Coupled Device), sensores de infra-vermelho, sensores laser, ou até mesmo um sistema de radar.

A ideia do PAS foi proposta inicialmente pela VolksWagen em seu carro conceito IRVW (Integrated Research Volkswagen), em 1992. O IRVW tinha embarcado um microcomputador (PC) do tamanho do porta malas para controlar o sistema que estacionou o carro perfeitamente, porém, esta tecnologia nunca foi oferecida em modelos de produção. A Toyota, em 2003, implementou a tecnologia IPAS (Intelligent Parking Assist System) lançando no mercado consumidor o que até o momento só existia em carros conceitos. O IPAS tem um conjunto de sonares e uma câmera, interligados a um processador central. O processador calcula o ângulo de direção com base nos sensores e exibe uma mapa de navegação em uma tela touchscreen instalado no painel do veículo (Grabianowski, 2007). O display (Figura 2.2) permite que o condutor faça alguns ajustes finos de direção da vaga e depois aperte um botão (ok) para ativar o sistema. Após apertar o botão, o sistema elétrico de estacionamento guia o motorista até o local escolhido, deixando para o condutor somente a função de aceleração e frenagem do automóvel. O IPAS foi implementado primeiro no modelo Prius e, mais tarde, no modelo Lexus LS.

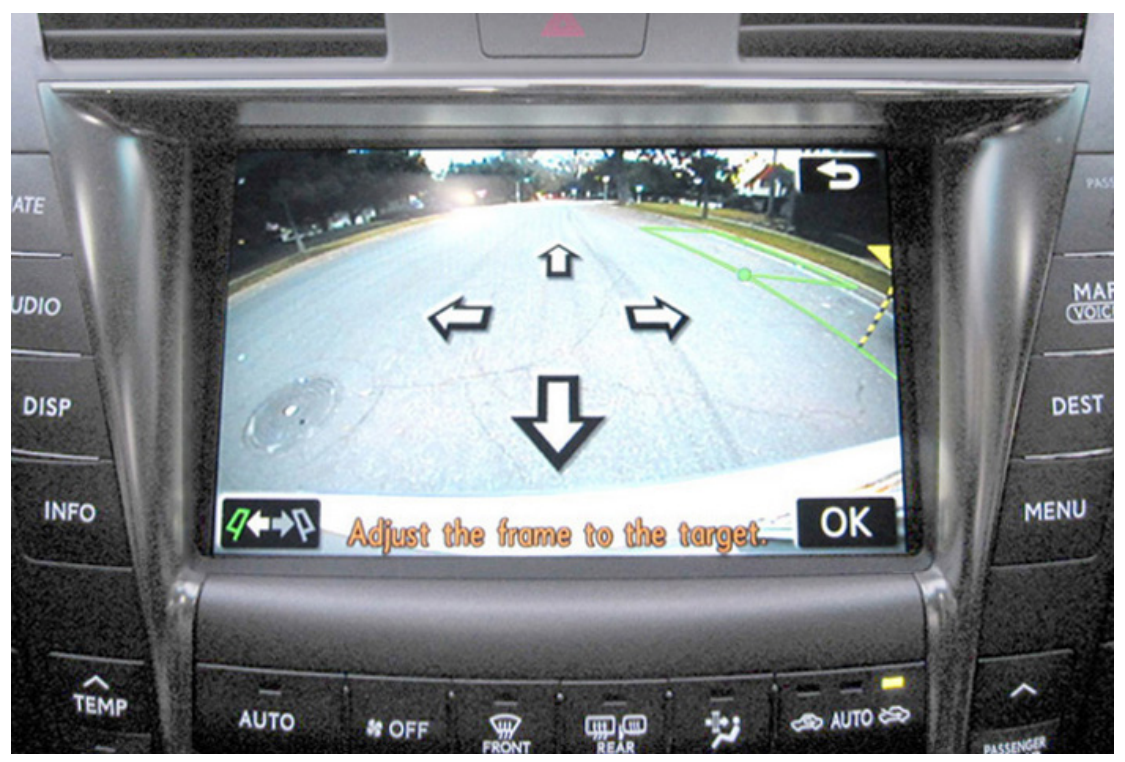

Figura 2.2: A tela do painel do Toyota Britânico com o Intelligent Parking Assist System (Retirado de http://wapedia.mobi/en/Advanced_Parking_Guidance_System). 
O Citroën C4 Picasso se tornou em 2006 o primeiro carro a apresentar um sistema integrado que auxilia o condutor a medir o tamanho da vaga e informa se o espaço é suficiente, apertado, ou pequeno demais para realizar a manobra. Este sistema foi desenvolvido pela empresa alemã Bosch $^{5}$ e é conhecido como Parking Aid. Ele é acionado pelo motorista através de um botão no volante e utiliza um sensor do tipo sonar na lateral do veículo para conseguir calcular o tamanho da vaga numa velocidade até $20 \mathrm{~km} / \mathrm{h}$ (Figura 2.3). Ao manobrar o veículo (o volante não gira sozinho) o Parking Aid continua dando suporte com os sensores emitindo sinais de medição ao redor do veículo, para que o mesmo não sofra colisão. Embora este sistema não estacione o carro em si, como o Lexus LS 460 ou o Toyota Prius, a Bosch lançou em 2007 um kit chamado ParkPilot URF6 que pode ser instalado em diversos veículos para completar o sistema e, em 2010, lançou uma atualização, o ParkPilot URF7 (Bosch, 2011). O ParkPilot é um conjunto de sensores tipo ultra-som instalado na parte frontal e traseira do veículo para indicar se o carro está perto de um obstáculo, através de avisos sonoros.

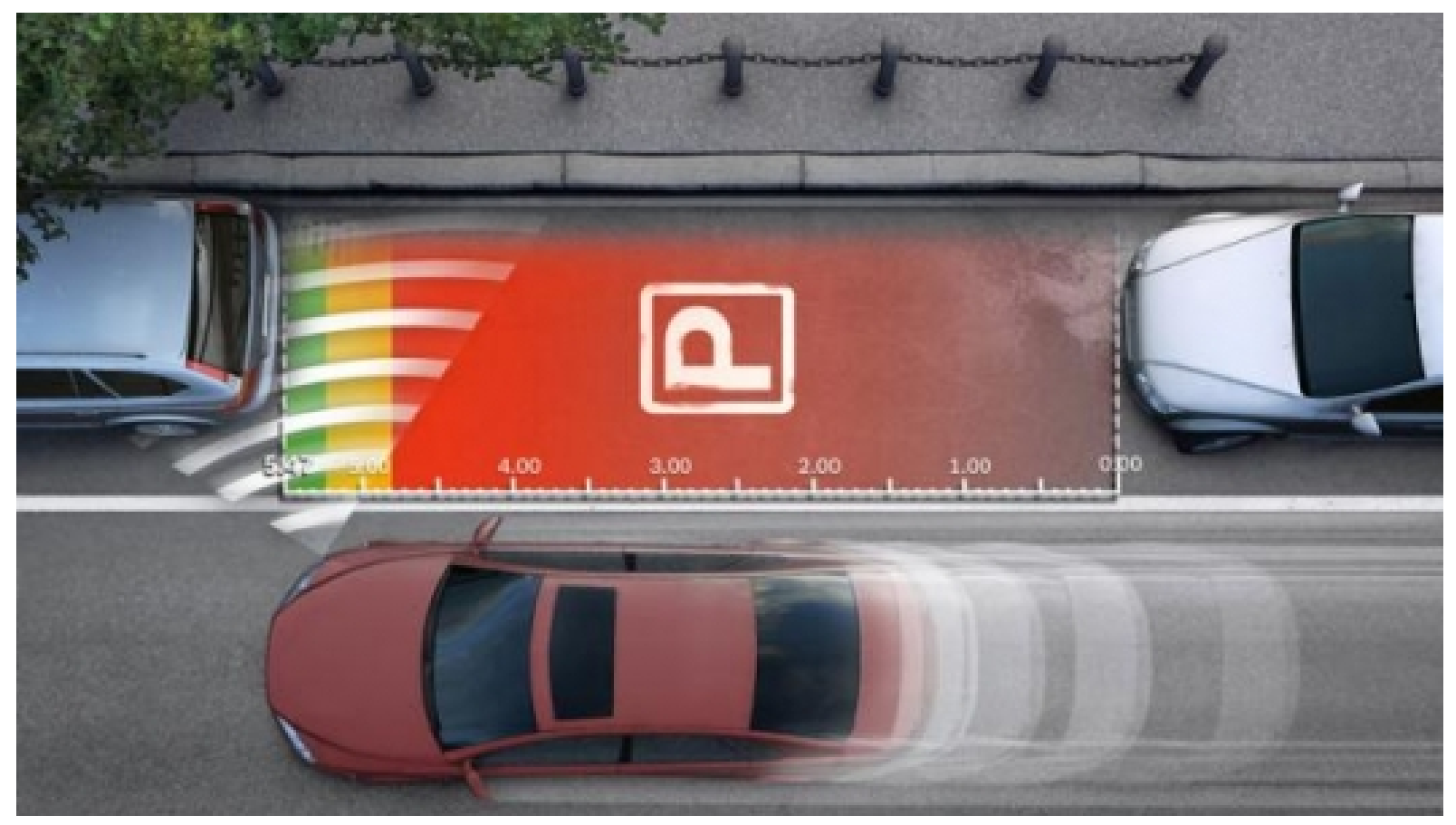

Figura 2.3: Exemplo de funcionamento do sistema da Bosch para medir o tamanho do espaço de estacionamento (Bosch, 2011).

Em 2009 a empresa Valeo cria o Park4U (Estaciona Para Você), que utiliza sonares ao redor do veículo e uma câmera, sendo muito parecido com o sistema da Toyota. Por intermédio dos sensores laterais, ele identifica o espaço (Figura 2.4(a) e Figura 2.4(b)) e verifica se é suficiente para realizar a manobra. Logo em seguida, informa o motorista por sinal sonoro que ele vai começar a manobra. Rapidamente é calculada a trajetória desejada e o sistema esterça o volante para entrar na vaga do tipo garagem (Figura 2.4(c)) ou paralela (Figura 2.4(d)), mantendo uma velocidade de aproximadamente $7 \mathrm{~km} / \mathrm{h}$. Ao motorista cabe somente a função de frear e acelerar,

\footnotetext{
${ }^{5}$ Bosch é uma empresa de inovação e tecnologia automotiva - http: / / www . bosch. com.br
} 
para concluir o estacionamento. O Park4U foi inicialmente instalado no Ford Lincoln MKS e MKT e, em 2010, foi aplicado nos automóveis VW Touran, Tiguan e Passat. A Valeo, a fim de melhorar a confiabilidade de seu sistema, recentemente fez parceria com a empresa Ibeo $^{6}$, que produz sensores laser automotivos, para que no futuro possa usufruir deste tipo de tecnologia (Valeo, 2010).

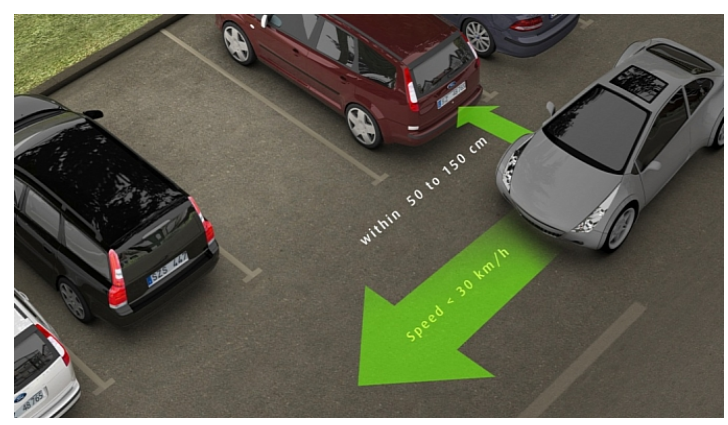

(a)

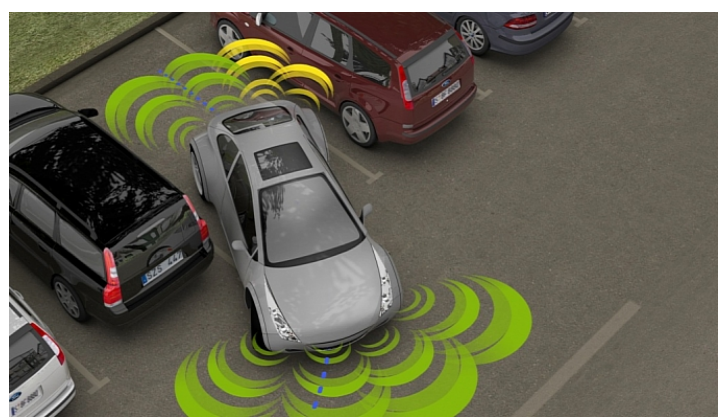

(c)

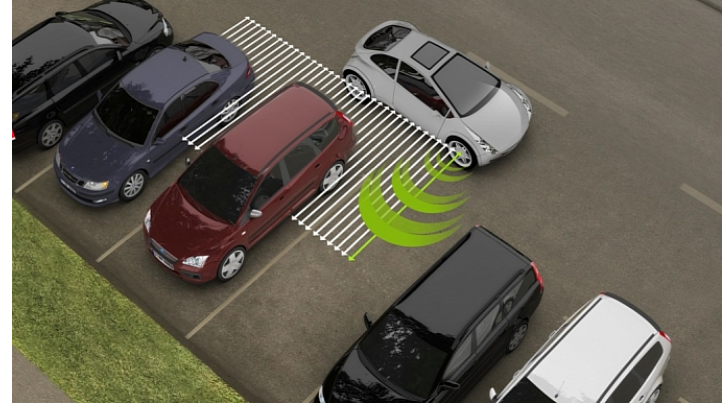

(b)

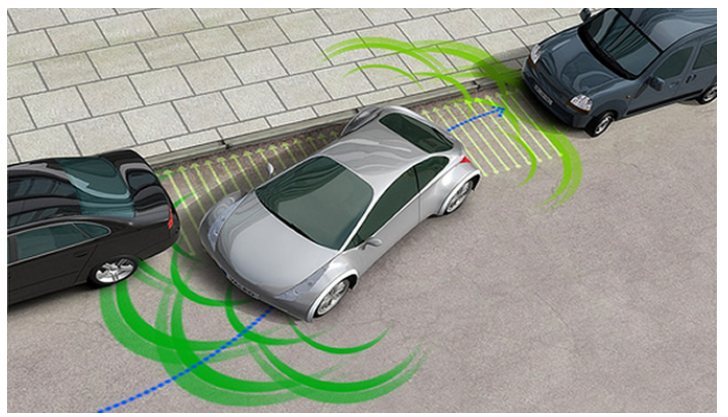

(d)

Figura 2.4: Sistema Park4U (Valeo, 2010) (a) e (b) procurando a vaga, em (c) entrando na vaga do tipo garagem e em (d) numa vaga paralela.

\subsection{Trabalhos Acadêmicos}

Os diversos trabalhos acadêmicos realizados nesta área costumam utilizar uma abordagem de planejamento de trajetória. O planejamento de trajetória consiste em gerar um caminho geometricamente viável planejado com antecedência (off-line), levando em consideração o modelo do ambiente, o modelo do veículo e suas restrições, permitindo ao sistema gerar controles para guiar o veículo no caminho definido. Ainda assim, nem todos trabalhos que serão apresentados a seguir em ordem cronológica, utilizam esta abordagem.

Gorinevsky et al. $(1994,1996)$ propuseram um controlador para um sistema autônomo de estacionamento em veículos não-holonômicos, baseado em uma rede neural de base radial (do inglês, Radial Basis Function - RBF) e usando um caminho do tipo senoidal (Murray e Sastry, 1993). O trabalho demonstra através de simulações númericas que o controle funciona em di-

\footnotetext{
${ }^{6}$ Ibeo Automotive Systems GmbH - http : / / www. ibeo-as. com/
} 
versos tipos de estacionamentos. Driss et al. (1994) apresentam um sistema capaz de detectar a vaga de estacionameno e manobrar o veículo utilizando informações de perfis 3D extraídos de uma sequência de imagens, treinando assim redes neurais em ambiente simulado. Paromtchik e Laugier (1996a,b); Laugier et al. (1998) equiparam um veículo Ligier elétrico com 14 sensores ultra-sônicos para realizar de forma autônoma o estacionamento paralelo e definiram três etapas para a manobra: a localização da vaga, o posicionamento do veículo e a manobra de estacionamento em si, que é realizada através de funções senoidais. Jiang e Seneviratne (1999) utilizam também sensores ultra-sônicos e as três etapas citadas anteriormente, porém o veículo é simulado e a trajetória seguida é composta por dois arcos de circunferências conhecido como curva em $\mathrm{S}$.

Kondak e Hommel (2001) apresentaram um método numérico utilizando conceitos de campos potenciais (Hui, 2010) para desviar dos obstáculos. Porém, o algoritmo tem um tempo médio de 10 segundos de processamento e, dependendo da configuração inicial, não consegue convergir. Autômatos Finitos (AF) foram aplicados para representar o conhecimento humano ao tentar realizar a baliza em ambiente simulado usando seis sensores ultra-sônicos, bússola e odometria em Heinen et al. (2001). Kaempchen et al. (2002) utilizaram visão estéreo para reconhecimento de vagas de forma tridimensional. Wada et al. (2003) descreveram uma solução em hardware e software para um sistema de assistente de estacionamento para o veículo Toyota-jZS147 usando GPS, odometria e giroscópio.

Outro estudo usando dois arcos de círculos como caminho para estacionar é apresentado por Lo et al. (2003). Porém, este utiliza sensores infra-vermelhos para detectar a vaga e os obstáculos. Um outro sistema de visão utilizando câmera CCD (localizada em cima da vaga, ou seja, fora do veículo) e marcações no chão foi proposto por Li e Chang (2003); Li et al. (2003b,a). Lee et al. $(2003,2004)$ combinaram o método de planejamento de movimento com controle de trajetória tentando obter uma solução rápida para a manobra de estacionamento em ambiente simulado. Oentaryo e Pasquier (2004) desenvolveu um controlador neuro-fuzzy baseado na Rede Neural Difusa GenSoYager ${ }^{7}$ e integrou ao simulador cardriving para fins de treinamento e testes. No trabalho de Chao et al. (2005) foi desenvolvido um sistema baseado em visão omni-direcional e a trajetória foi gerada por dois arcos de círculos iguais. No trabalho de Zhao e Jr. (2005) sonares foram usados para identificar o espaço de estacionamento e os parâmetros do controlador fuzzy foram ajustados pela aplicação de um algoritmo genético (AG) (Linden, 2008).

Li et al. (2006) fizeram uma fusão sensorial entre quatro sonares e seis infravermelhos para detectar o espaço de estacionamento e entrar na vaga. Heinen et al. (2007) apresentaram uma Rede Neural Artificial (RNA) (Haykin, 2001) que aprendeu o comportamento humando através de uma base de exemplos gerada pelo AF de Heinen et al. (2001), conseguindo assim manobrar o veículo simulado. Ill et al. (2007) utilizaram um mini-veículo equipado com dois motores DC

\footnotetext{
${ }^{7}$ GenSoYager-FNN é uma rede neural difusa desenvolvida no Centro de Inteligência Computacional (C2I, http://www.c2i.ntu.edu.sg).
} 
e oito sensores de distância do tipo PSD (Position Sensing Detector) para localizar e manobrar na vaga. Jung et al. (2007) propuseram um método de Light Strip Projection (LSP) para reconher vagas de estacionamento em diversas posições e em diversas condições de iluminação usando uma câmera e uma luz projetada no plano. Em Jung et al. (2008a) foram utilizados um sensor laser com uma câmera para detectar cantos e possivelmente a vaga de estacionamento, enquanto quem em Jung et al. (2008b) uma câmera foi empregada para encontrar marcações de estacionamento no chão. Park et al. (2008) criaram um método de detectar espaços de estacionamento usando sensor ultra-sônico do tipo Polaroid 600 e realizaram testes com um robô móvel PIONNER 2-AT2.

Hsu et al. (2008) implementaram um planejador de trajetória de menor caminho baseado em dois arcos de círculos, utilizando sensores ultra-sônicos, um RTK-GPS e uma câmera no veículo Mitsubishi Savrin para realizar baliza ou garagem. Cabrera-Cosetl et al. (2009) equiparam um robô móvel do tipo carro (do inglês, Car Like Mobile Robot - CLMR) com sensores de ultra-som e bússola para localizar a vaga de estacionamento e manobrar o veículo utilizando um controlador fuzzy em ambiente simulado (Matlab/Simulink) e com o CLMR em cima de uma bancada de teste. Khoukhi e Demirli (2009); Demirli e Khoshnejad (2009) implementaram um controlador neuro-fuzzy somente para realizar a manobra do veículo, não se preocupando em identificar a vaga. Ele utiliza como entrada parâmetros de três sensores ultra-som localizados na frente do veículo (entrada frontal na vaga). Deve-se ressaltar aqui que os dados foram gerados somente em ambiente simulado, usando um polinômio de quinta ordem como caminho de referência. Lee et al. (2009) utilizaram redes Petri para substituir os algoritmos tradicionais e algoritmos genéticos para encontrar a melhora trajetória. Em seguida o veículo simulado segue a trajetória utilizando lógica fuzzy.

Oetiker et al. (2009) apresentaram um sistema de campos numéricos em malha fechada aplicado ao veículo real, o qual é equipado com sonares e consegue se adaptar a mudanças no ambiente e evitar colisões. O trabalho apresentado por Huang e Lin (2010) usou um controlador de auto-organização fuzzy, dados de sonar como entrada e uma função sinusoidal como um caminho de referência para a manobra. Li et al. (2010) utilizaram vários sensores ultra-sônicos em um mini-veículo com regras fuzzy para realizar o estacionamento, enquanto Gupta et al. (2010) fizeram um estudo da manobra de estacionamento paralelo, criando um AF para estacionar o veículo simulado com quatro sensores ultra-sônicos: dois na lateral do veículo, um na frente e outro atrás. Usando uma câmera e lógica fuzzy Shaohua e Chao (2010) criaram um sistema de auxílio ao estacionamento.

\subsection{Considerações Finais}

Este capítulo abordou o problema do estacionamento paralelo e mostrou os principais sistemas de estacionamento assistivos existentes no mercado. Logo na sequência, foram apresen- 
tados diversos trabalhos acadêmicos que realizam a manobra de diversas formas, com diversos sensores. Uma boa parte desses trabalho utiliza lógica fuzzy e sensores do tipo ultra-som, além de ambientes simulados. Vale ressaltar que na maioria desses trabalhos, para identificar o espaço de estacionamento, é preciso detectar uma parede ou o meio-fio. Porém é apontado por Demirli e Khoshnejad (2009) que a dependência na detecção do meio-fio tem uma desvantagem significativa para conduzir o veículo na baliza, pois nem sempre o meio-fio se encontra na mesma altura, ou tem uma altura considerável para detecção ou até mesmo pode estar quebrado. 


\begin{tabular}{c|c|}
\hline CAPITULO \\
\hline \\
\hline \\
\hline Modelagem e Simulação
\end{tabular}

Este capítulo apresenta os princípios para a implementação de um simulador e uma breve descrição dos modelos utilizados neste trabalho. Logo em seguida é descrita a implementação do simulador e as suas capacidades e restrições.

\subsection{Modelos}

Com base nos estudos realizados sobre os robôs móveis autônomos, os sub-tópicos a seguir descrevem os diversos modelos (ambiente, cinemático e sensorial) que serão utilizados tanto no simulador quanto no sistema desenvolvido.

\subsubsection{Modelo do Ambiente}

Segundo Thrun (2003), os mapas que representam um ambiente onde um robô pode executar suas tarefas podem ser classificados em dois grandes grupos de acordo com sua estrutura: mapa métrico e mapa topológico. O mapa métrico captura as propriedades geométricas do ambiente e, entre os diversos modelos existentes, o mais comum é o mapa baseado em grades (ou grids). O mapa topológico por sua vez, descreve a sua conectividade entre os diferentes lugares baseada em grafos. Na Figura 3.1(a) é ilustrado um exemplo de mapa métrico baseado em grades e na Figura 3.1(b) é exibido o mesmo exemplo de mapa, mas com o modelo topológico. Existem também os modelos híbridos (Buschka e Saffiotti, 2004), que combinam as características positivas de ambos os modelos de mapas. 
Neste trabalho utiliza-se uma alternativa de mapa métrico proposta por Chatila e Laumond (1985) apud Thrun (2003) conhecida como mapa geométrico. Este modelo de ambiente é uma das representações mais tradicionais na área da robótica móvel, pois utiliza primitivas geométricas (segmentos de retas, poliedros, etc.) para construir uma abstração de alto nível do ambiente. Esta abordagem permite uma representação consistente e de fácil interpretação por parte dos seres humanos, além de ser facilmente manipulada pelos computadores. No entanto, este modelo é, muitas vezes, pouco representativo quando o ambiente depende de mais informações, principalmente do ponto de vista dos sensores do robô. Na Figura 3.1(c) é exibido um exemplo de mapa geométrico.

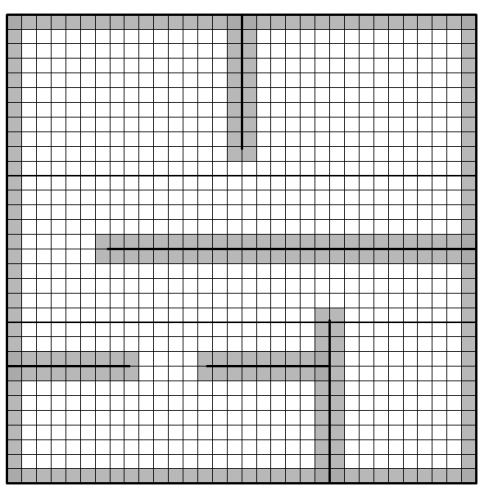

(a)

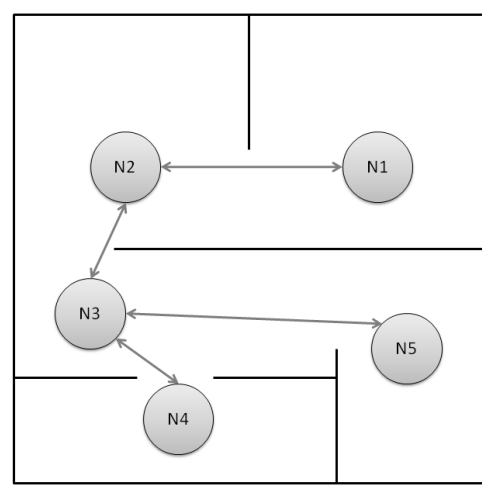

(b)

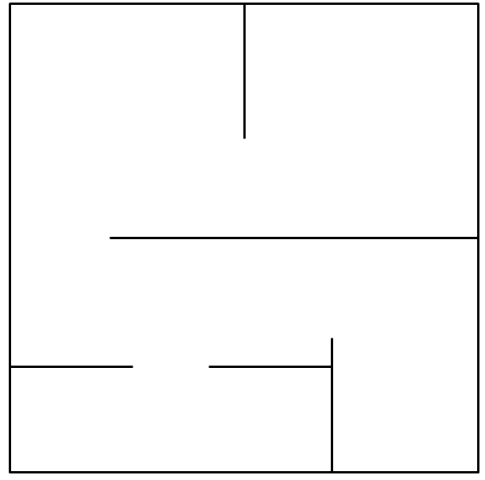

(c)

Figura 3.1: Tipos de mapas utilizados na robótica: (a) representação métrica baseado em grades; (b) representação topológica; (c) representação geométrica.

\subsubsection{Modelo do Veículo}

Existem na literatura diversos modelos já estudados que são bem fiéis ao comportamento real do robô, inclusive simulando os erros de resposta aos comandos de atuação (Dudek e Jenkin, 2000; Siegwart et al., 2011). O modelo do veículo, também conhecido como modelo cinemático, descreve a maneira como o robô movimenta-se pelo ambiente. A modelagem cinemática do sistema de esterçamento do veículo é conhecida como geometria de Ackerman (Gillespie, 1992). Esta modelagem é derivada da indústria automotiva, que utiliza um sistema mecânico no sistema de direção do veículo, permitindo que a roda interna a uma curva (roda do lado para o qual se deseja virar) gire com um ângulo maior que a roda externa à curva, para evitar derrapagens. Entretanto é importante notar que algumas hipóteses simplificadoras foram adotadas, de modo que o comportamento do veículo continue com uma resposta suficientemente aceitável e o processamento dos cálculos seja mais rápido. Levando isso em consideração, as hipóteses simplificadoras para as análises futuras são:

1. Roda sem escorregamento: todo o movimento no plano da roda deve ser compatível com o seu giro; 
2. Roda sem deslizamento lateral: movimento lateral da roda é igual a zero;

3. Veículos a baixas velocidades: a dinâmica do veículo (robô móvel) pode ser desprezada (Zhu e Rajamani, 2006).

Pode-se então definir:

$$
\left\{\begin{array}{l}
J_{1} R(\theta) \dot{\epsilon}_{I}-J_{2} \dot{\varphi}=0 \\
C_{1} R(\theta) \dot{\epsilon}_{I}=0
\end{array}\right.
$$

Assim, tem-se que a Equação 3.1 representa respectivamente a primeira e a segunda hipóteses simplificadoras. Nesta equação, o termo $R(\theta)$ representa a matriz de rotação do sistema de coordenadas inerciais fixo à Terra para o sistema de coordenadas do veículo. O termo $\dot{\epsilon}_{I}$

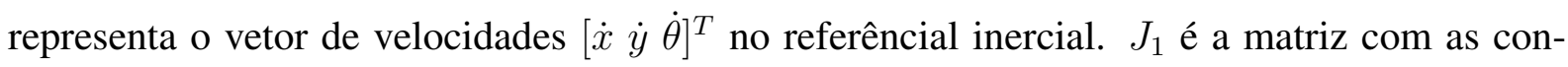
dições de contorno impostas pela hipótese simplificadora (1) (rodas sem escorregamento). Ela tem dimensão $\mathrm{N}$ x 3, onde $\mathrm{N}$ é o número de rodas presente no robô. $J_{2}$ é a matriz diagonal $\mathrm{N}$ $\mathrm{x} \mathrm{N}$ com os raios das rodas do robô móvel. O vetor $\dot{\varphi}$ representa as velocidades angulares de cada roda. Por fim, $C_{1}$ é a matriz ( $\mathrm{N}$ x 3 ) com as condições de contorno impostas pela hipótese simplificadora (2) rodas sem deslizamento lateral.

Ainda segundo Siegwart et al. (2011), o centro instantâneo de rotação de um robô móvel (ICR), o qual representa o centro da circunferência descrita instantaneamente pelo robô, depende somente das restrições impostas ao mesmo, independentemente do número de rodas presente. Essa consideração permite refletir sobre a simplificação do modelo do veículo. Assim, considerando as hipóteses simplificadoras de não-escorregamento e não-deslizamento, mais a garantia de movimentos em baixas velocidades nos quais a dinâmica é pouco relevante (Zhu e Rajamani, 2006), pode-se aproximar o modelo do carro por um modelo do tipo bicicleta (Pinheiro, 2009), cujas equações cinemáticas estão bem difundidas (Kochem et al., 2002). A Equação 3.2b mostra o modelo cinemático de bicicleta utilizado:

$$
\begin{gathered}
\theta=\frac{\theta_{l}+\theta_{r}}{2} \\
\left\{\begin{array}{l}
\dot{x}=V \cos \phi \\
\dot{y}=V \sin \phi \\
\dot{\phi}=\left(\frac{\tan \theta}{l}\right)
\end{array}\right.
\end{gathered}
$$

onde $V$ é a velocidade longitudinal do veículo, o vetor $\left[\begin{array}{lll}\dot{x} & \dot{y} & \phi\end{array}\right]^{T}$ representa as velocidades lineares e angular do robô com referência ao sistema inercial, $\phi$ é a orientação do robô em relação à abscissa do sistema inercial, $l$ é a distância entre eixos, $\theta$ é o ângulo do esterçamento da roda, simplificado conforme Equação 3.2a onde, $\theta_{l}$ é o angulo de esterçamento da roda esquerda e $\theta_{r}$ é o angulo de esterçamento da roda direita e. A Figura 3.2 exibe o modelo cinemático adotado e seus parâmetros, cujos detalhes estão compreendidos na Tabela 3.1. 


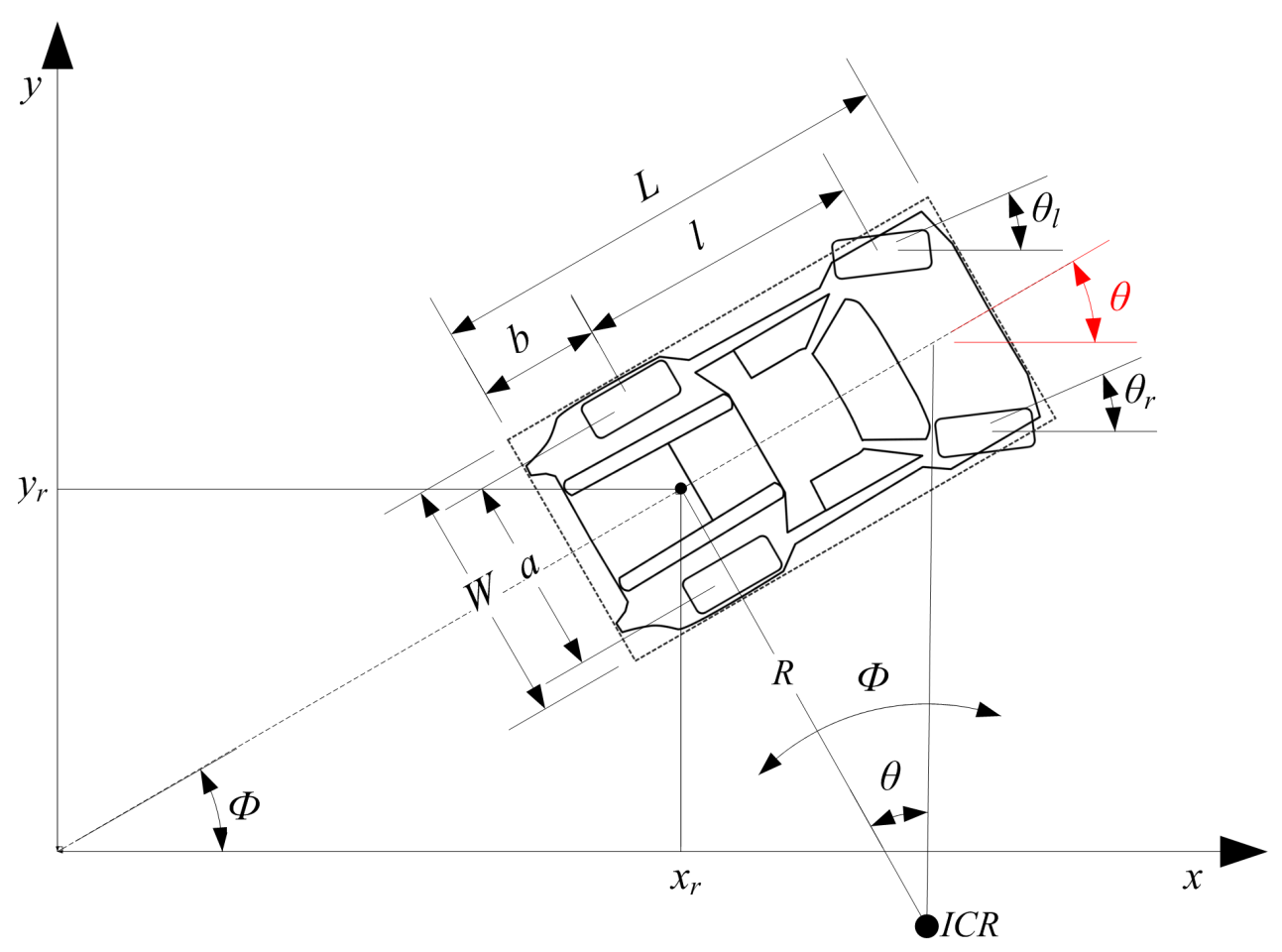

Figura 3.2: Modelo cinemático do veículo.

Tabela 3.1: Descrições dos parâmetros da cinemática do carro.

\begin{tabular}{cc}
\hline \hline Símbolo & Descrição \\
\hline$\theta$ & Ângulo de esterçamento do carro \\
$\theta_{l}$ & Ângulo de esterçamento da roda esquerda \\
$\theta_{r}$ & Ângulo de esterçamento da roda direita \\
$l$ & Distância entre eixos \\
$L$ & Comprimento do carro \\
$b$ & Distância entre o eixo traseiro e a traseira do carro \\
$a$ & Distância entre rodas \\
$\phi$ & Orientação do carro \\
$W$ & Largura do carro \\
$R$ & Raio descrito pela roda do carro \\
$V$ & Velocidade longitudinal do carro \\
$I C R$ & Centro Instantâneo de Rotação \\
{$[X, Y]$} & Referêncial inercial do carro \\
\hline
\end{tabular}

Com as equações cinemáticas apresentadas em Equação 3.2b, tem-se o vetor de velocidades do veículo em função de sua posição atual e o ângulo de esterçamento. Com isso pode-se estimar sua posição segundo a Equação 3.3 (Kochem et al. 2002):

$$
\left\{\begin{array}{l}
x(k+1)=x(k)+\dot{x} \Delta t \\
y(k+1)=y(k)+\dot{y} \Delta t \\
\phi(k+1)=\phi(k)+\dot{\phi} \Delta t
\end{array}\right.
$$


onde o vetor $\left[\begin{array}{lll}x & y & \phi\end{array}\right]^{T}$ representa as posições do veículo nas coordenadas globais (referencial

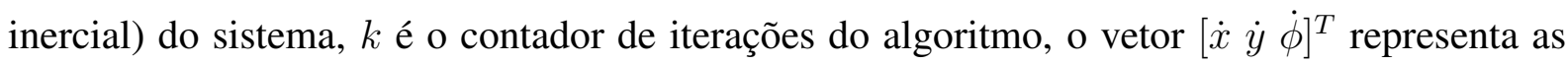
velocidades no instante $k$ do veículo, lembrando que as velocidades são funções da atual posição do robô e sua velocidade de cruzeiro. Por fim, o termo $t$ representa o intervalo de tempo entre a posição $k$ e a predição $k+1$.

Os parâmetros utilizados para implementação do robô móvel no simulador foram do miniveículo Kyosho DRT modificado e apresentado em Sampaio et al. (2011). Este veículo passou a ser chamado de HELVIS (Hybrid Electric Vehicle In Low Scale) pelo projeto de conversão de veículos de passeio convecionais $2 \times 4$ em um veículo hibrido $4 \times 4$. Os parâmetros do HELVIS utilizados na simulação são exibidos na Tabela 3.2 e o veículo é mostrado na Figura 3.3.

Tabela 3.2: Parâmetros do mini-veículo HELVIS utilizado na simulação.

\begin{tabular}{cc}
\hline \hline Símbolo & Valor \\
\hline$\theta$ & $-30^{\circ} / 30^{\circ}$ \\
$W$ & $260 \mathrm{~mm}$ \\
$R_{\min }$ & $580,24 \mathrm{~mm}$ \\
$l$ & $335 \mathrm{~mm}$ \\
$L$ & $480 \mathrm{~mm}$ \\
$b$ & $65 \mathrm{~mm}$ \\
\hline \hline
\end{tabular}

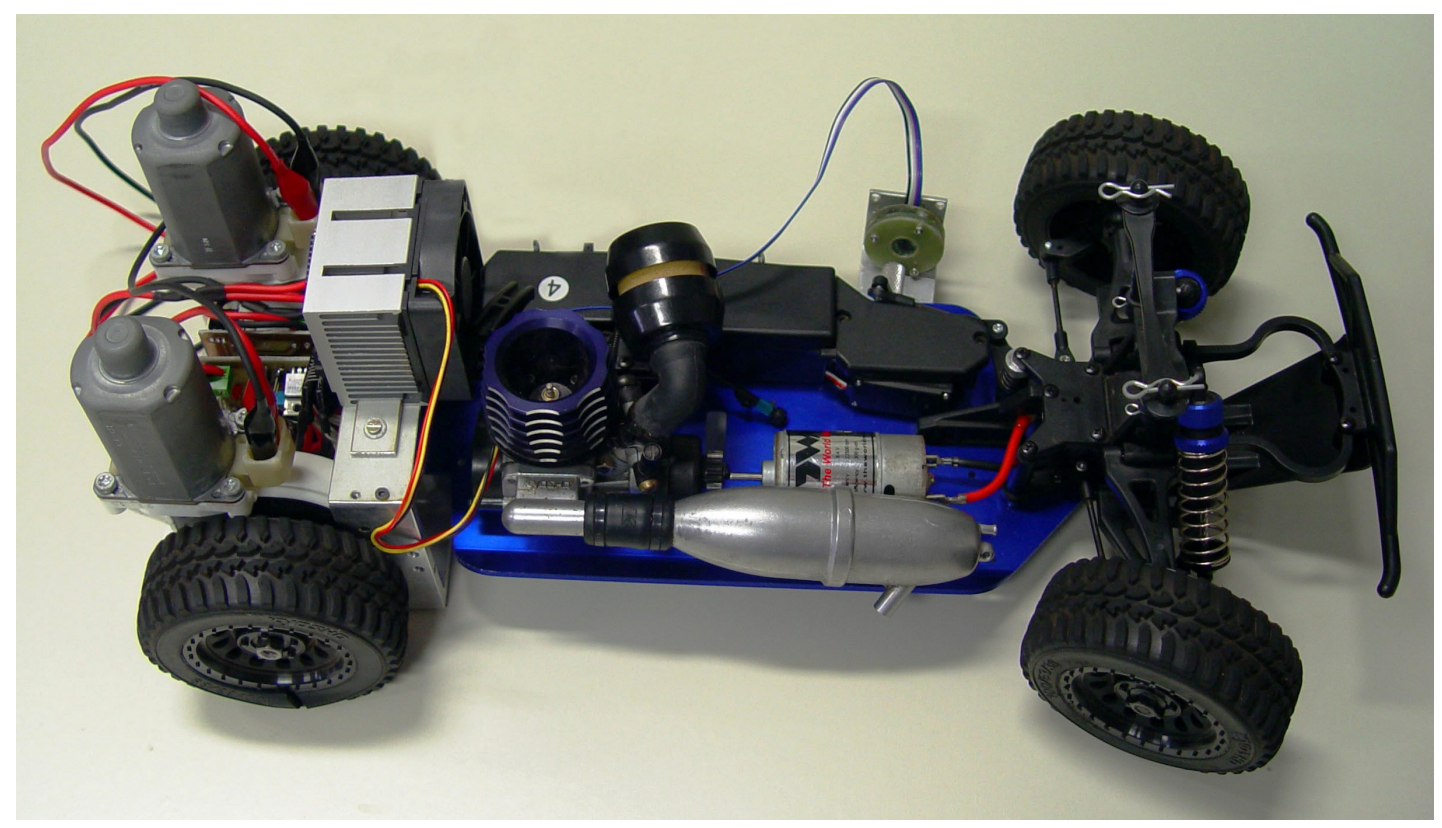

Figura 3.3: Mini-veículo HELVIS (Sampaio et al., 2011).

\subsubsection{Sensores}

Em um mundo não-determinístico, onde os modelos não são perfeitos, o sensoriamento é uma maneira de compensar aproximações e de estimar a configuração do ambiente de modo 
a facilitar o planejamento e realização de tarefas. Existe uma enorme gama de sensores que podem ser utilizados em robôs móveis autônomos e que, de acordo com Siegwart et al. (2011), podem ser classificados de duas formas. A primeira forma leva em conta o meio em que é efetuada a medição (proprioceptivos e exteroceptivos) e a segunda forma tem em vista a forma como os sensores capturam os sinais (passivo ou ativo).

- Proprioceptivo, são os sensores que medem valores internos ao sistema, como por exemplo a velocidade do motor e bateria.

- Exteroceptivo, são os sensores que adquirem informações sobre o ambiente do robô, como medidas de distância, intensidade de luz, amplitude do som.

- Passivos, são sensores que medem a energia do ambiente que entra no sensor. Por exemplo: sondas de temperatura, microfones e câmeras.

- Ativos, são sensores que emitem energia para o ambiente, então medem a reação do ambiente à essa energia. Exemplos de sensores ativos incluem sensores ultra-sônicos, sonares, e LASERs para medir distância (Siegwart et al., 2011).

A seguir, são descritos os modelos dos sensores utilizados neste trabalho.

\subsubsection{Encoders}

Os encoders (ou codificadores rotativos) são populares na robótica móvel, pois permitem realizar a medição da posição angular ou velocidade angular de um eixo em rotação, além de possuirem um ótimo custo

beneficio, boa precisão em curtas distâncias e apresentam alta taxa de amostragem (Borenstein et al., 1996, 1997). Esses sensores normalmente são ópticos incrementais, acoplado às rodas para medir as velocidades de rotação e poder assim estimar a sua posição baseando-se nas informações obtidas.

Para exemplificar o funcionamento de um encoder, tome-se como exemplo o encoder óptico (Figura 3.4). Ele possui um disco (máscara) perfurado em distâncias regulares. O disco é acoplado à roda do robô e assim ambos giram na mesma velocidade. Os furos do disco permitem, ou não, a passagem de um feixe de luz infravermelha enquanto a roda gira. Esse feixe é gerado por um emissor (LED) que se encontra de um dos lados do disco e captado por um receptor (Sensor de Luz) que se encontra do outro lado do disco, gerando uma onda quadrada que representa a frequência de leitura desse feixe. Dessa forma, a velocidade ou posicionamento é registrado contando-se o número de pulsos gerados.

A informação fornecida pelos encoders é conhecida como odometria. Contudo, essas informações são suscetíveis a erros, que aumentam proporcionalmente com a distância percorrida, e só podem ser corrigidos com a fusão de dados de outros sensores. Os erros que ocorrem na odometria podem ser classificados em dois principais tipos (Borenstein et al., 1997): 


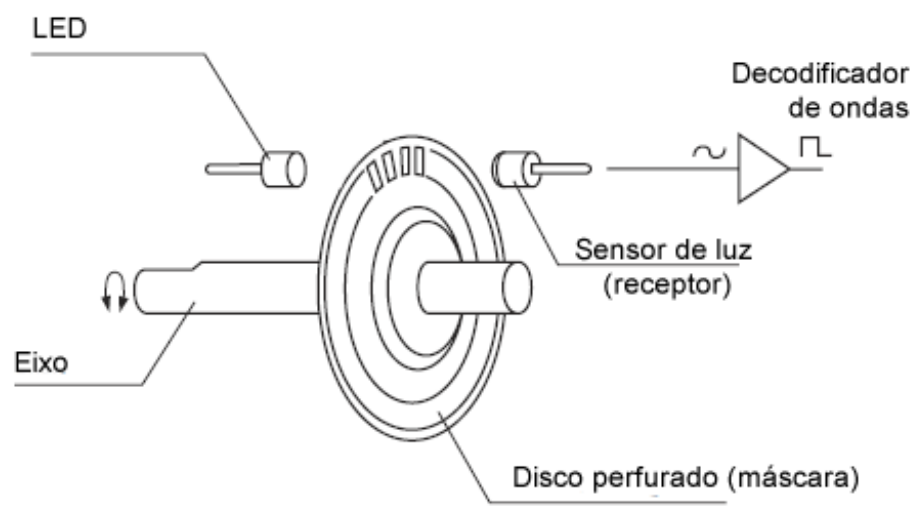

Figura 3.4: Princípios de funcionamento do encoder óptico (adaptado de Electronics (2009)).

- Erros sistemáticos: são erros causados pelas imperfeições construtivas do robô, por exemplo, rodas com diferentes diâmetros, desalinhamento das rodas, resolução do encoder limitada, etc. Esses erros acumulam-se constantemente e podem causar erros de medidas de deslocamento com o passar do tempo;

- Erros não-sistemáticos: são erros resultantes da interação entre as rodas do robô móvel com o solo, por exemplo, derrapagem das rodas, rachaduras no solo, intervenções externas (geralmente causadas por humanos, etc.). Esse tipo de erro é mais difícil de tratar por serem de natureza aleatória.

\subsubsection{Sensor Laser}

Outro tipo de sensor muito utilizado na robótica móvel é o sensor laser (do inglês, Light Detection and Ranging (LIDAR)). Sensores Laser são equipamentos que utilizam a energia eletromagnética em frequências altas para medir a distância a obstáculos presentes no ambiente. O método de medição comumente utilizado neste dispositivo é por tempo de voo, que consiste em medir o intervalo de tempo entre a emissão e o recebimento do pulso de laser (Borenstein et al., 1997). Os dispositivos do tipo LIDAR geralmente são acoplados a um espelho rotatório, possibilitando assim fazer uma varredura do ambiente. A Figura 3.5 exibe dois sensores laser comumente utilizados em aplicações no LabRoM, o primeiro é o SICK LMS-291 (Figura 3.5(a)) e o segundo o Hokuyo URG-04LX (Figura 3.5(b)).

Este tipo de sensor é utilizado em tarefas que exigem a cobertura de uma grande área, devido ao seu poder de varredura simultânea, além de grande precisão nas medidas. Esses sensores realizam apenas leituras planares, sendo assim chamados de sensores 2D. Para cada feixe de luz emitido e capturado são retornados os valores de distância e ângulo do ponto em relação à direção de emissão. A Tabela 3.3 faz comparações entre os sensores SICK LMS-291 e Hokuyo URG-04LX. 


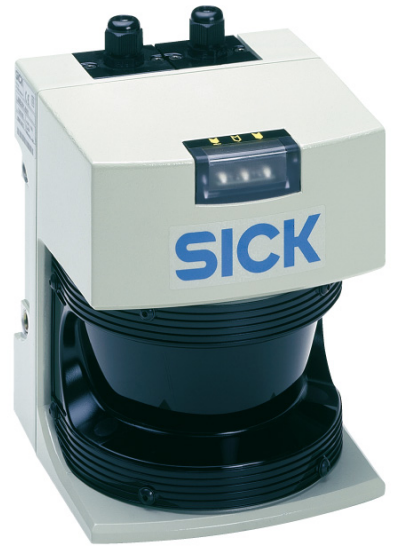

(a)

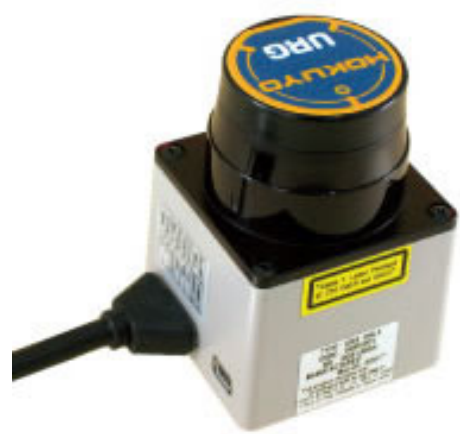

(b)

Figura 3.5: Alguns sensores laser: (a) Modelo de sensor laser SICK LMS 291; (b) Modelo do sensor laser Hokuyo URG-04LX.

Tabela 3.3: Comparação das especificações do sensor SICK e Hokuyo URG-04LX (Lee e Ehsani, 2008).

\begin{tabular}{cccc}
\hline \hline & Unidade & Sick LMS-291 & Hokuyo URG-04LX \\
\hline Max. Distância & $\mathrm{m}$ & 80 & 4,0 \\
Resolução & $\mathrm{mm}$ & 10 & 1 \\
Ângulo de Varredura & $\mathrm{grau}$ & $180 \mathrm{e} 100$ & 240 \\
Resolução Angular & $\mathrm{grau}$ & $1^{\circ}$ & 0,36 \\
Tempo de Varredura & scan/s & 75 & 10 \\
Interface com PC & & $\mathrm{RS}-232 / \mathrm{RS}-422$ & $\mathrm{USB} / \mathrm{RS}-232 \mathrm{C}$ \\
Tempo de transf. dados & $\mathrm{kb} / \mathrm{s}$ & $9,6-500$ & 12,000 (USB) e 19,2-750 (RS-232) \\
Dimensões & $\mathrm{mm}$ & $185 \times 156 \times 210$ & $50 \times 50 \times 70$ \\
Peso & $\mathrm{kg}$ & 4,5 & 0,16 \\
Energia consumida & $\mathrm{W}$ & 20 & 4,0 (máximo) \\
\hline
\end{tabular}

\subsubsection{Sensor Inercial}

Os sensores inerciais são constituídos de giroscópios e acelerômetros (Borenstein et al., 1997; Dudek e Jenkin, 2008). O giroscópio mede rotação em relação a um referencial inercial e o acelerômetro mede a aceleração própria nos três eixos ao longo do tempo. Através de cálculos integrais é possível obter velocidade e orientação sem depender de parâmetros externos. Os acelerômetros utilizados em robótica são comumente sistemas eletromecânicos (Microelectromechanical Systems - MEMS) e, os giroscópio podem ser ópticos, mecânicos ou por efeito de Coriolis (Forhan, 2010).

O sensor inercial utilizado no projeto SENA (IG-500N, fabricado pela SBG System) é atualmente o menor sistema do mundo em sua classe (Bonnevi et al., 2007). O IG-500N apresenta seis graus de liberdade, sendo composto de 3 giroscópios, 3 acelerômetros, 3 magnetômetros, sensor de temperatura, pressão e GPS, além de incorporar o algoritmo de Kalman, oferecendo 
uma boa precisão mesmo em condições dinâmicas. A Figura 3.6 exibe um diagrama de blocos simplificado do seu funcionamento.

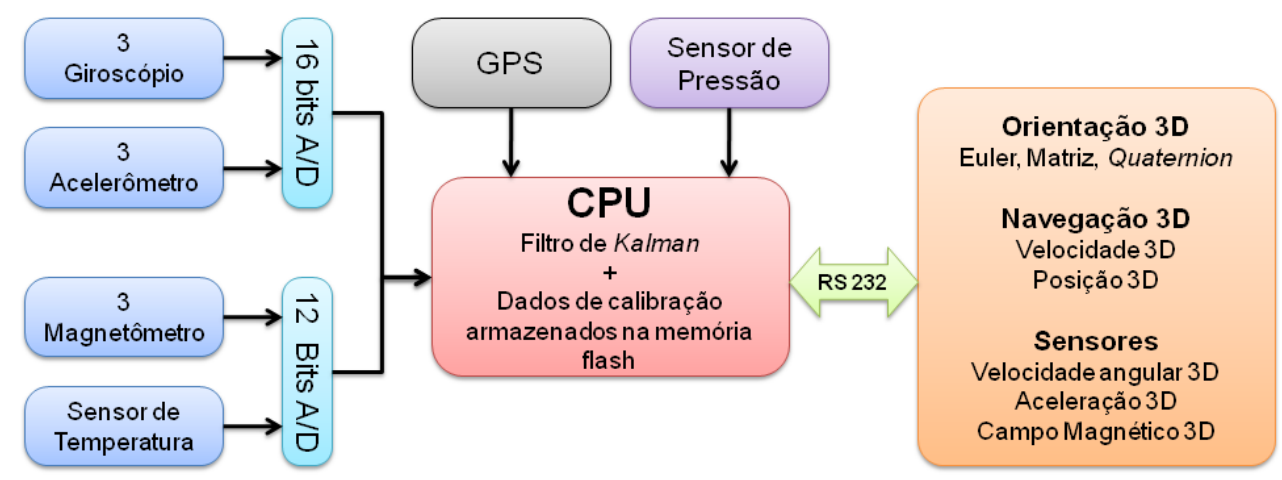

Figura 3.6: Diagrama de blocos simplificado do sensor IMU IG-500N (adaptado de (SBG Systems, 2011)).

Basicamente a CPU recebe as informações de todos os sensores mais os dados de calibração dos mesmos e aplica um filtro de Kalman (Sasiadek e Khe, 2001). O filtro de Kalman é utilizado na predição e ajuste dos parâmetros do modelo através de cada nova medição, obtendo-se a estimativa do erro em cada atualização. O sensor (Figura 3.7) utiliza comunicação RS232 para enviar os dados de orientação 3D (euler, matriz e quaternion), navegação 3D (velocidade e posição tridimensional) e dados dos sensores (velocidade angular, aceleração e campo magnético tridimensional).

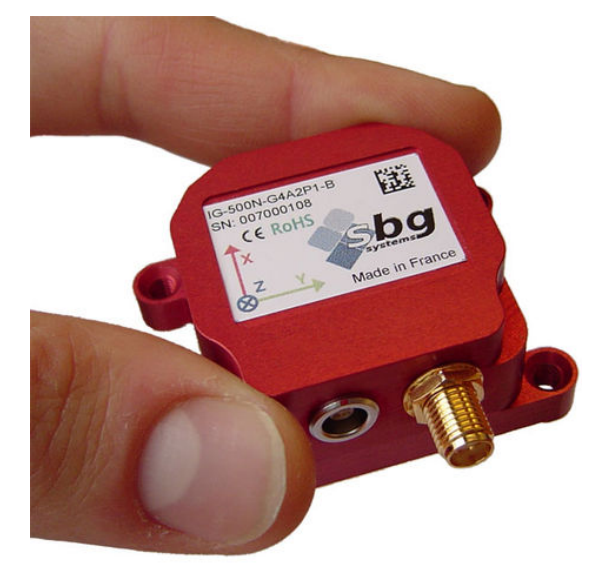

Figura 3.7: Imagem do sensor IMU IG-500N entre os dedos de uma pessoa para mostrar seu tamanho.

\subsection{Simulação}

As pesquisas em veículos autônomos podem ser iniciadas em ambientes virtuais, pois o veículo real pode sofrer danos durante os testes ou até mesmo por em risco a vida das pessoas a sua volta, além do alto custo inicial de equipá-lo com dispositivos a serem utilizados no sistema. Os 
simuladores são ferramentas muito importantes para pesquisadores, pois permitem total controle das variáveis do sistema, sendo possível replicar os experimentos e resultados, analisar os dados, comparar algoritmos, acelerar ou desacelerar os processos. Apesar disso, tudo depende do nível de confiança e precisão da simulação, pois a mesma não consegue modelar completamente os elementos do mundo real (Law e Kelton, 2000). A simulação virtual deve levar em consideração que em diversos pontos, algumas restrições devem ser criadas, ou seja, deve estar claro que a simulação não é o mundo real. Para criar um ambiente para este trabalho foi necessário desenvolver os modelos do ambiente, dos sensores e atuadores utilizados e também do comportamento físico do robô (Heinen et al., 2006b).

\subsubsection{Simuladores de Robôs Móveis}

Atualmente é possível encontrar na internet simuladores de robôs móveis que são livres para uso, outros que exigem a compra de licenças e alguns que são comercializados juntamente com o robô. Dentre os simuladores disponíveis que poderiam ser utilizados para este trabalho estão: Microsoft Robotics Studio (Morgan, 2008), Player/Stage/Gazebo (Player, 2011; Rusu et al., 2007), SimRob3D (Heinen, 2002) ou SEVA2D/3D (Heinen et al., 2001, 2007).

O Simulador de Estacionamento de Veículos Autônomos Bidimensional (SEVA2D), (Heinen et al., 2001) é o único simulador implementado especificamente para o controle da tarefa de estacionamento. Este simulador foi desenvolvido em Visual $\mathrm{C}++$, de forma modular utilizando bibliotecas da classe MFC (Microsoft Foundation Classes). Ele permite a visualização em janela gráfica da trajetória e do comportamento do veículo durante o processo de estacionamento. O SEVA2D possui alguns controladores já implementados como: SEVA-A baseado em um autômato (uma máquina de estados combinando técnicas reativas-deliberativas) e o SEVA$\mathrm{N}$ baseado em uma rede neural (implementa o autômato através do aprendizado a partir de um conjunto de exemplos) (Osório et al., 2002). O SEVA3D (Heinen et al., 2007) é a versão tridimensional do SEVA2D, baseado na biblioteca de funções fornecidas pelo SimRob3D. Esta nova versão consegue identificar o meio-fio aproximando mais o ambiente simulado do real. A Figura 3.8 exibe o ambiente de simulação do SEVA2D e 3D.

\subsubsection{Simulador Desenvolvido}

Após análise dos modelos a serem utilizados e dos simuladores existentes, optou-se por implementar um novo simulador que possuísse somente os recursos necessários para este projeto, a fim de ter o total controle do funcionamento do mesmo caso algum erro crítico aconteça. 


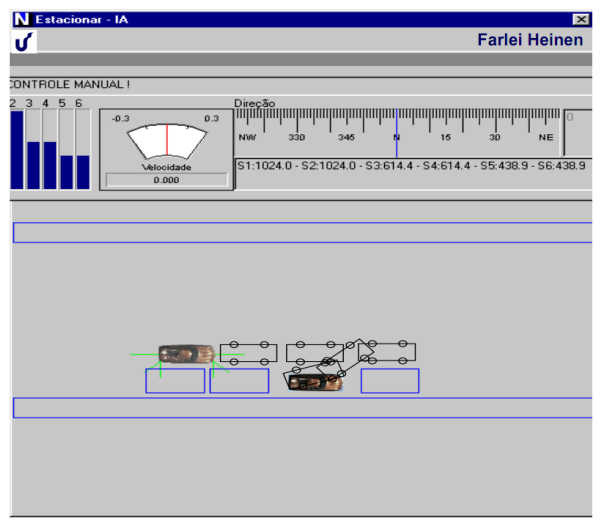

(a)

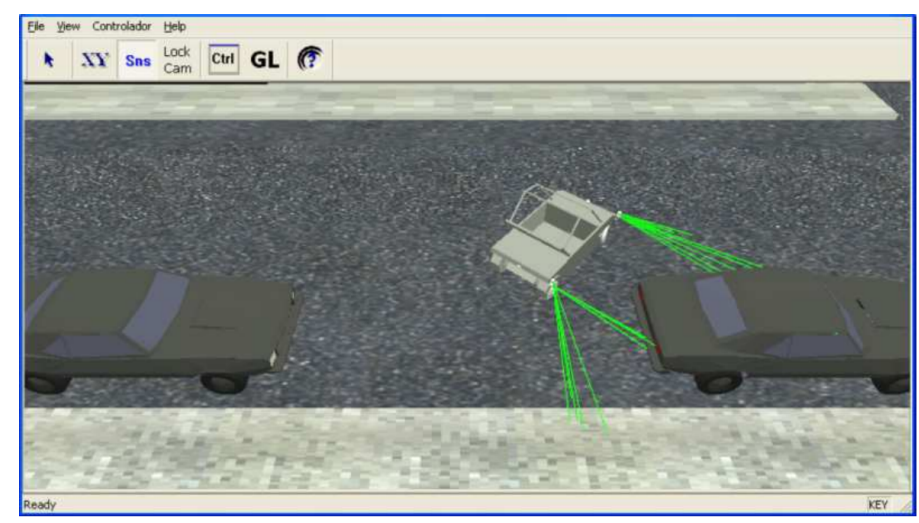

(b)

Figura 3.8: Simulador de Estacionamento de Veículos Autônomos (SEVA): (a) versão bidimensional do simulador (Heinen et al., 2001); (b) versão tridimensional do simulador (Heinen et al., 2007)

\subsubsection{Implementação do Simulador}

O simulador foi desenvolvido utilizando a linguagem C\# (lê-se, C Sharp) (Marshall, 2008) que é orientada a objetos, fortemente tipada ${ }^{8}$, criada pela Microsoft como parte da plataforma .Net. A linguagem C\# foi baseada na linguagem C++ mas inclui muitas influências de outras linguagens como Object Pascal e Java. Para auxiliar o desenvolvimento foi utilizado o Ambiente de Desenvolvimento Integrado (IDE) Visual C\# 2008 Express Edition (versão gratuita do Visual Studio). O ambiente bidimensional do simulador foi desenvolvido em Windows Forms e a biblioteca gráfica na plataforma .Net, que ajudou no processo de implementação por ser de simples uso.

Apesar do simulador ser implementado no Visual C\#, os controladores desenvolvidos podem ser implementados em MatLab e adicionados ao modelo de controle do veículo através de uma DLL (Dynamiclink library biblioteca de vínculo dinâmico) que o próprio MatLab consegue criar. O módulo de controle infelizmente não foi separado do simulador, o que possibilitaria ao usuário criar o controlador em outras linguagens de sua preferência e ampliaria a modularidade do simulador.

Esta abordagem apesar de não ser modular, implementa threads para os sensores, controle e visualização do ambiente. Esta separação tenta garantir que a visualização do ambiente não interfira nos passos da simulação que será executada em períodos diferentes de tempo. Este simulador é implementado conforme o digrama de classes da UML visto na Figura 3.9. Nesta figura tem-se que:

- Simulador: contém informações do funcionamento do simulador como o laço principal de controle do programa, alternando as informações de atualizações e desenho;

\footnotetext{
${ }^{8}$ Linguagens fortemente tipadas no contexto da Computação, são aquelas em que a declaração do tipo é obrigatória. Todas as variáveis têm um tipo específico que tem que ser explicitado. Java, C++, C\# e Fortran são exemplos deste tipo de linguagem.
} 


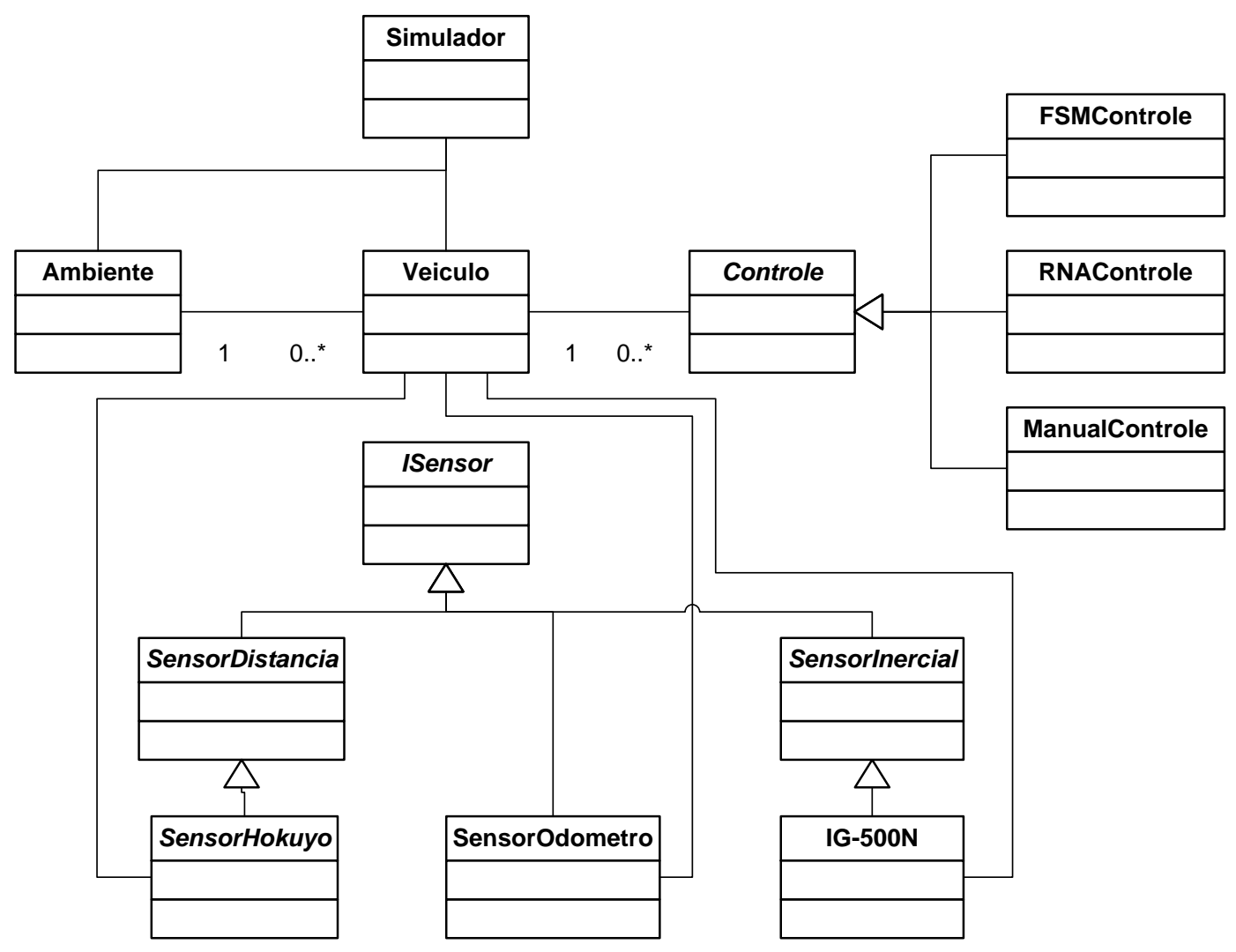

Figura 3.9: Diagrama de classes do simulador desenvolvido.

- Ambiente: esta classe permite adicionar, remover e posicionar objetos em tempo de execução, assim como alterar o tamanho de visualização dos mesmos;

- Veículo: contém os parâmetros do veículo, assim como seu modelo cinemático para simulação apresentado no início deste capítulo. Esta classe também recebe informações dos sensores que podem ser adicionados ou removidos via código;

- ISensor: uma interface comum para os sensores, no qual os mesmos podem implementar as funções para que o simulador utilize de forma genérica. A classes SensorHokuyo, SensorOdometro e IG-500N são derivadas desta classe e representam os sensores reais com seu funcionamento e erros simulados.

- Controle: classe abstrata que contém métodos para controle do veículo, de onde derivam o sistema de controle manual de deslocamento (avanço, recuo e velocidade) e esterçamento (rotação da direção) do veículo e sistema de controle autônomo do veículo (Autômato finito e Redes Neurais Artificiais).

\subsubsection{Interface do Simulador}

A interface gráfica do simulador foi implementada de forma que os elementos principais fiquem sempre visíveis ao usuário. A Figura 3.10 apresenta a interface gráfica do simulador 
desenvolvido. Nela define-se: (1) barra de menu de opções na parte superior; (2) barra de informações abaixo da barra de menu contendo botões para iniciar e reiniciar a simulação, informações dos sensores, de visualização da trajetória e de visualização do ambiente; (3) na lateral esquerda encontra-se informações dos veículos que estão no ambiente virtual; (4) controle manual do veículo e informação de orientação do carro com base no IMU; (5) botão para iniciar o controle autônomo do veículo com base em algum controlador selecionado no menu de opções; (6) escala de visualização do ambiente virtual; (7) progresso da manobra de estacionamento; (8) informações de entrada e saída da rede neural que estiver em execução; (9) visualização gráfica da simulação.

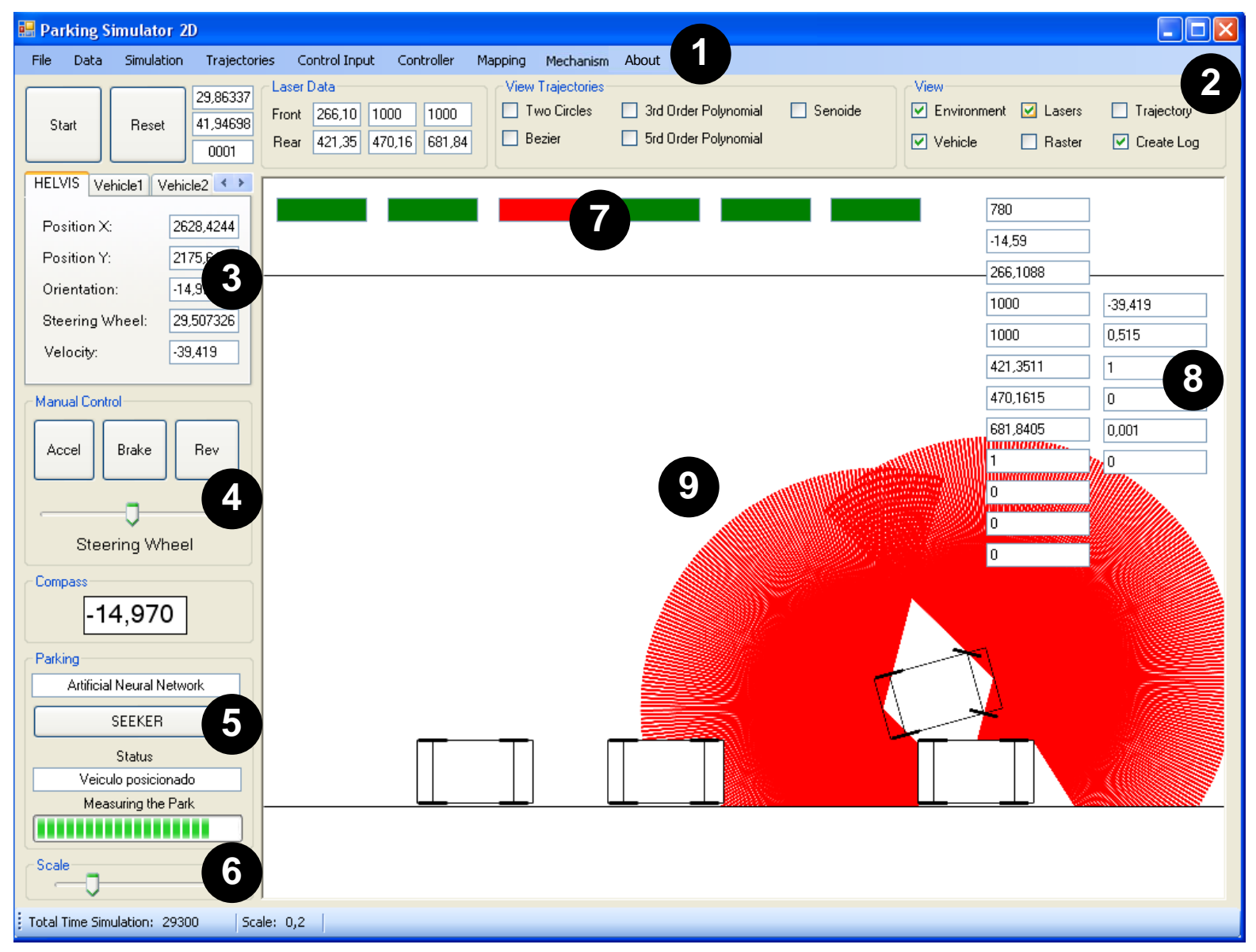

Figura 3.10: Interface do simulador

O menu de opções possibilita o acesso a todas ferramentas disponíveis para o controle do ambiente, dados dos sensores, controle da simulação e gerenciamento da manobra de estacionamento. A partir deste menu é possível acessar:

- Arquivo: permite carregar outros ambientes gráficos ou salvar alguma configuração realizada no ambiente atual;

- Dados: acesso as informações dos sensores, abrir arquivos e gravar;

- Simulação: opções para iniciar a simulação, pausar e até reiniciar; 
- Controle de Entrada: habilita o controle manual ou acesso a joystick (em desenvolvimento);

- Controlador: possibilita a seleção dos controladores uma vez que eles estejam implementados;

- Mapeamento: exibe os dados dos sensores em um plano cartesiano local (em desenvolvimento);

- Mecanismo: exibe o mecanismo de direção do veículo;

- Sobre: mantém informações dos criadores.

A movimentação dos objetos no ambiente acontece em tempo de execução, porém com velocidade menor à real, por causa da quantidade de polígonos desenhados na tela. Os objetos podem ser movimentados durante a simulação, possibilitando simular ambientes dinâmicos, alterando a posição dos objetos.

\subsection{Considerações Finais}

Este capítulo apresentou os principais recursos fundamentais para o desenvolvimento de um simulador específico para esta dissertação, no qual fosse possível ter controle total da situação. Dentre os recursos apresentados estão os modelos dos ambiente que permitem o robô realizar suas tarefas, navegando nele por meio de sua cinemática. Além da cinemática é necessário usar sensores que são os dispositivos mais fundamentais da robótica, pois é por meio deles que os robôs conseguem capturar informações do ambiente. Dentre os sensores apresentados estão os odômetros, sensor laser e sensor inercial.

Por fim, foi desenvolvido um software que possibilita a programação dos controladores para realizar a manobra de estacionamento. Este reduz o tempo de desenvolvimento e permite validar os algoritmos elaborados antes de implantá-los em um robô real. 


\section{Aprendizado Supervisionado e Redes Neurais}

Aprender significa "tornar-se apto ou capaz de alguma coisa, em consequência de estudo, observação, experiência, advertência, etc.” (Ferreira, 2004).

Em computação, Aprendizado de Máquina (AM, ou do inglês Machine Learning) é uma das áreas da Inteligência Artificial que tem por objetivo investigar técnicas computacionais para simular comportamentos inteligentes de aprendizagem e desenvolver métodos automáticos para obtenção de novos conhecimentos, novas habilidades e identificação de conhecimento já existente (Rezende, 2005; Hua et al., 2009). Russel e Norvig (2004) explicam o processo de AM a partir de observações, de modo que o sistema seja capaz de tomar decisões, atuar e aprender com o resultado de suas ações. O AM classifica os métodos de aprendizagem em três tipos: aprendizagem supervisionada, aprendizagem não-supervisionada e aprendizagem por reforço.

No algoritmo de aprendizagem supervisionada, padrões de valores (exemplos de entradas e saídas) que modelam o comportamento de um ambiente são apresentados a um sistema. O algoritmo deve extrair a representação do conhecimento a partir desses conjuntos de exemplos, ou seja, ele deve ser capaz de reproduzir corretamente o resultado desejado para cada entrada que alimente o modelo. Caso isto não aconteça, o modelo é modificado até que as saídas correspondam aproximadamente às entradas esperadas. Na aprendizagem não-supervisionada, seu objetivo é criar um sistema capaz de atuar sem prévio conhecimento de exemplos de saída. O sistema deve ser capaz de separá-los em grupos e estabelecer um padrão de acordo com os critérios do problema, somente com exemplos de entradas. Por último, a aprendizagem por reforço consiste no aperfeiçoamento do sistema a partir do reforço (punição ou recompensa). 
O sistema dessa vez não tem dados de exemplos, mas sim um instrutor em tempo de execução, que avalia os resultados de suas ações em relação ao ambiente.

A seção seguinte apresenta uma revisão sucinta do método de aprendizado supervisionado adotado neste projeto (Redes Neurais Artificiais - RNA). O uso de RNA para o problema de estacionamento é justificado por ser uma técnica robusta em relação a situações novas e inesperadas, por possuir um alto grau de generalização e eficiência comprovada em diferentes áreas de aplicação.

\subsection{Redes Neurais Artificiais - RNAs}

As RNAs são modelos matemático-computacionais inspirados no sistema nervoso dos seres vivos e que possuem a capacidade de adquirir conhecimento através de experiências (Haykin, 2001; Braga et al., 2007; Silva et al., 2010). RNAs estão inseridas dentro da área conhecida como sistemas inteligentes (conexionista) e, segundo Silva et al. (2010), as características mais relevantes em aplicações que usam as RNAs são a generalização e aprendizado. As RNAs são normalmente utilizadas em problemas de classificação e de regressão.

As pesquisas em RNAs foram iniciadas em 1943 e, desde então, os resultados alcançados se devem à primeira analogia feita com o cérebro humano, na qual um interesse por um processamento diferente do usual foi buscado (Haykin, 2001). Os elementos computacionais, ou unidades processadoras, denominadas neurônios artificiais (Figura 4.1(b)) são modelos bem simplificados dos neurônios biológicos (Figura 4.1(a)).

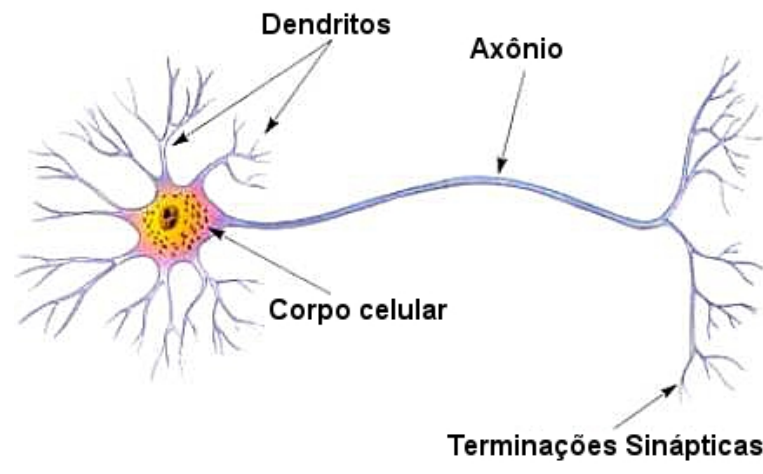

(a)

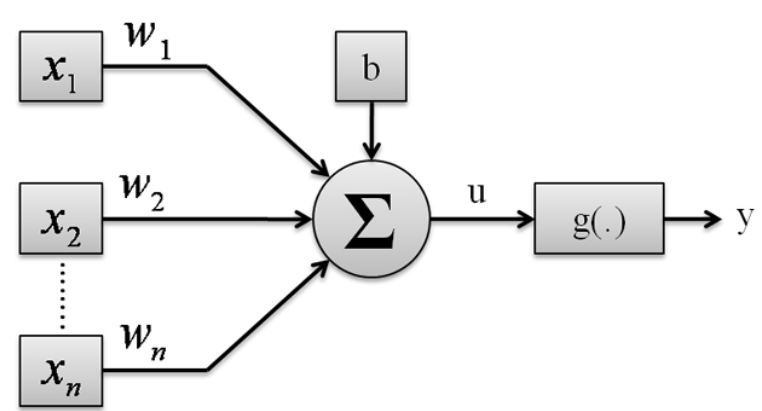

(b)

Figura 4.1: Neurônio: (a) Representação do neurônio biológico (retirado de http://www.sogab.com.br/anatomia/neuronio.jpg); (b) Representação do neurônio artificial segundo McCulloch e Pitts (adaptado de (Silva et al., 2010).

O funcionamento do neurônio artificial pode ser resumido da seguinte forma: os estímulos recebidos pelos dendritos (diversos sinais de entrada advindos do meio externo) são apresentados à camada de entrada $\left[x_{1}, x_{2}, \ldots, x_{n}\right]^{T}$. Cada uma dessas entradas é ponderada pelo seu respectivo peso sináptico $w_{i}$, cujo papel é atenuar ou amplificar o sinal da sinapse durante a troca de informações entre o axônio e o dendrito. O modelo neural matemático inclui uma bias 
representado pela letra $b$, a qual tem o intuito de aumentar o grau de liberdade da função de ativação, ou até mesmo não possibilitar saídas nulas mesmo que todas as suas entradas sejam nulas. Por fim, o corpo celular tem a função de produzir um valor potencial de ativação $u$ descrito na Equação (4.1):

$$
u=\sum_{i=1}^{n} w_{i} \cdot x_{i}+b
$$

O valor produzido pela Equação (4.1) é então apresentado a uma função de transferência ou função de ativação, que é análoga ao axônio biológico. Este componente tem a finalidade de restringir os valores da saída em um intervalo determinado. A saída do neurônio é representada pela Equação (4.2):

$$
y=g(u)
$$

Os resultados gerados em y são calculados através das funções de ativação, sendo as mais comuns as funções degrau, degrau bipolar, rampa simétrica, logística, tangente hiperbólica e linear (respectivamente Figura 4.2(a) à 4.2(f)). Segundo Silva et al. (2010) essas funções de ativação podem ser divididas em dois grupos principais: funções de ativação parcialmente diferenciáveis (que possuem pontos cujas derivadas de primeira ordem são inexistentes) e funções de ativação totalmente diferenciáveis (cujas derivadas de primeira ordem existem e são conhecidas em todos os pontos de seu domínio de definição).

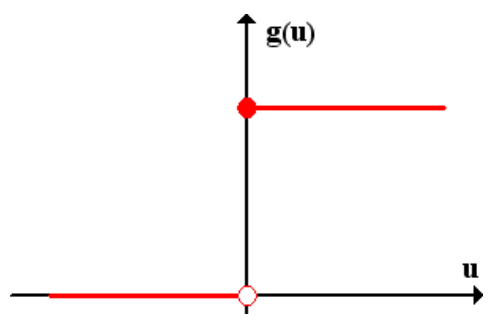

(a)

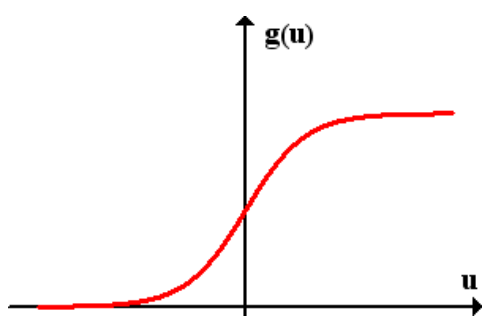

(d)

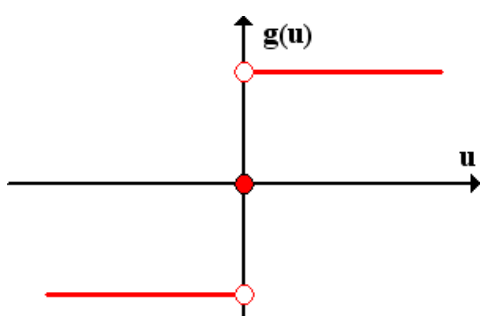

(b)

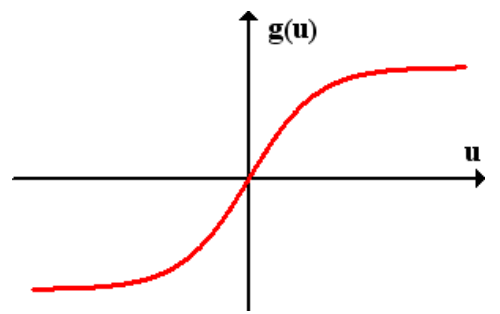

(e)

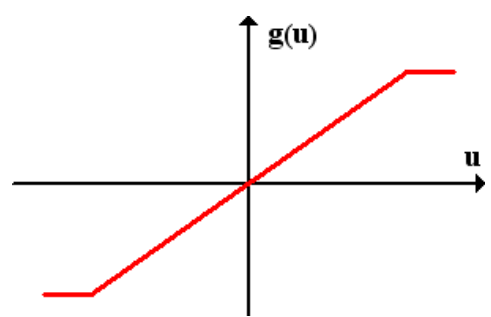

(c)

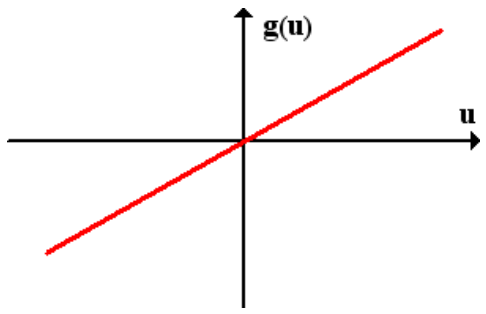

(f)

Figura 4.2: Funções de ativação parcialmente diferenciáveis: (a) degrau; (b) degrau bipolar; (c) rampa simétrica; e funções de ativação totalmente diferenciáveis: (d) logística; (e) tangente hiperbólica; (f) linear. 
O equacionamento matemático para cada uma das funções de ativação apresentadas na Figura 4.2, é mostrado nas Equações (4.3a) a (4.3f), respectivamente.

$$
\begin{gathered}
g(u)=\left\{\begin{array}{l}
1, \text { se } u \geq 0 \\
0, \text { se } u<0
\end{array}\right. \\
g(u)=\left\{\begin{array}{l}
1, \text { se } u>0 \\
0, \text { se } u=0 \\
-1, \text { se } u<0
\end{array}\right. \\
g(u)=\left\{\begin{array}{l}
a, \text { se } u>a \\
u, \text { se }-a \leq u \leq a \\
-a, \text { se } u<a
\end{array}\right. \\
g(u)=\frac{1}{1+e^{-\beta u}} \\
g(u)=\frac{1-e^{-\beta u}}{1+e^{-\beta u}} \\
g(u)=u
\end{gathered}
$$

Vale ressaltar que a velocidade de processamento da RNA está basicamente relacionado com o número de operações por segundo dos computadores (Haykin, 2001).

\subsubsection{Arquiteturas de RNAs}

A RNA é formada por um conjunto estruturado de neurônios e esta combinação permite que a rede possa resolver problemas complexos. A arquitetura da RNA está diretamente ligada ao algoritmo de aprendizado a ser utilizado. Segundo Haykin (2001) uma RNA pode ser dividida em três partes, denominadas camadas, as quais são descritas como: camada de entrada, responsável pelo recebimento dos sinais de entrada (dados); camadas intermediárias ou ocultas, responsáveis por extrair as características associadas ao processo, além de possibilitarem a representação de problemas que não sejam linearmente separáveis; camada de saída, responsável pela apresentação dos resultados obtidos pela rede. As principais arquiteturas de RNAs, considerando a disposição de seus neurônios, assim como suas formas de interligação entre eles e a constituição de suas camadas, podem ser dividas em: redes feedforward (alimentação à frente) de camada simples, redes feedforward de camadas múltiplas, redes recorrentes e redes reticuladas. 


\subsubsection{Redes feedforward de Camada Simples}

As redes feedforward (alimentação à frente) de camada simples são de um tipo de arquitetura com somente uma camada de entrada e uma de saída. Seu fluxo de informação segue sempre na direção da camada de saída. Geralmente essas redes são empregadas em problemas envolvendo classificação de padrões e filtragem linear. Os tipos de redes mais conhecidos são o Perceptron e o Adaline. A Figura 4.3 exibe um exemplo de rede neural de camadas simples.

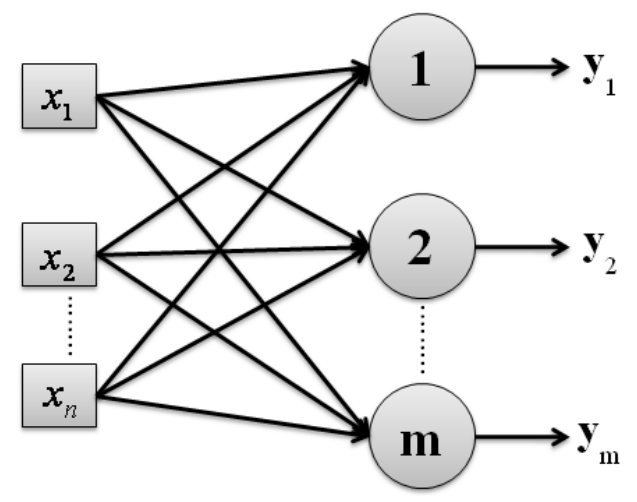

Figura 4.3: Exemplo de rede com arquitetura do tipo feedforward de camada simples.

\subsubsection{Redes feedforward de Camadas Múltiplas}

Diferentemente da rede de camada simples, a rede feedforward de camadas múltiplas é constituída de uma ou muitas camadas escondidas de neurônios. Este tipo de rede é empregado em problemas relacionados à aproximação de funções, classificação de padrões, identificação de sistemas, otimização, robótica, etc. Os tipos mais comuns dessa arquitetura são as redes Perceptron multicamadas (do inglês, Multilayer Perceptron - MLP) e as redes de base radial (do inglês, Radial Basis Function - RBF). Na Figura 4.4 pode-se verificar um exemplo de rede neural de camadas múltiplas.

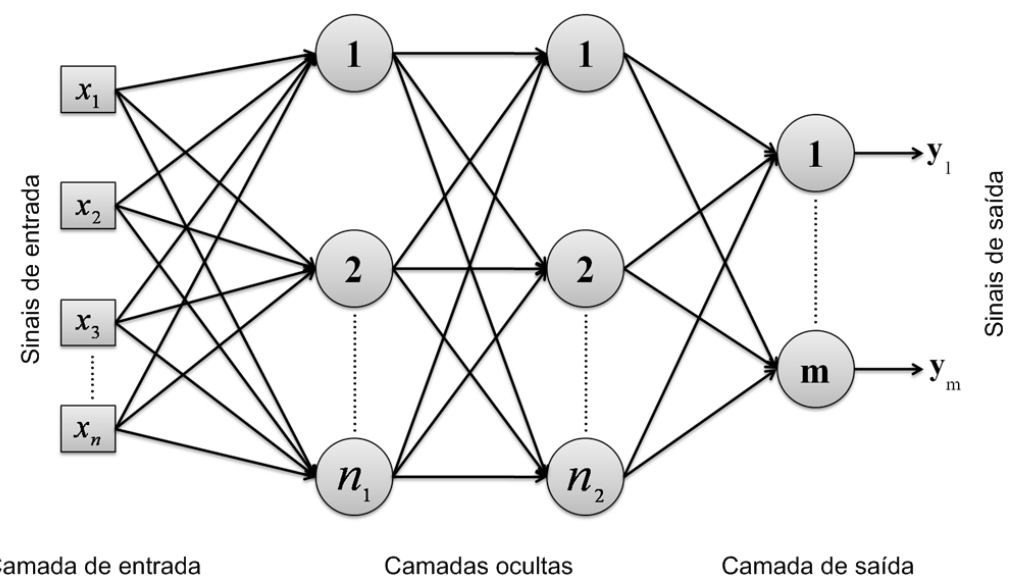

Figura 4.4: Exemplo de rede com arquitetura do tipo feedforward de camada múltiplas. 


\subsubsection{Redes Recorrentes}

Redes recorrentes ou realimentadas são redes em que as saídas dos neurônios são realimentadas como sinais de entrada para outros neurônios. Este tipo de rede é empregado em sistemas dinâmicos, justamente pela sua realimentação e podem ser empregados em previsão de séries temporais, otimização e identificação de sistemas, controle de processos, etc. Os tipos de redes mais comuns são as rede de Hopfield e MLP com realimentação. A Figura 4.5 mostra um exemplo de rede do tipo recorrente.

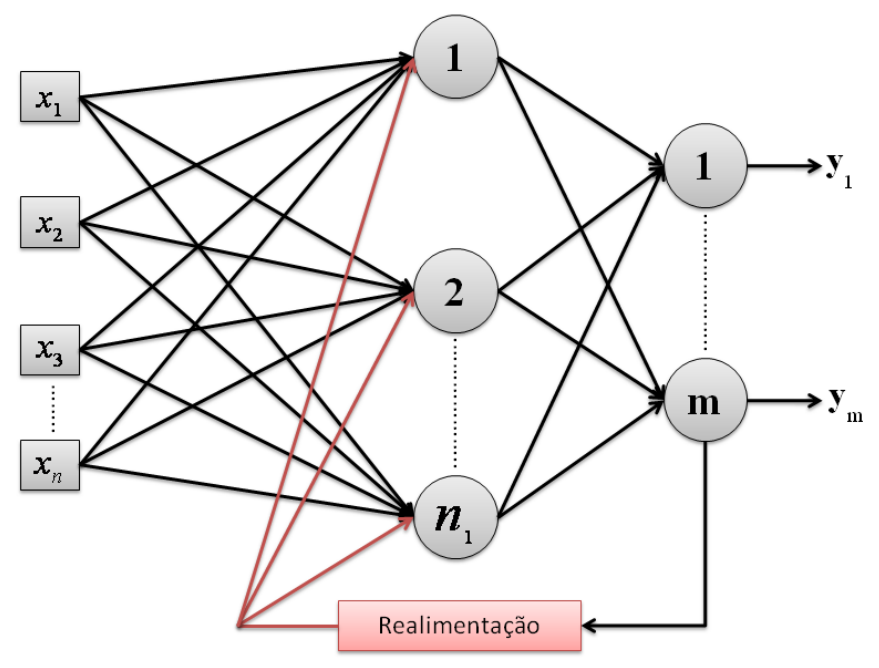

Figura 4.5: Exemplo de rede com arquitetura do tipo recorrente ou realimentada.

\subsubsection{Redes Reticuladas}

Por fim, a estrutura reticulada leva em consideração a disposição espacial dos neurônios visando propósitos de extração de caraterísticas. Existem várias aplicações para esse tipo de rede, que variam desde problemas de agrupamento (clustering), reconhecimento de padrões, otimização de sistemas, grafos, etc. Sua principal representante é a rede de Kohonen. Na Figura 4.6 pode-se verificar um exemplo de rede neural de estrutura reticulada.

\subsection{Aspectos Topológicos da RNA}

As topologias em RNAs determinam as diferentes formas de composições estruturais que uma arquitetura poderá assumir. As topologias são usualmente especificadas de forma empírica, pois tal dimensionamento depende de muitos fatores. Esses fatores podem variar com o algoritmo de aprendizado utilizado, inicialização das matrizes de pesos, qualidade do conjunto de treinamento, complexidade do problema, etc (Ludwig Jr. e Costa, 2007; Silva et al., 2010).

Existem diversas técnicas estatísticas que auxiliam a seleção de uma boa topologia candidata para um problema entre elas a mais utilizada é a validação cruzada (do inglês, cross-validation) (Silva et al., 2010). 


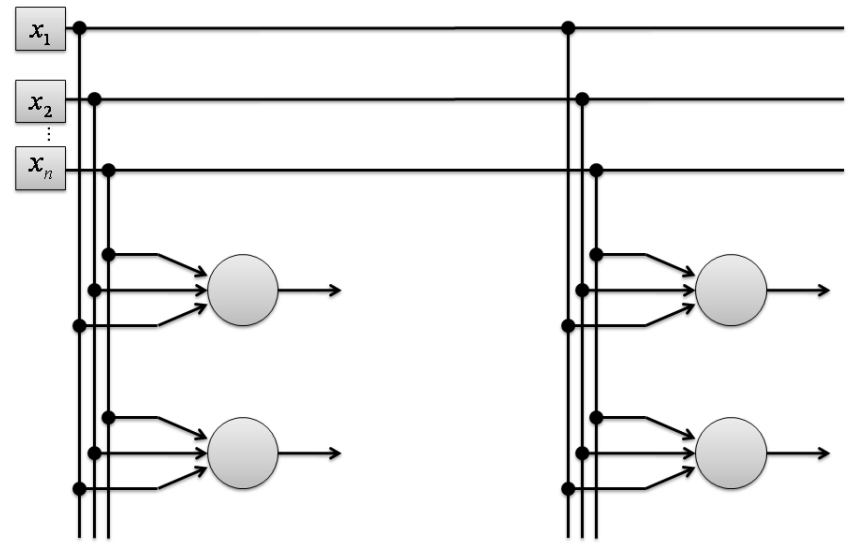

Figura 4.6: Exemplo de rede com arquitetura do tipo reticulada.

\subsubsection{Validação Cruzada}

O método de validação cruzada não é um único método, mas sim uma classe de métodos para estimar a taxa de erro verdadeira da RNA. Esses métodos também são conhecidos como $k$-fold cross-validation, onde $k$ representa o número de partições geradas aleatoriamente a partir da amostra de exemplos para treinar e testar a RNA. O processo consiste em dividir a amostra em $k$ partições mutuamente exclusivas. A cada iteração uma partição diferente é utilizada para testar a RNA e todas as outras $k-1$ partições são utilizadas para treinamento. Por conseguinte, o processo se repete $k$ vezes até que todas as partições tenham sido utilizadas como subconjunto de teste. A taxa de erro é a média das taxas de erro calculadas para as $k$ iterações. A Figura 4.7 mostra um exemplo de 5-fold cross-validation, no qual o número de partições $k=5$.

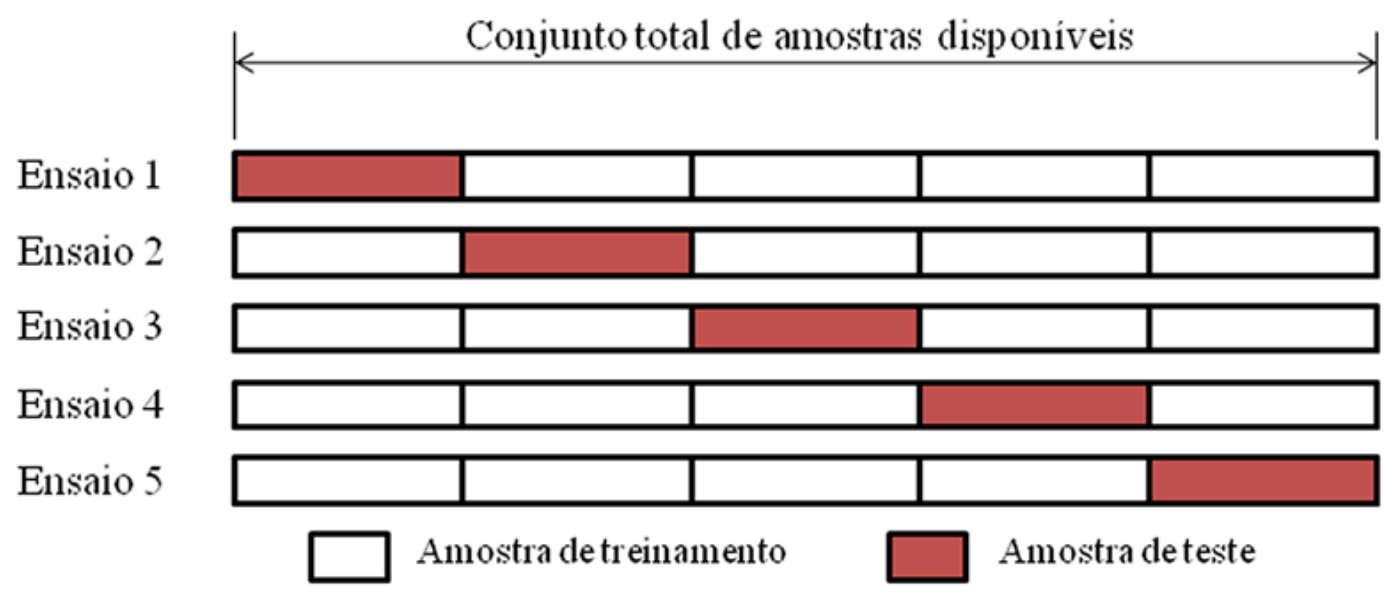

Figura 4.7: Esquema para o método 5-fold cross-validation. 


\subsubsection{Overfitting e Underfitting}

É bom sempre ressaltar que o aumento exagerado do número de neurônios ou de camadas intermediárias não assegura a generalização apropriada da rede MLP. A generalização é atingida quando a RNA consegue determinar corretamente uma saída, dada uma entrada nunca apresentada à rede durante a fase de treinamento. Existem dois conceitos associados a generalização: o overfitting e o underfitting. O primeiro acontece quando o treinamento é exagerado, ocasionando a memorização das respostas frente aos estímulos apresentados. No overfitting é comum um erro quadrático muito baixo na fase de aprendizado, porém na fase de teste (generalização) o erro quadrático tente a aumentar. No segundo caso (underfitting) é ocasionado pela falta de treinamento, ou seja, o erro quadrático tanto na fase de aprendizado como generalização serão bem significativos. A Figura 4.8 mostra uma situação de overfitting e underfitting usando validação cruzada com inclusão da parada antecipada.

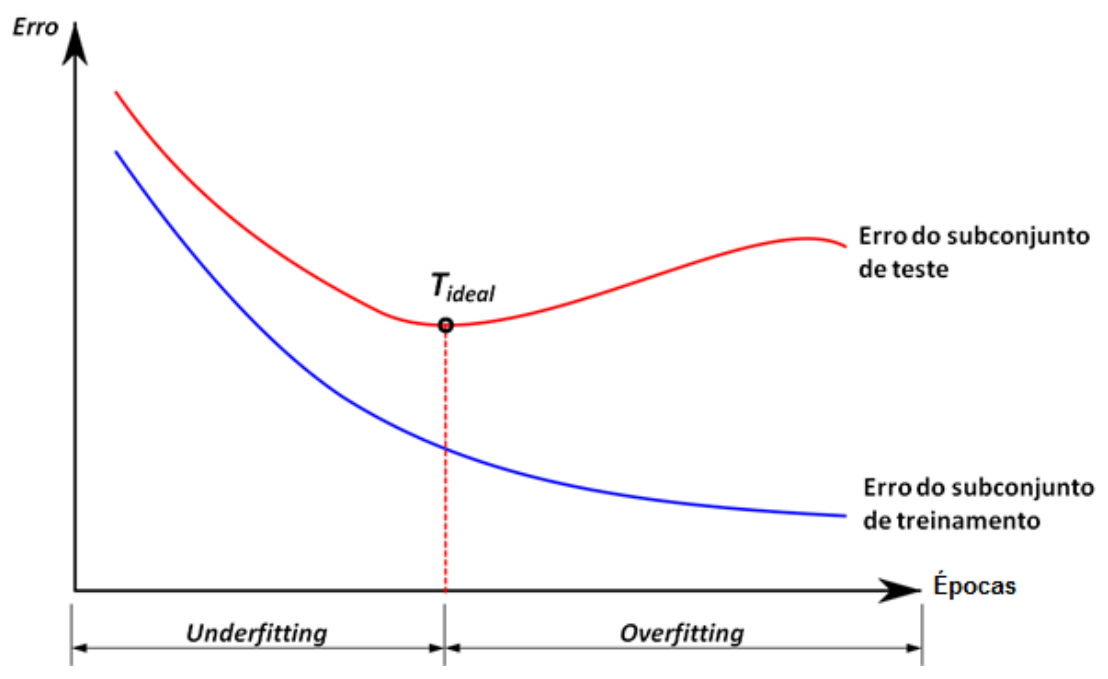

Figura 4.8: Situações envolvendo underfitting e overfitting usando parada antecipada.

\subsubsection{Parada Antecipada}

Para que a rede possa generalizar de maneira satisfatória, um simples procedimento também tem sido inserido na implementação da técnica validação cruzada, que é a parada antecipada ou prematura (do inglês, early stopping). Esta técnica é utilizada para encontrar um ponto ótimo de aprendizado na topologia candidata que é constantemente checado pela aplicação do subconjunto de testes, sendo finalizado quando começar a haver elevação do erro quadrático entre épocas sucessivas, fazendo com que a rede não decore os dados (Haykin, 2001). A Figura 4.8 mostra um exemplo de parada antecipada para evitar o overfitting, onde $T_{\text {ideal }}$ é o ponto desejado. 


\subsection{Algoritmo de Aprendizado de RNAs}

O processo de aprendizado pode ser definido como o mecanismo de aquisição de conhecimento, desenvolvimento de competência e mudança de comportamento. Nas RNAs esse mecanismo encontra-se na capacidade da rede de adaptar os seus parâmetros livres (bias e pesos das conexões) a partir da iteração com o meio, buscando aumentar o desempenho da rede em executar a função para a qual foi desenvolvida. Este processo é a fase preliminar da RNA necessária para a resolução dos problemas (Haykin, 2001; Russel e Norvig, 2004). Conforme visto no início deste capítulo, existem três paradigmas de aprendizado que são: aprendizado supervisionado, aprendizado não supervisionado, e aprendizado por reforço. Cada um deles possui técnicas diferentes para adaptar os parâmetros da rede. Porém, neste projeto de pesquisa, adotou-se apenas o primeiro paradigma, e por isso será o único abordado nesta seção.

No algoritmo de aprendizado supervisionado, o processo de treinamento da RNA é realizado através de um conjunto de exemplos de entrada e suas respectivas saídas desejadas, evitando que a rede entre em contato ou receba informações diretamente do ambiente onde vai atuar. Há nesse aprendizado a presença de um supervisor que é responsável por fornecer as respostas desejadas para cada conjunto de entradas. Um diagrama simplificado do funcionamento pode ser visto na Figura 4.9.

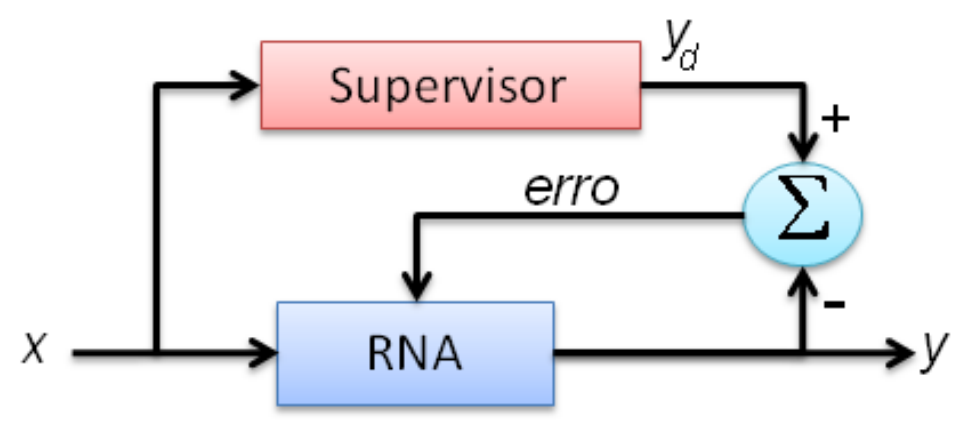

Figura 4.9: Diagrama simplificado do funcionamento do aprendizado supervisionado em uma RNA.

O erro da rede é o resultado da comparação entre a resposta da rede e a resposta desejada. Assim, o ajuste de pesos da rede é feito em cima do erro de cada iteração até que ele seja minimizado, alcançando níveis considerados satisfatórios (Ludwig Jr. e Costa, 2007). Segundo (Silva et al., 2010) Um dos algoritmos de aprendizado mais importante utilizado é o backpropagation. No entanto, sua taxa de convergência é muito pobre. Em função disso foram propostas derivações do algoritmo backpropagation ao longo dos anos, sendo descritos a seguir o algoritmo Resilient Propagation e o algoritmo de Levenberg-Marquardt que tem eficiência reconhecida para solucionar o problema de minimização de quadrados para funções não-lineares. 


\subsubsection{Resilient Backpropagation}

O algoritmo Resilient Propagation (RPROP) (Riedmiller e Braun, 1993) é obtido através da modificação do algoritmo backpropagation, na qual não se consideram as variações das magnitudes do gradiente da função erro, mas somente o sinal da derivada parcial nas atualizações dos pesos. Isto faz com que a convergência se torne mais rápida quando estiver próximo do mínimo local (fase de treinamento), eliminando assim os problemas do algoritmo backpropagation (Riedmiller e Braun, 1993; Haykin, 2001). A Equação (4.4) representa a avaliação da condição de mudança de sinal do gradiente.

$$
\Delta_{i j}(t)= \begin{cases}n^{+} \cdot \Delta_{i j}(t-1), & \text { se } \frac{\partial E(t-1)}{\partial w_{i j}} \cdot \frac{\partial E(t)}{\partial w_{i j}}>0 \\ n^{-} \cdot \Delta_{i j}(t-1), & \text { se } \frac{\partial E(t-1)}{\partial w_{i j}} \cdot \frac{\partial E(t)}{\partial w_{i j}}<0 \\ \Delta_{i j}(t-1), & \text { caso contrário. }\end{cases}
$$

onde: se a derivada parcial do peso corresponde $w_{i j}$ troca seu sinal, isto indica que o algoritmo ultrapassou o mínimo local na última atualização, assim o valor da taxa de aprendizado $\Delta_{i j}$ é reduzido. Se a derivada mantém seu sinal, a taxa de aprendizado é incrementada para acelerar a convergência nas regiões rasas. Sendo que $0<\mu^{-}<1<\mu^{+}$são constantes responsáveis por incrementar ou decrementar as taxas de aprendizado individuais de cada um dos pesos. Finalmente, a atualização dos pesos das matrizes da rede é dada pela Equação 4.5:

$$
\Delta w_{j i}(t)= \begin{cases}-\Delta_{j i}(t), & \text { se } \frac{\partial E(t)}{\partial w_{j i}}>0 \\ +\Delta_{j i}(t), & \text { se } \frac{\partial E(t)}{\partial w_{j i}}<0 \\ 0, & \text { caso contrário. }\end{cases}
$$

Observa-se que na Equação (4.5) as modificações nas matrizes de pesos da rede são limitadas em função das variações dos valores dos sinais das derivadas parciais.

\subsubsection{Levenberg-Marquardt}

O algoritmo Levenberg-Marquardt (LM) representa uma aproximação do método de GaussNewton (Dan Foresee e Hagan, 1997), que é obtida introduzindo-se o parâmetro $\mu$ na equação original (Hagan e Menhaj, 1994), resultando na Equação (4.6). O algoritmo LM foi projetado para atingir a velocidade de treinamento de um método de segunda ordem sem a necessidade de calcular a matriz Hessiana (matriz de derivadas de segunda ordem).

$$
\Delta x=\left[J^{T}(x) \cdot J(x)+\mu \cdot I\right]^{-1} \cdot J^{T}(x) e(x)
$$

Na Equação 4.6, $J$ é a matriz Jacobiana que contém as primeiras derivadas dos erros da rede em relação aos seus pesos e bias, $I$ é a matriz identidade e $e(x)$ é o vetor de erros. Quando o 
escalar $\mu$ é nulo, a equação que resta é idêntica ao método de Newton se usada a aproximação Hessiana. Entretanto, quando esse escalar é muito grande, a fórmula equivaler-se-á do gradiente descendente com um passo pequeno. O primeiro método é mais eficaz perto do erro mínimo. Assim, a ideia é conseguir mudar para o método de Newton o mais rápido possível. Deste modo, $\mu$ é decrementado toda vez que o valor do desempenho também decresce, e incrementado quando o contrário ocorra.

O parâmetro $\mu$ funciona como um fator de estabilização do treinamento, que ajusta a aproximação de forma a utilizar a rápida convergência do método de Newton e assim evitar passos muito grandes que possam levar a um erro de convergência. Este método apresenta convergências em menos iterações, mas requer mais cálculos por iteração devido ao cálculo de matrizes inversas. O LM é o algoritmo mais rápido quando se trabalha com poucos parâmetros na rede. Se esse número de parâmetros for elevado, a utilização desse algoritmo é pouco prática pois, haverá um grande esforço computacional (Saini e Soni, 2002).

\subsection{Considerações Finais}

O aprendizado supervisionado é um dos paradigmas mais utilizados em problemas de classificação e regressão. Isto se deve principalmente à facilidade de uso de seus métodos e aos seus resultados positivos. Além da sua inspiração biológica, foram cobertos os principais tópicos referentes ao projeto de RNAs, com foco nas redes MLP como, por exemplo, os tipos de função de ativação, o algoritmo de treinamento e a arquitetura. Foram também apresentados alguns algoritmos para aprendizado supervisionado derivados do algoritmo backpropagation. Neste projeto, foi escolhida a rede neural do tipo MLP para desempenhar a tarefa de estacionamento paralelo. Esta aplicação será vista no Capítulo 6. 



\section{Abordagem do Estacionamento Paralelo}

O seis passos para se realizar a manobra apresentada no ínicio do Capítulo 2, podem ser classificados em três importantes etapas, que são: (1) detectar a vaga de estacionamento, (2) posicionar o veículo para se iniciar a manobra; (3) manobrar o veículo para dentro da vaga sem colidir (Demirli e Khoshnejad, 2009). Nesta seção, são discutidas essas etapas e como serão realizadas neste trabalho mas, antes de tudo, será apresentada a trajetória guia.

\subsection{Detecção do Espaço}

Detectar a vaga de estacionamento consiste em procurar um espaço de tamanho adequado no qual o veículo possa entrar. Para procurar um espaço suficiente para estacionar o carro, o sistema manterá uma velocidade mínima (aproximadamente $0,15 \mathrm{~m} / \mathrm{s}$ - veículo HELVIS) controlada em linha reta e analisará o valor de distância do feixe $S F 1$ do sensor (Figura 5.1(a)). Se $S F 1$ for maior que a lateral de um carro mais a medida de segurança $(d=1,57 \cdot W)$ significa que existe um possível espaço que o carro possa entrar. Assim, o sistema inicia a contagem do tamanho da vaga $P$ usando a odometria (Figura 5.1(b)). Quando o sensor $S F 1$ detectar uma medida menor que $d$ significa que a distância lateral não é mais recomendada, ou seja, pode ter um obstáculo. Então o contador para de contar e armazena o valor para usar no controlador (Figura 5.1(c)).

Para dar foco ao projeto do controlador, presume-se que o espaço de estacionamento a ser detectado é à direita do veículo. Assim é fácil generalizar os resultados para o caso em que o espaço de estacionamento é do lado esquerdo (uma sugestão para trabalhos futuros). 


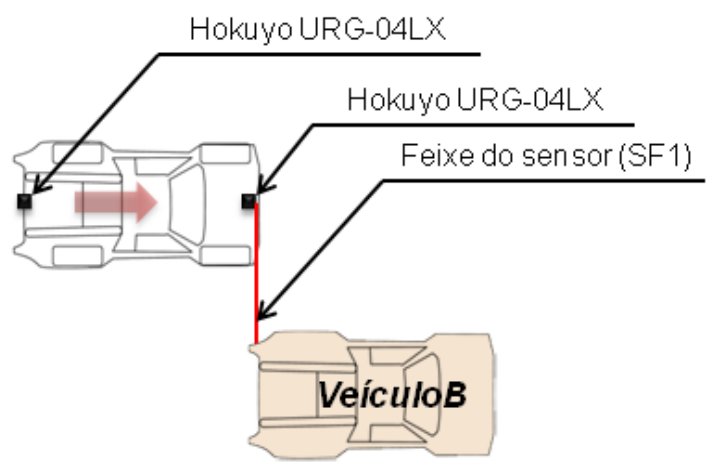

(a)

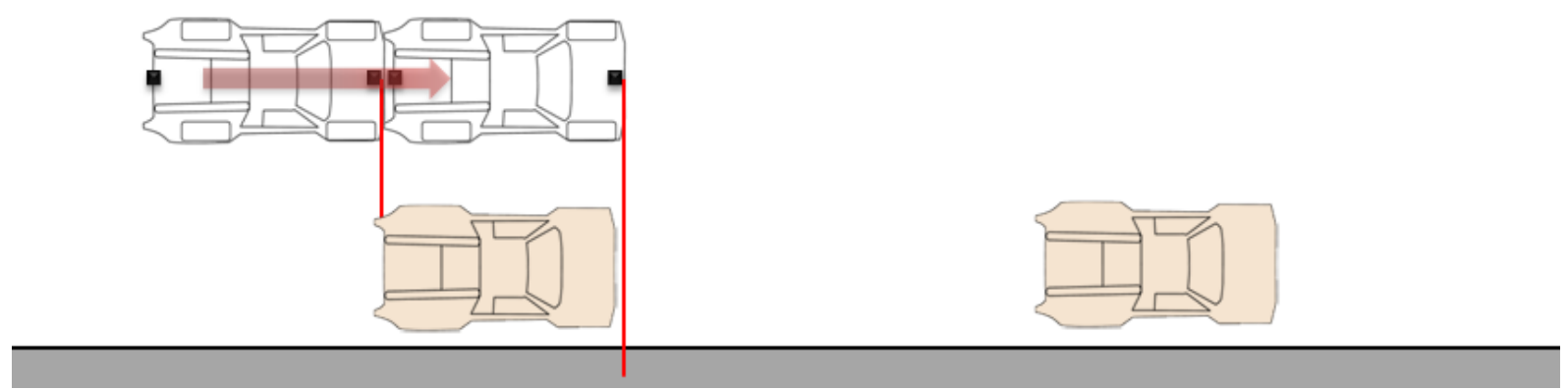

(b)

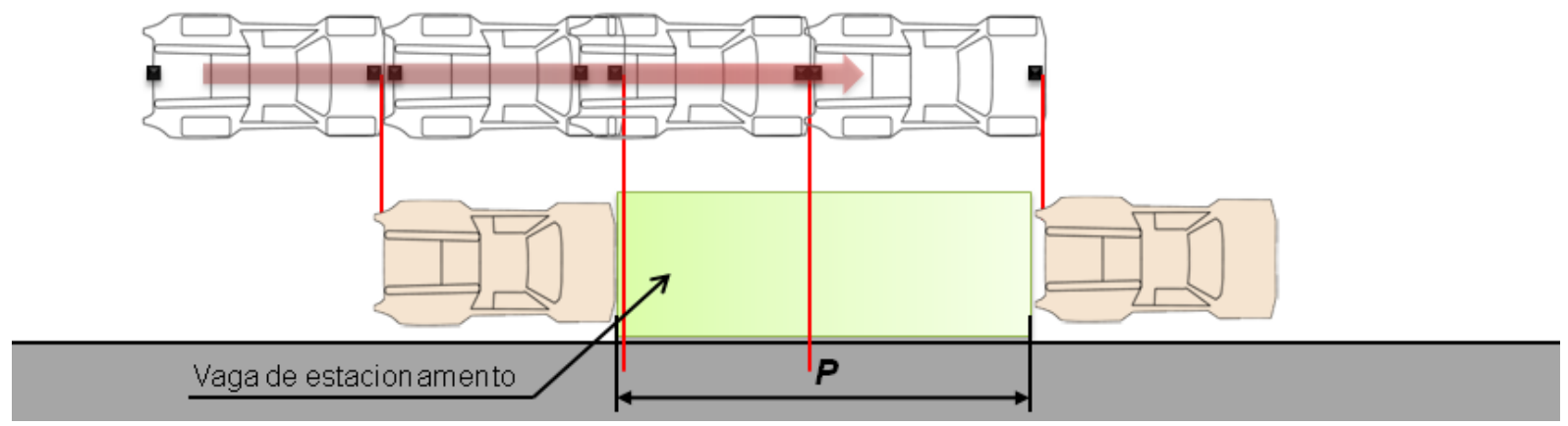

(c)

Figura 5.1: Passos para se encontrar uma vaga paralela: (a) início da procura por uma vaga;

(b) detecta um possível espaço e começa a contar; (c) termina a contagem e armazena o tamanho da vaga encontrado.

\subsection{Posicionando o Veículo}

Após encontrar a vaga (Figura 5.2(a)), deve-se posicionar o veículo para iniciar a manobra. Conforme o procedimento apresentado no início do Capítulo 2, o posicionamento funciona de tal forma que o veículo deve avançar paralelamente ao veículo em frente à vaga localizada (Veículo A), emparelhando os para-choques traseiros de ambos os carros. O veículo avança em uma velocidade de $0,15 \mathrm{~m} / \mathrm{s}$ paralelo aos veículos (ou mantém a direção que estava antes), até o que o feixe do sensor $S R 1$ detecte uma medida menor que $d$. Sendo assim, é possível que ele esteja emparelhado com o veículo a frente da vaga (Figura 5.2(b)). Para se ter certeza, é 
verificado se a valor da odometria ao se encontrar a vaga mais o deslocamento até posicionar o veículo é maior ou igual ao tamanho da vaga mais o tamanho do carro (Odometria $\geq P+L$ ).

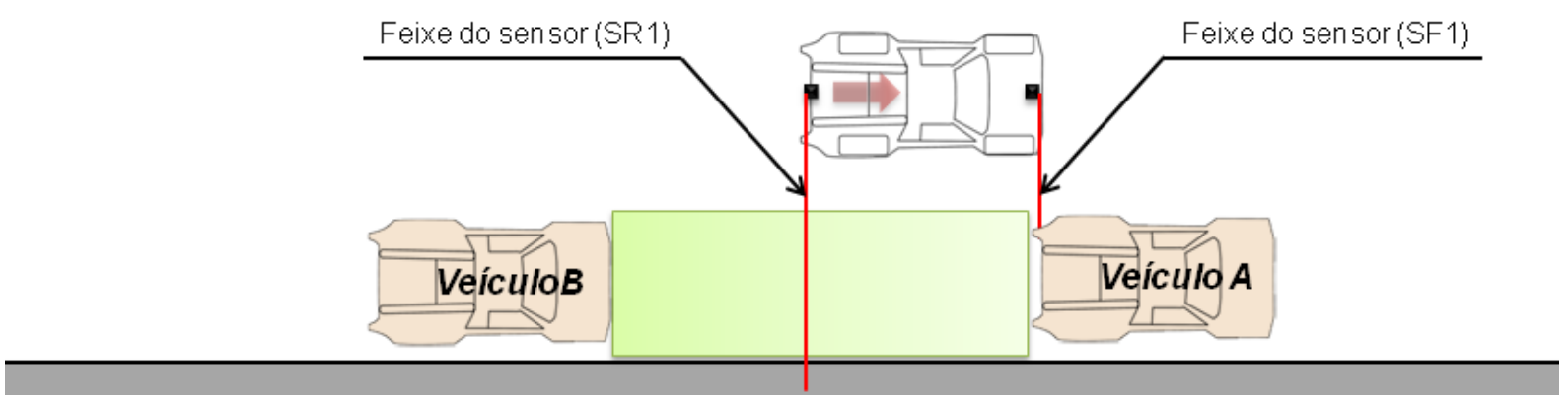

(a)

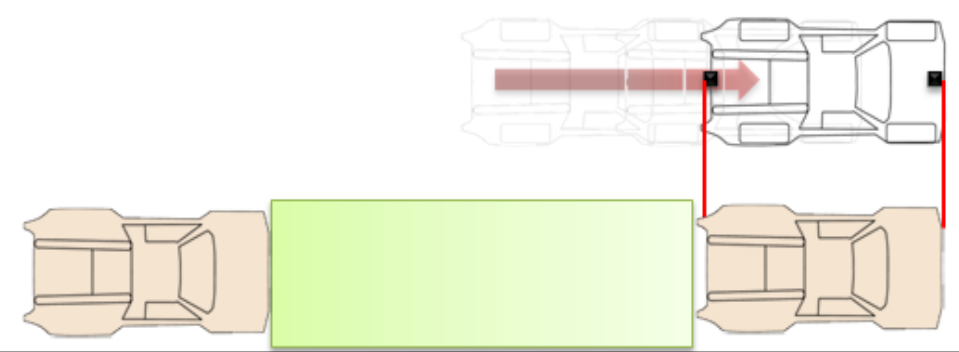

(b)

Figura 5.2: Posicionado na vaga: (a) o veículo acaba de mudar para o estado posicionando e em (b) o veículo chegou na posição desejada.

\subsection{Trajetória de Referência}

Para realizar a terceira etapa é necessário verificar se a manobra do veículo para dentro da vaga é possível de acontecer. Sendo assim, este trabalho adota a trajetória desenvolvida nos trabalhos de Hoyle (2003); Herrmann (2003); Roth (2009), conhecida como trajetória em S. Como pode ser visto na Figura 5.3, esta trajetória em forma de S é obtida posicionando-se corretamente duas circunferências. Considerando este tipo de trajetória, a vaga mínima para que ocorra o estacionamento sem choques com outros veículos é dada pela Equação 5.1 (Herrmann, 2003) e seus parâmetros visualizados na Figura 5.3:

$$
P=\sqrt{2 R W+(L-b)^{2}}+b
$$

onde $R$ é o raio determinado pela barra de direção que depende do ângulo de esterçamento das rodas dianteiras. Quanto maior o ângulo de esterçamento, menor será o raio e, consequentemente, menor será a vaga necessária para estacionar. O valor $P$ é o tamanho mínimo necessário para estacionar perfeitamente o veículo sem colisão, $b$ é a distância entre o eixo traseiro e o 
pára-choque traseiro do veículo e $W, L$ são, respectivamente, a largura e o comprimento do veículo.

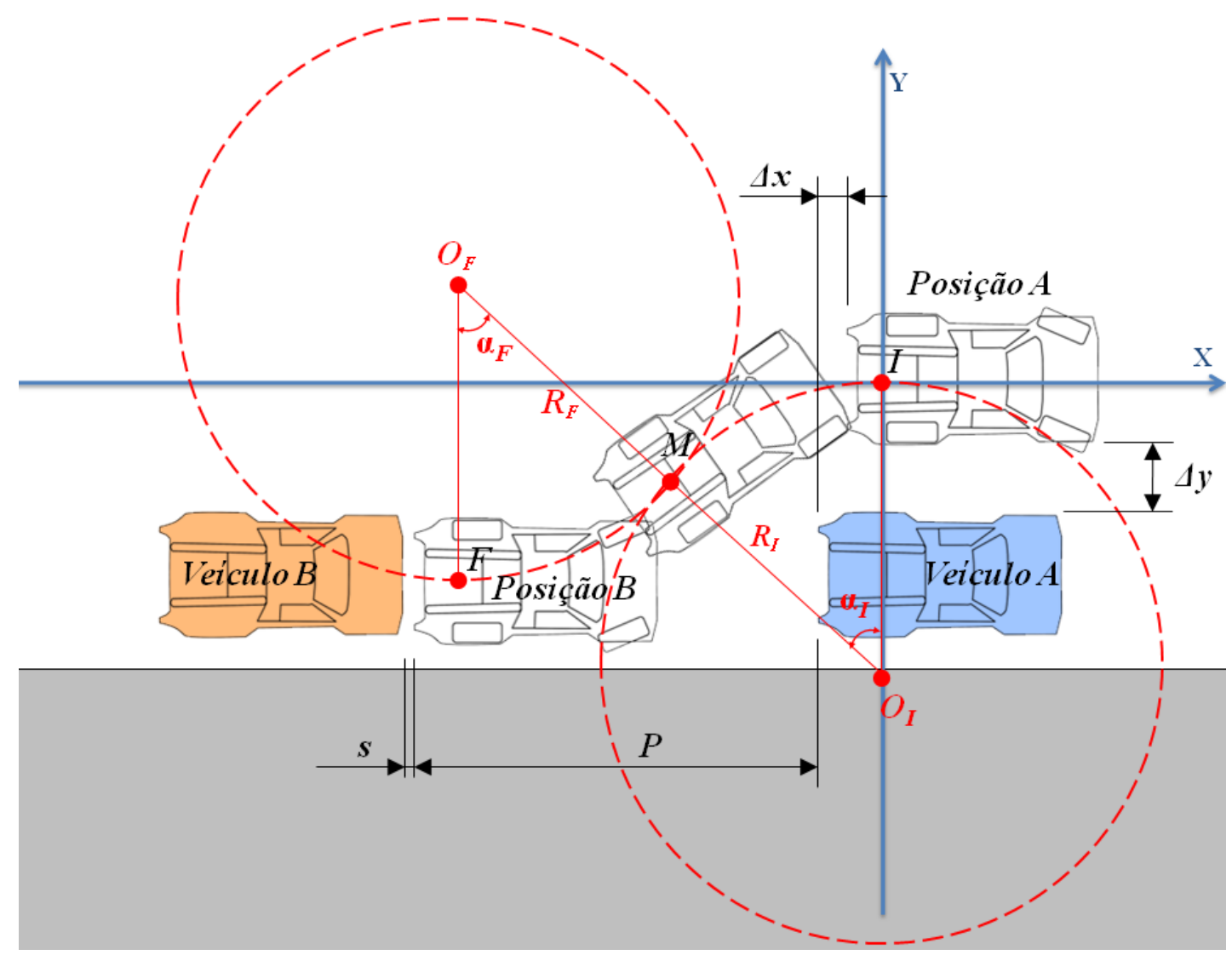

Figura 5.3: Tragetória de Estacionamento Paralelo

Inicialmente são marcados os pontos de início do estacionamento $(I)$ e final do estacionamento $(F)$, respectivamente seguem as Equações 5.2a e 5.2b. I recebe a origem do sistema de coordenadas, e está relacionada com a posição inicial do veículo, que depende de $\Delta x$ e $\Delta y$. $\Delta y$ é a distância entre a lateral do veículo em $I$ e a lateral do veículo estacionado, $\Delta x$ é a distância horizontal entre as traseiras desses mesmo dois veículos, conforme mostrado na Figura 5.3. O valor de $\Delta x$ é fácil de ser modificado, bastando movimentar o veículo para frente ou para trás (ré), porém $\Delta y$ permanecerá constante já que movimentar o veículo em $y$ é bem mais complicado.

$$
\begin{gathered}
I=(0,0) \\
F=(-(P+\Delta x),-(W+\Delta y))
\end{gathered}
$$

Para determinar o posicionamento das circunferências é preciso primeiro encontrar a coordenada do ponto de intersecção entre as circunferências $M$, pois é neste ponto que ocorre a mudança de ângulo da direção do veículo (ponto de virada). Pode-se calcular o ângulo $\beta$ pela 
Equação 5.3a e, assim, pode-se determinar o ponto $M$ projetando-a nas coordenadas, usando a Equação $5.3 \mathrm{~b}$ e Equação 5.3c.

$$
\begin{gathered}
\beta=\arctan \left(\frac{I_{x}-F_{x}}{I_{y}-F_{y}}\right) \\
D_{I F}=\frac{\sqrt{\left(I_{x}-F_{x}\right)^{2}+\left(I_{y}-F_{y}\right)^{2}}}{2} \\
M=\left(I_{x}-D_{I F} \cos (\beta), I_{y}-D_{I F} \sin (\beta)\right)
\end{gathered}
$$

Os centros das circunferências $O_{I}$ e $O_{F}$ são obtidos de forma análoga, podendo ser definidos após a determinação dos pontos $I, F$ e $M$. O primeiro passo será determinar a posição $x$ de $O_{I}$ e $O_{F}$ que, respectivamente recebem os valores da abscissa do CG na posição A (posição inicial do estacionamento) $O_{I, x}=I_{x}$ e na posição B (posicão final do estacionamento) $O_{F, x}=I_{x}$. Logo em seguida são definidas algumas condições de contorno, para que o carro sempre esteja paralelo ao meio-fio:

1. As derivadas da curva em $I$ e $F$ são iguais à 0 ;

2. O ponto $M$ deve pertencer às duas circunferências.

Pela condição de contorno (1), a coordenada $O_{I, x}$ do centro da circunferência é determinada pela derivada implícita da equação paramétrica da circunferência (Equação 5.4a), chegando-se na Equação 5.4b.

$$
\begin{gathered}
\left(x-x_{o}\right)^{2}+\left(y-y_{o}\right)^{2}=R^{2} \\
\frac{d y}{d x}=-\frac{(x-x o)}{(y-y o)}
\end{gathered}
$$

Sabendo-se que, pela condição de contorno (2), os pontos I e M devem pertencer ao mesmo arco de circunferência, para se encontrar o ponto $O_{I, y}$, tem-se a Equação 5.5a, na qual deseja-se isolar o valor de $O_{I, y}$. Isto resulta na Equação 5.5b:

$$
\begin{gathered}
\left(M_{y}-O_{I, y}\right)^{2}+\left(M_{x}-O_{I, x}\right)^{2}=\left(I_{y}-O_{I, y}\right)^{2}+\left(I_{x}-O_{I, x}\right)^{2} \\
O_{I, y}=\frac{\left(M_{x}-O_{I, x}\right)^{2}+\left(M_{y}^{2}-I_{y}^{2}\right)}{2\left(M_{y}-I_{y}\right)}
\end{gathered}
$$


Com a Equação 5.5b pode-se substituir os parâmetros e encontrar os centros das duas circunferências pelas Equações 5.6a e 5.6b. Logo em seguida é possível definir o raio das circunferências pela Equação 5.6c

$$
\begin{gathered}
O_{I}=\left(I_{x},-\frac{(W+\Delta y)^{2}+P^{2}}{4(W+d)}\right) \\
O_{F}=\left(F_{x},-\frac{3(W+\Delta y)^{2}-P^{2}}{4(W+d)}\right) \\
R=R_{I}=R_{F}=\frac{\sqrt{\left(O_{I, x}-O_{F, x}\right)^{2}+\left(O_{I, y}-O_{F, y}\right)^{2}}}{2}
\end{gathered}
$$

Assim que todos os pontos são determinados é possível saber o ângulo $\theta$ de esterçamento do veículo que o mesmo deverá usar para fazer a manobra sem colidir com os veículos e entrar com uma única manobra na vaga (Equação 5.7a). Logo em seguida, como este trabalho não mantém um mapa interno, é necessário saber o ângulo de orientação $\phi$ no ponto de virada, para que o veículo possa esterçar inversamente o mesmo raio, e assim executar os dois círculos (Equação 5.7b). Esses dois valores serão utilizados durante o treinamento supervisionado da rede neural.

$$
\begin{aligned}
& \theta=\tan ^{-1}\left(\frac{l}{R}\right) \\
& \phi=\sin ^{-1}\left(\frac{P}{2 R}\right)
\end{aligned}
$$

\subsection{Realizando a Manobra}

Logo após calcular a trajetória e verificar que é possível executar a manobra, o volante do veículo deve ser esterçado para o lado do meio fio, de tal forma que o valor da Equação 5.7a seja menor que o raio máximo de esterçamento do veículo, e então engatar a marcha ré. O veículo então deve entrar no espaço escolhido até alcançar a orientação indicada pela Equação 5.7b e, caso alcançado, constata-se que o veículo chegou ao ponto de virada $M$ (Figura 5.4(a)).

Neste momento o veículo para e deve esterçar o mesmo valor de $R$ inversamente e depois continuar em marcha ré (Figura 5.4(b)) até o valor de $S R 3$ seja menor ou igual alguma medida de segurança $S$ (neste momento o veículo estará paralelo ao meio-fio), ou a diferença da orientação inicial do veículo ao iniciar a manobra seja menor que zero (Figura 5.4(c)). Em seguida o veículo para, esterça o volante, até ficar centralizado e desloca-se para frente até o centro da vaga à $5 \mathrm{~km} / \mathrm{h}$, verificando as diferenças de medidas entre os feixes $S F 3$ e $S R 3$ (Equação 5.8). 


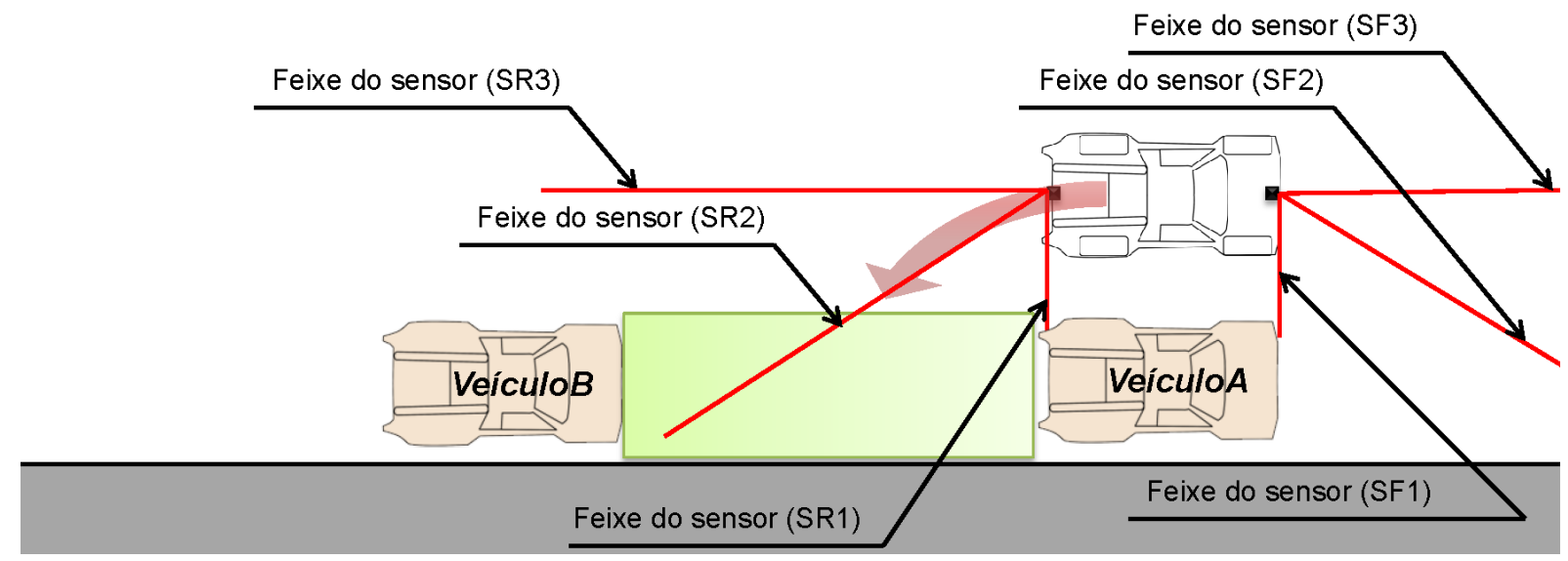

(a)

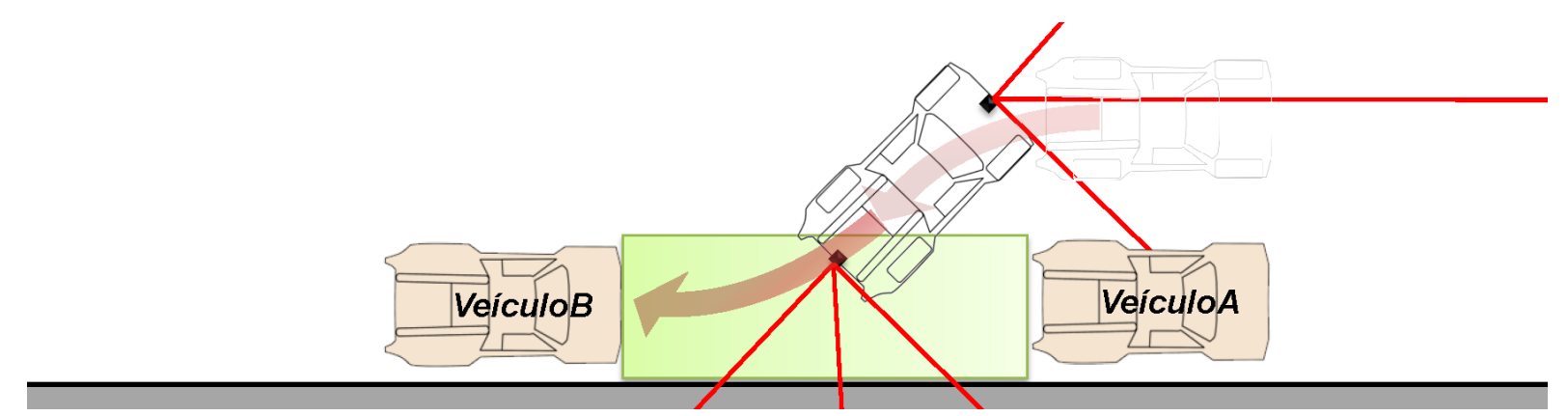

(b)

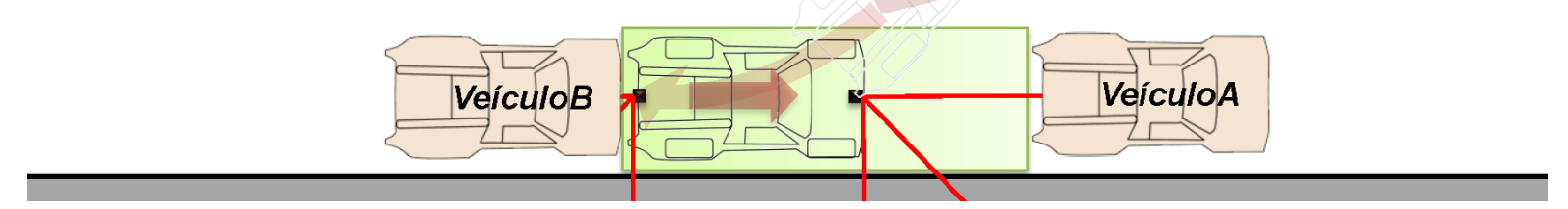

(c)

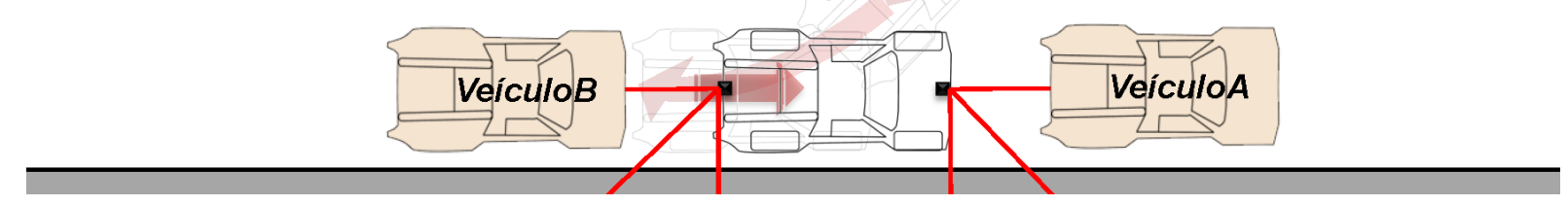

(d)

Figura 5.4: Manobrando o veículo para dentro da vaga encontrada: (a) entrando na vaga; (b) esterçando inversamente para posicionar o veículo na vaga; (c) aproximando-se do veículo, tomando cuidado para não bater a traseira; (d) ajustando o carro à vaga e parando-o. 


$$
V= \begin{cases}-5 & \text { se } S F 3-S R 3>\text { erro } \\ +5 & \text { se } S R 3-S F 3>\text { erro } \\ 0 & \text { se }|S F 3-S R 3| \leq \text { erro }\end{cases}
$$

Caso a diferença entre $S F 3$ e $S R 3$ sejam maior que um erro pré-definido pelo sistema de centralização, a velocidade $V$ do veículo pode ser positiva (movimenta-se para frente), negativa (movimenta-se para trás) ou nula (o veículo para). Quando o veículo para a baliza terá sido realizado com sucesso (Figura 5.4(d)).

\subsection{Considerações Finais}

Este capítulo discorreu sobre a abordagem utilizada em que a manobra de estacionamento é dividida em três etapas. Para cada etapa são descritos os passos realizados utilizando-se dos sensores definidos no Capítulo 3. As duas primeiras etapas são realizadas utilizando-se de príncipios de contagem baseados na odometria do veículo. Na última etapa é utilizada uma curva em $S$ definida matematicamente na sequência desse capítulo, utilizando dois arcos de circunferências. Logo, o conteúdo apresentado oferece suporte à escolha dos dados de treinamento para o aprendizado supervisionado a ser usado no sistema neural. 


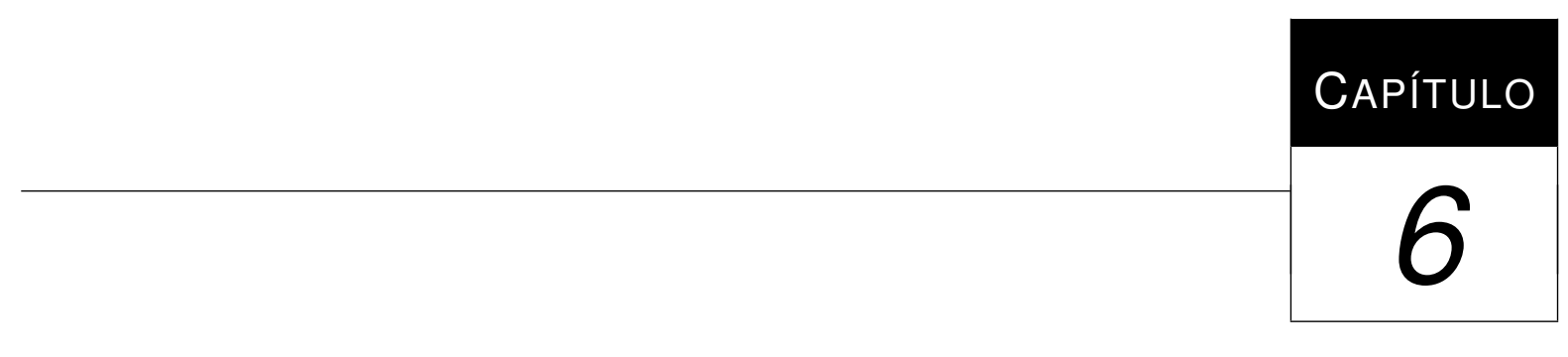

\section{Sistema Neural Desenvolvido}

Neste capítulo são descritos os procedimentos e os métodos utilizados para o desenvolvimento do sistema neural para estacionar o veículo em vagas paralelas, de modo que a entrada na vaga seja realizada com uma única manobra.

\subsection{O Controlador Neural}

O modelo de RNA adotado nesta dissertação foi o MLP apresentado no Capítulo 4, com aprendizado supervisionado do tipo RPROP e LM. Este tipo de abordagem foi adotado porque a RNA apresenta grande robustez com relação à presença de ruídos no sistema, como valores inexatos dos sensores e situações imprevistas.

O princípio de funcionamento segue o mesmo apresentado por Osório et al. (2002). O controlador neural deve receber um conjunto de entradas referentes ao estado atual do veículo (dados dos sensores e o estado atual da manobra) e o conjunto de saída para essas respectivas entradas (velocidade, esterçamento e qual seria o próximo estado da manobra). Deste modo, quando a rede neural estiver sendo treinada, ao receber os dados de entrada a rede conseguirá prever o próximo estado, baseada nas informações apresentadas. O próximo estado da manobra obtido na saída da rede substitui o estado atual, o que faz a rede ser capaz de prever as mudanças de estados. Isto é importante para que a rede possa interpretar corretamente os dados dos sensores enviados a ela, não definindo velocidades e ângulos de esterçamento errôneos. A Figura 6.1 descreve o funcionamento do controlador neural. 


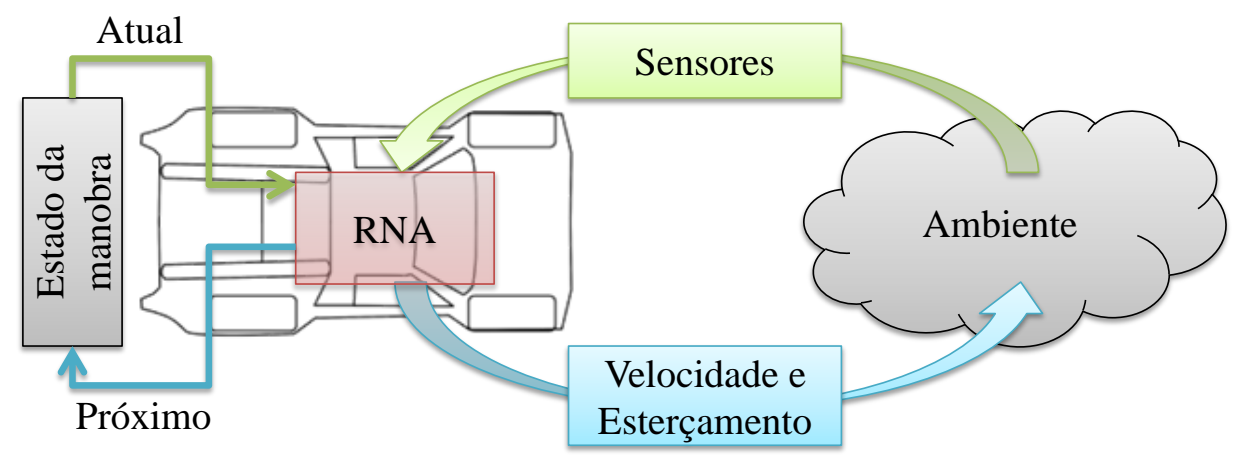

Entradas da Rede Neural

Saídas da Rede Neural

Figura 6.1: Descrição da Rede Neuralutilizada para controlar o veículo.

\subsubsection{Geração da Base de Exemplos}

A primeira etapa consiste em obter exemplos da manobra para que se possa treinar a RNA. Para isso os dados de treinamento são baseadas em dois sensores laser e no sensor inercial. A ideia básica é realizar um mapeamento da manobra usando as medidas dos sensores laser, velocidade e direção do veículo, ângulo de esterçamento, orientação dada pelo sensor inercial e tamanho da vaga medida pela odometria. Essas informações são suficientes para que o veículo possa estacionar em vagas paralelas com um comportamento reativo.

Neste momento é importante lembrar que os dados são obtidos a partir do terceiro estado, no qual o veículo realiza a manobra com base na curva em $\mathrm{S}$ apresentada no Capítulo 5. Antes de adquirir os dados foi feita uma análise dos possíveis pontos iniciais onde o veículo conseguiria realizar a trajetória em S. Para isso variou-se $\Delta y$ entre $\Delta y_{\min }$ (encostado no veículo A, ou seja, igual a zero) e $\Delta y_{\max }$ (distância da largura do veículo), enquanto $P$ foi variado entre $P_{\min }$ (tamanho da vaga é igual ao comprimento do veículo) e $P_{\max }$ (tamanho da vaga é igual a duas vezes o comprimento do veículo). A Figura 6.2 exibe com mais detalhes a análise realizada para descobrir as configurações iniciais aceitáveis.

Nestas condições, foram criadas possíveis curvas em MatLab discretizando-as em aproximadamente 500 pontos. Para cada ponto é verificado se acontece colisão, o que impossibilitaria a entrada do veículo em uma única manobra. A Figura 6.3 mostra um gráfico que indica a área onde é possível realizar a manobra.

Percebe-se pela Figura 6.3 que, dada a configuração do veículo utilizado neste trabalho, o mesmo só consegue iniciar o estacionamento se $P \geq 1,67 \cdot L$. Este resultado valida a Equação 5.1 com uma pequena ressalva, pois Herrmann (2003) diz que $\Delta y$ deveria ser zero e isso não acontece, mas ele também diz que não seria recomendado realizar a manobra com o veículo encostrado. Então, pela Figura 6.3, define-se $\Delta y \geq 0,05 \cdot W$ para segurança e realmente conseguir realizar a manobra.

Após encontrar a região possível de se realizar a manobra, adaptou-se o simulador para criar um arquivo de dados $(\log )$, contendo os estado dos sensores, estados da manobra (atual e pró- 


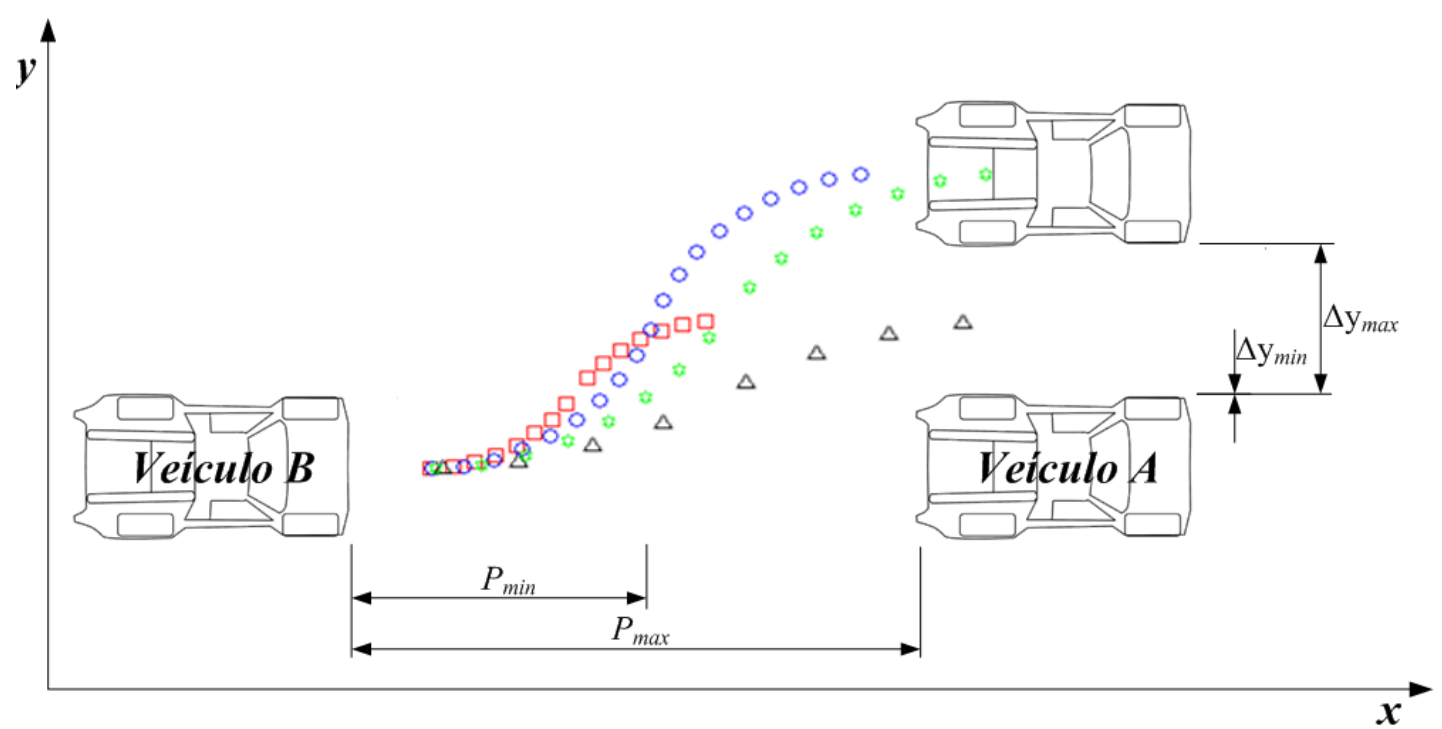

Figura 6.2: Detalhes da análise realizada para descobrir as configurações iniciais aceitáveis, na qual foram variados os parâmetros $\Delta y$ e $P$, onde quatro trajetórias limitantes são representadas.

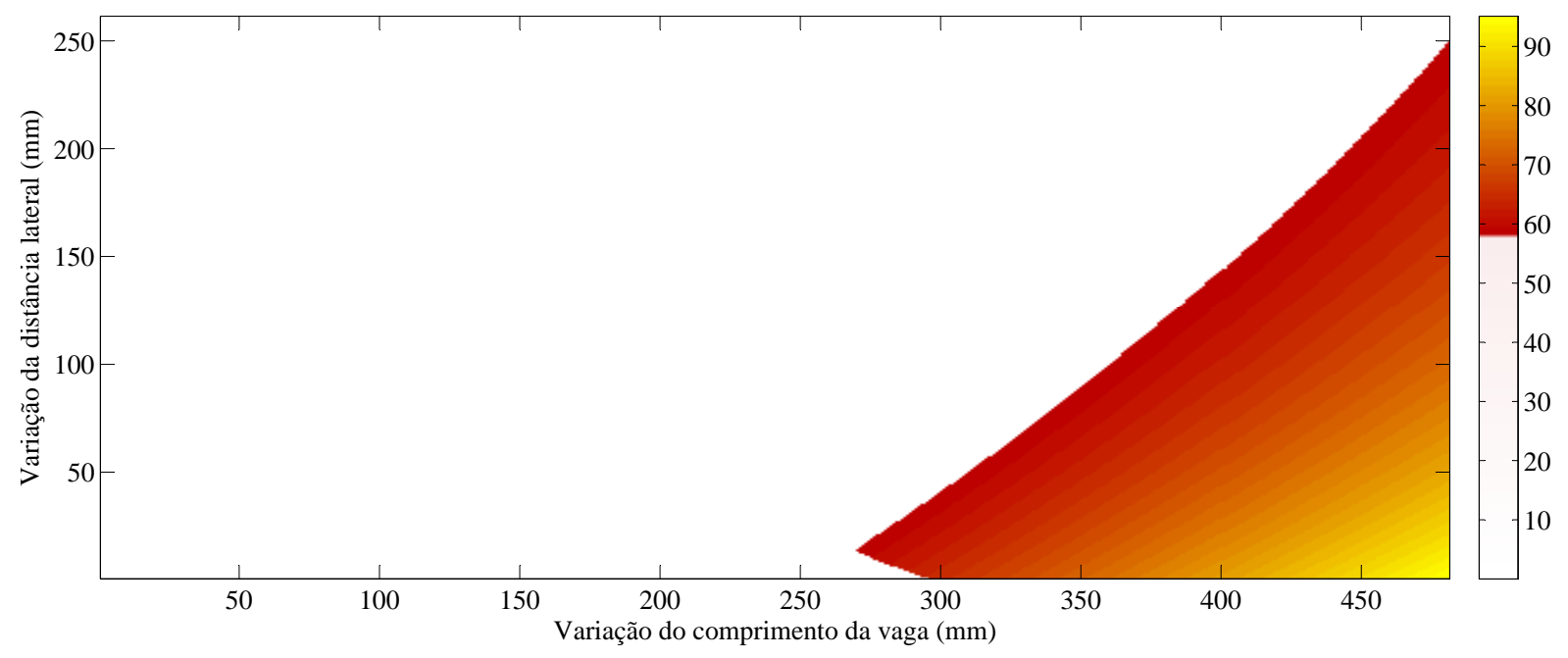

Figura 6.3: Área de estacionamento paralelo: a área branca indica que é impossível estacionar em uma única manobra, enquanto a cor vermelha mais escura indica o ponto máximo de esterçamento e a cor amarela indica um ângulo menor de esterçamento.

ximo) e os atuadores de velocidade e rotação. Este arquivo permite que sejam gravados todos os dados referentes à execução de uma tarefa de estacionamento, seja esta tarefa controlada pelo autômato finito (apresentado no próximo sub-tópico) ou por um usuário que pode controlar o veículo através do controle manual do simulador. A base de treinamento criada tem 55 manobras e cada manobra tem aproximadamente 320 pontos de coleta de dados, somando um total de 17.625 exemplos. Lembrando que cada exemplo possui 12 valores, resultando em uma matriz de $17.625 \times 12$. 
A Figura 6.4 apresenta uma pequena amostra da base de aprendizado utilizada para treinar as redes neurais. A primeira coluna armazena o tamanho da vaga de estacionamento encontrado em milímetros, o segundo valor recebe a diferença de orientação do veículo na posição inicial até a posição atual. Os seis próximos itens são os valores dos feixes do sensor da frente e do sensor traseiro, no qual os valores são limitados em $1.010,00 \mathrm{~mm}$, e os próximo quatro itens são referentes ao estado atual do veículo codificado em binário do tipo "1 entre N". Este tipo de codificação é o mais adequado, pois possui uma diferenciação equilibrada entre as diferentes codificações de cada valor. Os próximos valores diz em respeito à velocidade do veículo dada em pixels/s e o giro de esterçamento do veículo dado em radianos. Os últimos quatro valores representam o próximo estado da manobra, também representados em binário do tipo "1 entre N".

\begin{tabular}{|c|c|c|c|c|c|c|c|c|c|c|c|c|c|c|c|c|c|}
\hline $\boldsymbol{P}$ & $\Phi$ & SF1 & $S F 2$ & SF3 & SR1 & $S R 2$ & SR3 & \multicolumn{4}{|c|}{ Estado atual } & $\boldsymbol{V}$ & $\theta$ & \multicolumn{4}{|c|}{ Próximo estado } \\
\hline 858,000 & $-39,260$ & 397,180 & 994,000 & 1004,000 & 996,000 & 1007,000 & 1004,000 & 1 & 0 & 0 & 0 & -40 & 0,5 & 1 & 0 & 0 & 0 \\
\hline 858,000 & $-39,200$ & 400,420 & 994,000 & 1002,000 & 995,000 & 990,000 & 1002,000 & 1 & 0 & 0 & 0 & -40 & 0,5 & 1 & 0 & 0 & 0 \\
\hline 858,000 & $-39,610$ & 401,660 & 1007,000 & 992,000 & 998,000 & 998,000 & 992,000 & 1 & 0 & 0 & 0 & -40 & 0,5 & 1 & 0 & 0 & 0 \\
\hline 858,000 & $-40,220$ & 414,890 & 997,000 & 992,000 & 998,000 & 1000,000 & 992,000 & 1 & 0 & 0 & 0 & -40 & 0,5 & 1 & 0 & 0 & 0 \\
\hline 858,000 & $-41,110$ & 407,110 & 1002,000 & 1001,000 & 1010,000 & 1002,000 & 1001,000 & 1 & 0 & 0 & 0 & -40 & $-0,5$ & 0 & 1 & 0 & 0 \\
\hline 858,000 & $-41,180$ & 400,000 & 1002,000 & 1010,000 & 1005,000 & 997,000 & 1010,000 & 0 & 1 & 0 & 0 & -40 & $-0,5$ & 0 & 1 & 0 & 0 \\
\hline 858,000 & $-40,260$ & 394,000 & 1003,000 & 1010,000 & 1004,000 & 993,000 & 1010,000 & 0 & 1 & 0 & 0 & -40 & $-0,5$ & 0 & 1 & 0 & 0 \\
\hline 858,000 & $-40,560$ & 376,110 & 1001,000 & 1008,000 & 991,000 & 990,000 & 1008,000 & 0 & 1 & 0 & 0 & -40 & $-0,5$ & 0 & 1 & 0 & 0 \\
\hline 858,000 & $-39,920$ & 382,320 & 1004,000 & 1006,000 & 993,000 & 1003,000 & 1006,000 & 0 & 1 & 0 & 0 & -40 & $-0,5$ & 0 & 1 & 0 & 0 \\
\hline 858,000 & $-39,900$ & 364,640 & 1006,000 & 1008,000 & 1002,000 & 992,000 & 1008,000 & 0 & 1 & 0 & 0 & -40 & $-0,5$ & 0 & 1 & 0 & 0 \\
\hline 858,000 & $-39,520$ & 353,050 & 993,000 & 1009,000 & 991,000 & 1004,000 & 1009,000 & 0 & 1 & 0 & 0 & -40 & $-0,5$ & 0 & 1 & 0 & 0 \\
\hline 858,000 & $-39,110$ & 357,570 & 990,000 & 1005,000 & 1004,000 & 997,000 & 1005,000 & 0 & 1 & 0 & 0 & -40 & $-0,5$ & 0 & 1 & 0 & 0 \\
\hline 858,000 & $-39,010$ & 354,180 & 993,000 & 1008,000 & 1007,000 & 991,000 & 1008,000 & 0 & 1 & 0 & 0 & -40 & $-0,5$ & 0 & 1 & 0 & 0 \\
\hline
\end{tabular}

Figura 6.4: Amostra da base de exemplos usada para o aprendizado supervisionado da rede neural.

\subsubsection{Controlador Baseado em Regras - Autômato Finito}

Pensando em facilitar e agilizar a coleta de dados foi implementado o Autômato Finito (AF) criado por Heinen et al. (2006a), no qual busca-se através de seis estados descrever a evolução do comportamento de um motorista ao realizar a tarefa de estacionamento paralelo. A Figura 6.5 mostra o diagrama de estados do AF utilizando a abordagem definida anteriormente, que foi codificado em um conjunto de regras:

1. Procurando vaga: $O$ início do processo de estacionamento começa com o veículo se deslocando para frente em velocidade constante de $0,15 \mathrm{~m} / \mathrm{s}$ com a direção reta tentando detectar e calcular o tamanho de uma vaga. Se encontrar, o estado muda para "Posicionando o veículo";

2. Posicionando o veículo: $O$ veículo continua se deslocando para frente, a fim de se emparelhar ao veículo da frente (posição de início da manobra) e também para verificar se 


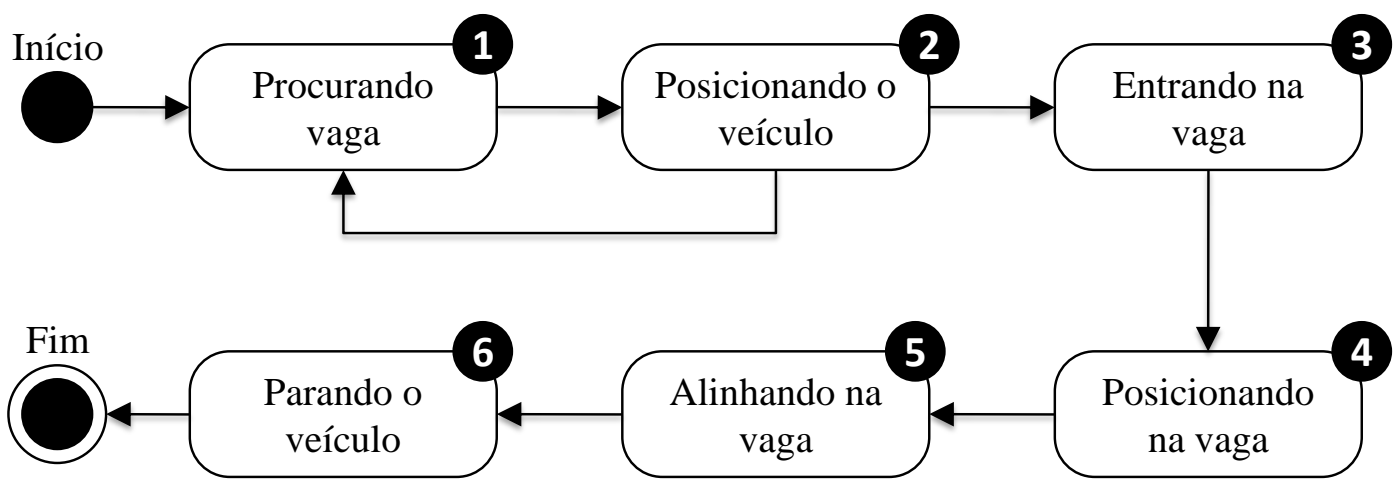

Figura 6.5: Autômato Finito que representa o conhecimento humano para realizar o estacionamento paralelo em seis etapas.

é possível esterçar o veículo usando a abordagem de dois arcos de círculos descrita anteriormente. Se não for possível, o estado volta para "Procurando vaga". Se for possível esterçar, o estado muda para "Entrando na vaga";

3. Entrando na vaga: $O$ carro vira a direção para a direita conforme Equação 5.7a e começa se movimentar para trás, de forma a entrar na vaga. Quando a orientação do veículo satisfizer a Equação 5.7b o estado passa para "Posicionando na vaga";

4. Posicionando na vaga: neste estado o veículo prossegue para trás, mas com a direção do volante inversa à do estado "Entrando na vaga". Quando o $S R 3 \leq s$, ou a orientação do veículo for menor ou igual à medida inicial em que a manobra foi iniciada (neste momento o veículo estará paralelo ao meio-fio), o estado muda para "Alinhando na vaga";

5. Alinhando na vaga: neste estado o veículo é movimentado de forma a satisfazer a Equação 5.8. Após o alinhamento estar concluído, o estado muda para "Parado" e a manobra é encerrada com sucesso;

6. Parado: o veículo reduz a velocidade a zero e desliga o carro;

A codificação em pseudo-algoritmo do AF é apresentado no Apêndice B.

\subsubsection{Pré-processamento dos dados}

Esta etapa implica em dimensionar as amostras geradas para a faixa de variação dinâmica das funções de ativação das camadas escondidas (foi assumida a tangente hiperbólica com o intuito de evitar a saturação dos neurônios). A função tangente hiperbólica tem por característica a anti-simetria, que contribui para melhorar o processo de convergência da rede durante o aprendizado. Uma das técnicas mais utilizadas é baseada no teorema de Tales, em que o conjunto de valores definidos num intervalo fechado entre $x^{\text {min }}$ e $x^{\text {max }}$ será convertido para um domínio proporcional entre -1 e 1, o qual representa as variações da função escolhida. A Equação 6.1 
exibe o princípio de normalização dos padrões de entrada (treinamento e teste), onde $z$ é o valor normalizado e $x$ é o dado de entrada, tal que $x \in\left[x^{\min }, x^{\max }\right]$.

$$
z=\frac{x-x^{\min }}{x^{\max }-x^{\min }}
$$

Além dos padrões de entrada, os padrões de saída também devem ser normalizados e, mais importante que isso, todos os dados devem ser individualmente normalizados em relação aos seus respectivos valores mínimos e máximos. Vale ressaltar que os valores mínimos e máximos devem compor o conjunto de treinamento. Caso contrário implicarão na redução do domínio de treinamento, existindo provavelmente dados de teste que possam estar na zona de saturação dos neurônios, prejudicando o aprendizado da rede.

\subsubsection{Definição das Topologias Candidatas}

Com os dados normalizados, é necessário definir as topologias candidatas que serão submetidas ao aprendizado e depois serão avaliadas. Mas antes de definir essas topologias, foram adotadas duas estratégias. A primeira estratégia consiste em ter todas as saídas (esterçamento, velocidade e estados) na mesma rede, enquanto na segunda estratégia, criam-se redes especializadas para cada tipo de saída, visando melhorar o desempenho e reduzir a complexidade. Além disso, para cada estratégia são apresentadas exemplos de quatro cenários diferentes: sensores sem ruído e espaço de estacionamento sem parede; sem ruído e com parede; com ruído e sem parede; com ruído e com parede.

Para a primeira estratégia tem-se a seguinte topologia para a rede MLP:

- Camada de entrada $\rightarrow 12$ entradas, correspondendo aos seguintes dados: tamanho da vaga, feixe laser SF1, feixe laser SF2, feixe laser SF3, feixe laser SR1, feixe laser SR2, feixe laser SR3, orientação dada pelo IMU, terceiro estado da manobra, quarto estado da manobra, quinto estado da manobra, sexto e último estado da manobra;

- Camada escondida $\rightarrow 5,10,15$ e 20 neurônios, podendo ter 1,2 ou 3 camadas escondidas;

- Camada de saída $\rightarrow 10$ neurônios, representando: um sinal contínuo de esterçamento, um valor contínuo representando a velocidade, terceiro estado da manobra, quarto estado da manobra, quinto estado da manobra, sexto e último estado da manobra;

A topologia da rede neural utilizada na primeira estratégia pode ser mais bem compreendida por meio da Figura 6.6

A segunda estratégia apresenta uma topologia na qual cada conjunto de saída será representado por uma rede neural, que se tornará especialista naqueles exemplos de saídas. Este tipo de configuração costuma fornecer melhores resultados que outras estratégias, pois reduz o esforço 


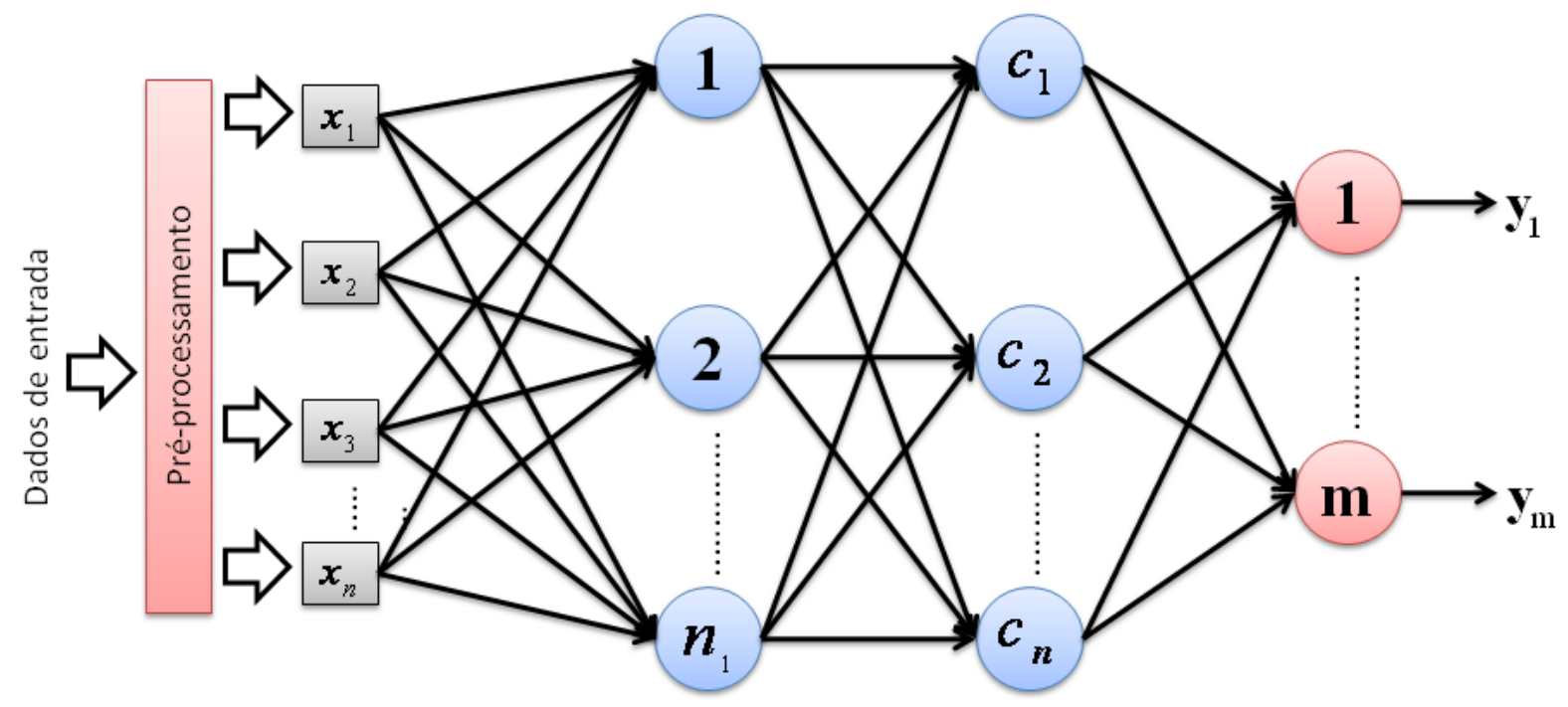

Figura 6.6: Topologia da rede neural para a primeira estratégia de estacionamento paralelo.

computacional utilizado nas fases de treinamento e ajustes das topologias neurais. A topologia para a rede MLP utilizando esta estratégia é apresentada na Figura 6.7

Cada saída é representada por uma rede neural que contém a mesma topologia da primeira estratégia, com mudanças na camada de saída. A camada de saída de cada rede neural é responsável por dados específicos de funcionalidade, então a primeira tem somente um neurônio para esterçamento do veículo, a segunda tem somente um neurônio para a velocidade e a última é responsável por definir se o estado do veículo será modificado. Ela contém quatro neurônios para o terceiro estado da manobra, quarto estado da manobra, quinto estado da manobra, sexto e último estado da manobra.

\subsection{Resultados de Aprendizado dos Controladores}

Neste seção serão apresentados resultados do aprendizado supervisionado realizado nas redes neurais e também resultados simulados do sistema. A primeira estratégia ficou composta de 20 topologias candidatas utilizando o algoritmo RPROP e mais 20 com o método LM, para cada controlador neural. Para a segunda estratégia obtém-se 60 topologias candidatas (20 para cada rede especialista) para RPROP e mais 60 topologias para o método LM. Enfim, somam-se 640 topologias que serão treinadas para análise de eficiência e assim escolher a melhor para cada caso.

Para avaliar o desempenho das topologias candidatas, foi quantificado o erro de percentagem média absoluta (do inglês, Mean Absolute Percentage Error - MAPE), onde na Equação 6.2 a resposta desejada é indicada por $A_{t}$ e a obtida por $F_{t}$ :

$$
M A P E=\frac{1}{n} \sum_{t=1}^{n}\left|\frac{A_{t}-F_{t}}{A_{t}} \cdot 100\right|
$$




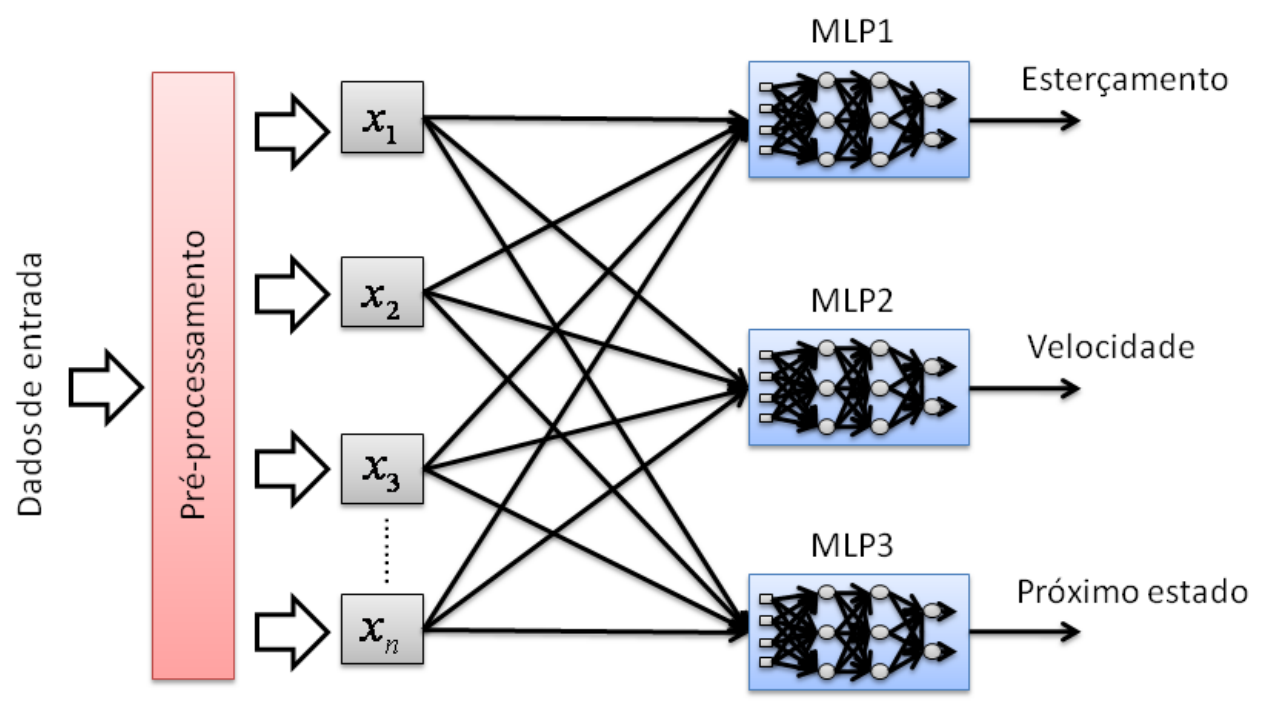

Figura 6.7: Topologia da rede neural especialista para a segunda estratégia de estacionamento paralelo.

\subsubsection{Controlador Neural I}

No primeiro controlador neural utilizou-se a primeira estratégia definida anteriormente, assumindo a tangente hiperbólica como função de ativação para todas camadas e os algoritmos de aprendizado RPROP e LM. Este controlador utiliza dados coletados de 55 manobras de estacionamento paralelos, nas quais os sensores simulados não possuem ruídos (não é acrescentado erro aos sensores). Para realizar a manobra o veículo autônomo não conta com a presença de uma parede de auxílio, o que facilitaria a manobra. As 55 manobras resultam em 17.625 exemplos de dados, sendo que, com o uso do 5-fold cross-validation, $\frac{4}{5}$ dos dados serão usados para treinamento (14.100 exemplos), enquanto $\frac{1}{5}$ serão usado para validação (3.525 exemplos). Foram testadas 20 topologias (Tabela C.1 do Apêndice C) usando o algoritmo RPROP e o algoritmo LM (Tabela C.2 do Apêndice C). A Tabela 6.1 apresenta as três melhores topologias usando RPROP e as três melhores usando LM, levando em consideração a menor quantidade de camadas e a menor quantidade de neurônios.

Tabela 6.1: Resultado das três melhores topologias candidatas para a primeira estratégia (sem ruídos no sensores e sem a presença de parede) usando o algoritmo de aprendizado Resilient Propagation e o algoritmo de aprendizado Levenberg-Marquardt para o controlador neural I.

\begin{tabular}{|c|c|c|c|c|c|c|c|}
\hline \multirow[t]{2}{*}{ Ref. (RPROP) } & \multirow{2}{*}{$\begin{array}{l}\text { Neurônios } \\
\text { Escondidos }\end{array}$} & \multicolumn{2}{|c|}{$\begin{array}{c}\text { Média Final } \\
\text { MAPE (\% acertos) }\end{array}$} & \multirow[t]{2}{*}{ Ref. (LM) } & \multirow{2}{*}{$\begin{array}{l}\text { Neurônios } \\
\text { Escondidos }\end{array}$} & \multicolumn{2}{|c|}{$\begin{array}{c}\text { Média Final } \\
\text { MAPE (\% acertos) }\end{array}$} \\
\hline & & Trein. & Val. & & & Trein. & Val \\
\hline $\mathrm{M}$ & 20 & 98, & 98,4 & & 10 & 99,5 & 99,5 \\
\hline MLP-17 & $20-5$ & 98,3 & 98,3 & 7 & $20-5$ & 99,5 & 99,4 \\
\hline MLP-6 & 10 & 98,3 & 98,2 & MLP-25 & $5-20$ & 99,2 & 99,2 \\
\hline
\end{tabular}




\subsubsection{Controlador Neural II}

No segundo teste utilizou-se a mesma configuração, porém com a presença de parede para auxiliar o estacionamento, o que pode facilitar a manobra do veículo. A Tabela 6.2 apresenta as três melhores topologias usando RPROP e as três melhores usando LM, levando em consideração a menor quantidade de camadas e a menor quantidade de neurônios. Todos os resultados podem ser visualizados respectivamente na Tabela C.3 e na Tabela C.4, presentes no Apêndice C.

Tabela 6.2: Resultado das três melhores topologias candidatas para a primeira estratégia (sem ruídos no sensores e com a presença de parede) usando o algoritmo de aprendizado Resilient Propagation e o algoritmo de aprendizado Levenberg-Marquardt para o controlador neural II.

\begin{tabular}{c|c|cc|c|l|cc}
\hline \hline \multirow{2}{*}{ Ref. (RPROP) } & \multirow{2}{*}{$\begin{array}{c}\text { Neurônios } \\
\text { Escondidos }\end{array}$} & \multicolumn{2}{|c|}{ Média Final } & \multicolumn{2}{c|}{ MAPE (\% acertos) } & Ref. (LM) & \multicolumn{2}{c}{$\begin{array}{l}\text { Neurônios } \\
\text { Escondidos }\end{array}$} & \multicolumn{2}{c}{$\begin{array}{c}\text { Média Final } \\
\text { MAPE (\% acertos) } \\
\text { Trein. }\end{array}$} & Val. & & Val \\
\hline MLP-54 & $15-15$ & 98,8 & 98,8 & MLP-72 & $15-5$ & 99,7 & 99,6 \\
MLP-53 & $15-10$ & 98,7 & 98,7 & MLP-78 & $20-10$ & 99,7 & 99,6 \\
MLP-51 & 15 & 98,6 & 98,6 & MLP-74 & $15-15$ & 99,6 & 99,6 \\
\hline \hline
\end{tabular}

\subsubsection{Controlador Neural III}

Os testes do terceiro controlador neural também possuem a mesma configuração, porém os dados dos sensores agora têm ruídos e não se utiliza a parede para auxiliar a manobra, o que poderia ser o pior caso para o controlador neural. A Tabela 6.3 apresenta as três melhores topologias usando RPROP e as três melhores usando LM, levando em consideração a menor quantidade de camadas e a menor quantidade de neurônios. Todos os resultados podem ser visualizados respectivamente na Tabela C.5 e na Tabela C.6, presentes no Apêndice C.

Tabela 6.3: Resultado das três melhores topologias candidatas para a primeira estratégia (sensores com ruídos e sem a presença de parede) usando o algoritmo de aprendizado Resilient Propagation e o algoritmo de aprendizado Levenberg-Marquardt para o controlador neural III.

\begin{tabular}{|c|c|c|c|c|c|c|c|}
\hline \multirow{2}{*}{ Ref. (RPROP) } & \multirow{2}{*}{$\begin{array}{l}\text { Neurônios } \\
\text { Escondidos }\end{array}$} & \multicolumn{2}{|c|}{$\begin{array}{c}\text { Média Final } \\
\text { MAPE (\% acertos) }\end{array}$} & \multirow{2}{*}{ Ref. (LM) } & \multirow{2}{*}{$\begin{array}{l}\text { Neurônios } \\
\text { Escondidos }\end{array}$} & \multicolumn{2}{|c|}{$\begin{array}{c}\text { Média Final } \\
\text { MAPE (\% acertos) }\end{array}$} \\
\hline & & Trein. & Val. & & & Trein. & Val \\
\hline MLP-98 & $20-10$ & 98,4 & 98,4 & MLP-108 & $10-10$ & 99,1 & 99,1 \\
\hline MLP-93 & $15-10$ & 98,3 & 98,3 & MLP-110 & $10-20$ & 99,0 & 99,0 \\
\hline MLP-96 & 20 & 98,2 & 98,2 & MLP-113 & $15-10$ & 99,0 & 99,0 \\
\hline
\end{tabular}




\subsubsection{Controlador Neural IV}

Para concluir os testes com controladores usando a primeira estratégia, este último utiliza dados dos sensores com ruídos e novamente existe uma parede para auxiliar a manobra. A Tabela 6.4 apresenta as três melhores topologias usando RPROP e as três melhores usando LM, levando em consideração a menor quantidade de camadas e a menor quantidade de neurônios. Todas os resultados podem ser visualizados respectivamente na Tabela C.7 e na Tabela C.8, presentes no Apêndice C.

Tabela 6.4: Resultado das três melhores topologias candidatas para a primeira estratégia (sensores com ruídos e com a presença de parede) usando o algoritmo de aprendizado Resilient Propagation e o algoritmo de aprendizado Levenberg-Marquardt para o controlador neural IV.

\begin{tabular}{c|c|cc|c|c|cc}
\hline \hline \multirow{2}{*}{ Ref. (RPROP) } & \multirow{2}{*}{$\begin{array}{c}\text { Neurônios } \\
\text { Escondidos }\end{array}$} & \multicolumn{2}{|c|}{ Média Final } & \multicolumn{2}{c|}{ MAPE (\% acertos) } & \multirow{2}{*}{ Ref. (LM) } & \multicolumn{2}{c}{$\begin{array}{c}\text { Neurônios } \\
\text { Escondidos }\end{array}$} & \multicolumn{2}{c}{$\begin{array}{c}\text { Média Final } \\
\text { MAPE (\% acertos) } \\
\text { Trein. }\end{array}$} & Val. & & & Val \\
\hline MLP-136 & 20 & 98,4 & 98,4 & MLP-151 & 15 & 99,2 & 99,1 \\
MLP-132 & $15-5$ & 98,4 & 98,4 & MLP-155 & $15-20$ & 99,2 & 99,1 \\
MLP-133 & $15-10$ & 98,4 & 98,4 & MLP-152 & $15-5$ & 99,1 & 99,1 \\
\hline \hline
\end{tabular}

\subsubsection{Controlador Neural V}

Este quinto controlador neural é o primeiro a utilizar a segunda estratégia definida, assumindo as mesmas condições dos outros controladores da primeira estratégia. Os testes foram realizados com dados coletados dos sensores sem ruído e sem a presença de parede para auxílio à manobra de estacionamento. A Tabela 6.5 exibe os resultados das três melhores topologias para a rede especialista em esterçamento usando o algoritmo RPROP (Tabela C.9) e LM(Tabela C.10). Também apresenta os três melhores resultados treinados para a rede que define a velocidade do veículo durante a manobra (repectivamente aos algoritmos de treinamento, a Tabela C.11 e Tabela C.12) e, por fim, as três melhores para a rede que apresenta o próximo estado do veículo (Tabela C.13 e Tabela C.14).

\subsubsection{Controlador Neural VI}

Os testes com o sexto controlador neural, que é o segundo a utilizar a segunda estratégia definida, foram realizados com dados coletados dos sensores sem ruído e com a presença de parede para auxílio a manobra de estacionamento. A Tabela 6.6 exibe os resultados das três melhores topologias para a rede especialista em esterçamento usando o algoritmo RPROP (Tabela C.15) e LM(Tabela C.16). Também apresenta os três melhores para a rede que define a velocidade do veículo durante a manobra (repectivamente aos algoritmos de treinamento, a Ta- 
Tabela 6.5: Resultado das três melhores topologias candidatas para cada rede da segunda estratégia, usando o algoritmo de aprendizado Resilient Propagation e o algoritmo de aprendizado Levenberg-Marquardt para o controlador neural V.

\begin{tabular}{|c|c|c|c|c|c|c|c|}
\hline \multirow[t]{2}{*}{ Ref. (RPROP) } & \multirow{2}{*}{$\begin{array}{l}\text { Neurônios } \\
\text { Escondidos }\end{array}$} & \multicolumn{2}{|c|}{$\begin{array}{c}\text { Média Final } \\
\text { MAPE (\% acertos) }\end{array}$} & \multirow[t]{2}{*}{ Ref. (LM) } & \multirow{2}{*}{$\begin{array}{l}\text { Neurônios } \\
\text { Escondidos }\end{array}$} & \multicolumn{2}{|c|}{$\begin{array}{c}\text { Média Final } \\
\text { MAPE (\% acertos) }\end{array}$} \\
\hline & & Trein. & Val. & & & Trein. & Val \\
\hline MLP-161 & 5 & 100,0 & 100,0 & MLP-181 & 5 & 100,0 & 100,0 \\
\hline MLP-171 & 15 & 100,0 & 100,0 & MLP-182 & $5-5$ & 100,0 & 100,0 \\
\hline MLP-176 & 20 & 100,0 & 100,0 & MLP-191 & 15 & 100,0 & 100,0 \\
\hline MLP-217 & $20-5$ & 95,8 & 95,8 & MLP-238 & $20-10$ & 98,2 & 98,1 \\
\hline MLP-219 & $20-15$ & 95,8 & 95,8 & MLP-236 & $10-10$ & 98,2 & 98,0 \\
\hline MLP-212 & $15-5$ & 95,8 & 95,7 & MLP-228 & 20 & 98,0 & 97,9 \\
\hline MLP-249 & $10-15$ & 98,7 & 98,7 & MLP-267 & $10-5$ & 99,9 & 99,8 \\
\hline MLP-257 & $20-5$ & 98,5 & 98,5 & MLP-264 & $5-15$ & 99,8 & 99,8 \\
\hline MLP-256 & 20 & 98,4 & 98,4 & MLP-261 & 5 & 99,7 & 99,6 \\
\hline
\end{tabular}

bela C.17 e Tabela C.18) e, por fim, as três melhores para a rede que apresenta o próximo estado do veículo (Tabela C.19 e Tabela C.20).

Tabela 6.6: Resultado das três melhores topologias candidatas para cada rede da segunda estratégia usando o algoritmo de aprendizado Resilient Propagation e o algoritmo de aprendizado Levenberg-Marquardt para o controlador neural VI.

\begin{tabular}{|c|c|c|c|c|c|c|c|}
\hline \multirow[t]{2}{*}{ Ref. (RPROP) } & \multirow{2}{*}{$\begin{array}{l}\text { Neurônios } \\
\text { Escondidos }\end{array}$} & \multicolumn{2}{|c|}{$\begin{array}{c}\text { Média Final } \\
\text { MAPE (\% acertos) }\end{array}$} & \multirow[t]{2}{*}{ Ref. (LM) } & \multirow{2}{*}{$\begin{array}{l}\text { Neurônios } \\
\text { Escondidos }\end{array}$} & \multicolumn{2}{|c|}{$\begin{array}{c}\text { Média Final } \\
\text { MAPE (\% acertos) }\end{array}$} \\
\hline & & Trein. & Val. & & & Trein. & Val \\
\hline MLP-296 & 20 & 100,0 & 100,0 & MLP-301 & 5 & 100,0 & 100,0 \\
\hline MLP-289 & $10-15$ & 100,0 & 100,0 & MLP-302 & $5-5$ & 100,0 & 100,0 \\
\hline MLP-281 & 5 & 99,9 & 99,9 & MLP-311 & 15 & 100,0 & 100,0 \\
\hline MLP-339 & $20-15$ & 97,60 & 97,5 & MLP-349 & $10-15$ & 99,1 & 99,0 \\
\hline MLP-334 & $15-15$ & 97,5 & 97,5 & MLP-351 & 15 & 99,0 & 98,9 \\
\hline MLP-332 & $15-5$ & 97,4 & 97,4 & MLP-356 & 20 & 99,0 & 98,9 \\
\hline MLP-374 & $15-15$ & 99,2 & 99,2 & MLP-381 & 5 & 99,9 & 99,9 \\
\hline MLP-371 & 15 & 99,2 & 99,1 & MLP-388 & $10-10$ & 99,9 & 99,8 \\
\hline MLP-376 & 20 & 99,1 & 99,1 & MLP-394 & $15-15$ & 99,8 & 99,7 \\
\hline
\end{tabular}

\subsubsection{Controlador Neural VII}

O sétimo controlador utiliza dados dos sensores com ruído e sem a presença de parede para auxílio a manobra de estacionamento, ressaltando que este seria o pior caso. A Tabela 6.7 exibe os resultados das três melhores topologias para a rede especialista em esterçamento usando o algoritmo RPROP (Tabela C.21) e LM(Tabela C.22). Também apresenta os três melhores para a rede que define a velocidade do veículo durante a manobra (repectivamente aos algoritmos de 
treinamento, a Tabela C.23 e Tabela C.24) e, por fim, as três melhores para a rede que apresenta o próximo estado do veículo (Tabela C.25 e Tabela C.26).

Tabela 6.7: Resultado das três melhores topologias candidatas para cada rede da segunda estratégia usando o algoritmo de aprendizado Resilient Propagation e o algoritmo de aprendizado Levenberg-Marquardt para o controlador neural VII.

\begin{tabular}{|c|c|c|c|c|c|c|c|}
\hline \multirow[t]{2}{*}{ Ref. (RPROP) } & \multirow{2}{*}{$\begin{array}{l}\text { Neurônios } \\
\text { Escondidos }\end{array}$} & \multicolumn{2}{|c|}{$\begin{array}{c}\text { Média Final } \\
\text { MAPE (\% acertos) }\end{array}$} & \multirow[t]{2}{*}{ Ref. (LM) } & \multirow{2}{*}{$\begin{array}{l}\text { Neurônios } \\
\text { Escondidos }\end{array}$} & \multicolumn{2}{|c|}{$\begin{array}{c}\text { Média Final } \\
\text { MAPE (\% acertos) }\end{array}$} \\
\hline & & Trein. & Val. & & & Trein. & Val \\
\hline MLP-410 & $10-20$ & 100,0 & 100,0 & MLP-421 & 5 & 100,0 & 100,0 \\
\hline MLP-414 & $15-15$ & 100,0 & 100,0 & MLP-427 & $10-5$ & 100,0 & 100,0 \\
\hline MLP-401 & 5 & 99,9 & 99,9 & MLP-431 & 15 & 100,0 & 100,0 \\
\hline MLP-458 & $20-10$ & 96,0 & 96,0 & MLP-447 & $20-5$ & 96,8 & 96,7 \\
\hline MLP-447 & $10-5$ & 95,9 & 95,9 & MLP-476 & 20 & 96,6 & 96,6 \\
\hline MLP-453 & $15-10$ & 95,9 & 95,9 & MLP-461 & 5 & 96,5 & 96,5 \\
\hline MLP-499 & $20-15$ & 98,7 & 98,7 & MLP-505 & $5-20$ & 99,3 & 99,3 \\
\hline MLP-493 & $15-10$ & 98,6 & 98,6 & MLP-511 & 15 & 99,3 & 99,2 \\
\hline MLP-496 & 20 & 98,5 & 98,5 & MLP-502 & $5-5$ & 99,2 & 99,2 \\
\hline
\end{tabular}

\subsubsection{Controlador Neural VIII}

O último controlar neural testado utiliza dados dos sensores com ruído e com a presença de parede para auxílio a manobra de estacionamento. A Tabela 6.8 exibe os resultados das três melhores topologias para a rede especialista em esterçamento usando o algoritmo RPROP (Tabela C.27) e LM(Tabela C.28). Também apresenta os três melhores para a rede que define a velocidade do veículo durante a manobra (repectivamente aos algoritmos de treinamento, a Tabela C.29 e Tabela C.30) e, por fim, as três melhores para a rede que apresenta o próximo estado do veículo (Tabela C.31 e Tabela C.32).

\subsection{Resultados Simulados e Discussão}

Os resultados de aprendizado dos controladores foram satisfatórios, obtendo no pior caso (sensores com ruído e sem parede de auxílio) da primeira estratégia um valor de aprendizado de $99 \%$, o que quer dizer que a rede deixou de aprender $1 \%$ dos exemplos passados para ela. Como a amostra de exemplos é grande (17.625 exemplos) este valor pode representar problemas, pois equivale a não aprender 176 exemplos. Na segunda estratégia obteve 100\% de acertos na rede que realiza o esterçamento do veículo e $99 \%$ na rede que troca os estados da manobra. Porém, nota-se um baixo aprendizado de $96,6 \%$ na rede que troca a velocidade do veículo. Valor este que representa 1.058 exemplos não aprendidos.

Os controladores foram avaliados através do mesmo conjunto de coleta de dados (55 manobras, variando-se o tamanho da vaga e a distância lateral do veículo) para o pior caso de cada 
Tabela 6.8: Resultado das três melhores topologias candidatas para cada rede da segunda estratégia usando o algoritmo de aprendizado Resilient Propagation e o algoritmo de aprendizado Levenberg-Marquardt para o controlador neural VIII.

\begin{tabular}{c|c|cc|c|c|cc}
\hline \hline \multirow{2}{*}{ Ref. (RPROP) } & \multirow{2}{*}{ Neurônios } & \multicolumn{2}{|c|}{ Média Final } & \multicolumn{2}{c|}{ MAPE (\% acertos) } & Ref. (LM) & \multicolumn{2}{c}{$\begin{array}{l}\text { Neurônios } \\
\text { Escondidos }\end{array}$} & \multicolumn{2}{c}{$\begin{array}{c}\text { Média Final } \\
\text { MAPE (\% acertos) } \\
\text { Escondidos }\end{array}$} \\
& & Trein. & Val. & & & Val \\
\hline MLP-530 & $10-20$ & 100,0 & 100,0 & MLP-542 & $5-5$ & 100,0 & 100,0 \\
MLP-540 & $20-20$ & 100,0 & 100,0 & MLP-551 & 15 & 100,0 & 100,0 \\
MLP-531 & 15 & 99,9 & 99,9 & MLP-556 & 20 & 100,0 & 100,0 \\
\hline MLP-572 & $15-5$ & 96,3 & 96,3 & MLP-598 & $20-10$ & 97,0 & 97,0 \\
MLP-577 & $20-5$ & 96,3 & 96,3 & MLP-594 & $15-15$ & 97,0 & 96,9 \\
MLP-564 & $15-15$ & 96,2 & 96,2 & MLP-589 & $10-15$ & 96,9 & 96,8 \\
\hline MLP-618 & $20-10$ & 98,7 & 98,6 & MLP-634 & $15-15$ & 99,5 & 99,4 \\
MLP-608 & $10-10$ & 98,6 & 98,6 & MLP-640 & $20-20$ & 99,5 & 99,3 \\
MLP-601 & 5 & 98,5 & 98,5 & MLP-626 & 10 & 99,4 & 99,3 \\
\hline \hline
\end{tabular}

estratégia adotada, ou seja, foi testada a melhor topologia do controlador III e a melhor topologia do controlador VII. Os resultados simulados realizados foram todos satisfatórios, mostrando que ambos os controladores conseguiram, nas 55 manobras, realizar todos os estacionamentos. A Figura 6.8(a) à Figura 6.8(b) exibem duas manobras executadas com o controlador III, e a Figura 6.9(a) e a Figura 6.9(b) exibe à mesma configuração da manobra, mas agora executada no controlador VII.

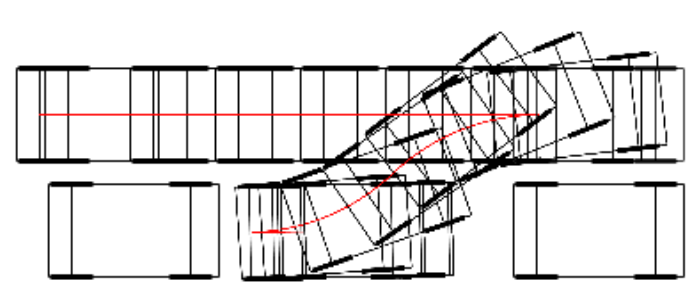

(a)

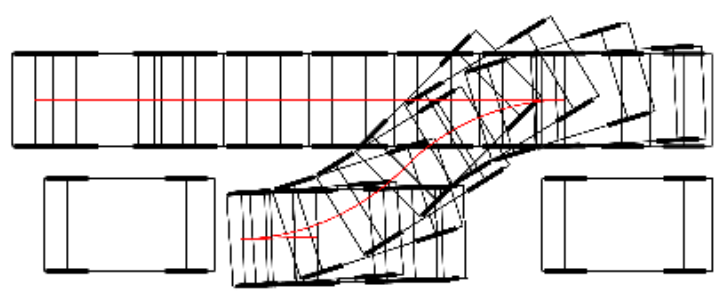

(b)

Figura 6.8: Manobras realizadas com o controlador III no simulador e analisadas visualmente: (a) $P=830,00 \mathrm{~mm}$ e $\Delta y=43,00 \mathrm{~mm}$; (b) $P=908,00 \mathrm{~mm}$ e $\Delta y=65,00$.

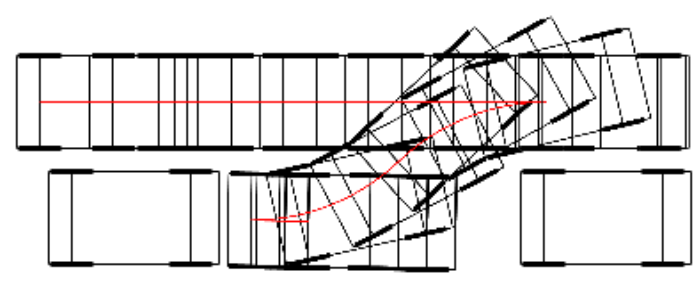

(a)

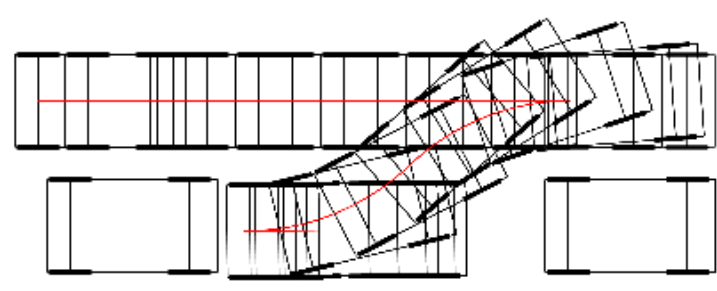

(b)

Figura 6.9: Manobras realizadas com o controlador VII no simulador e analisadas visualmente: (a) $P=830,00 \mathrm{~mm}$ e $\Delta y=43,00 \mathrm{~mm}$; (b) $P 908,00=m m$ e $\Delta y=65,00$. 
Após verificar na simulação que todos os estacionamentos foram realizados com sucesso, ainda era complicado avaliar o quão bem um veículo está estacionado. Para isso foi realizada uma pesquisa na literatura por medidas que pudessem avaliar este problema, mas nada foi encontrado. Tendo esta dificuldade em vista, foi proposto um método de similaridade baseado em regiões, na qual é calculada a área (expressa em número de pixels) que compreende o veículo após a manobra. Assim, são coletadas as posições e orientações dos três veículos (veículo A, veículo $B$ e veículo manobrado) no final de cada simulação e verifica-se o mesmo está dentro de uma área estacionável e perto da posição desejável (Figura 6.10).
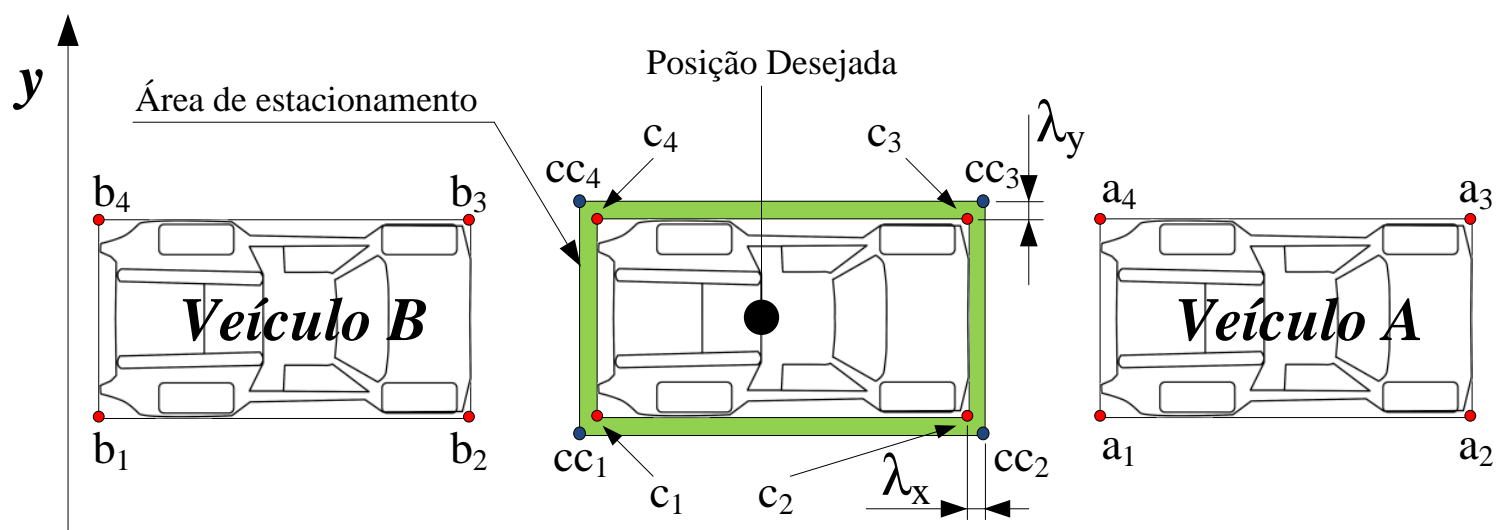

\section{$x$}

Figura 6.10: Representação da área de estacionamento e da área posição final desejada do veículo dentro da área de estacionamento.

A posição desejável que o carro deve estar após manobrá-lo é o centro da vaga. Esta posição pode ser calculada através dos vértices dos veículos A e B. Para definir uma região de estacionamento (não existe na literatura), foi considerada para $\lambda_{x}$ uma distância de $10 \%$ do comprimento do veículo $\left(\lambda_{x}=\frac{L \cdot 0,1}{2}\right)$. Ela poderia ser maior, uma vez que parar um pouco para frente ou para trás do centro não quer dizer que o motorista errou a manobra. Para $\lambda_{y}$ foram encontradas variações nas leis de trânsito dependendo do país. No caso do Brasil o veículo pode estar até $50 \mathrm{~cm}$ distante do meio-fio. Realizando as conversões para o mini-veículo de teste deste trabalho, o valor foi de $25 \%$ da largura do mini-veículo utilizado $\left(\lambda_{y}=\frac{W \cdot 0,25}{2}\right)$. Como os veículos neste trabalho são expressos em objetos retangulares e com dimensões de $m \mathrm{X} n$ pixels, esses pixels $f(x, y)$ do veículo são representados pelo valor 1 (levando em consideração uma imagem binária). A Equação 6.3, define como a área é calculada

$$
\text { Área }=\sum_{x=0}^{m-1} \sum_{y=0}^{n-1} f(x, y)
$$

A medida de similaridade leva em consideração a intersecção dos pontos de um objeto A (posição desejável de estacionamento) com um objeto B (posição obtida de estacionamento), 
conforme a Equação 6.4. Com isto é encontrado o quão próximo o veículo estacionado está do posição desejável:

$$
A \cap B=\{c \mid c \in A \text { e } c \in B\}
$$

Foram definidos dois critérios para verificar o quão bem o veículo está estacionado. No primeiro critério analisa-se todos os vértices do veículo se encontram dentro da área de estacionamento. Se algum vértice não estiver dentro, a posição do veículo é definida como não permitida e a manobra é dita inválida. O segundo critério leva em consideração a medida de similaridade proposta. Após a definição dos critérios, foram realizadas análises em todas as manobras antes definidas como realizadas com sucesso para verificar o quão bem elas foram executadas. A Figura 6.11 exibe um exemplo exagerado do funcionamento da medida proposta.

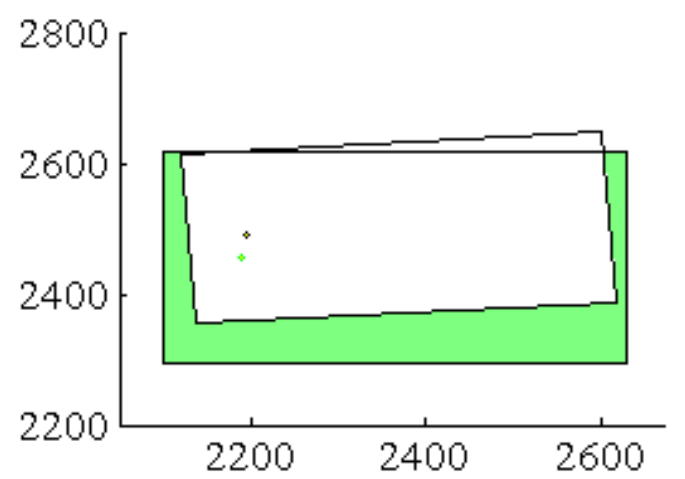

(a)

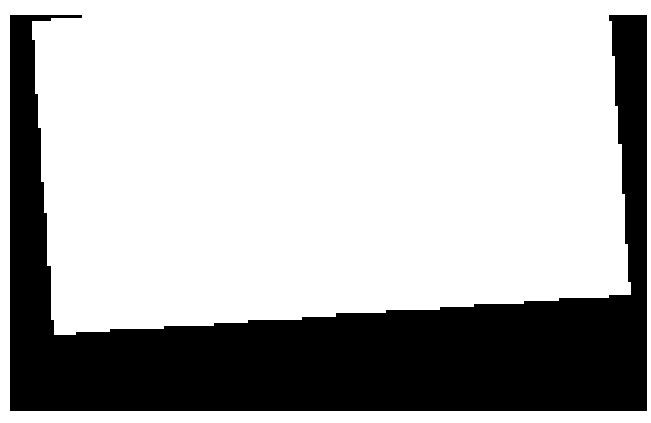

(c)

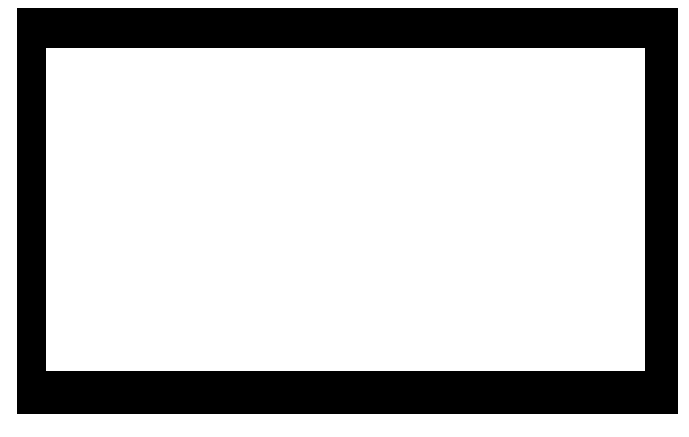

(b)

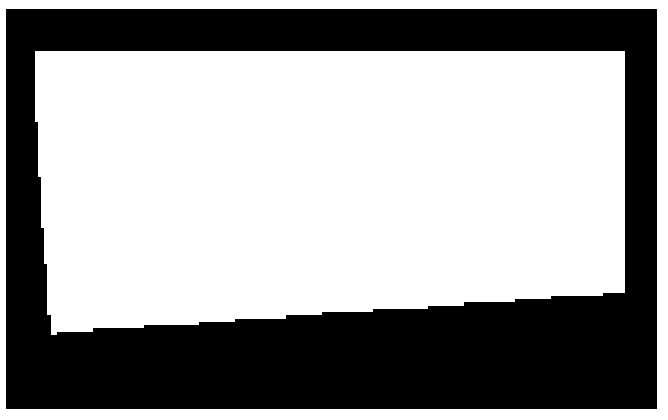

(d)

Figura 6.11: Exemplo da medida de similaridade: (a) mostra como o veículo ficou posicionado na região de estacionamento desejada; (b) imagem binária da área de estacionamento desejada; (c) posição obtida do veículo dentro da área desejada; (d) área final de similaridade deste exemplo com $81,4 \%$.

Na Figura 6.11(a) é exibido a região de estacionamento desejável e como o veículo ficou posicionado após a manobra. A Figura 6.11(b) exibe a posição desejável de parada do veículo em uma imagem binária. A Figura 6.11(c) mostra a posição obtida do veículo também em binário, para que se possa comparar as regiões. Sendo assim, a Figura 6.11(d) apresenta a área 
de similaridade entre a posição desejável e a posição obtida. Vale lembrar que, para esta posição, o estacionamento já seria dito inválido, pois o veículo ficou fora da área de estacionamento.

Com o primeiro critério de avaliação (todos os vértices do veículo devem estar dentro da área de estacionamento) tem-se que o controlador neural III conseguiu somente estacionar bem em 53 dos 55 casos, ou seja, aproximadamente $96 \%$ das manobras realizadas obtiveram sucesso no estacionamento. O controlador VII foi melhor, acertando 54 dos 55 casos, obtendo aproximadamente $98 \%$ de sucesso. Sendo assim, dentre as regiões analisadas para o controlador III conseguiu-se obter, no pior caso, $85,4 \%$ de similaridade e para o melhor caso, 98,6\% de similaridade. O controlador VII conseguiu para o pior caso $87,5 \%$ e para o melhor caso $99,0 \%$. Isso confirma que a segunda estratégia é melhor que a primeira, tanto nos resultados de treinamento da rede, como nas métricas definidas para saber o quão bem o carro parou na vaga de estacionamento.

\subsection{Considerações Finais}

Este capítulo descreveu a abordagem desenvolvida para construção do controlador neural. Esta abordagem levou em consideração as entradas e saídas dos sensores, assim como o estado da manobra em que o veículo se encontrava. Além disso, foi demonstrada através de simulações realizadas no MatLab a região onde o veículo poderia iniciar a manobra. Através desta região e das etapas de estacionamento, foi implementado um Autômato Finito para coletar os dados durante a trajetória de estacionamento. Na sequência estes dados foram apresentados a diversas topologias de duas estratégias diferentes, obtendo resultados de treinamento superiores à $96 \%$ de sucesso. Os piores casos (sensores com ruídos e sem a presença de paredes) foram implementados no simulador e definidas métricas para avaliação. O controlador neural III conseguiu obter $96 \%$ de sucesso, pois duas manobras ficaram um pouco fora da vaga, e o controlador VII teve $98 \%$ de sucesso, sendo que somente uma manobra ficou com uma pequena ponta fora da área de estacionamento. 


\section{CAPÍTULO \\ 7 \\ Conclusões e Perspectivas Futuras}

Esta dissertação apresentou um sistema inteligente para realizar a manobra de estacionamento paralelo com uma única manobra entre dois veículos, utilizando técnicas de aprendizado supervisionado com Redes Neurais Artificiais (RNA). Os resultados das simulações demonstram um sistema que possui a capacidade de realizar a manobra, sem bater nos demais obstáculos ao seu redor até mesmo para novos casos apresentados ao controlador neural.

O desenvolvimento deste trabalho teve início com o levantamento bibliográfico dos principais trabalhos sobre estacionamento autônomo das últimas duas décadas. Foi verificado que poucos são os trabalhos atualmente que utilizam RNA para realizar a manobra, menos ainda os que fazem uso de arquiteturas robóticas reativas. Por isso foi estudada uma técnica de aprendizado de máquina supervisionado que seria utilizado nesta pesquisa (RNA). Logo em seguida foram apresentadas informações dos modelos de ambientes, da cinemática que é utilizada para movimentar o veículo e dos sensores que servem para o veículo perceber o ambiente. Assim, foi desenvolvido um simulador específico para o trabalho que utiliza as informações estudadas. Resultados simulados expressivos foram obtidos com o controlador neural desenvolvido.

Quanto ao desenvolvimento do controlador neural é necessário enfatizar que o processo é quase exclusivamente empírico, demandando experiência ao se definir uma arquitetura de RNA para qualquer tipo de problema. Ressalta-se também a importância de pré-processamento dos dados das entrada do controlador, devido a sua influência direta no aprendizado da RNA. Haja vista a diferença nos resultados dos treinamentos das RNAs de arquiteturas equivalentes apenas substituindo-se os dados de entrada. O interessante de usar RNA é que, depois de bem treinada, ela é capaz de responder satisfatoriamente a casos não apresentados. Foram realizados diversos testes, levando em consideração sensores sem erros e com erros, além de vagas sem e com 
a presença de paredes. Vale ressaltar que todas as RNAs foram implementadas em MatLab, dado o conhecimento prévio da ferramenta e sua facilidade de prototipagem rápida. Logo em seguida o sistema neural (DLL gerada pelo MatLab) era importado no simulador, a fim de avaliar o resultado final em diferentes casos.

Este projeto demonstrou que as simulações realizadas utilizando o controlador desenvolvido foram capazes de alcançar com sucesso os objetivos previstos, tanto no que se refere ao aprendizado da tarefa, quanto ao que se refere ao controle do veículo durante a manobra de estacionamento. Mesmo com resultados simulados deve-se levar em consideração que o controle do robô é reativo, o que não sofreria muitas modificações se implementado e testado no mundo real, pois ele não depende de outras informações além das implementadas neste trabalho. Para validar o quão bom o veículo está estacionado na vaga, foram criados dois critérios de avaliação, que consistiram em verificar se o veículo estava dentro de uma área de estacionamento e na sequência fez uso de uma medidade de similaridade por regiões.

Apesar disto o trabalho possui algumas limitações em relação ao simulador e ao controlador. São elas, até o momento: o veículo protótipo somente procura vaga, e estaciona à direita; o controlador somente serve para vagas paralelas; o ambiente desenvolvido é bidimensional o que reduz o realismo da simulação; somente foram simulados veículos geometricamente quadrados, sendo que a maioria dos veículos tem os cantos arredondados.

Este trabalho contribui para o projeto do Laboratório de Robótica Móvel da EESC-USP em parceria com o INCT-INOF e INCT-SEC, e tem como proposta o desenvolvimento de um carro autônomo. O veículo, dentre todos os problemas de navegação, mapeamento e localização, também deverá realizar a manobra de estacionamento de forma autônoma no futuro. Desta forma, o sistema inteligente de estacionamento paralelo perfeito apresentado pode ser visto também como uma contribuição para o sistema inteligente total do projeto, sendo este apenas o início de outros trabalhos.

\subsection{Trabalhos Futuros}

Como perspectiva para trabalho futuros inclui-se o desenvolvimento de um simulador tridimensional para o Laboratório de Robótica Móvel da EESC-USP. Este simulador já se encontra em desenvolvimento por dois alunos do curso de Ciência da Computação da Escola de Engenharia de Piracicaba (EEP) em seus Trabalho de Conclusão de Curso (TCC). Os alunos da EEP estão neste primeiro momento integrando a linguagem $\mathrm{C}++$, a biblioteca auxiliar Boost, a engine $^{9}$ gráfica Ogre3D e a engine de física Bullet. Outro aluno da EESC também esta participando e ficou encarregado de simular os sensores usando multithreads ${ }^{1}$ no ambiente gráfico.

\footnotetext{
${ }^{9}$ Engine na computação é um conjunto de funcinoalidades que são disponibilizadas para facilitar o desenvolvimento de aplicações na parte gráfica, ou na parte física, ou na parte de inteligência artificial, etc.

${ }^{1}$ Multithread na computação é a característica dos sistemas que permitem repartir a utilização do processador entre várias tarefas aparentemente simultaneamente
} 
Atualmente o veículo real que serviu de modelo para o veículo simulado está sendo equipado com dois sensores laser Hokuyo e um sensor inercial, para validar de forma realista o sistema desenvolvido no mundo real. O grupo já estuda outras técnicas como Algoritmos Genéticos, Fuzzy e Híbridas para integrar ao sistema desenvolvido e fazer novos testes. Estudos relacionados à abordagem por planejamento de trajetórias serão feitos no futuro como forma integrar todos os trabalhos realizados pelos outros mestrandos e doutorandos, a fim de tornar o sistema de estacionamento do veículo ainda mais robusto. Por fim, outro trabalho interessante e que também se encontra em andamento por um aluno de Iniciação Científica é a criação de uma função para localizar a vaga, esteja ela à direita, à esquerda ou em outro lugar do ambiente (mesmo em curvas). 



\section{Referências Bibliográficas}

Andrade, K. O.; Jardim, B.; JoAquim, R. C.; Ito, G. G.; Siqueira, A. A. G.; Caurin, G. A. P.; Amaral, L. M. S. A game-based framework for robotic rehabilitation. In: DINAME, ed. 14th International Symposium on Dynamic Problems of Mechanics -, Anais do DINAME 2011, 2011.

Bajracharya, M.; TAng, B.; Howard, A.; Turmon, M.; Matthies, L. Learning longrange terrain classification for autonomous navigation. In: IEEE International Conference on Robotics and Automation, ICRA 2008, 2008, p. 4018-4024.

BAKER, C.; Dolan, J. Street smarts for boss. IEEE Robotics \& Automation Magazine, v. 16, n. 1, p. $78-87,2009$.

Bonnevi, T.; Siryani, R.; Guinamard, A. IG-500, world smallest inertial navigation system. In: 3rd US-European Competition and Workshop on Micro Air Vehicle Systems (MAV07) \& European Micro Air Vehicle Conference and Flight Competition (EMAV2007), Toulouse - France, 2007.

Borenstein, J.; Everett, H. R.; Feng, L.; Wehe, D. Mobile robot positioning: Sensors and techniques. Journal of Robotic Systems, v. 14, n. 4, p. 231-249, 1997.

Borenstein, J.; Feng, L.; Borenstein, C. J. Measurement and correction of systematic odometry errors in mobile robots. IEEE Transactions on Robotics and Automation, v. 12, p. 869-880, 1996.

BoscH Parking made easy - parking assistance systems from bosh. http://twixar.com/nspkIn9ygpc, acesso em: 21 mar. 2011, 2011.

Braga, A. P.; Ludemir, T. B.; Carvalho, A. C. P. L. F. Redes neurais artificiais: Teoria e aplicações. 2 ed. LTC Editora, 283 p., 2007. 
BuschKa, P.; SAfFiotti, R. Some notes on the use of hybrid maps for mobile robots. In: Proceedings of the 8th International. Conference on Inlligent Autonomous Systems (IAS), 2004, p. 547-556.

Cabrera-Cosetl, R.; Mora-Alvarez, M. Z.; Alejos-Palomares, R. Self-parking system based in a fuzzy logic approach. In: Proceedings of the 2009 International Conference on Electrical, Communications, and Computers, CONIELECOMP '09, Washington, DC, USA: IEEE Computer Society, 2009, p. 119-124.

ChaO, C.-H.; Ho, C.-H.; Lin, S.-H.; LI, T. H. S. Omni-directional vision-based parallelparking control design for car-like mobile robot. In: Proc.eedings of IEEE International Conference Mechatronics ICM '05, 2005, p. 562-567.

Chatila, R.; Laumond, J. Position referencing and consistent world modeling for mobile robots. In: Proceedings of IEEE International Conference Robotics and Automation, 1985, p. 138-145.

Chu, A.; Kazerooni, H.; Zoss, A. On the biomimetic design of the Berkeley Lower Extremity Exoskeleton (BLEEX). In: Proceedings of the 2005 IEEE International Conference on Robotics and Automation, Barcelona, 2005, p. 4345 - 4352.

DAn Foresee, F.; HAgAn, M. T. Gauss-newton approximation to bayesian learning. In: International Conference on Neural Networks, 1997, p. 1930-1935.

Demirli, K.; KhoshneJAD, M. Autonomous parallel parking of a car-like mobile robot by a neuro-fuzzy sensor-based controller. Fuzzy Sets and Systems, v. 160, n. 19, p. 2876-2891, 2009.

Driss, A.; Rodrigues, V.; Cohens, P. Parking a vision-guided automobile vehicle. In: Proceedings of the Third IEEE Conference on Control Applications, 1994, p. 59-64.

DudeK, G.; JEnKIn, M. Computational principles of mobile robotics. New York, NY, USA: Cambridge University Press, 2000.

DudeK, G.; Jenkin, M. Inertial sensors, gps, and odometry. In: Siciliano, B.; Khatib, O., eds. Springer Handbook of Robotics, Springer Berlin Heidelberg, p. 477-490, 2008.

EleCtronics, C. Rotary encoders: Operating principles. http://copalelectronics.info/en/00097/00e87.pdf, acesso em: 30 junho. de 2011., 2009.

FERreirA, A. B. H. Dicionário novo aurélio século xxi língua portuguesa grande. 3 ed. Positivo, 2004.

Forhan, N. A. E. Giroscópios MEMS. Relatório técnico-científico, Instituto Nacional de Pesquisas Espaciais - INPE, São José dos Campos - SP - Brasil, iNPE-16671-RPQ/848, 2010. 
GILlESPIE, T. D. Fundamentals of vehicle dynamics. SAE International, 519 p., 1992.

Gorinevsky, D.; Kapitanovsky, A.; Goldenberg, A. Design of radial basis functionbased controller for autonomous parking of wheeled vehicles. In: American Control Conference, 1994, 1994, p. 806-810.

Gorinevsky, D.; Kapitanovsky, A.; Goldenberg, A. Neural network architecture for trajectory generation and control of automated car parking. IEEE Transactions on Control Systems Technology, v. 4, n. 1, p. 50-56, 1996.

GRABIANOWSKI, E. How self-parking car works. http://auto.howstuffworks.com/cardriving-safety/safety-regulatory-devices/self-parking-car.htm, acesso em: 21 mar. de 2011., 2007.

Gupta, A.; Divekar, R.; Agrawal, M. Autonomous parallel parking system for ackerman steering four wheelers. In: Proceedings of IEEE International Conference Computational Intelligence and Computing Research (ICCIC), 2010, p. 1-6.

Hagan, M. T.; MenhaJ, M. B. Training feedforward networks with the marquardt algorithm. IEEE Transactions on Neural Networks, v. 5, n. 6, p. 989-993, 1994.

HaYkin, S. Redes neurais: Princípios e prática. 2 ed. Bookman, 2001.

Heinen, F.; Fortes, L.; Osório, F. S. Controle inteligente de veículos autônomos: Automatização do processo de estacionamento de carros. In: Anais do SEMINCO 2001 - FURB, Blumenau, 2001, p. 35-46.

HeInEN, F. J. Sistema de controle híbrido para robôs móveis autônomos. Dissertação de mestrado, Unisinos, São Leopoldo, RS, 2002.

Heinen, M.; Osório, F.; Heinen, F.; Kelber, C. Estacionamento de um veículo de forma autônoma utilizando redes neurais artificiais. In: XXVI Congresso da Sociedade Brasileira de Computação, UFMS - Campo Grande, 2006a.

Heinen, M. R.; OSório, F. S.; Heinen, F.; Kelber, C. Uso de realidade virtual no desenvolvimento de um sistema de controle do estacionamento de veículos autônomos. In: Anais do VIII Simpósio Brasileiro de Realidade Virtual (SVR), Belém, Pará, 2006b, p. 245256.

Heinen, M. R.; Osório, F. S.; Heinen, F. J.; Kelber, C. SEVA3D: autonomous vehicles parking simulator in a three-dimensional environment. INFOCOMP Journal of Computer Science, v. 6, n. 2, p. 63-70, 2007. 
Hernandes, A. C.; MendonçA, A. S. B.; Andrade, K. O.; Becker, M. Redes neurais artificiais aplicadas à baliza paralela de veículo de passeio em ambiente simulado. In: Anais do CONEM 2010, Campina Grande - PB: CONEM 2010 - Congresso Nacional de Engenharia Mecânica, 2010, p. 1-10.

Herrmann, N. Ein mathematisches modell zum parallelparken. http://www.ifam.unihannover.de/ herrmann/PARKEN.PDF, acesso em: 3 dez. 2010, 2003.

HONDA Humanoid robot asimo. http://world.honda.com/ASIMO/, acesso em 28/03/2011, 2011.

HOYLE, R. Requirements for a perfect s-shaped parallel parking manoeuvre in a simple mathematical model. http://personal.maths.surrey.ac.uk/st/R.Hoyle/papers/parkingformula.pdf, acesso em: 3 dez. 2010, 2003.

HSU, T.-H.; LIU, J.-F.; YU, P.-N.; LEE, W.-S.; HSU, J.-S. Development of an automatic parking system for vehicle. In: Proceedings of IEEE Vehicle Power and Propulsion Conference. VPPC'08, 2008, p. 1-6.

HuA, W.; Cuiqin, M.; LiJuAn, Z. A brief review of machine learning and its application. In: International Conference on Information Engineering and Computer Science, 2009. ICIECS 2009, 2009, p. 1 -4.

HUANG, S.-J.; LIN, G.-Y. Parallel auto-parking of a model vehicle using a self-organizing fuzzy controller. Proceedings of The Institution of Mechanical Engineers Part D-journal of Automobile Engineering, v. 224, p. 997-1012, 2010.

HUI, N. B. Coordinated motion planning of multiple mobile robots using potential field method. In: International Conference on Industrial Electronics, Control \& Robotics (IECR), 2010, p. 6-11.

HUSQVARnA Automower (Robotic lawn mower). http://www.husqvarna.com, acesso em 28/03/2011, 2011.

IBGE Censo 2010: população do brasil é de 190.732 .694 pessoas. http://veja.abril.com.br/noticia/brasil/populacao-brasileira-e-de-190-732-694-pessoasrevela-censo, acesso em: 21 mar. 2011, 2011.

ILL, Z. J.; JI, X. D.; WAN, K. J.; BAE, K. Y. A study of autonomous parking for a 4-wheel driven mobile robot. In: Proceedings of Chinese Control Conference. CCC 2007, 2007, p. 179-184.

IRoвот Cleaning robots (Roomba, Scooba, Dirt Dog, Verro). http://www.irobot.com/, acesso em 28/03/2011, 2011. 
JiAnG, K.; Seneviratne, L. D. A sensor guided autonomous parking system for nonholonomic mobile robots. In: Proceedings. 1999 IEEE International Conference on Robotics and Automation, 1999, 1999, p. 311-316.

Jung, H. G.; Cho, Y. H.; Yoon, P. J.; KIM, J. Scanning laser radar-based target position designation for parking aid system. IEEE Transactions on Intelligent Transportation Systems, v. 9, n. 3, p. 406-424, 2008a.

JUnG, H. G.; KIM, D. S.; YoOn, P. J.; KIM, J. Light stripe projection based parking space detection for intelligent parking assist system. In: Proceedings of IEEE Intelligent Vehicles Symposium, 2007, p. 962-968.

Jung, H. G.; KIM, D. S.; Yoon, P. J.; KIM, J. Two-touch type parking slot marking recognition for target parking position designation. In: Proceedings of IEEE Intelligent Vehicles Symposium, 2008b, p. 1161-1166.

KAEMPChen, N.; Franke, U.; OtT, R. Stereo vision based pose estimation of parking lots using 3d vehicle models. In: Proceedings of IEEE Intelligent Vehicle Symposium, 2002, p. $459-464$.

Khoukhi, A.; Demirli, K. Near-optimal energy fuzzy parking of mobile robots. In: Proceedings of 5th IEEE GCC Conference Exhibition, 2009, p. 1-8.

Kochem, M.; NeddenrieP, R.; Isermann, R. Accurate local vehicle dead-reckoning for a parking assistance system. In: Proceedings of the American Control Conference, 2002, p. 6.

KondaK, K.; Hommel, G. Computation of time optimal movements for autonomous parking of non-holonomic mobile platforms. In: Proceedings of IEEE ICRA International Conference Robotics and Automation, 2001, p. 2698-2703.

Krebs, H.; Dipietro, L.; Levy-Tzedek, S.; Fasoli, S.; Rykman-Berland, A.; Zipse, J.; Fawcett, J.; Stein, J.; Poizner, H.; Lo, A.; Volpe, B.; Hogan, N. A paradigm shift for rehabilitation robotics. IEEE Engineering in Medicine and Biology Magazine, v. 27, n. 4, p. 61-70, 2008.

Laugier, C.; Fraichard, T.; Paromtchik, I. E.; Garnier, P. Sensor-based control architecture for a car-like vehicle. In: Proceedings of IEEE/RSJ International Conference on Intelligent Robots and Systems, 1998, p. 216-222.

LAw, A. M.; Kelton, W. D. Simulation modeling and analysis. 3 ed. New York, NY: McGraw-Hill, 2000. 
LEE, C.-K.; Lin, C.-L.; SHIU, B.-M. Autonomous vehicle parking using artificial intelligent approach. In: 4th International Conference on Autonomous Robots and Agents, 2009. ICARA 2009., 2009, p. 496-501.

LeE, K.-H.; EhSAnI, R. Comparison of two 2d laser scanners for sensing object distances, shapes, and surface patterns. Computers and Electronics in Agriculture, v. 60, n. 2, p. 250 262, 2008.

LEE, T.-C.; TSAI, C.-Y.; SonG, K.-T. A motion planning approach to fast parking control of mobile robots. In: Proceedings. ICRA 'O3. IEEE International Conference on Robotics and Automation, 2003, p. 905-910.

LEE, T.-C.; TSAI, C.-Y.; Song, K.-T. Fast parking control of mobile robots: a motion planning approach with experimental validation. IEEE Transactions on Control Systems Technology, v. 12, n. 5, p. 661-676, 2004.

LI, T.-H.; Chang, C.-C.; Ye, Y.-J.; TASI, G.-R. Autonomous parking control design for car-like mobile robot by using ultrasonic and infrared sensors. In: BREDENFELD, A.; JACOFF, A.; NodA, I.; TAKAhASHI, Y., eds. RoboCup 2005: Robot Soccer World Cup IX, v. 4020 de Lecture Notes in Computer Science, Springer Berlin / Heidelberg, p. 472-479, 2006.

LI, T.-H.; ChAng, S.-J. Autonomous fuzzy parking control of a car-like mobile robot. IEEE Transactions on Systems, Man and Cybernetics, Part A: Systems and Humans, v. 33, n. 4, p. 451-465, 2003.

LI, T.-H.; YeH, Y.-C.; WU, J.-D.; HsiAO, M.-Y.; CHEN, C.-Y. Multifunctional intelligent autonomous parking controllers for carlike mobile robots. IEEE Transactions on Industrial Electronics, v. 57, n. 5, p. 1687-1700, 2010.

LI, T.-H. S.; Chang, S.-J.; Chen, Y.-X. Implementation of autonomous fuzzy garageparking control by an fpga-based car-like mobile robot using infrared sensors. In: Proceedings. ICRA 2003. IEEE International Conference on Robotics and Automation, 2003a, p. 3776-3781.

LI, T.-H. S.; ChAnG, S.-J.; CHEN, Y.-X. Implementation of human-like driving skills by autonomous fuzzy behavior control on an FPGA-based car-like mobile robot. IEEE Transactions on Industrial Electronics, v. 50, n. 5, p. 867-880, 2003 b.

Linden, R. Algoritmos genéticos. 2 ed. Brasport, 428 p., 2008.

Lo, Y.; RAD, A.; Wong, C.; Ho, M. Automatic parallel parking. In: Proceedings of IEEE Intelligent Transportation Systems, 2003, p. 1190-1193. 
LUdWIG JR., O.; CostA, E. M. M. Redes neurais - fundamentos e aplicações com programas em C. Rio de Janeiro: Ciência Moderna, 136 p., 2007.

Marshall, D. Programming microsoft visual c\# 2008: The language. 2nd ed. Microsoft Press, 2008.

Medeiros, A. Introdução à robótica. In: Anais do XVII Encontro Nacional de Automática, Natal - RN: 50a reunião anual da Sociedade Brasileira para o Progresso da Ciência - SBPC, 1998, p. 56-65.

Morgan, S. Programming microsoft robotics studio. Redmond, WA - USA: Microsoft Press, 2008.

Murray, R. M.; SAStry, S. S. Nonholonomic motion planning: steering using sinusoids. IEEE Transactions on Automatic Control, v. 38, n. 5, p. 700-716, 1993.

NAO Aldebaran robotics. http://www.aldebaran-robotics.com/, acesso em: 5 mai. de 2011, 2011.

Oentaryo, R. J.; PASquier, M. Self-trained automated parking system. In: 8th International Conference on Control, Automation, Robotics and Vision, Kunming - China, 2004, p. 1005-1010.

Oetiker, M. B.; Baker, G. P.; Guzzella, L. A navigation-field-based semi-autonomous nonholonomic vehicle-parking assistant. IEEE Transactions on Vehicular Technology, v. 58, n. 3, p. 1106-1118, 2009.

Osório, F. S.; HeInen, F.; Fortes, L. Controle da tarefa de estacionamento de um veículo autônomo através do aprendizado de um autômato finito usando uma rede neural j-cc. In: VII Simpósio Brasileiro de Redes Neurais, Porto de Galinhas - Recife: Anais do VII SBRN, 2002, p. 1-6.

PARK, W.-J.; Kim, B.-S.; SEO, D.-E.; Kim, D.-S.; LEE, K.-H. Parking space detection using ultrasonic sensor in parking assistance system. In: Proceedings of IEEE Intelligent Vehicles Symposium, 2008, p. 1039-1044.

PARomtchiK, I. E.; LAUGIER, C. Autonomous parallel parking of a nonholonomic vehicle. In: Proceedings of the 1996 IEEE Intelligent Vehicles Symposium, 1996a, p. 13-18.

PAROMTChiK, I. E.; LAUgier, C. Motion generation and control for parking an autonomous vehicle. In: Proceedings of IEEE International Conference ont Robotics and Automation, 1996b, p. 3117-3122.

Pinheiro, B. C. Sistema de controle tempo real embarcado para automação de manobra de estacionamento. In: Proceedings of the American Control Conference, Florianópolis, 2009. 
PLAYER The player project. http://playerstage.sourceforge.net/, acesso em: 21 mar. de 2011., 2011.

REZEnde, S. O. Sistemas inteligentes: Fundamentos e aplicações. Barueri, SP, Brasil: Manole, 2005.

Riedmiller, M.; BRAUn, H. A direct adaptive method for faster backpropagation learning: the rprop algorithm. In: Proceedings of IEEE International Conference on Neural Networks, 1993, p. 586-591.

Rossi, A.; Rosati, G. Rehabilitation robotics in padua, italy. In: Proc. IEEE 10th Int. Conf. Rehabilitation Robotics ICORR 2007, 2007, p. 323-327.

Rотн, W. J. Einparken - ein ideales thema für experimentelle geometrie und projektarbeit. http://www.mathematik.tu-dortmund.de/ieem/cms/media/BzMU/BzMU2007/Roth.pdf, acesso em: 5 dez. de 2010, 2009.

Russel, S.; Norvig, P. Inteligencia artificial. São Paulo: Editora Campus, 1040 p., 2004.

Rusu, R. B.; Maldonado, A.; Beetz, M.; Gerkey, B. Extending Player/Stage/Gazebo towards Cognitive Robots Acting in Ubiquitous Sensor-equipped Environments. In: Proceedings of the IEEE International Conference on Robotics and Automation (ICRA) Workshop for Network Robot Systems, Rome, Italy, 2007.

SAHIN, H.; GuVEnC, L. Household robotics: autonomous devices for vacuuming and lawn mowing [applications of control]. IEEE Control Systems, v. 27, n. 2, p. 20-96, 2007.

SAINI, L. M.; Soni, M. K. Artificial neural network based peak load forecasting using levenberg-marquardt and quasi-newton methods. IEE Proceedings-Generation, Transmission and Distribution, v. 149, n. 5, p. 578-584, 2002.

Sampaio, R. C. B.; Fernandes, V. V. M.; Becker HelVIS: a Mini Plataform in the Research of HEVs. In: Vehicle Power and Propulsion Conference (VPPC), Chicago, USA, 2011, p. 1-6.

SASIADEK, J. Z.; KHE, J. Sensor fusion based on fuzzy kalman filter. In: Proceedings of the Second International Workshop on Robot Motion and Control, 2001, p. 275-283.

SBG SySTEMS Ig-500n Leaflet. http://www.sbg-systems.com/docs/IG-500N-Leaflet.pdf, acesso em: 30 jun. 2011, 2011.

ShaOHUA, M.; ChaO, W. Assistant-parking system based on vision perception system and fuzzy logic controller. WRI Global Congress on Intelligent Systems, v. 1, p. 381-384, 2010.

Siciliano, B.; Kнатів, O. Springer handbook of robotics. Springer, 2008. 
Siegwart, R.; Nourbakhsh, I. R.; SCARAmuZZA, D. Introduction to Autonomous Mobile Robots. 2nd ed. The MIT Press, 453 p., 2011.

Silva, I. N.; SPATti, D. H.; FlauZINO, R. A. Redes neurais artificiais para engenharia e ciências aplicadas: curso prático. 1 ed. São Paulo: ArtLiber, 399 p., 2010.

SONY Aibo entertainment robots. http://support.sony-europe.com/aibo/, acesso em 28/03/2011, 2011.

Thrun, S. Robotic mapping: a survey. In: Exploring Artificial Intelligence in the New Millenium, San Francisco, CA, USA: Morgan Kaufmann Publishers Inc., p. 1-35, 2003.

Thrun, S.; Montemerlo, M.; Dahlkamp, H.; Stavens, D.; Aron, A.; Diebel, J.; Fong, P.; Gale, J.; Halpenny, M.; Hoffmann, G.; LaU, K.; OAKley, C.; Palatucci, M.; Pratt, V.; Stang, P.; Strohband, S.; Dupont, C.; Jendrossek, L.-E.; Koelen, C.; Markey, C.; Rummel, C.; Niekerk, J.; Jensen, E.; Alessandrini, P.; Bradski, G.; Davies, B.; Ettinger, S.; Kaehler, A.; Nefian, A.; Mahoney, P. Stanley: The robot that won the darpa grand challenge. Journal of Field Robotics, v. 23, n. 9, p. 661-692, 2006.

VALEO Press releases - signature of a cooperation agreement between valeo and ibeo. http://acessa.me/f5xb, acesso em: 30 jun. 2011, 2010.

Vlacic, L.; Parent, M.; Harashima, F. Intelligent vehicle technologies: Theory and applications. Society of Automotive Engineers. Oxford, United Kingdom: ButterworthHeinemann, 498 p., 2001.

Wada, M.; Yoon, K. S.; Hashimoto, H. Development of advanced parking assistance system. IEEE Transactions on Industrial Electronics, v. 50, n. 1, p. 4-17, 2003.

ZhAO, Y.; JR., E. G. C. Robust automatic parallel parking in tight spaces via fuzzy logic. Robotics and Autonomous Systems, v. 51, n. 2-3, p. 111-127, 2005.

Zhu, C.; RAJAMANI, R. Global positioning system-based vehicle control for automated parking. Proceedings of the I MECH E Part D Journal of Automobile Engineering, v. 220, n. 1, p. 37-52, 2006. 

APÊNDICE

\section{$A$}

\section{Mapa conceitual do projeto SENA}

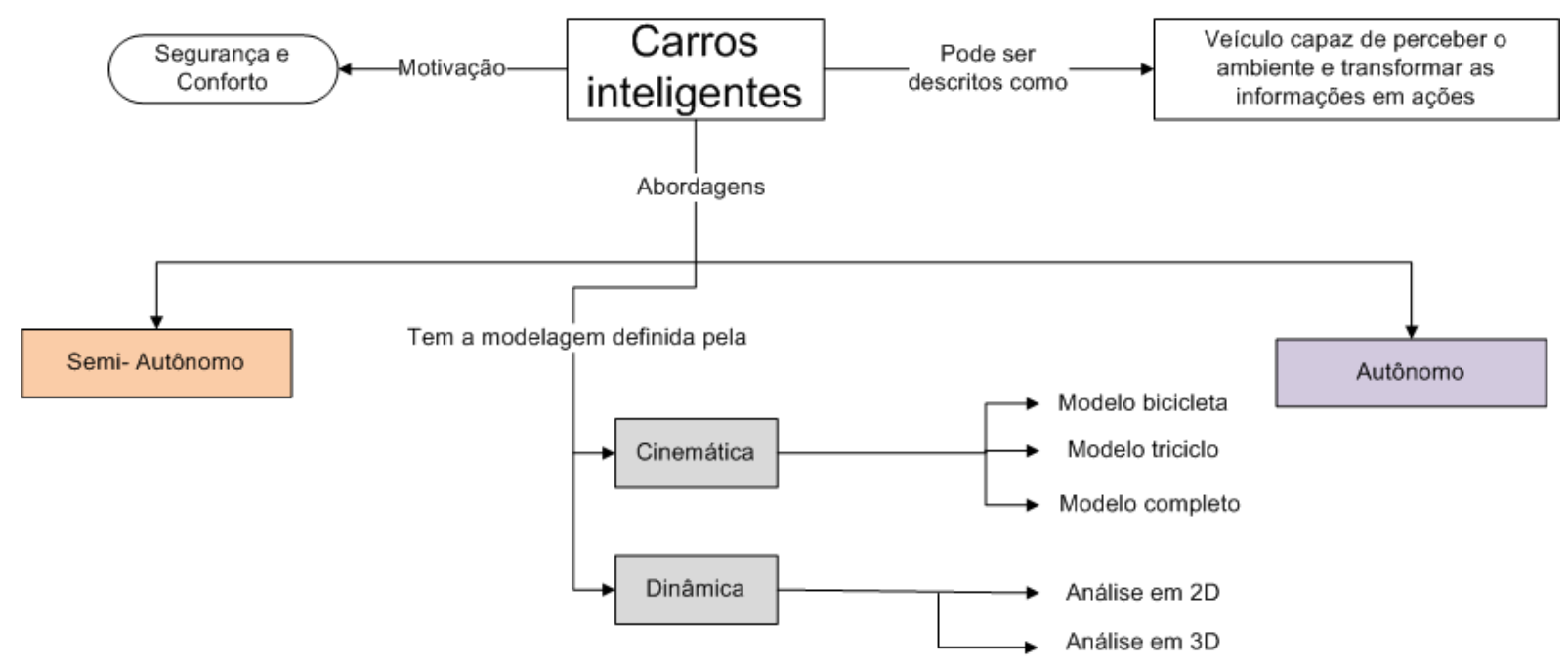

Figura A.1: Mapa global do projeto SENA 


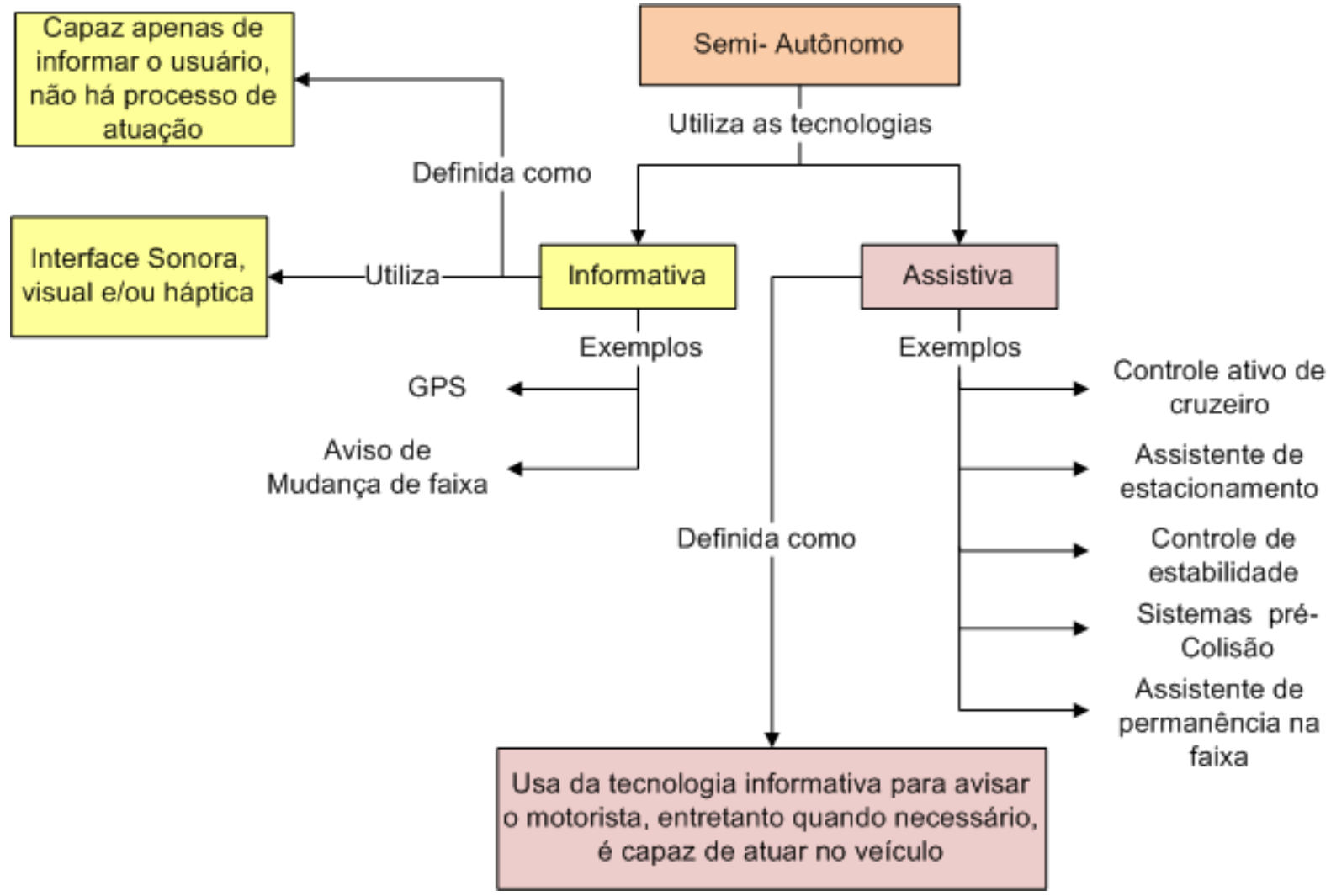

Figura A.2: Mapa do problema de veículos semi-autônomos 


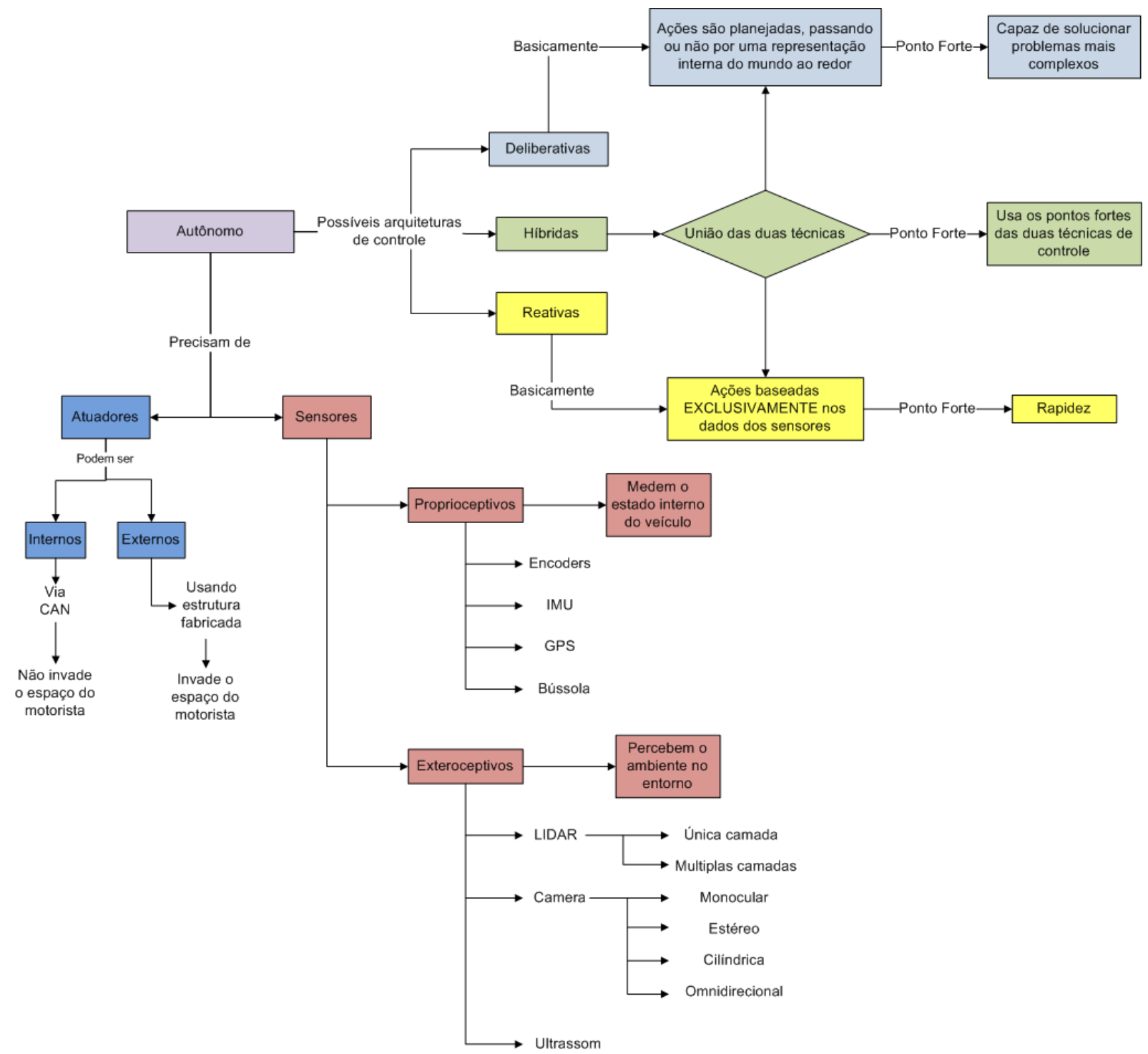

Figura A.3: Mapa do problema de veículos autônomos 


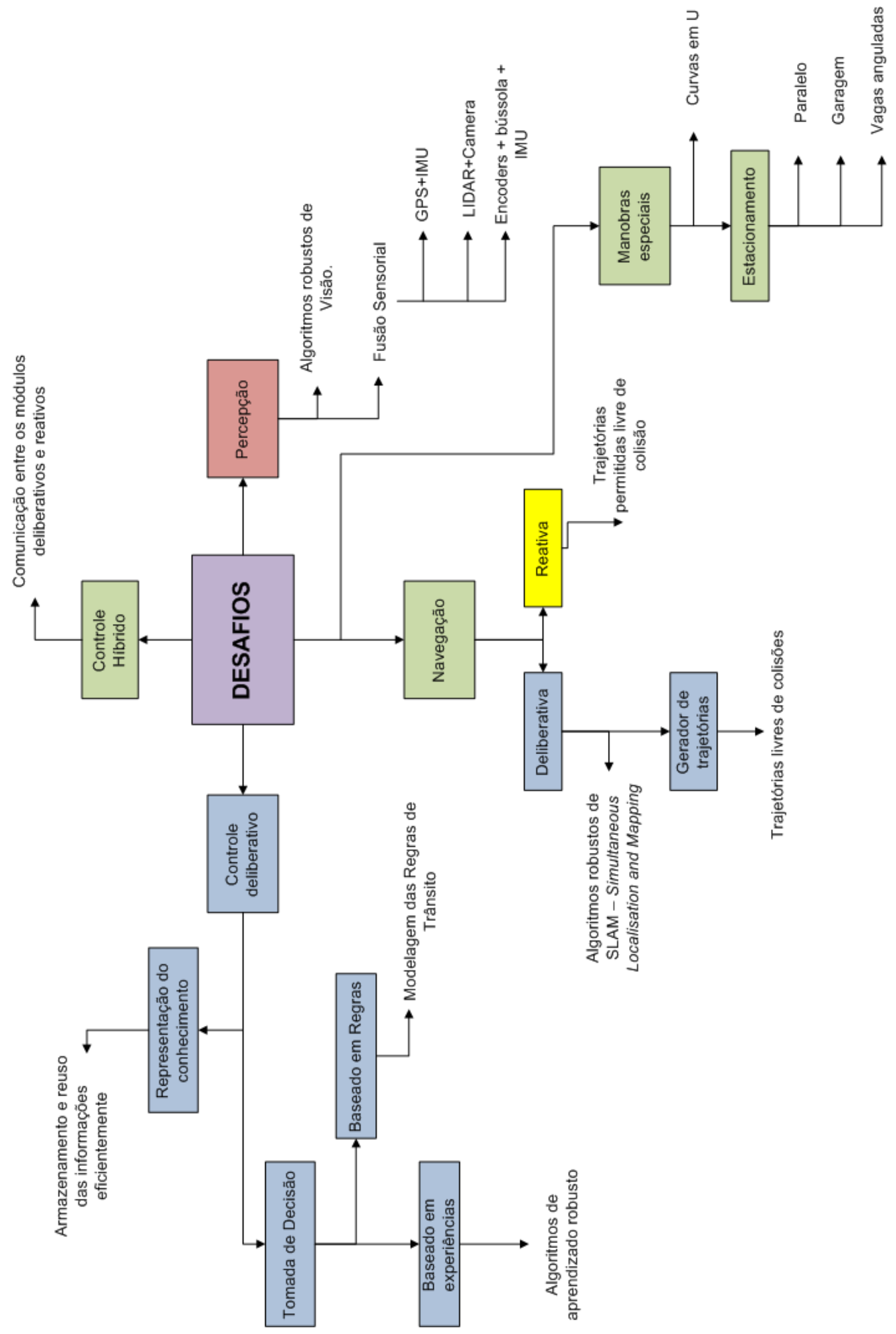

Figura A.4: Mapa dos desafios do projeto SENA 
APÊNDICE

\section{$B$}

\section{Pseudo-Algoritmo do Autômato Finito}
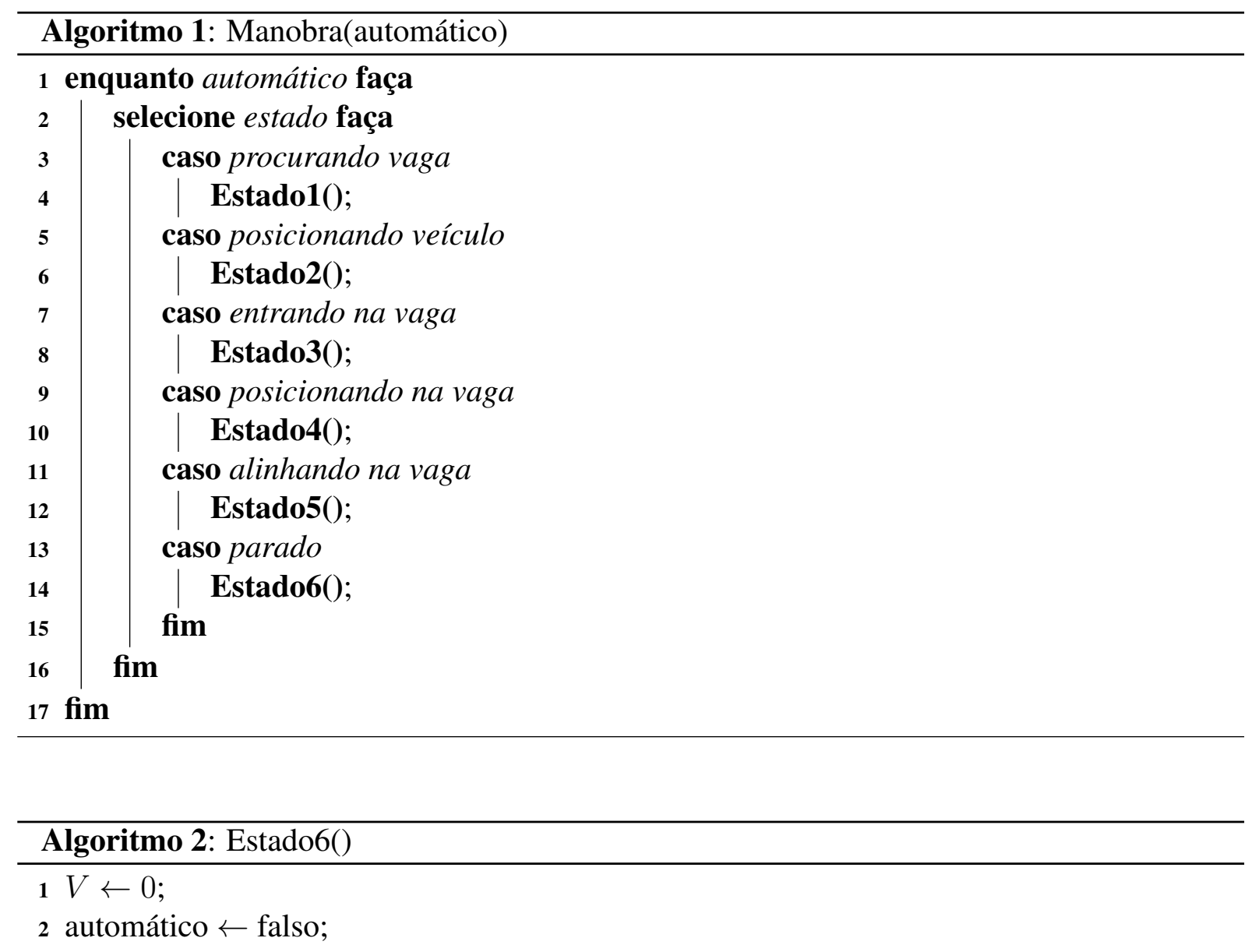

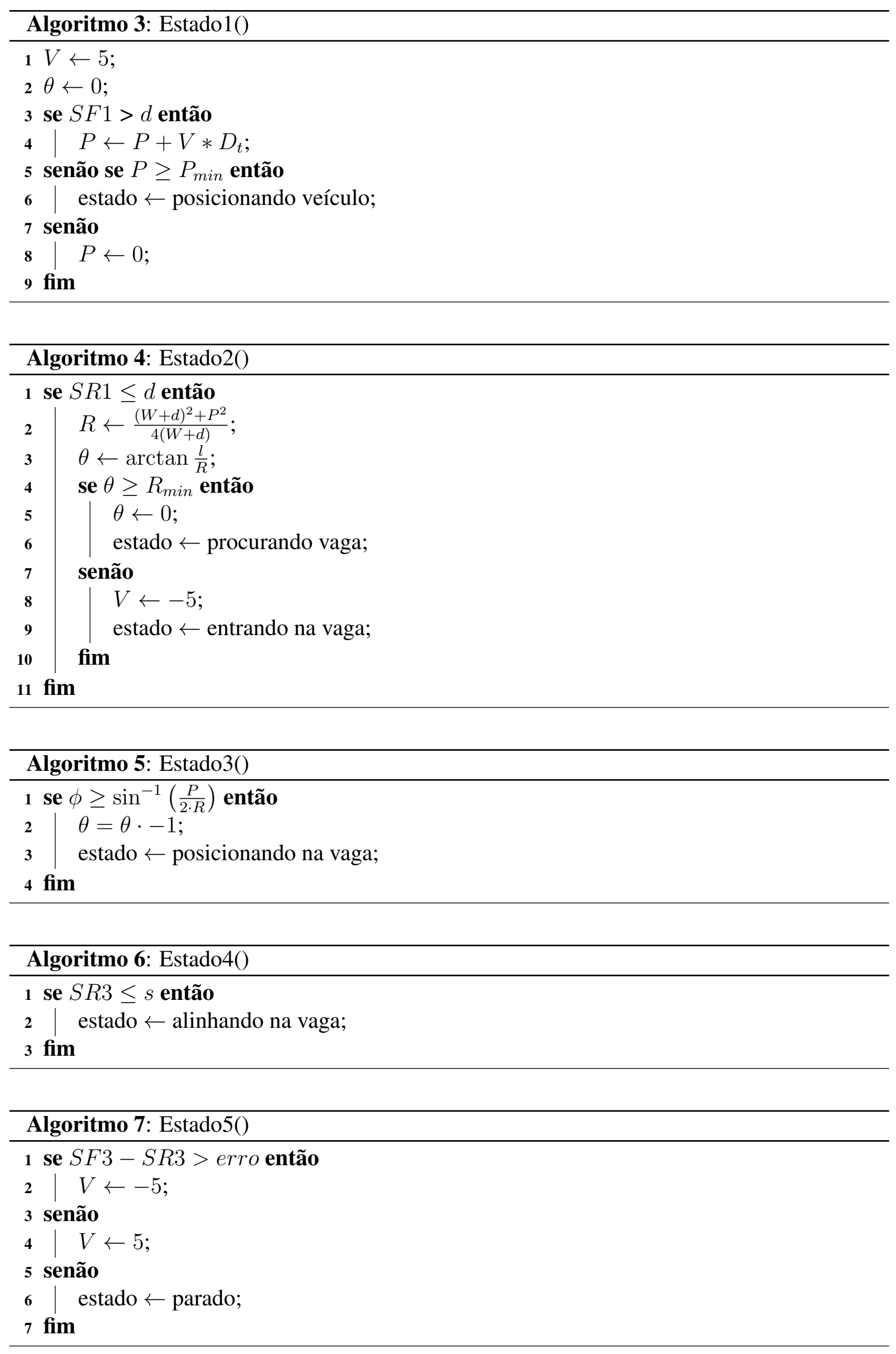
APÊNDICE

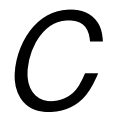

\section{Resultados das Topologias das Redes}

Neurais

Tabela C.1: Resultados do Treinamento e validação das topologias candidatas para o primeiro sistema neural (dados sem ruídos e sem parede), usando o algoritmo Resilient Propagation.

\begin{tabular}{|c|c|c|c|c|c|c|c|c|c|c|c|c|c|}
\hline \multirow[t]{2}{*}{ Ref. } & \multirow{2}{*}{$\begin{array}{l}\text { Neurônios } \\
\text { Escondidos }\end{array}$} & \multicolumn{5}{|c|}{$\begin{array}{c}\text { Treinamento } \\
\text { MAPE (\% acertos) }\end{array}$} & \multicolumn{5}{|c|}{$\begin{array}{c}\text { Validação } \\
\text { MAPE (\% acertos) }\end{array}$} & \multicolumn{2}{|c|}{$\begin{array}{c}\text { Média Final } \\
\text { MAPE (\% acertos) }\end{array}$} \\
\hline & & $\mathrm{C} 1$ & $\mathrm{C} 2$ & $\mathrm{C} 3$ & $\mathrm{C} 4$ & C5 & $\mathrm{C} 1$ & $\mathrm{C} 2$ & C3 & $\mathrm{C} 4$ & $\mathrm{C} 5$ & Trein. & Val. \\
\hline MLP-1 & 5 & 97,3 & 97,8 & 97,6 & 97,8 & 98,1 & 97,2 & 97,6 & 97,5 & 98,0 & 98,1 & 97,7 & 97,7 \\
\hline MLP-2 & $5-5$ & 97,6 & 98,0 & 97,7 & 98,0 & 98,1 & 97,5 & 97,9 & 97,7 & 98,1 & 98,1 & 97,9 & 97,9 \\
\hline MLP-3 & $5-10$ & 98,1 & 98,0 & 98,0 & 97,9 & 98,0 & 98,0 & 97,9 & 98,0 & 98,0 & 97,9 & 98,0 & 98,0 \\
\hline MLP-4 & $5-15$ & 97,8 & 98,0 & 97,9 & 97,6 & 98,2 & 97,9 & 97,9 & 97,9 & 97,7 & 98,1 & 97,9 & 97,9 \\
\hline MLP-5 & $5-20$ & 98,1 & 97,5 & 97,5 & 97,9 & 98,0 & 98,1 & 97,4 & 97,5 & 98,0 & 98,0 & 97,8 & 97,8 \\
\hline MLP-6 & 10 & 98,6 & 98,2 & 98,2 & 98,2 & 98,2 & 98,5 & 98,1 & 98,2 & 98,3 & 98,2 & 98,3 & 98,2 \\
\hline MLP-7 & $10-5$ & 97,9 & 98,3 & 98,1 & 98,1 & 98,5 & 97,8 & 98,2 & 98,2 & 98,1 & 98,5 & 98,2 & 98,1 \\
\hline MLP-8 & $10-10$ & 97,5 & 98,1 & 98,4 & 98,3 & 98,1 & 97,5 & 98,0 & 98,4 & 98,4 & 98,1 & 98,1 & 98,1 \\
\hline MLP-9 & $10-15$ & 98,3 & 98,0 & 98,1 & 98,4 & 98,3 & 98,2 & 97,9 & 98,1 & 98,5 & 98,3 & 98,2 & 98,2 \\
\hline MLP-10 & $10-20$ & 97,9 & 98,0 & 97,8 & 98,0 & 98,0 & 97,8 & 98,0 & 97,8 & 98,1 & 98,0 & 97,9 & 98,0 \\
\hline MLP-11 & 15 & 97,8 & 97,9 & 98,3 & 98,5 & 98,4 & 97,7 & 97,9 & 98,4 & 98,6 & 98,4 & 98,2 & 98,2 \\
\hline MLP-12 & $15-5$ & 97,9 & 98,2 & 98,0 & 98,4 & 98,3 & 97,8 & 98,1 & 98,0 & 98,6 & 98,3 & 98,2 & 98,2 \\
\hline MLP-13 & $15-10$ & 98,3 & 98,3 & 97,6 & 98,7 & 98,2 & 98,2 & 98,3 & 97,6 & 98,8 & 98,2 & 98,2 & 98,2 \\
\hline MLP-14 & $15-15$ & 98,3 & 98,0 & 98,4 & 98,3 & 97,8 & 98,2 & 97,9 & 98,5 & 98,3 & 97,8 & 98,2 & 98,1 \\
\hline MLP-15 & $15-20$ & 98,5 & 98,1 & 98,4 & 98,7 & 98,0 & 98,4 & 98,0 & 98,4 & 98,8 & 98,0 & 98,3 & 98,3 \\
\hline MLP-16 & 20 & 97,8 & 98,2 & 98,0 & 98,6 & 98,4 & 97,7 & 98,1 & 97,9 & 98,7 & 98,4 & 98,2 & 98,2 \\
\hline MLP-17 & $20-5$ & 98,5 & 98,2 & 97,9 & 98,5 & 98,7 & 98,4 & 98,1 & 97,9 & 98,6 & 98,7 & 98,3 & 98,3 \\
\hline MLP-18 & $20-10$ & 97,7 & 98,1 & 97,7 & 98,2 & 98,3 & 97,7 & 98,0 & 97,8 & 98,2 & 98,3 & 98,0 & 98,0 \\
\hline MLP-19 & $20-15$ & 98,3 & 98,5 & 98,4 & 98,5 & 98,3 & 98,2 & 98,4 & 98,4 & 98,5 & 98,3 & 98,4 & 98,4 \\
\hline MLP-20 & $20-20$ & 98,3 & 98,3 & 97,2 & 98,2 & 98,4 & 98,2 & 98,3 & 97,2 & 98,3 & 98,4 & 98,1 & 98,1 \\
\hline
\end{tabular}


Tabela C.2: Resultados do Treinamento e validação das topologias candidatas para o primeiro sistema neural (dados sem ruídos e sem parede), usando o algoritmo Levenberg-Marquardt.

\begin{tabular}{|c|c|c|c|c|c|c|c|c|c|c|c|c|c|}
\hline \multirow[t]{2}{*}{ Ref. } & \multirow{2}{*}{$\begin{array}{l}\text { Neurônios } \\
\text { Escondidos }\end{array}$} & \multicolumn{5}{|c|}{$\begin{array}{c}\text { Treinamento } \\
\text { MAPE (\% acertos) }\end{array}$} & \multicolumn{5}{|c|}{$\begin{array}{c}\text { Validação } \\
\text { MAPE (\% acertos) }\end{array}$} & \multicolumn{2}{|c|}{$\begin{array}{c}\text { Média Final } \\
\text { MAPE (\% acertos) }\end{array}$} \\
\hline & & $\mathrm{C} 1$ & $\mathrm{C} 2$ & $\mathrm{C} 3$ & $\mathrm{C} 4$ & C5 & $\mathrm{C} 1$ & $\mathrm{C} 2$ & $\mathrm{C} 3$ & $\mathrm{C} 4$ & $\mathrm{C} 5$ & Trein. & Val. \\
\hline MLP-21 & 5 & 98,6 & 91,0 & 98,3 & 98,7 & 96,4 & 98,7 & 90,8 & 98,3 & 98,7 & 96,0 & 96,6 & 96,5 \\
\hline MLP-22 & $5-5$ & 98,4 & 84,4 & 88,4 & 98,8 & 98,2 & 98,5 & 84,8 & 88,2 & 98,8 & 98,0 & 93,6 & 93,7 \\
\hline MLP-23 & $5-10$ & 88,0 & 98,2 & 94,0 & 97,9 & 98,3 & 88,3 & 98,1 & 93,9 & 97,9 & 98,2 & 95,3 & 95,3 \\
\hline MLP-24 & $5-15$ & 78,1 & 95,0 & 97,4 & 74,9 & 93,9 & 78,7 & 94,5 & 97,6 & 74,3 & 93,8 & 87,9 & 87,8 \\
\hline MLP-25 & $5-20$ & 99,3 & 99,1 & 99,2 & 99,2 & 99,3 & 99,3 & 99,1 & 99,1 & 99,2 & 99,3 & 99,2 & 99,2 \\
\hline MLP-26 & 10 & 99,3 & 99,5 & 99,4 & 99,7 & 99,5 & 99,3 & 99,4 & 99,4 & 99,7 & 99,4 & 99,5 & 99,4 \\
\hline MLP-27 & $10-5$ & 75,5 & 74,2 & 57,3 & 67,5 & 64,8 & 75,8 & 74,1 & 56,5 & 66,6 & 64,4 & 67,9 & 67,5 \\
\hline MLP-28 & $10-10$ & 61,7 & 88,9 & 88,6 & 92,4 & 94,5 & 62,0 & 87,8 & 88,7 & 92,0 & 94,6 & 85,2 & 85,0 \\
\hline MLP-29 & $10-15$ & 99,0 & 99,0 & 95,5 & 98,9 & 95,5 & 99,1 & 98,9 & 95,8 & 98,8 & 95,1 & 97,6 & 97,5 \\
\hline MLP-30 & $10-20$ & 93,5 & 95,3 & 94,6 & 99,2 & 87,2 & 93,5 & 95,0 & 94,4 & 99,2 & 87,2 & 94,0 & 93,9 \\
\hline MLP-31 & 15 & 97,5 & 93,5 & 96,3 & 95,3 & 97,2 & 97,3 & 93,5 & 96,5 & 95,4 & 97,1 & 96,0 & 96,0 \\
\hline MLP-32 & $15-5$ & 89,1 & 91,5 & 99,2 & 80,3 & 97,0 & 89,0 & 91,1 & 99,3 & 81,8 & 97,2 & 91,5 & 91,7 \\
\hline MLP-33 & $15-10$ & 91,0 & 75,5 & 78,5 & 65,6 & 91,8 & 91,2 & 73,9 & 78,0 & 65,6 & 91,7 & 80,5 & 80,1 \\
\hline MLP-34 & $15-15$ & 97,4 & 97,3 & 89,2 & 86,7 & 94,7 & 97,2 & 97,0 & 89,2 & 87,2 & 94,4 & 93,0 & 93,0 \\
\hline MLP-35 & $15-20$ & 78,5 & 89,2 & 78,9 & 89,7 & 74,1 & 78,9 & 88,9 & 78,3 & 90,1 & 74,4 & 82,1 & 82,1 \\
\hline MLP-36 & 20 & 98,7 & 99,1 & 98,1 & 99,2 & 97,3 & 98,8 & 99,0 & 98,4 & 99,2 & 97,1 & 98,5 & 98,5 \\
\hline MLP-37 & $20-5$ & 99,3 & 99,5 & 99,4 & 99,5 & 99,5 & 99,3 & 99,4 & 99,4 & 99,5 & 99,5 & 99,5 & 99,4 \\
\hline MLP-38 & $20-10$ & 89,1 & 89,5 & 89,7 & 89,7 & 89,2 & 89,3 & 89,7 & 89,3 & 89,4 & 89,3 & 89,5 & 89,4 \\
\hline MLP-39 & $20-15$ & 86,4 & 87,6 & 85,6 & 87,9 & 97,5 & 86,7 & 87,0 & 85,5 & 88,6 & 97,2 & 89,0 & 89,0 \\
\hline MLP-40 & $20-20$ & 77,4 & 90,8 & 97,6 & 90,9 & 81,3 & 78,2 & 90,6 & 97,7 & 91,4 & 81,3 & 87,6 & 87,8 \\
\hline
\end{tabular}

Tabela C.3: Resultados do Treinamento e validação das topologias candidatas para o segundo sistema neural (dados sem ruídos e com parede), usando o algoritmo Resilient Propagation.

\begin{tabular}{|c|c|c|c|c|c|c|c|c|c|c|c|c|c|}
\hline \multirow[t]{2}{*}{ Ref. } & \multirow{2}{*}{$\begin{array}{l}\text { Neurônios } \\
\text { Escondidos }\end{array}$} & \multicolumn{5}{|c|}{$\begin{array}{c}\text { Treinamento } \\
\text { MAPE (\% acertos) }\end{array}$} & \multicolumn{5}{|c|}{$\begin{array}{c}\text { Validação } \\
\text { MAPE (\% acertos) }\end{array}$} & \multicolumn{2}{|c|}{$\begin{array}{c}\text { Média Final } \\
\text { MAPE (\% acertos) }\end{array}$} \\
\hline & & $\mathrm{C} 1$ & $\mathrm{C} 2$ & C3 & $\mathrm{C} 4$ & $\mathrm{C} 5$ & $\mathrm{C} 1$ & $\mathrm{C} 2$ & $\mathrm{C} 3$ & $\mathrm{C} 4$ & $\mathrm{C} 5$ & Trein. & Val. \\
\hline MLP-41 & 5 & 98,0 & 97,7 & 98,0 & 98,4 & 97,8 & 97,9 & 97,8 & 98,0 & 98,5 & 97,6 & 98,0 & 98,0 \\
\hline MLP-42 & $5-5$ & 98,3 & 98,0 & 98,3 & 98,5 & 98,0 & 98,2 & 98,1 & 98,4 & 98,6 & 97,9 & 98,2 & 98,2 \\
\hline MLP-43 & $5-10$ & 97,9 & 97,7 & 97,7 & 97,6 & 97,7 & 97,8 & 97,7 & 97,8 & 97,7 & 97,6 & 97,7 & 97,7 \\
\hline MLP-44 & $5-15$ & 98,1 & 98,1 & 98,3 & 98,2 & 97,8 & 97,9 & 98,2 & 98,4 & 98,3 & 97,6 & 98,1 & 98,1 \\
\hline MLP-45 & $5-20$ & 98,1 & 97,9 & 98,0 & 98,1 & 98,0 & 98,0 & 98,0 & 98,1 & 98,2 & 97,9 & 98,1 & 98,0 \\
\hline MLP-46 & 10 & 98,4 & 98,5 & 98,5 & 98,5 & 98,6 & 98,3 & 98,6 & 98,6 & 98,5 & 98,5 & 98,5 & 98,5 \\
\hline MLP-47 & $10-5$ & 98,1 & 98,2 & 98,3 & 98,4 & 98,1 & 97,8 & 98,3 & 98,4 & 98,5 & 98,0 & 98,2 & 98,2 \\
\hline MLP-48 & $10-10$ & 98,5 & 98,7 & 98,6 & 98,5 & 98,3 & 98,4 & 98,8 & 98,7 & 98,6 & 98,1 & 98,5 & 98,5 \\
\hline MLP-49 & $10-15$ & 98,4 & 98,2 & 98,7 & 98,7 & 98,6 & 98,2 & 98,2 & 98,8 & 98,8 & 98,5 & 98,5 & 98,5 \\
\hline MLP-50 & $10-20$ & 98,6 & 98,2 & 98,4 & 98,4 & 98,6 & 98,5 & 98,3 & 98,6 & 98,5 & 98,4 & 98,5 & 98,4 \\
\hline MLP-51 & 15 & 98,4 & 98,4 & 98,5 & 98,8 & 98,9 & 98,3 & 98,5 & 98,5 & 98,8 & 98,7 & 98,6 & 98,6 \\
\hline MLP-52 & $15-5$ & 98,5 & 98,2 & 98,4 & 98,5 & 98,4 & 98,3 & 98,3 & 98,4 & 98,6 & 98,2 & 98,4 & 98,4 \\
\hline MLP-53 & $15-10$ & 98,6 & 98,7 & 98,7 & 98,8 & 98,8 & 98,4 & 98,8 & 98,8 & 98,8 & 98,6 & 98,7 & 98,7 \\
\hline MLP-54 & $15-15$ & 98,7 & 98,6 & 98,8 & 98,9 & 98,9 & 98,5 & 98,7 & 98,9 & 99,0 & 98,8 & 98,8 & 98,8 \\
\hline MLP-55 & $15-20$ & 98,5 & 98,6 & 98,4 & 98,5 & 98,8 & 98,3 & 98,8 & 98,5 & 98,7 & 98,6 & 98,6 & 98,6 \\
\hline MLP-56 & 20 & 98,7 & 98,6 & 98,4 & 98,7 & 98,7 & 98,6 & 98,6 & 98,5 & 98,8 & 98,6 & 98,6 & 98,6 \\
\hline MLP-57 & $20-5$ & 98,5 & 97,9 & 98,6 & 98,7 & 98,0 & 98,3 & 98,0 & 98,6 & 98,8 & 97,9 & 98,3 & 98,3 \\
\hline MLP-58 & $20-10$ & 98,9 & 98,9 & 98,8 & 98,7 & 98,4 & 98,7 & 98,9 & 98,9 & 98,8 & 98,3 & 98,7 & 98,7 \\
\hline MLP-59 & $20-15$ & 98,8 & 98,7 & 98,8 & 98,8 & 99,0 & 98,7 & 98,8 & 98,9 & 98,8 & 98,8 & 98,8 & 98,8 \\
\hline MLP-60 & $20-20$ & 98,4 & 98,7 & 98,8 & 98,8 & 98,5 & 98,3 & 98,8 & 98,8 & 98,9 & 98,3 & 98,6 & 98,6 \\
\hline
\end{tabular}


Tabela C.4: Resultados do Treinamento e validação das topologias candidatas para o segundo sistema neural(dados sem ruídos e com parede), usando o algoritmo Levenberg-Marquardt.

\begin{tabular}{|c|c|c|c|c|c|c|c|c|c|c|c|c|c|}
\hline \multirow[t]{2}{*}{ Ref. } & \multirow{2}{*}{$\begin{array}{l}\text { Neurônios } \\
\text { Escondidos }\end{array}$} & \multicolumn{5}{|c|}{$\begin{array}{c}\text { Treinamento } \\
\text { MAPE (\% acertos) }\end{array}$} & \multicolumn{5}{|c|}{$\begin{array}{c}\text { Validação } \\
\text { MAPE (\% acertos) }\end{array}$} & \multicolumn{2}{|c|}{$\begin{array}{c}\text { Média Final } \\
\text { MAPE (\% acertos) }\end{array}$} \\
\hline & & $\mathrm{C} 1$ & $\mathrm{C} 2$ & $\mathrm{C} 3$ & $\mathrm{C} 4$ & $\mathrm{C} 5$ & $\mathrm{C} 1$ & $\mathrm{C} 2$ & $\mathrm{C} 3$ & $\mathrm{C} 4$ & $\mathrm{C} 5$ & Trein. & Val. \\
\hline MLP-61 & 5 & 99,2 & 76,3 & 98,5 & 99,4 & 89,5 & 99,1 & 76,8 & 98,4 & 99,4 & 89,5 & 92,6 & 92,6 \\
\hline MLP-62 & $5-5$ & 98,7 & 99,2 & 98,7 & 86,5 & 98,8 & 98,5 & 99,3 & 98,6 & 86,6 & 98,8 & 96,4 & 96,4 \\
\hline MLP-63 & $5-10$ & 86,3 & 98,5 & 95,7 & 96,1 & 89,2 & 86,3 & 98,7 & 95,6 & 96,2 & 88,9 & 93,2 & 93,1 \\
\hline MLP-64 & $5-15$ & 98,9 & 98,9 & 84,4 & 75,3 & 94,9 & 98,7 & 99,0 & 84,6 & 75,3 & 95,3 & 90,5 & 90,6 \\
\hline MLP-65 & $5-20$ & 99,8 & 99,7 & 99,6 & 99,2 & 99,5 & 99,7 & 99,7 & 99,6 & 99,2 & 99,4 & 99,5 & 99,5 \\
\hline MLP-66 & 10 & 75,8 & 98,5 & 66,0 & 87,6 & 97,9 & 75,5 & 98,7 & 66,1 & 87,3 & 98,3 & 85,2 & 85,2 \\
\hline MLP-67 & $10-5$ & 98,4 & 99,5 & 90,3 & 90,0 & 90,0 & 98,1 & 99,5 & 89,9 & 89,9 & 89,9 & 93,6 & 93,5 \\
\hline MLP-68 & $10-10$ & 99,4 & 99,5 & 99,5 & 99,6 & 99,7 & 99,2 & 99,4 & 99,5 & 99,6 & 99,7 & 99,5 & 99,5 \\
\hline MLP-69 & $10-15$ & 99,3 & 99,6 & 99,4 & 99,7 & 99,7 & 99,1 & 99,6 & 99,4 & 99,7 & 99,6 & 99,6 & 99,5 \\
\hline MLP-70 & $10-20$ & 99,5 & 99,4 & 99,6 & 99,5 & 99,7 & 99,4 & 99,5 & 99,5 & 99,6 & 99,7 & 99,6 & 99,5 \\
\hline MLP-71 & 15 & 87,2 & 87,2 & 99,7 & 87,2 & 87,2 & 87,2 & 87,0 & 99,7 & 87,2 & 87,3 & 89,7 & 89,7 \\
\hline MLP-72 & $15-5$ & 99,8 & 99,6 & 99,8 & 99,6 & 99,8 & 99,6 & 99,5 & 99,8 & 99,6 & 99,7 & 99,7 & 99,6 \\
\hline MLP-73 & $15-10$ & 98,7 & 86,1 & 99,8 & 99,2 & 99,3 & 98,5 & 85,9 & 99,7 & 99,0 & 99,4 & 96,6 & 96,5 \\
\hline MLP-74 & $15-15$ & 99,7 & 99,5 & 99,6 & 99,6 & 99,7 & 99,5 & 99,5 & 99,5 & 99,6 & 99,7 & 99,6 & 99,6 \\
\hline MLP-75 & $15-20$ & 99,5 & 99,5 & 99,8 & 99,4 & 99,7 & 99,4 & 99,5 & 99,8 & 99,4 & 99,6 & 99,6 & 99,6 \\
\hline MLP-76 & 20 & 99,5 & 99,2 & 99,7 & 90,5 & 99,7 & 99,3 & 99,2 & 99,6 & 90,5 & 99,7 & 97,7 & 97,7 \\
\hline MLP-77 & $20-5$ & 96,0 & 99,3 & 99,4 & 99,3 & 99,1 & 95,9 & 99,3 & 99,3 & 99,4 & 99,0 & 98,6 & 98,6 \\
\hline MLP-78 & $20-10$ & 99,7 & 99,7 & 99,7 & 99,7 & 99,7 & 99,5 & 99,7 & 99,7 & 99,7 & 99,6 & 99,7 & 99,6 \\
\hline MLP-79 & $20-15$ & 99,6 & 99,7 & 99,6 & 99,4 & 99,6 & 99,5 & 99,6 & 99,6 & 99,5 & 99,6 & 99,6 & 99,6 \\
\hline MLP-80 & $20-20$ & 99,0 & 99,7 & 99,7 & 99,6 & 99,8 & 98,8 & 99,7 & 99,6 & 99,6 & 99,6 & 99,5 & 99,5 \\
\hline
\end{tabular}

Tabela C.5: Resultados do Treinamento e validação das topologias candidatas para o terceiro sistema neural (dados com ruídos e sem parede), usando o algoritmo Resilient Propagation.

\begin{tabular}{|c|c|c|c|c|c|c|c|c|c|c|c|c|c|}
\hline \multirow[t]{2}{*}{ Ref. } & \multirow{2}{*}{$\begin{array}{l}\text { Neurônios } \\
\text { Escondidos }\end{array}$} & \multicolumn{5}{|c|}{$\begin{array}{c}\text { Treinamento } \\
\text { MAPE }(\% \text { acertos })\end{array}$} & \multicolumn{5}{|c|}{$\begin{array}{c}\text { Validação } \\
\text { MAPE (\% acertos) }\end{array}$} & \multicolumn{2}{|c|}{$\begin{array}{c}\text { Média Final } \\
\text { MAPE (\% acertos) }\end{array}$} \\
\hline & & $\mathrm{C} 1$ & $\mathrm{C} 2$ & $\mathrm{C} 3$ & $\mathrm{C} 4$ & C5 & $\mathrm{C} 1$ & $\mathrm{C} 2$ & $\mathrm{C} 3$ & $\mathrm{C} 4$ & $\mathrm{C} 5$ & Trein. & Val. \\
\hline MLP-81 & 5 & 97,8 & 97,8 & 97,6 & 97,8 & 97,7 & 97,8 & 97,6 & 97,9 & 97,7 & 97,8 & 97,8 & 97,8 \\
\hline MLP-82 & $5-5$ & 98,0 & 98,0 & 97,4 & 97,8 & 97,9 & 97,9 & 97,7 & 97,7 & 97,7 & 98,0 & 97,8 & 97,8 \\
\hline MLP-83 & $5-10$ & 97,8 & 97,9 & 97,9 & 97,9 & 97,8 & 97,7 & 97,6 & 98,1 & 97,9 & 97,9 & 97,9 & 97,9 \\
\hline MLP-84 & $5-15$ & 98,0 & 98,2 & 98,0 & 98,0 & 98,2 & 97,9 & 97,9 & 98,2 & 98,0 & 98,2 & 98,1 & 98,1 \\
\hline MLP-85 & $5-20$ & 97,9 & 98,1 & 97,6 & 97,8 & 97,2 & 97,8 & 97,8 & 97,8 & 97,8 & 97,3 & 97,7 & 97,7 \\
\hline MLP-86 & 10 & 98,1 & 98,3 & 97,6 & 98,0 & 98,1 & 98,0 & 98,0 & 97,9 & 98,0 & 98,1 & 98,0 & 98,0 \\
\hline MLP-87 & $10-5$ & 98,3 & 98,4 & 97,9 & 98,1 & 97,9 & 98,2 & 98,1 & 98,2 & 98,1 & 97,9 & 98,1 & 98,1 \\
\hline MLP-88 & $10-10$ & 98,2 & 98,1 & 97,9 & 97,8 & 98,2 & 98,1 & 97,8 & 98,2 & 97,8 & 98,2 & 98,0 & 98,0 \\
\hline MLP-89 & $10-15$ & 98,3 & 98,0 & 98,0 & 97,9 & 98,3 & 98,2 & 97,8 & 98,2 & 97,9 & 98,3 & 98,1 & 98,1 \\
\hline MLP-90 & $10-20$ & 97,8 & 98,6 & 98,0 & 98,2 & 98,4 & 97,7 & 98,3 & 98,3 & 98,2 & 98,4 & 98,2 & 98,2 \\
\hline MLP-91 & 15 & 98,2 & 98,0 & 97,8 & 98,4 & 98,1 & 98,2 & 97,8 & 98,1 & 98,4 & 98,1 & 98,1 & 98,1 \\
\hline MLP-92 & $15-5$ & 98,3 & 98,5 & 97,7 & 98,1 & 98,4 & 98,2 & 98,3 & 98,0 & 98,0 & 98,4 & 98,2 & 98,2 \\
\hline MLP-93 & $15-10$ & 98,2 & 98,5 & 98,2 & 98,2 & 98,5 & 98,1 & 98,3 & 98,4 & 98,2 & 98,5 & 98,3 & 98,3 \\
\hline MLP-94 & $15-15$ & 98,2 & 98,4 & 97,8 & 98,2 & 98,3 & 98,1 & 98,2 & 98,1 & 98,2 & 98,3 & 98,2 & 98,2 \\
\hline MLP-95 & $15-20$ & 97,9 & 98,2 & 98,0 & 98,3 & 98,0 & 97,8 & 98,0 & 98,3 & 98,3 & 98,1 & 98,1 & 98,1 \\
\hline MLP-96 & 20 & 98,1 & 98,4 & 98,1 & 98,1 & 98,2 & 98,1 & 98,2 & 98,4 & 98,1 & 98,2 & 98,2 & 98,2 \\
\hline MLP-97 & $20-5$ & 98,3 & 98,4 & 97,5 & 98,2 & 98,2 & 98,3 & 98,1 & 97,8 & 98,2 & 98,2 & 98,1 & 98,1 \\
\hline MLP-98 & $20-10$ & 98,3 & 98,6 & 98,0 & 98,5 & 98,5 & 98,2 & 98,4 & 98,3 & 98,5 & 98,5 & 98,4 & 98,4 \\
\hline MLP-99 & $20-15$ & 98,2 & 98,2 & 98,0 & 98,0 & 98,3 & 98,1 & 98,0 & 98,2 & 98,0 & 98,3 & 98,1 & 98,1 \\
\hline MLP-100 & $20-20$ & 98,1 & 98,3 & 97,9 & 98,2 & 98,4 & 98,0 & 98,0 & 98,2 & 98,2 & 98,4 & 98,2 & 98,2 \\
\hline
\end{tabular}


Tabela C.6: Resultados do Treinamento e validação das topologias candidatas para o terceiro sistema neural (dados com ruídos e sem parede), usando o algoritmo Levenberg-Marquardt.

\begin{tabular}{|c|c|c|c|c|c|c|c|c|c|c|c|c|c|}
\hline \multirow[t]{2}{*}{ Ref. } & \multirow{2}{*}{$\begin{array}{l}\text { Neurônios } \\
\text { Escondidos }\end{array}$} & \multicolumn{5}{|c|}{$\begin{array}{c}\text { Treinamento } \\
\text { MAPE (\% acertos) }\end{array}$} & \multicolumn{5}{|c|}{$\begin{array}{c}\text { Validação } \\
\text { MAPE (\% acertos) }\end{array}$} & \multicolumn{2}{|c|}{$\begin{array}{c}\text { Média Final } \\
\text { MAPE (\% acertos) }\end{array}$} \\
\hline & & $\mathrm{C} 1$ & $\mathrm{C} 2$ & $\mathrm{C} 3$ & $\mathrm{C} 4$ & $\mathrm{C} 5$ & $\mathrm{C} 1$ & $\mathrm{C} 2$ & C3 & $\mathrm{C} 4$ & $\mathrm{C} 5$ & Trein. & Val. \\
\hline MLP-101 & 5 & 72,4 & 83,5 & 87,4 & 87,4 & 87,7 & 72,4 & 83,1 & 87,1 & 87,2 & 88,1 & 83,7 & 83,6 \\
\hline MLP-102 & $5-5$ & 98,6 & 99,0 & 99,0 & 98,9 & 98,7 & 98,5 & 99,0 & 99,0 & 98,8 & 98,7 & 98,8 & 98,8 \\
\hline MLP-103 & $5-10$ & 75,7 & 97,6 & 97,7 & 85,3 & 67,6 & 75,4 & 97,4 & 97,6 & 85,8 & 67,5 & 84,8 & 84,7 \\
\hline MLP-104 & $5-15$ & 99,0 & 99,0 & 98,9 & 99,0 & 98,9 & 98,8 & 99,0 & 99,0 & 99,0 & 99,0 & 99,0 & 98,9 \\
\hline MLP-105 & $5-20$ & 85,3 & 98,1 & 84,8 & 98,2 & 98,6 & 85,4 & 97,9 & 85,1 & 98,3 & 98,6 & 93,0 & 93,1 \\
\hline MLP-106 & 10 & 87,7 & 95,0 & 84,6 & 97,4 & 92,4 & 87,7 & 94,4 & 84,5 & 97,6 & 92,2 & 91,4 & 91,3 \\
\hline MLP-107 & $10-5$ & 99,0 & 98,9 & 99,2 & 99,0 & 99,0 & 98,7 & 98,8 & 99,2 & 99,0 & 99,1 & 99,0 & 98,9 \\
\hline MLP-108 & $10-10$ & 99,1 & 99,4 & 99,2 & 99,0 & 98,9 & 98,9 & 99,3 & 99,2 & 98,9 & 99,0 & 99,1 & 99,1 \\
\hline MLP-109 & $10-15$ & 98,4 & 86,5 & 90,5 & 99,0 & 98,9 & 98,2 & 86,6 & 91,1 & 98,9 & 99,0 & 94,7 & 94,8 \\
\hline MLP-110 & $10-20$ & 99,1 & 99,1 & 98,8 & 99,0 & 99,0 & 98,9 & 99,0 & 99,0 & 99,0 & 99,1 & 99,0 & 99,0 \\
\hline MLP-111 & 15 & 98,8 & 99,1 & 99,2 & 98,8 & 99,0 & 98,7 & 99,0 & 99,3 & 98,8 & 98,9 & 99,0 & 98,9 \\
\hline MLP-112 & $15-5$ & 98,9 & 99,1 & 99,0 & 98,6 & 99,0 & 98,7 & 99,0 & 99,1 & 98,5 & 99,1 & 98,9 & 98,9 \\
\hline MLP-113 & $15-10$ & 99,0 & 99,1 & 98,9 & 99,0 & 99,1 & 98,8 & 99,0 & 99,0 & 98,9 & 99,1 & 99,0 & 99,0 \\
\hline MLP-114 & & 98,5 & 98,8 & 98,7 & 98,8 & 99,0 & 98,3 & 98,6 & 98,7 & 98,7 & 98,9 & 98,7 & 98,7 \\
\hline MLP-115 & $15-20$ & 98,5 & 71,4 & 98,4 & 70,7 & 79,5 & 98,2 & 70,9 & 98,2 & 70,4 & 79,6 & 83,7 & 83,5 \\
\hline MLP-116 & 20 & 97,3 & 98,1 & 98,6 & 95,2 & 95,5 & 96,7 & 97,7 & 98,5 & 94,8 & 95,9 & 96,9 & 96,7 \\
\hline MLP-117 & $20-5$ & 98,3 & 99,1 & 98,0 & 99,1 & 98,5 & 98,1 & 99,0 & 98,1 & 99,0 & 98,6 & 98,6 & 98,5 \\
\hline MLP-118 & $20-10$ & 90,6 & 85,1 & 96,5 & 98,5 & 98,4 & 90,0 & 84,7 & 96,9 & 98,5 & 98,5 & 93,8 & 93,7 \\
\hline MLP-119 & $20-15$ & 98,8 & 99,1 & 98,5 & 99,0 & 98,8 & 98,6 & 98,9 & 98,6 & 98,9 & 98,9 & 98,8 & 98,8 \\
\hline MLP-120 & $20-20$ & 84,9 & 85,0 & 86,8 & 88,8 & 84,8 & 84,5 & 84,4 & 87,2 & 88,7 & 84,1 & 86,0 & 85,8 \\
\hline
\end{tabular}

Tabela C.7: Resultados do Treinamento e validação das topologias candidatas para o quarto sistema neural (dados com ruídos e com parede), usando o algoritmo Resilient Propagation.

\begin{tabular}{|c|c|c|c|c|c|c|c|c|c|c|c|c|c|}
\hline \multirow[t]{2}{*}{ Ref. } & \multirow{2}{*}{$\begin{array}{l}\text { Neurônios } \\
\text { Escondidos }\end{array}$} & \multicolumn{5}{|c|}{$\begin{array}{c}\text { Treinamento } \\
\text { MAPE (\% acertos) }\end{array}$} & \multicolumn{5}{|c|}{$\begin{array}{c}\text { Validação } \\
\text { MAPE (\% acertos) }\end{array}$} & \multicolumn{2}{|c|}{$\begin{array}{c}\text { Média Final } \\
\text { MAPE (\% acertos) }\end{array}$} \\
\hline & & $\mathrm{C} 1$ & $\mathrm{C} 2$ & $\mathrm{C} 3$ & $\mathrm{C} 4$ & $\mathrm{C} 5$ & $\mathrm{C} 1$ & $\mathrm{C} 2$ & C3 & $\mathrm{C} 4$ & $\mathrm{C} 5$ & Trein. & Val. \\
\hline MLP-121 & 5 & 97,6 & 98,0 & 98,1 & 97,9 & 97,9 & 97,8 & 97,8 & 97,8 & 98,1 & 97,9 & 97,9 & 97,9 \\
\hline MLP-122 & $5-5$ & 97,4 & 97,9 & 97,9 & 97,8 & 97,9 & 97,7 & 97,7 & 97,7 & 97,9 & 98,0 & 97,8 & 97,8 \\
\hline MLP-123 & $5-10$ & 97,0 & 97,1 & 97,9 & 97,3 & 97,4 & 97,2 & 97,0 & 97,7 & 97,5 & 97,4 & 97,3 & 97,3 \\
\hline MLP-124 & $5-15$ & 97,2 & 97,9 & 97,3 & 98,1 & 97,4 & 97,4 & 97,8 & 97,1 & 98,3 & 97,4 & 97,6 & 97,6 \\
\hline MLP-125 & $5-20$ & 97,8 & 98,1 & 98,2 & 97,9 & 97,8 & 98,0 & 97,9 & 97,9 & 98,0 & 97,9 & 98,0 & 98,0 \\
\hline MLP-126 & 10 & 97,4 & 98,2 & 98,3 & 98,2 & 98,4 & 97,5 & 98,1 & 98,1 & 98,3 & 98,3 & 98,1 & 98,1 \\
\hline MLP-127 & $10-5$ & 97,8 & 98,4 & 98,4 & 98,4 & 98,2 & 98,1 & 98,3 & 98,2 & 98,5 & 98,2 & 98,2 & 98,2 \\
\hline MLP-128 & $10-10$ & 97,8 & 98,2 & 98,4 & 98,4 & 98,1 & 98,0 & 98,0 & 98,2 & 98,6 & 98,1 & 98,2 & 98,2 \\
\hline MLP-129 & $10-15$ & 97,9 & 98,2 & 98,3 & 98,1 & 98,0 & 98,1 & 98,1 & 98,1 & 98,2 & 98,1 & 98,1 & 98,1 \\
\hline MLP-130 & $10-20$ & 98,1 & 98,3 & 98,5 & 98,3 & 98,2 & 98,3 & 98,2 & 98,3 & 98,4 & 98,2 & 98,3 & 98,3 \\
\hline MLP-131 & 15 & 97,7 & 98,2 & 98,4 & 97,9 & 97,9 & 98,0 & 98,0 & 98,2 & 98,0 & 97,9 & 98,0 & 98,0 \\
\hline MLP-132 & $15-5$ & 98,1 & 98,5 & 98,5 & 98,6 & 98,3 & 98,3 & 98,5 & 98,3 & 98,7 & 98,3 & 98,4 & 98,4 \\
\hline MLP-133 & $15-10$ & 98,3 & 98,5 & 98,4 & 98,4 & 98,4 & 98,4 & 98,3 & 98,2 & 98,6 & 98,4 & 98,4 & 98,4 \\
\hline MLP-134 & $15-15$ & 98,3 & 98,3 & 98,2 & 98,2 & 98,3 & 98,4 & 98,1 & 97,9 & 98,4 & 98,3 & 98,3 & 98,2 \\
\hline MLP-135 & $15-20$ & 98,1 & 98,2 & 98,2 & 98,5 & 98,2 & 98,4 & 98,1 & 98,0 & 98,5 & 98,2 & 98,3 & 98,2 \\
\hline MLP-136 & 20 & 98,2 & 98,5 & 98,5 & 98,3 & 98,3 & 98,4 & 98,4 & 98,3 & 98,4 & 98,3 & 98,4 & 98,4 \\
\hline MLP-137 & $20-5$ & 98,2 & 98,4 & 98,5 & 98,4 & 98,4 & 98,4 & 98,2 & 98,3 & 98,5 & 98,4 & 98,4 & 98,4 \\
\hline MLP-138 & $20-10$ & 98,2 & 98,1 & 98,3 & 98,1 & 98,1 & 98,4 & 98,0 & 98,1 & 98,2 & 98,1 & 98,1 & 98,1 \\
\hline MLP-139 & $20-15$ & 97,9 & 98,3 & 98,5 & 98,0 & 98,3 & 98,1 & 98,2 & 98,3 & 98,2 & 98,3 & 98,2 & 98,2 \\
\hline MLP-140 & $20-20$ & 98,3 & 98,4 & 98,4 & 98,3 & 98,4 & 98,5 & 98,3 & 98,1 & 98,4 & 98,3 & 98,3 & 98,3 \\
\hline
\end{tabular}


Tabela C.8: Resultados do Treinamento e validação das topologias candidatas para o quarto sistema neural (dados com ruídos e com parede), usando o algoritmo Levenberg-Marquardt.

\begin{tabular}{l|c|cccc|ccccc|ccc}
\hline \hline & \multirow{2}{*}{$\begin{array}{c}\text { Neurônios } \\
\text { Escondidos. }\end{array}$} & \multicolumn{4}{|c|}{ Treinamento } & \multicolumn{5}{c|}{ Validação } & \multicolumn{3}{c}{ Média Final } \\
& & C1 & C2 & C3 & C4 & C5 & C1 & C2 & C3 & C4 & C5 & \multicolumn{2}{c}{ MAPE (\% acertos) } \\
\hline MLP-141 & 5 & 98,3 & 88,8 & 98,1 & 86,0 & 88,7 & 98,3 & 89,2 & 98,1 & 86,0 & 88,0 & 92,0 & 91,9 \\
MLP-142 & $5-5$ & 98,5 & 99,1 & 98,7 & 98,5 & 98,0 & 98,4 & 99,0 & 98,6 & 98,4 & 97,9 & 98,5 & 98,5 \\
MLP-143 & $5-10$ & 98,5 & 98,9 & 80,3 & 98,7 & 80,2 & 98,4 & 98,8 & 80,6 & 98,7 & 80,5 & 91,3 & 91,4 \\
MLP-144 & $5-15$ & 98,9 & 98,8 & 98,9 & 99,0 & 98,9 & 98,9 & 98,7 & 98,7 & 99,1 & 98,9 & 98,9 & 98,8 \\
MLP-145 & $5-20$ & 99,1 & 99,1 & 98,2 & 99,0 & 97,3 & 99,0 & 99,0 & 98,1 & 99,0 & 97,2 & 98,5 & 98,5 \\
\hline MLP-146 & 10 & 89,3 & 89,3 & 76,1 & 89,5 & 89,8 & 89,2 & 88,7 & 76,0 & 89,7 & 89,8 & 86,8 & 86,7 \\
MLP-147 & $10-5$ & 70,6 & 70,5 & 80,1 & 86,0 & 70,3 & 70,6 & 69,2 & 80,3 & 85,9 & 70,5 & 75,5 & 75,3 \\
MLP-148 & $10-10$ & 89,7 & 98,1 & 98,6 & 79,3 & 99,1 & 89,7 & 98,1 & 98,6 & 79,8 & 99,0 & 93,0 & 93,0 \\
MLP-149 & $10-15$ & 98,9 & 98,8 & 98,8 & 99,0 & 98,8 & 98,9 & 98,7 & 98,7 & 98,9 & 98,7 & 98,9 & 98,8 \\
MLP-150 & $10-20$ & 99,1 & 98,7 & 89,5 & 88,8 & 87,9 & 98,9 & 98,5 & 89,6 & 89,1 & 87,9 & 92,8 & 92,8 \\
\hline MLP-151 & 15 & 99,1 & 99,2 & 99,3 & 99,2 & 99,2 & 99,1 & 99,1 & 99,2 & 99,2 & 99,1 & 99,2 & 99,1 \\
MLP-152 & $15-5$ & 99,2 & 99,2 & 99,2 & 99,1 & 99,1 & 99,1 & 99,0 & 99,1 & 99,1 & 99,1 & 99,1 & 99,1 \\
MLP-153 & $15-10$ & 95,7 & 98,3 & 98,7 & 98,9 & 98,4 & 95,8 & 98,2 & 98,6 & 98,8 & 98,4 & 98,0 & 98,0 \\
MLP-154 & $15-15$ & 99,3 & 98,5 & 99,3 & 98,9 & 98,4 & 99,2 & 98,4 & 99,2 & 98,8 & 98,3 & 98,9 & 98,8 \\
MLP-155 & $15-20$ & 99,1 & 99,1 & 99,1 & 99,1 & 99,4 & 99,1 & 98,9 & 99,1 & 99,1 & 99,3 & 99,2 & 99,1 \\
\hline MLP-156 & 20 & 98,7 & 86,6 & 98,5 & 98,7 & 98,5 & 98,7 & 86,8 & 98,3 & 98,5 & 98,4 & 96,2 & 96,1 \\
MLP-157 & $20-5$ & 89,0 & 72,1 & 99,2 & 99,4 & 99,4 & 89,0 & 70,1 & 99,1 & 99,3 & 99,1 & 91,8 & 91,3 \\
MLP-158 & $20-10$ & 98,8 & 98,9 & 99,2 & 99,1 & 99,2 & 98,8 & 98,8 & 99,1 & 99,1 & 99,1 & 99,1 & 99,0 \\
MLP-159 & $20-15$ & 84,1 & 98,6 & 99,2 & 99,1 & 85,0 & 84,2 & 98,5 & 99,1 & 99,1 & 85,1 & 93,2 & 93,2 \\
MLP-160 & $20-20$ & 79,7 & 90,1 & 89,3 & 98,5 & 98,7 & 79,4 & 89,1 & 89,3 & 98,2 & 98,7 & 91,3 & 90,9 \\
\hline \hline
\end{tabular}

Tabela C.9: Resultados do Treinamento e validação das topologias especialistas candidatas (12 entradas e uma saída com esterçamento do veículo) para o quinto sistema neural (dados sem ruídos e sem parede), usando o algoritmo Resilient Propagation.

\begin{tabular}{|c|c|c|c|c|c|c|c|c|c|c|c|c|c|}
\hline \multirow[t]{2}{*}{ Ref. } & \multirow{2}{*}{$\begin{array}{l}\text { Neurônios } \\
\text { Escondidos }\end{array}$} & \multicolumn{5}{|c|}{$\begin{array}{c}\text { Treinamento } \\
\text { MAPE (\% acertos) }\end{array}$} & \multicolumn{5}{|c|}{$\begin{array}{c}\text { Validação } \\
\text { MAPE (\% acertos) }\end{array}$} & \multicolumn{2}{|c|}{$\begin{array}{c}\text { Média Final } \\
\text { MAPE }(\% \text { acertos })\end{array}$} \\
\hline & & $\mathrm{C} 1$ & $\mathrm{C} 2$ & C3 & $\mathrm{C} 4$ & C5 & C1 & $\mathrm{C} 2$ & C3 & $\mathrm{C} 4$ & C5 & Trein. & Val. \\
\hline MLP-161 & 5 & 100,0 & 100,0 & 99,9 & 100,0 & 100,0 & 100,0 & 100,0 & 100,0 & 100,0 & 100,0 & 100,0 & 100,0 \\
\hline MLP-162 & $5-5$ & 99,9 & 99,9 & 99,9 & 99,9 & 99,9 & 100,0 & 99,9 & 99,9 & 99,9 & 99,9 & 99,9 & 99,9 \\
\hline MLP-163 & $5-10$ & 99,9 & 99,9 & 100,0 & 100,0 & 99,9 & 99,9 & 99,9 & 100,0 & 100,0 & 99,9 & 99,9 & 99,9 \\
\hline MLP-164 & $5-15$ & 99,9 & 99,9 & 99,9 & 99,9 & 99,9 & 99,9 & 99,9 & 99,9 & 99,9 & 99,9 & 99,9 & 99,9 \\
\hline MLP-165 & $5-20$ & 99,9 & 100,0 & 99,9 & 100,0 & 99,9 & 99,9 & 100,0 & 99,9 & 100,0 & 99,9 & 99,9 & 99,9 \\
\hline MLP-166 & 10 & 99,9 & 99,9 & 99,9 & 99,9 & 99,9 & 99,9 & 99,9 & 99,9 & 99,9 & 99,9 & 99,9 & 99,9 \\
\hline MLP-167 & $10-5$ & 100,0 & 99,9 & 99,9 & 100,0 & 100,0 & 100,0 & 99,9 & 99,9 & 100,0 & 100,0 & 99,9 & 99,9 \\
\hline MLP-168 & $10-10$ & 99,9 & 99,9 & 99,8 & 99,9 & 99,9 & 99,9 & 99,9 & 99,8 & 99,9 & 99,9 & 99,9 & 99,9 \\
\hline MLP-169 & $10-15$ & 99,9 & 99,9 & 99,9 & 99,9 & 99,9 & 99,9 & 99,9 & 99,9 & 99,9 & 99,9 & 99,9 & 99,9 \\
\hline MLP-170 & $10-20$ & 100,0 & 100,0 & 100,0 & 100,0 & 100,0 & 100,0 & 100,0 & 100,0 & 100,0 & 100,0 & 100,0 & 100,0 \\
\hline MLP-171 & 15 & 100,0 & 100,0 & 100,0 & 99,9 & 100,0 & 100,0 & 100,0 & 100,0 & 99,9 & 100,0 & 100,0 & 100,0 \\
\hline MLP-172 & $15-5$ & 99,9 & 100,0 & 99,9 & 100,0 & 99,9 & 99,9 & 100,0 & 99,9 & 100,0 & 99,9 & 99,9 & 99,9 \\
\hline MLP-173 & $15-10$ & 99,9 & 99,9 & 99,9 & 100,0 & 100,0 & 99,9 & 99,9 & 99,9 & 100,0 & 100,0 & 99,9 & 99,9 \\
\hline MLP-174 & $15-15$ & 99,9 & 99,9 & 99,9 & 99,9 & 99,9 & 99,9 & 99,9 & 99,9 & 99,9 & 99,9 & 99,9 & 99,9 \\
\hline MLP-175 & $15-20$ & 99,8 & 99,9 & 99,9 & 99,9 & 99,9 & 99,8 & 99,9 & 99,9 & 99,9 & 99,9 & 99,9 & 99,9 \\
\hline MLP-176 & 20 & 100,0 & 100,0 & 100,0 & 100,0 & 100,0 & 100,0 & 100,0 & 100,0 & 100,0 & 100,0 & 100,0 & 100,0 \\
\hline MLP-177 & $20-5$ & 99,9 & 99,9 & 100,0 & 100,0 & 100,0 & 99,9 & 100,0 & 100,0 & 100,0 & 100,0 & 99,9 & 99,9 \\
\hline MLP-178 & $20-10$ & 99,9 & 99,9 & 99,9 & 100,0 & 100,0 & 99,9 & 99,9 & 99,9 & 100,0 & 100,0 & 99,9 & 99,9 \\
\hline MLP-179 & $20-15$ & 99,9 & 99,9 & 99,9 & 100,0 & 100,0 & 99,9 & 99,9 & 99,9 & 100,0 & 99,9 & 99,9 & 99,9 \\
\hline MLP-180 & $20-20$ & 99,9 & 99,9 & 99,9 & 99,9 & 99,9 & 99,9 & 99,9 & 99,9 & 99,9 & 99,9 & 99,9 & 99,9 \\
\hline
\end{tabular}


Tabela C.10: Resultados do Treinamento e validação das topologias especialistas candidatas (12 entradas e uma saída com esterçamento do veículo) para o quinto sistema neural (dados sem ruídos e sem parede), usando o algoritmo Levenberg-Marquardt.

\begin{tabular}{|c|c|c|c|c|c|c|c|c|c|c|c|c|c|}
\hline \multirow[t]{2}{*}{ Ref. } & \multirow{2}{*}{$\begin{array}{l}\text { Neurônios } \\
\text { Escondidos }\end{array}$} & \multicolumn{5}{|c|}{$\begin{array}{c}\text { Treinamento } \\
\text { MAPE }(\% \text { acertos })\end{array}$} & \multicolumn{5}{|c|}{$\begin{array}{c}\text { Validação } \\
\text { MAPE (\% acertos) }\end{array}$} & \multicolumn{2}{|c|}{$\begin{array}{c}\text { Média Final } \\
\text { MAPE (\% acertos) }\end{array}$} \\
\hline & & $\mathrm{C} 1$ & $\mathrm{C} 2$ & $\mathrm{C} 3$ & $\mathrm{C} 4$ & $\mathrm{C} 5$ & $\mathrm{C} 1$ & $\mathrm{C} 2$ & $\mathrm{C} 3$ & $\mathrm{C} 4$ & $\mathrm{C} 5$ & Trein. & Val. \\
\hline MLP-181 & 5 & 100,0 & 100,0 & 100,0 & 100,0 & 100,0 & 100,0 & 100,0 & 100,0 & 100,0 & 100,0 & 100,0 & 100,0 \\
\hline MLP-182 & $5-5$ & 100,0 & 100,0 & 100,0 & 100,0 & 100,0 & 100,0 & 100,0 & 100,0 & 100,0 & 100,0 & 100,0 & 100,0 \\
\hline MLP-183 & $5-10$ & 100,0 & 100,0 & 100,0 & 100,0 & 100,0 & 100,0 & 100,0 & 100,0 & 100,0 & 100,0 & 100,0 & 100,0 \\
\hline MLP-184 & $5-15$ & 97,4 & 100,0 & 97,7 & 97,6 & 97,8 & 98,5 & 100,0 & 97,4 & 97,7 & 96,8 & 98,1 & 98,1 \\
\hline MLP-185 & $5-20$ & 98,7 & 98,8 & 98,9 & 100,0 & 100,0 & 99,3 & 98,9 & 98,7 & 100,0 & 100,0 & 99,3 & 99,4 \\
\hline MLP-186 & 10 & 41,6 & 41,5 & 93,4 & 100,0 & 70,9 & 41,2 & 41,3 & 92,8 & 99,9 & 70,2 & 69,5 & 69,1 \\
\hline MLP-187 & $10-5$ & 100,0 & 92,2 & 98,8 & 80,6 & 97,0 & 100,0 & 91,9 & 98,7 & 78,8 & 96,1 & 93,7 & 93,1 \\
\hline MLP-188 & $10-10$ & 100,0 & 100,0 & 100,0 & 100,0 & 100,0 & 100,0 & 100,0 & 100,0 & 100,0 & 100,0 & 100,0 & 100,0 \\
\hline MLP-189 & 15 & 100,0 & 100,0 & 100,0 & 100,0 & 100,0 & 100,0 & 100,0 & 100,0 & 100,0 & 100,0 & 100,0 & 100,0 \\
\hline MLP-190 & $10-20$ & 100,0 & 64,4 & 100,0 & 86,0 & 97,8 & 100,0 & 64,2 & 100,0 & 84,2 & 96,8 & 89,6 & 89,0 \\
\hline MLP-191 & 15 & 100,0 & 100,0 & 100,0 & 100,0 & 100,0 & 100,0 & 100,0 & 100,0 & 100,0 & 100,0 & 100,0 & 100,0 \\
\hline MLP-192 & $15-5$ & 100,0 & 100,0 & 100,0 & 100,0 & 100,0 & 100,0 & 100,0 & 100,0 & 100,0 & 100,0 & 100,0 & 100,0 \\
\hline MLP-193 & $15-10$ & 88,7 & 91,5 & 85,6 & 61,7 & 98,1 & 89,7 & 91,0 & 86,8 & 61,2 & 97,2 & 85,1 & 85,2 \\
\hline MLP-194 & $15-15$ & 100,0 & 100,0 & 100,0 & 100,0 & 100,0 & 100,0 & 100,0 & 100,0 & 100,0 & 100,0 & 100,0 & 100,0 \\
\hline MLP-195 & $15-20$ & 100,0 & 100,0 & 100,0 & 100,0 & 100,0 & 100,0 & 100,0 & 100,0 & 100,0 & 100,0 & 100,0 & 100,0 \\
\hline MLP-196 & 20 & 97,4 & 97,6 & 100,0 & 97,6 & 97,8 & 98,5 & 97,7 & 100,0 & 97,7 & 96,8 & 98,1 & 98,2 \\
\hline MLP-197 & $20-5$ & 100,0 & 100,0 & 100,0 & 100,0 & 100,0 & 100,0 & 100,0 & 100,0 & 100,0 & 100,0 & 100,0 & 100,0 \\
\hline MLP-198 & $20-10$ & 73,0 & 100,0 & 88,9 & 88,4 & 75,2 & 73,8 & 100,0 & 89,1 & 88,4 & 76,7 & 85,1 & 85,6 \\
\hline MLP-199 & $20-15$ & 83,1 & 100,0 & 98,5 & 93,9 & 98,9 & 83,9 & 100,0 & 98,1 & 93,2 & 98,4 & 94,9 & 94,7 \\
\hline MLP-200 & $20-20$ & 100,0 & 100,0 & 100,0 & 100,0 & 100,0 & 100,0 & 100,0 & 100,0 & 100,0 & 100,0 & 100,0 & 100,0 \\
\hline
\end{tabular}

Tabela C.11: Resultados do Treinamento e validação das topologias especialistas candidatas (12 entradas e uma saída com a velocidade do veículo) para o quinto sistema neural (dados sem ruídos e sem parede), usando o algoritmo Resilient Propagation.

\begin{tabular}{|c|c|c|c|c|c|c|c|c|c|c|c|c|c|}
\hline \multirow[t]{2}{*}{ Ref. } & \multirow{2}{*}{$\begin{array}{l}\text { Neurônios } \\
\text { Escondidos }\end{array}$} & \multicolumn{5}{|c|}{$\begin{array}{c}\text { Treinamento } \\
\text { MAPE (\% acertos) }\end{array}$} & \multicolumn{5}{|c|}{$\begin{array}{c}\text { Validação } \\
\text { MAPE (\% acertos) }\end{array}$} & \multicolumn{2}{|c|}{$\begin{array}{c}\text { Média Final } \\
\text { MAPE (\% acertos) }\end{array}$} \\
\hline & & $\mathrm{C} 1$ & $\mathrm{C} 2$ & $\mathrm{C} 3$ & $\mathrm{C} 4$ & $\mathrm{C} 5$ & $\mathrm{C} 1$ & $\mathrm{C} 2$ & $\mathrm{C} 3$ & $\mathrm{C} 4$ & $\mathrm{C} 5$ & Trein. & Val. \\
\hline MLP-201 & 5 & 95,6 & 94,0 & 93,7 & 94,4 & 95,2 & 95,5 & 93,7 & 94,2 & 94,0 & 95,4 & 94,6 & 94,5 \\
\hline MLP-202 & $5-5$ & 95,3 & 95,5 & 94,8 & 95,1 & 95,3 & 95,2 & 95,2 & 95,3 & 94,8 & 95,5 & 95,2 & 95,2 \\
\hline MLP-203 & $5-10$ & 96,0 & 95,3 & 95,4 & 95,7 & 95,6 & 96,1 & 95,0 & 95,8 & 95,3 & 95,8 & 95,6 & 95,6 \\
\hline MLP-204 & $5-15$ & 96,0 & 95,1 & 95,4 & 95,1 & 94,9 & 95,9 & 94,8 & 95,8 & 94,7 & 95,1 & 95,3 & 95,2 \\
\hline MLP-205 & $5-20$ & 94,4 & 93,6 & 95,1 & 95,2 & 94,3 & 94,5 & 93,2 & 95,6 & 94,9 & 94,6 & 94,5 & 94,5 \\
\hline MLP-206 & 10 & 95,5 & 94,8 & 95,1 & 95,5 & 95,2 & 95,5 & 94,4 & 95,6 & 95,1 & 95,4 & 95,2 & 95,2 \\
\hline MLP-207 & $10-5$ & 95,5 & 95,4 & 95,0 & 95,7 & 95,5 & 95,6 & 95,1 & 95,4 & 95,3 & 95,6 & 95,4 & 95,4 \\
\hline MLP-208 & $10-10$ & 95,7 & 95,7 & 95,3 & 95,5 & 95,5 & 95,7 & 95,3 & 95,8 & 95,1 & 95,7 & 95,5 & 95,5 \\
\hline MLP-209 & $10-15$ & 95,7 & 95,9 & 95,3 & 95,6 & 95,5 & 95,7 & 95,6 & 95,7 & 95,2 & 95,7 & 95,6 & 95,6 \\
\hline MLP-210 & $10-20$ & 95,9 & 96,0 & 95,3 & 95,7 & 95,3 & 96,0 & 95,7 & 95,7 & 95,4 & 95,5 & 95,6 & 95,7 \\
\hline MLP-211 & 15 & 96,0 & 95,6 & 94,8 & 95,3 & 95,6 & 96,0 & 95,2 & 95,3 & 95,0 & 95,8 & 95,5 & 95,5 \\
\hline MLP-212 & $15-5$ & 95,9 & 96,0 & 95,3 & 96,0 & 95,7 & 95,9 & 95,6 & 95,7 & 95,6 & 95,9 & 95,8 & 95,7 \\
\hline MLP-213 & $15-10$ & 96,3 & 95,4 & 95,2 & 95,6 & 95,4 & 96,2 & 95,0 & 95,6 & 95,2 & 95,6 & 95,6 & 95,5 \\
\hline MLP-214 & $15-15$ & 95,4 & 96,0 & 95,2 & 95,7 & 95,4 & 95,4 & 95,6 & 95,6 & 95,3 & 95,6 & 95,5 & 95,5 \\
\hline MLP-215 & $15-20$ & 96,1 & 95,1 & 94,5 & 96,0 & 95,2 & 96,1 & 94,8 & 94,9 & 95,7 & 95,4 & 95,4 & 95,4 \\
\hline MLP-216 & 20 & 96,4 & 95,8 & 95,2 & 95,5 & 95,7 & 96,4 & 95,4 & 95,7 & 95,1 & 95,9 & 95,7 & 95,7 \\
\hline MLP-217 & $20-5$ & 96,0 & 96,1 & 95,7 & 95,7 & 95,6 & 96,1 & 95,8 & 96,1 & 95,4 & 95,8 & 95,8 & 95,8 \\
\hline MLP-218 & $20-10$ & 95,4 & 95,6 & 95,3 & 95,6 & 95,5 & 95,4 & 95,2 & 95,7 & 95,2 & 95,8 & 95,5 & 95,5 \\
\hline MLP-219 & $20-15$ & 95,9 & 96,4 & 95,6 & 95,6 & 95,7 & 95,9 & 96,0 & 96,1 & 95,2 & 95,8 & 95,8 & 95,8 \\
\hline MLP-220 & $20-20$ & 95,7 & 95,6 & 95,1 & 95,6 & 88,0 & 95,7 & 95,1 & 95,5 & 95,2 & 88,3 & 94,0 & 94,0 \\
\hline
\end{tabular}


Tabela C.12: Resultados do Treinamento e validação das topologias especialistas candidatas (12 entradas e uma saída com a velocidade do veículo) para o quinto sistema neural (dados sem ruídos e sem parede), usando o algoritmo Levenberg-Marquardt.

\begin{tabular}{|c|c|c|c|c|c|c|c|c|c|c|c|c|c|}
\hline \multirow[t]{2}{*}{ Ref. } & \multirow{2}{*}{$\begin{array}{l}\text { Neurônios } \\
\text { Escondidos }\end{array}$} & \multicolumn{5}{|c|}{$\begin{array}{c}\text { Treinamento } \\
\text { MAPE }(\% \text { acertos })\end{array}$} & \multicolumn{5}{|c|}{$\begin{array}{c}\text { Validação } \\
\text { MAPE (\% acertos) }\end{array}$} & \multicolumn{2}{|c|}{$\begin{array}{c}\text { Média Final } \\
\text { MAPE (\% acertos) }\end{array}$} \\
\hline & & $\mathrm{C} 1$ & $\mathrm{C} 2$ & $\mathrm{C} 3$ & $\mathrm{C} 4$ & C5 & $\mathrm{C} 1$ & $\mathrm{C} 2$ & $\mathrm{C} 3$ & $\mathrm{C} 4$ & C5 & Trein. & Val. \\
\hline MLP-221 & 5 & 97,5 & 96,1 & 97,4 & 97,4 & 97,5 & 97,5 & 96,1 & 97,5 & 97,0 & 97,4 & 97,2 & 97,1 \\
\hline MLP-222 & $5-5$ & 97,6 & 97,4 & 97,5 & 97,4 & 96,3 & 97,5 & 97,5 & 97,7 & 97,0 & 96,2 & 97,2 & 97,2 \\
\hline MLP-223 & $5-10$ & 97,2 & 97,2 & 97,0 & 97,1 & 97,4 & 97,1 & 97,3 & 97,3 & 96,7 & 97,4 & 97,2 & 97,1 \\
\hline MLP-224 & $5-15$ & 97,9 & 94,9 & 97,3 & 96,1 & 94,7 & 97,8 & 94,6 & 97,5 & 95,7 & 94,9 & 96,2 & 96,1 \\
\hline MLP-225 & $5-20$ & 97,4 & 96,4 & 96,8 & 97,6 & 96,9 & 97,5 & 96,4 & 96,9 & 97,2 & 96,7 & 97,0 & 97,0 \\
\hline MLP-226 & 10 & 98,1 & 97,7 & 97,8 & 98,0 & 97,6 & 98,0 & 97,7 & 97,9 & 97,5 & 97,5 & 97,8 & 97,7 \\
\hline MLP-227 & $10-5$ & 98,0 & 98,6 & 97,7 & 96,9 & 98,1 & 98,1 & 98,5 & 97,8 & 96,5 & 98,0 & 97,9 & 97,8 \\
\hline MLP-228 & $10-10$ & 98,2 & 98,4 & 97,9 & 98,4 & 97,9 & 98,1 & 98,3 & 98,0 & 98,0 & 97,8 & 98,2 & 98,0 \\
\hline MLP-229 & $10-15$ & 97,8 & 98,0 & 98,1 & 97,7 & 98,3 & 97,9 & 97,9 & 98,1 & 97,3 & 98,2 & 98,0 & 97,9 \\
\hline MLP-230 & $10-20$ & 97,0 & 97,8 & 97,6 & 96,1 & 97,6 & 96,9 & 97,8 & 97,7 & 95,6 & 97,5 & 97,2 & 97,1 \\
\hline MLP-231 & 15 & 97,7 & 91,6 & 92,5 & 98,2 & 97,4 & 97,7 & 91,1 & 92,7 & 97,8 & 97,4 & 95,5 & 95,3 \\
\hline MLP-232 & $15-5$ & 97,7 & 93,2 & 97,0 & 97,8 & 97,4 & 97,7 & 93,2 & 97,0 & 97,4 & 97,4 & 96,6 & 96,5 \\
\hline MLP-233 & $15-10$ & 96,6 & 97,4 & 98,3 & 97,3 & 98,1 & 96,7 & 97,3 & 98,3 & 97,0 & 98,0 & 97,5 & 97,5 \\
\hline MLP-234 & $15-15$ & 97,7 & 98,2 & 97,9 & 98,1 & 97,9 & 97,7 & 98,3 & 97,9 & 97,7 & 97,8 & 98,0 & 97,9 \\
\hline MLP-235 & $15-20$ & 94,1 & 97,9 & 97,9 & 97,9 & 98,3 & 93,5 & 97,9 & 98,0 & 97,5 & 98,2 & 97,2 & 97,0 \\
\hline MLP-236 & 20 & 97,8 & 98,0 & 98,2 & 97,9 & 98,3 & 97,9 & 97,9 & 98,2 & 97,5 & 98,1 & 98,0 & 97,9 \\
\hline MLP-237 & $20-5$ & 89,7 & 97,9 & 97,3 & 98,7 & 91,0 & 89,9 & 97,8 & 97,4 & 98,4 & 90,7 & 94,9 & 94,8 \\
\hline MLP-238 & $20-10$ & 98,1 & 98,1 & 98,0 & 98,6 & 98,4 & 98,2 & 97,9 & 98,1 & 98,1 & 98,2 & 98,2 & 98,1 \\
\hline MLP-239 & $20-15$ & 93,1 & 96,7 & 95,0 & 97,3 & 93,4 & 92,8 & 96,6 & 95,1 & 96,9 & 92,9 & 95,1 & 94,9 \\
\hline MLP-240 & $20-20$ & 97,7 & 97,7 & 98,1 & 98,2 & 97,3 & 97,8 & 97,5 & 98,1 & 97,8 & 97,3 & 97,8 & 97,7 \\
\hline
\end{tabular}

Tabela C.13: Resultados do Treinamento e validação das topologias especialistas candidatas (12 entradas e três saídas com os próximos estados da manobra) para o quinto sistema neural (dados sem ruídos e sem parede), usando o algoritmo Resilient Propagation.

\begin{tabular}{|c|c|c|c|c|c|c|c|c|c|c|c|c|c|}
\hline \multirow[t]{2}{*}{ Ref. } & \multirow{2}{*}{$\begin{array}{l}\text { Neurônios } \\
\text { Escondidos }\end{array}$} & \multicolumn{5}{|c|}{$\begin{array}{c}\text { Treinamento } \\
\text { MAPE }(\% \text { acertos })\end{array}$} & \multicolumn{5}{|c|}{$\begin{array}{c}\text { Validação } \\
\text { MAPE (\% acertos) }\end{array}$} & \multicolumn{2}{|c|}{$\begin{array}{c}\text { Média Final } \\
\text { MAPE (\% acertos) }\end{array}$} \\
\hline & & $\mathrm{C} 1$ & $\mathrm{C} 2$ & $\mathrm{C} 3$ & $\mathrm{C} 4$ & C5 & $\mathrm{C} 1$ & $\mathrm{C} 2$ & $\mathrm{C} 3$ & $\mathrm{C} 4$ & C5 & Trein. & Val. \\
\hline MLP-241 & 5 & 98,3 & 98,1 & 98,5 & 98,4 & 98,2 & 98,4 & 98,1 & 98,2 & 98,7 & 98,0 & 98,3 & 98,3 \\
\hline MLP-242 & $5-5$ & 98,3 & 97,9 & 98,5 & 97,9 & 98,5 & 98,4 & 98,0 & 98,2 & 98,2 & 98,3 & 98,2 & 98,2 \\
\hline MLP-243 & $5-10$ & 98,5 & 97,9 & 98,2 & 97,9 & 98,1 & 98,6 & 97,9 & 97,9 & 98,2 & 98,0 & 98,1 & 98,1 \\
\hline MLP-244 & $5-15$ & 98,8 & 98,4 & 98,2 & 98,1 & 98,2 & 98,9 & 98,4 & 97,9 & 98,4 & 98,1 & 98,4 & 98,3 \\
\hline MLP-245 & $5-20$ & 98,8 & 97,7 & 98,8 & 98,0 & 98,3 & 98,9 & 97,8 & 98,5 & 98,3 & 98,1 & 98,3 & 98,3 \\
\hline MLP-246 & 10 & 98,4 & 79,8 & 98,3 & 97,8 & 98,9 & 98,6 & 79,8 & 98,0 & 98,1 & 98,7 & 94,6 & 94,6 \\
\hline MLP-247 & $10-5$ & 98,4 & 98,3 & 98,4 & 97,8 & 98,8 & 98,5 & 98,4 & 98,0 & 98,2 & 98,6 & 98,3 & 98,3 \\
\hline MLP-248 & $10-10$ & 98,5 & 98,9 & 98,5 & 98,1 & 97,9 & 98,6 & 99,0 & 98,3 & 98,3 & 97,8 & 98,4 & 98,4 \\
\hline MLP-249 & $10-15$ & 98,7 & 98,7 & 98,8 & 98,2 & 99,0 & 98,7 & 98,9 & 98,5 & 98,4 & 98,8 & 98,7 & 98,7 \\
\hline MLP-250 & $10-20$ & 98,5 & 98,1 & 98,8 & 97,9 & 98,1 & 98,6 & 98,2 & 98,5 & 98,2 & 97,9 & 98,3 & 98,3 \\
\hline MLP-251 & 15 & 98,1 & 98,1 & 98,8 & 97,8 & 98,8 & 98,2 & 98,1 & 98,5 & 98,1 & 98,6 & 98,3 & 98,3 \\
\hline MLP-252 & $15-5$ & 98,6 & 98,0 & 99,1 & 97,8 & 97,9 & 98,6 & 98,1 & 98,8 & 98,1 & 97,8 & 98,3 & 98,3 \\
\hline MLP-253 & $15-10$ & 98,5 & 98,4 & 98,9 & 97,8 & 98,5 & 98,6 & 98,5 & 98,6 & 98,2 & 98,3 & 98,4 & 98,4 \\
\hline MLP-254 & $15-15$ & 98,4 & 98,2 & 98,8 & 97,7 & 98,0 & 98,4 & 98,3 & 98,6 & 98,0 & 97,9 & 98,2 & 98,2 \\
\hline MLP-255 & $15-20$ & 98,0 & 97,7 & 99,1 & 97,7 & 98,5 & 98,1 & 97,8 & 98,8 & 98,0 & 98,3 & 98,2 & 98,2 \\
\hline MLP-256 & 20 & 98,3 & 98,6 & 98,4 & 98,2 & 98,7 & 98,4 & 98,6 & 98,0 & 98,4 & 98,4 & 98,4 & 98,4 \\
\hline MLP-257 & $20-5$ & 98,7 & 98,5 & 98,8 & 97,7 & 99,0 & 98,8 & 98,6 & 98,5 & 98,1 & 98,7 & 98,5 & 98,5 \\
\hline MLP-258 & $20-10$ & 98,4 & 98,5 & 98,6 & 97,7 & 98,7 & 98,4 & 98,6 & 98,3 & 98,1 & 98,6 & 98,4 & 98,4 \\
\hline MLP-259 & $20-15$ & 98,5 & 98,9 & 98,8 & 98,0 & 98,3 & 98,6 & 99,0 & 98,5 & 98,3 & 98,2 & 98,5 & 98,5 \\
\hline MLP-260 & $20-20$ & 98,5 & 98,0 & 98,9 & 98,1 & 98,9 & 98,6 & 98,1 & 98,5 & 98,4 & 98,6 & 98,5 & 98,5 \\
\hline
\end{tabular}


Tabela C.14: Resultados do Treinamento e validação das topologias especialistas candidatas (12 entradas e três saídas com os próximos estados da manobra) para o quinto sistema neural (dados sem ruídos e sem parede), usando o algoritmo Levenberg-Marquardt.

\begin{tabular}{|c|c|c|c|c|c|c|c|c|c|c|c|c|c|}
\hline \multirow[t]{2}{*}{ Ref. } & \multirow{2}{*}{$\begin{array}{l}\text { Neurônios } \\
\text { Escondidos }\end{array}$} & \multicolumn{5}{|c|}{$\begin{array}{c}\text { Treinamento } \\
\text { MAPE }(\% \text { acertos })\end{array}$} & \multicolumn{5}{|c|}{$\begin{array}{c}\text { Validação } \\
\text { MAPE (\% acertos) }\end{array}$} & \multicolumn{2}{|c|}{$\begin{array}{c}\text { Média Final } \\
\text { MAPE ( } \% \text { acertos) }\end{array}$} \\
\hline & & $\mathrm{C} 1$ & $\mathrm{C} 2$ & $\mathrm{C} 3$ & $\mathrm{C} 4$ & C5 & $\mathrm{C} 1$ & $\mathrm{C} 2$ & $\mathrm{C} 3$ & $\mathrm{C} 4$ & C5 & Trein. & Val. \\
\hline MLP-261 & 5 & 99,9 & 99,3 & 99,9 & 99,3 & 99,9 & 99,9 & 99,2 & 99,7 & 99,3 & 99,9 & 99,7 & 99,6 \\
\hline MLP-262 & $5-5$ & 68,3 & 38,4 & 28,0 & 87,6 & 98,3 & 67,9 & 38,4 & 28,1 & 87,8 & 98,3 & 64,1 & 64,1 \\
\hline MLP-263 & $5-10$ & 99,2 & 92,0 & 99,4 & 96,9 & 85,2 & 99,3 & 91,6 & 99,2 & 97,1 & 85,5 & 94,5 & 94,6 \\
\hline MLP-264 & $5-15$ & 99,7 & 99,9 & 99,8 & 99,4 & 99,9 & 99,7 & 99,9 & 99,7 & 99,6 & 99,9 & 99,8 & 99,8 \\
\hline MLP-265 & $5-20$ & 49,4 & 82,2 & 93,1 & 77,0 & 79,3 & 50,2 & 82,6 & 92,7 & 77,4 & 79,4 & 76,2 & 76,4 \\
\hline MLP-266 & 10 & 99,4 & 99,9 & 99,9 & 99,0 & 99,9 & 99,3 & 99,9 & 99,7 & 99,3 & 99,8 & 99,6 & 99,6 \\
\hline MLP-267 & $10-5$ & 100,0 & 99,9 & 99,9 & 99,9 & 99,6 & 99,9 & 99,9 & 99,7 & 99,8 & 99,6 & 99,9 & 99,8 \\
\hline MLP-268 & $10-10$ & 81,2 & 71,8 & 53,4 & 76,6 & 81,6 & 81,4 & 71,3 & 53,9 & 76,4 & 81,6 & 72,9 & 72,9 \\
\hline MLP-269 & $10-15$ & 99,6 & 99,7 & 99,8 & 99,8 & 99,7 & 99,5 & 99,7 & 99,6 & 99,8 & 99,6 & 99,7 & 99,6 \\
\hline MLP-270 & $10-20$ & 98,7 & 99,3 & 99,3 & 99,3 & 72,9 & 98,7 & 99,2 & 99,1 & 99,3 & 73,3 & 93,9 & 93,9 \\
\hline MLP-271 & 15 & 99,2 & 99,5 & 99,7 & 99,7 & 97,9 & 99,3 & 99,6 & 99,5 & 99,8 & 97,6 & 99,2 & 99,2 \\
\hline MLP-272 & $15-5$ & 70,3 & 67,6 & 75,5 & 83,1 & 85,0 & 70,5 & 67,5 & 74,9 & 82,6 & 85,2 & 76,3 & 76,2 \\
\hline MLP-273 & $15-10$ & 99,6 & 99,8 & 99,7 & 99,7 & 99,4 & 99,6 & 99,8 & 99,6 & 99,8 & 99,3 & 99,7 & 99,6 \\
\hline MLP-274 & $15-15$ & 99,9 & 99,6 & 99,8 & 99,4 & 99,7 & 99,8 & 99,6 & 99,7 & 99,4 & 99,6 & 99,7 & 99,6 \\
\hline MLP-275 & $15-20$ & 94,3 & 85,9 & 85,9 & 85,5 & 85,6 & 94,2 & 85,6 & 85,7 & 85,0 & 85,9 & 87,4 & 87,3 \\
\hline MLP-276 & 20 & 99,2 & 99,7 & 99,0 & 99,8 & 99,4 & 99,2 & 99,7 & 98,8 & 99,8 & 99,3 & 99,5 & 99,4 \\
\hline MLP-277 & $20-5$ & 90,8 & 82,6 & 99,5 & 96,6 & 88,0 & 90,2 & 82,8 & 99,3 & 96,5 & 88,3 & 91,5 & 91,4 \\
\hline MLP-278 & $20-10$ & 82,1 & 99,5 & 81,9 & 99,8 & 82,2 & 81,6 & 99,6 & 81,6 & 99,9 & 81,6 & 89,1 & 88,9 \\
\hline MLP-279 & $20-15$ & 82,2 & 93,9 & 88,0 & 72,8 & 87,9 & 83,3 & 94,0 & 87,8 & 73,4 & 87,3 & 84,9 & 85,2 \\
\hline MLP-280 & $20-20$ & 99,4 & 99,8 & 99,8 & 98,7 & 99,8 & 99,3 & 99,8 & 99,6 & 98,9 & 99,7 & 99,5 & 99,4 \\
\hline
\end{tabular}

Tabela C.15: Resultados do Treinamento e validação das topologias especialistas candidatas (12 entradas e uma saída com esterçamento do veículo) para o quinto sistema neural (dados sem ruídos e com parede), usando o algoritmo Resilient Propagation.

\begin{tabular}{|c|c|c|c|c|c|c|c|c|c|c|c|c|c|}
\hline \multirow[t]{2}{*}{ Ref. } & \multirow{2}{*}{$\begin{array}{l}\text { Neurônios } \\
\text { Escondidos }\end{array}$} & \multicolumn{5}{|c|}{$\begin{array}{c}\text { Treinamento } \\
\text { MAPE }(\% \text { acertos })\end{array}$} & \multicolumn{5}{|c|}{$\begin{array}{c}\text { Validação } \\
\text { MAPE (\% acertos) }\end{array}$} & \multicolumn{2}{|c|}{$\begin{array}{c}\text { Média Final } \\
\text { MAPE (\% acertos) }\end{array}$} \\
\hline & & $\mathrm{C} 1$ & $\mathrm{C} 2$ & C3 & $\mathrm{C} 4$ & C5 & $\mathrm{C} 1$ & $\mathrm{C} 2$ & C3 & $\mathrm{C} 4$ & $\mathrm{C} 5$ & Trein. & Val. \\
\hline MLP-281 & 5 & 99,9 & 99,9 & 99,9 & 99,9 & 99,9 & 99,9 & 99,9 & 99,9 & 99,9 & 99,9 & 99,9 & 99,9 \\
\hline MLP-282 & $5-5$ & 99,9 & 99,9 & 99,9 & 99,8 & 99,9 & 99,9 & 99,9 & 99,9 & 99,7 & 99,9 & 99,9 & 99,9 \\
\hline MLP-283 & $5-10$ & 99,9 & 99,9 & 99,9 & 100,0 & 99,9 & 99,9 & 99,9 & 99,9 & 99,9 & 99,9 & 99,9 & 99,9 \\
\hline MLP-284 & $5-15$ & 99,9 & 99,9 & 99,9 & 99,9 & 99,9 & 99,9 & 99,9 & 99,9 & 99,9 & 99,9 & 99,9 & 99,9 \\
\hline MLP-285 & $5-20$ & 100,0 & 100,0 & 100,0 & 100,0 & 100,0 & 100,0 & 100,0 & 100,0 & 100,0 & 100,0 & 100,0 & 100,0 \\
\hline MLP-286 & 10 & 99,9 & 99,9 & 99,9 & 99,9 & 100,0 & 99,9 & 99,9 & 99,9 & 99,8 & 100,0 & 99,9 & 99,9 \\
\hline MLP-287 & $10-5$ & 99,9 & 99,9 & 99,9 & 99,9 & 99,9 & 99,9 & 99,9 & 99,9 & 99,9 & 99,9 & 99,9 & 99,9 \\
\hline MLP-288 & $10-10$ & 100,0 & 99,4 & 99,9 & 99,9 & 100,0 & 100,0 & 99,4 & 99,9 & 99,9 & 100,0 & 99,8 & 99,8 \\
\hline MLP-289 & $10-15$ & 100,0 & 100,0 & 100,0 & 100,0 & 100,0 & 100,0 & 100,0 & 100,0 & 100,0 & 100,0 & 100,0 & 100,0 \\
\hline MLP-290 & $10-20$ & 100,0 & 100,0 & 100,0 & 100,0 & 100,0 & 100,0 & 100,0 & 100,0 & 100,0 & 100,0 & 100,0 & 100,0 \\
\hline MLP-291 & 15 & 99,9 & 99,9 & 99,8 & 99,9 & 99,9 & 99,9 & 99,9 & 99,8 & 99,9 & 99,9 & 99,9 & 99,9 \\
\hline MLP-292 & $15-5$ & 99,9 & 99,9 & 100,0 & 99,8 & 99,9 & 99,9 & 99,9 & 100,0 & 99,8 & 99,9 & 99,9 & 99,9 \\
\hline MLP-293 & $15-10$ & 99,9 & 99,9 & 99,9 & 99,9 & 99,9 & 99,9 & 99,9 & 99,9 & 99,9 & 99,9 & 99,9 & 99,9 \\
\hline MLP-294 & $15-15$ & 100,0 & 100,0 & 99,9 & 99,9 & 100,0 & 100,0 & 100,0 & 99,9 & 99,9 & 100,0 & 99,9 & 99,9 \\
\hline MLP-295 & $15-20$ & 100,0 & 100,0 & 100,0 & 100,0 & 100,0 & 100,0 & 100,0 & 100,0 & 100,0 & 100,0 & 100,0 & 100,0 \\
\hline MLP-296 & 20 & 100,0 & 100,0 & 100,0 & 100,0 & 100,0 & 100,0 & 100,0 & 100,0 & 100,0 & 100,0 & 100,0 & 100,0 \\
\hline MLP-297 & $20-5$ & 99,9 & 99,9 & 99,9 & 99,9 & 99,9 & 99,9 & 99,9 & 99,9 & 99,9 & 99,9 & 99,9 & 99,9 \\
\hline MLP-298 & $20-10$ & 100,0 & 99,9 & 100,0 & 100,0 & 100,0 & 100,0 & 99,9 & 100,0 & 100,0 & 100,0 & 100,0 & 100,0 \\
\hline MLP-299 & $20-15$ & 100,0 & 100,0 & 100,0 & 100,0 & 100,0 & 100,0 & 100,0 & 100,0 & 100,0 & 100,0 & 100,0 & 100,0 \\
\hline MLP-300 & $20-20$ & 100,0 & 100,0 & 100,0 & 100,0 & 100,0 & 100,0 & 100,0 & 100,0 & 100,0 & 100,0 & 100,0 & 100,0 \\
\hline
\end{tabular}


Tabela C.16: Resultados do Treinamento e validação das topologias especialistas candidatas (12 entradas e uma saída com esterçamento do veículo) para o quinto sistema neural (dados sem ruídos e com parede), usando o algoritmo Levenberg-Marquardt.

\begin{tabular}{|c|c|c|c|c|c|c|c|c|c|c|c|c|c|}
\hline \multirow[t]{2}{*}{ Ref. } & \multirow{2}{*}{$\begin{array}{l}\text { Neurônios } \\
\text { Escondidos }\end{array}$} & \multicolumn{5}{|c|}{$\begin{array}{c}\text { Treinamento } \\
\text { MAPE (\% acertos) }\end{array}$} & \multicolumn{5}{|c|}{$\begin{array}{c}\text { Validação } \\
\text { MAPE (\% acertos) }\end{array}$} & \multicolumn{2}{|c|}{$\begin{array}{c}\text { Média Final } \\
\text { MAPE }(\% \text { acertos })\end{array}$} \\
\hline & & $\mathrm{C} 1$ & $\mathrm{C} 2$ & $\mathrm{C} 3$ & $\mathrm{C} 4$ & $\mathrm{C} 5$ & $\mathrm{C} 1$ & $\mathrm{C} 2$ & C3 & $\mathrm{C} 4$ & $\mathrm{C} 5$ & Trein. & Val. \\
\hline MLP-301 & 5 & 100,0 & 100,0 & 100,0 & 100,0 & 100,0 & 100,0 & 100,0 & 100,0 & 100,0 & 100,0 & 100,0 & 100,0 \\
\hline MLP-302 & $5-5$ & 100,0 & 100,0 & 100,0 & 100,0 & 100,0 & 100,0 & 100,0 & 100,0 & 100,0 & 100,0 & 100,0 & 100,0 \\
\hline MLP-303 & $5-10$ & 81,7 & 51,2 & 100,0 & 78,6 & 99,8 & 83,0 & 54,8 & 100,0 & 78,1 & 99,9 & 82,3 & 83,2 \\
\hline MLP-304 & $5-15$ & 100,0 & 100,0 & 100,0 & 100,0 & 100,0 & 100,0 & 100,0 & 100,0 & 100,0 & 100,0 & 100,0 & 100,0 \\
\hline MLP-305 & $5-20$ & 100,0 & 100,0 & 95,3 & 45,7 & 100,0 & 100,0 & 100,0 & 94,9 & 46,5 & 100,0 & 88,2 & 88,3 \\
\hline MLP-306 & 10 & 100,0 & 100,0 & 100,0 & 99,6 & 100,0 & 100,0 & 100,0 & 100,0 & 99,6 & 100,0 & 99,9 & 99,9 \\
\hline MLP-307 & $10-5$ & 100,0 & 100,0 & 100,0 & 100,0 & 100,0 & 100,0 & 100,0 & 100,0 & 100,0 & 100,0 & 100,0 & 100,0 \\
\hline MLP-308 & $10-10$ & 100,0 & 100,0 & 100,0 & 100,0 & 100,0 & 100,0 & 100,0 & 100,0 & 100,0 & 100,0 & 100,0 & 100,0 \\
\hline MLP-309 & $10-15$ & 97,5 & 98,1 & 97,6 & 97,6 & 94,2 & 97,2 & 98,3 & 97,4 & 96,5 & 95,8 & 97,0 & 97,0 \\
\hline MLP-310 & $10-20$ & 100,0 & 100,0 & 100,0 & 100,0 & 100,0 & 100,0 & 100,0 & 100,0 & 100,0 & 100,0 & 100,0 & 100,0 \\
\hline MLP-311 & 15 & 100,0 & 100,0 & 100,0 & 100,0 & 100,0 & 100,0 & 100,0 & 100,0 & 100,0 & 100,0 & 100,0 & 100,0 \\
\hline MLP-312 & $15-5$ & 100,0 & 100,0 & 100,0 & 100,0 & 100,0 & 100,0 & 100,0 & 100,0 & 100,0 & 100,0 & 100,0 & 100,0 \\
\hline MLP-313 & $15-10$ & 100,0 & 100,0 & 97,6 & 100,0 & 100,0 & 100,0 & 100,0 & 97,4 & 99,9 & 100,0 & 99,5 & 99,5 \\
\hline MLP-314 & $15-15$ & 100,0 & 100,0 & 100,0 & 100,0 & 100,0 & 100,0 & 100,0 & 100,0 & 100,0 & 100,0 & 100,0 & 100,0 \\
\hline MLP-315 & $15-20$ & 100,0 & 100,0 & 100,0 & 100,0 & 100,0 & 100,0 & 100,0 & 100,0 & 100,0 & 100,0 & 100,0 & 100,0 \\
\hline MLP-316 & 20 & 99,9 & 98,7 & 45,4 & 97,7 & 97,2 & 100,0 & 98,9 & 43,4 & 96,7 & 98,5 & 87,8 & 87,5 \\
\hline MLP-317 & $20-5$ & 45,8 & 98,8 & 45,7 & 98,6 & 67,2 & 47,5 & 99,0 & 43,9 & 98,0 & 66,4 & 71,2 & 71,0 \\
\hline MLP-318 & $20-10$ & 100,0 & 100,0 & 100,0 & 100,0 & 100,0 & 100,0 & 100,0 & 100,0 & 100,0 & 100,0 & 100,0 & 100,0 \\
\hline MLP-319 & $20-15$ & 100,0 & 100,0 & 100,0 & 100,0 & 100,0 & 100,0 & 100,0 & 100,0 & 100,0 & 100,0 & 100,0 & 100,0 \\
\hline MLP-320 & $20-20$ & 100,0 & 100,0 & 100,0 & 100,0 & 100,0 & 100,0 & 100,0 & 100,0 & 100,0 & 100,0 & 100,0 & 100,0 \\
\hline
\end{tabular}

Tabela C.17: Resultados do Treinamento e validação das topologias especialistas candidatas (12 entradas e uma saída com a velocidade do veículo) para o quinto sistema neural (dados sem ruídos e com parede), usando o algoritmo Resilient Propagation.

\begin{tabular}{|c|c|c|c|c|c|c|c|c|c|c|c|c|c|}
\hline \multirow[t]{2}{*}{ Ref. } & \multirow{2}{*}{$\begin{array}{l}\text { Neurônios } \\
\text { Escondidos }\end{array}$} & \multicolumn{5}{|c|}{$\begin{array}{c}\text { Treinamento } \\
\text { MAPE }(\% \text { acertos })\end{array}$} & \multicolumn{5}{|c|}{$\begin{array}{c}\text { Validação } \\
\text { MAPE (\% acertos) }\end{array}$} & \multicolumn{2}{|c|}{$\begin{array}{c}\text { Média Final } \\
\text { MAPE (\% acertos) }\end{array}$} \\
\hline & & $\mathrm{C} 1$ & $\mathrm{C} 2$ & $\mathrm{C} 3$ & $\mathrm{C} 4$ & C5 & $\mathrm{C} 1$ & $\mathrm{C} 2$ & $\mathrm{C} 3$ & $\mathrm{C} 4$ & C5 & Trein. & Val. \\
\hline MLP-321 & 5 & 96,4 & 96,6 & 96,7 & 96,6 & 96,8 & 96,7 & 96,4 & 96,6 & 96,8 & 96,8 & 96,6 & 96,6 \\
\hline MLP-322 & $5-5$ & 96,8 & 97,2 & 97,3 & 97,5 & 97,8 & 97,0 & 97,0 & 97,1 & 97,6 & 97,8 & 97,3 & 97,3 \\
\hline MLP-323 & $5-10$ & 94,6 & 96,5 & 97,0 & 98,1 & 96,9 & 94,7 & 96,4 & 96,9 & 98,1 & 96,9 & 96,6 & 96,6 \\
\hline MLP-324 & $5-15$ & 97,0 & 97,0 & 97,1 & 96,8 & 97,3 & 97,0 & 96,9 & 97,0 & 96,9 & 97,3 & 97,0 & 97,0 \\
\hline MLP-325 & $5-20$ & 95,8 & 95,9 & 95,5 & 94,4 & 96,9 & 95,8 & 95,7 & 95,3 & 94,5 & 96,8 & 95,7 & 95,6 \\
\hline MLP-326 & 10 & 96,9 & 97,0 & 96,7 & 95,3 & 97,0 & 97,1 & 96,8 & 96,4 & 95,5 & 96,9 & 96,6 & 96,6 \\
\hline MLP-327 & $10-5$ & 97,0 & 97,4 & 97,4 & 95,9 & 97,6 & 97,1 & 97,3 & 97,2 & 96,1 & 97,6 & 97,1 & 97,1 \\
\hline MLP-328 & $10-10$ & 96,9 & 97,2 & 97,1 & 97,5 & 98,1 & 96,9 & 97,0 & 97,0 & 97,5 & 98,1 & 97,3 & 97,3 \\
\hline MLP-329 & $10-15$ & 96,7 & 97,1 & 96,8 & 97,6 & 97,2 & 96,9 & 97,0 & 96,8 & 97,7 & 97,2 & 97,1 & 97,1 \\
\hline MLP-330 & $10-20$ & 96,9 & 97,3 & 96,3 & 98,0 & 96,8 & 97,1 & 97,1 & 96,0 & 98,0 & 96,7 & 97,0 & 97,0 \\
\hline MLP-331 & 15 & 97,1 & 97,0 & 96,9 & 97,1 & 97,1 & 97,3 & 96,9 & 96,6 & 97,3 & 97,1 & 97,0 & 97,0 \\
\hline MLP-332 & $15-5$ & 97,0 & 96,6 & 97,3 & 98,4 & 97,7 & 97,2 & 96,4 & 97,1 & 98,4 & 97,7 & 97,4 & 97,4 \\
\hline MLP-333 & $15-10$ & 97,7 & 96,4 & 97,2 & 97,2 & 97,9 & 97,8 & 96,2 & 97,1 & 97,1 & 97,9 & 97,3 & 97,2 \\
\hline MLP-334 & $15-15$ & 97,1 & 97,5 & 97,6 & 97,8 & 97,6 & 97,3 & 97,4 & 97,4 & 97,9 & 97,6 & 97,5 & 97,5 \\
\hline MLP-335 & $15-20$ & 97,3 & 97,1 & 97,2 & 95,6 & 97,8 & 97,4 & 97,0 & 97,0 & 95,8 & 97,8 & 97,0 & 97,0 \\
\hline MLP-336 & 20 & 97,2 & 97,2 & 97,0 & 96,1 & 97,3 & 97,4 & 97,1 & 96,7 & 96,4 & 97,2 & 97,0 & 97,0 \\
\hline MLP-337 & $20-5$ & 96,9 & 97,7 & 96,6 & 97,7 & 97,2 & 97,0 & 97,6 & 96,5 & 97,9 & 97,2 & 97,2 & 97,2 \\
\hline MLP-338 & $20-10$ & 96,2 & 96,9 & 96,9 & 97,5 & 98,5 & 96,3 & 96,7 & 96,8 & 97,7 & 98,5 & 97,2 & 97,2 \\
\hline MLP-339 & $20-15$ & 97,1 & 97,7 & 97,7 & 98,5 & 96,9 & 97,1 & 97,6 & 97,5 & 98,6 & 96,8 & 97,6 & 97,5 \\
\hline MLP-340 & $20-20$ & 96,4 & 96,5 & 97,4 & 98,0 & 97,7 & 96,6 & 96,4 & 97,2 & 98,1 & 97,7 & 97,2 & 97,2 \\
\hline
\end{tabular}


Tabela C.18: Resultados do Treinamento e validação das topologias especialistas candidatas (12 entradas e uma saída com a velocidade do veículo) para o quinto sistema neural (dados sem ruídos e com parede), usando o algoritmo Levenberg-Marquardt.

\begin{tabular}{|c|c|c|c|c|c|c|c|c|c|c|c|c|c|}
\hline \multirow[t]{2}{*}{ Ref. } & \multirow{2}{*}{$\begin{array}{l}\text { Neurônios } \\
\text { Escondidos }\end{array}$} & \multicolumn{5}{|c|}{$\begin{array}{c}\text { Treinamento } \\
\text { MAPE (\% acertos) }\end{array}$} & \multicolumn{5}{|c|}{$\begin{array}{c}\text { Validação } \\
\text { MAPE (\% acertos) }\end{array}$} & \multicolumn{2}{|c|}{$\begin{array}{c}\text { Média Final } \\
\text { MAPE (\% acertos) }\end{array}$} \\
\hline & & $\mathrm{C} 1$ & $\mathrm{C} 2$ & $\mathrm{C} 3$ & $\mathrm{C} 4$ & $\mathrm{C} 5$ & $\mathrm{C} 1$ & $\mathrm{C} 2$ & $\mathrm{C} 3$ & $\mathrm{C} 4$ & $\mathrm{C} 5$ & Trein. & Val. \\
\hline MLP-341 & 5 & 98,6 & 97,8 & 98,0 & 98,3 & 98,7 & 98,5 & 97,7 & 98,0 & 98,4 & 98,7 & 98,3 & 98,3 \\
\hline MLP-342 & $5-5$ & 98,6 & 98,2 & 98,5 & 98,9 & 98,7 & 98,5 & 98,1 & 98,4 & 98,9 & 98,7 & 98,6 & 98,5 \\
\hline MLP-343 & $5-10$ & 98,8 & 98,5 & 98,7 & 99,1 & 98,8 & 98,8 & 98,4 & 98,5 & 99,1 & 98,7 & 98,8 & 98,7 \\
\hline MLP-344 & $5-15$ & 99,0 & 98,3 & 98,7 & 99,3 & 99,1 & 99,0 & 98,2 & 98,6 & 99,3 & 99,1 & 98,9 & 98,8 \\
\hline MLP-345 & $5-20$ & 98,8 & 98,3 & 97,7 & 99,4 & 99,4 & 98,7 & 98,1 & 97,6 & 99,4 & 99,4 & 98,7 & 98,6 \\
\hline MLP-346 & 10 & 98,9 & 98,7 & 98,4 & 99,3 & 99,3 & 98,9 & 98,6 & 98,4 & 99,3 & 99,2 & 98,9 & 98,9 \\
\hline MLP-347 & $10-5$ & 99,1 & 98,5 & 98,7 & 99,4 & 98,8 & 99,1 & 98,3 & 98,6 & 99,4 & 98,8 & 98,9 & 98,8 \\
\hline MLP-348 & $10-10$ & 98,9 & 98,8 & 98,5 & 98,8 & 99,4 & 98,8 & 98,6 & 98,4 & 98,9 & 99,4 & 98,9 & 98,8 \\
\hline MLP-349 & $10-15$ & 98,8 & 98,7 & 98,8 & 99,4 & 99,7 & 98,7 & 98,5 & 98,7 & 99,4 & 99,6 & 99,1 & 99,0 \\
\hline MLP-350 & $10-20$ & 98,9 & 98,6 & 98,7 & 99,7 & 99,5 & 98,8 & 98,5 & 98,5 & 99,7 & 99,5 & 99,1 & 99,0 \\
\hline MLP-351 & 15 & 99,2 & 98,6 & 98,5 & 99,5 & 99,2 & 99,1 & 98,4 & 98,4 & 99,5 & 99,2 & 99,0 & 98,9 \\
\hline MLP-352 & $15-5$ & 98,8 & 98,5 & 98,4 & 99,4 & 99,2 & 98,7 & 98,4 & 98,3 & 99,4 & 99,2 & 98,9 & 98,8 \\
\hline MLP-353 & $15-10$ & 98,7 & 98,0 & 98,7 & 99,4 & 99,4 & 98,7 & 97,9 & 98,5 & 99,4 & 99,4 & 98,8 & 98,8 \\
\hline MLP-354 & $15-15$ & 98,9 & 98,3 & 98,6 & 99,4 & 98,5 & 98,8 & 98,2 & 98,5 & 99,4 & 98,4 & 98,7 & 98,7 \\
\hline MLP-355 & $15-20$ & 90,4 & 91,9 & 92,0 & 96,8 & 96,4 & 90,2 & 91,5 & 92,0 & 96,7 & 96,1 & 93,5 & 93,3 \\
\hline MLP-356 & 20 & 98,8 & 98,5 & 98,6 & 99,5 & 99,5 & 98,8 & 98,4 & 98,5 & 99,5 & 99,5 & 99,0 & 98,9 \\
\hline MLP-357 & $20-5$ & 98,0 & 98,5 & 98,9 & 99,7 & 99,5 & 98,0 & 98,4 & 98,7 & 99,7 & 99,5 & 98,9 & 98,9 \\
\hline MLP-358 & $20-10$ & 98,8 & 98,4 & 98,7 & 99,6 & 95,8 & 98,7 & 98,2 & 98,5 & 99,6 & 96,0 & 98,2 & 98,2 \\
\hline MLP-359 & $20-15$ & 98,0 & 98,1 & 97,6 & 99,4 & 99,8 & 97,9 & 97,8 & 97,5 & 99,4 & 99,7 & 98,6 & 98,5 \\
\hline MLP-360 & $20-20$ & 98,6 & 98,5 & 98,6 & 99,7 & 99,0 & 98,5 & 98,4 & 98,4 & 99,7 & 99,0 & 98,9 & 98,8 \\
\hline
\end{tabular}

Tabela C.19: Resultados do Treinamento e validação das topologias especialistas candidatas (12 entradas e três saídas com os próximos estados da manobra) para o quinto sistema neural (dados sem ruídos e com parede), usando o algoritmo Resilient Propagation.

\begin{tabular}{|c|c|c|c|c|c|c|c|c|c|c|c|c|c|}
\hline \multirow[t]{2}{*}{ Ref. } & \multirow{2}{*}{$\begin{array}{l}\text { Neurônios } \\
\text { Escondidos }\end{array}$} & \multicolumn{5}{|c|}{$\begin{array}{c}\text { Treinamento } \\
\text { MAPE (\% acertos) }\end{array}$} & \multicolumn{5}{|c|}{$\begin{array}{c}\text { Validação } \\
\text { MAPE (\% acertos) }\end{array}$} & \multicolumn{2}{|c|}{$\begin{array}{c}\text { Média Final } \\
\text { MAPE (\% acertos) }\end{array}$} \\
\hline & & $\mathrm{C} 1$ & $\mathrm{C} 2$ & $\mathrm{C} 3$ & $\mathrm{C} 4$ & $\mathrm{C} 5$ & $\mathrm{C} 1$ & $\mathrm{C} 2$ & $\mathrm{C} 3$ & $\mathrm{C} 4$ & $\mathrm{C} 5$ & Trein. & Val. \\
\hline MLP-361 & 5 & 99,1 & 98,3 & 98,7 & 98,6 & 98,7 & 99,0 & 98,4 & 98,7 & 98,5 & 98,7 & 98,7 & 98,7 \\
\hline MLP-362 & $5-5$ & 99,4 & 98,8 & 98,5 & 98,8 & 98,7 & 99,3 & 98,8 & 98,6 & 98,4 & 98,9 & 98,8 & 98,8 \\
\hline MLP-363 & $5-10$ & 98,9 & 99,1 & 98,7 & 99,0 & 99,0 & 98,8 & 99,2 & 98,7 & 98,9 & 99,1 & 98,9 & 98,9 \\
\hline MLP-364 & $5-15$ & 99,3 & 99,1 & 99,0 & 98,9 & 99,3 & 99,1 & 99,2 & 99,2 & 98,8 & 99,4 & 99,1 & 99,1 \\
\hline MLP-365 & $5-20$ & 99,1 & 99,2 & 99,0 & 99,2 & 99,2 & 99,0 & 99,4 & 99,0 & 99,1 & 99,2 & 99,1 & 99,1 \\
\hline MLP-366 & 10 & 99,1 & 98,9 & 99,0 & 99,0 & 99,0 & 99,0 & 99,0 & 99,0 & 98,9 & 99,1 & 99,0 & 99,0 \\
\hline MLP-367 & $10-5$ & 99,1 & 99,2 & 98,9 & 98,7 & 99,1 & 99,1 & 99,3 & 98,9 & 98,6 & 99,2 & 99,0 & 99,0 \\
\hline MLP-368 & $10-10$ & 99,4 & 99,0 & 98,9 & 98,4 & 99,2 & 99,3 & 99,1 & 99,0 & 98,3 & 99,2 & 99,0 & 99,0 \\
\hline MLP-369 & $10-15$ & 99,5 & 98,8 & 99,2 & 99,1 & 99,0 & 99,5 & 98,9 & 99,1 & 98,9 & 99,1 & 99,1 & 99,1 \\
\hline MLP-370 & $10-20$ & 99,3 & 98,6 & 98,9 & 99,2 & 99,0 & 99,3 & 98,6 & 98,9 & 99,0 & 99,0 & 99,0 & 99,0 \\
\hline MLP-371 & 15 & 99,3 & 99,0 & 99,0 & 99,1 & 99,3 & 99,2 & 99,1 & 99,1 & 99,0 & 99,3 & 99,2 & 99,1 \\
\hline MLP-372 & $15-5$ & 99,3 & 98,6 & 98,7 & 99,0 & 99,2 & 99,3 & 98,8 & 98,8 & 98,9 & 99,2 & 99,0 & 99,0 \\
\hline MLP-373 & $15-10$ & 99,4 & 99,1 & 98,9 & 98,9 & 99,4 & 99,3 & 99,2 & 98,8 & 98,8 & 99,4 & 99,1 & 99,1 \\
\hline MLP-374 & $15-15$ & 99,2 & 99,3 & 99,2 & 99,3 & 99,3 & 99,1 & 99,4 & 99,2 & 99,1 & 99,2 & 99,2 & 99,2 \\
\hline MLP-375 & $15-20$ & 99,5 & 97,9 & 98,9 & 98,9 & 98,9 & 99,4 & 98,0 & 98,9 & 98,7 & 98,9 & 98,8 & 98,8 \\
\hline MLP-376 & 20 & 99,2 & 98,9 & 99,2 & 99,3 & 98,9 & 99,1 & 99,1 & 99,2 & 99,2 & 99,0 & 99,1 & 99,1 \\
\hline MLP-377 & $20-5$ & 98,8 & 98,8 & 98,4 & 98,8 & 99,4 & 98,8 & 98,8 & 98,5 & 98,5 & 99,4 & 98,8 & 98,8 \\
\hline MLP-378 & $20-10$ & 98,9 & 99,2 & 99,2 & 98,5 & 98,6 & 98,7 & 99,3 & 99,1 & 98,4 & 98,7 & 98,9 & 98,8 \\
\hline MLP-379 & $20-15$ & 99,5 & 99,0 & 99,2 & 99,5 & 99,2 & 99,4 & 99,1 & 99,2 & 99,4 & 99,2 & 99,3 & 99,2 \\
\hline MLP-380 & $20-20$ & 99,4 & 98,7 & 99,0 & 99,1 & 99,0 & 99,4 & 98,7 & 99,0 & 98,7 & 99,2 & 99,0 & 99,0 \\
\hline
\end{tabular}


Tabela C.20: Resultados do Treinamento e validação das topologias especialistas candidatas (12 entradas e três saídas com os próximos estados da manobra) para o quinto sistema neural (dados sem ruídos e com parede), usando o algoritmo Levenberd-Marquardt.

\begin{tabular}{|c|c|c|c|c|c|c|c|c|c|c|c|c|c|}
\hline \multirow[t]{2}{*}{ Ref. } & \multirow{2}{*}{$\begin{array}{l}\text { Neurônios } \\
\text { Escondidos }\end{array}$} & \multicolumn{5}{|c|}{$\begin{array}{c}\text { Treinamento } \\
\text { MAPE (\% acertos) }\end{array}$} & \multicolumn{5}{|c|}{$\begin{array}{c}\text { Validação } \\
\text { MAPE (\% acertos) }\end{array}$} & \multicolumn{2}{|c|}{$\begin{array}{c}\text { Média Final } \\
\text { MAPE (\% acertos) }\end{array}$} \\
\hline & & $\mathrm{C} 1$ & $\mathrm{C} 2$ & C3 & $\mathrm{C} 4$ & $\mathrm{C} 5$ & $\mathrm{C} 1$ & $\mathrm{C} 2$ & $\mathrm{C} 3$ & $\mathrm{C} 4$ & $\mathrm{C} 5$ & Trein. & Val. \\
\hline MLP-381 & 5 & 99,9 & 99,9 & 99,9 & 100,0 & 100,0 & 99,9 & 99,8 & 99,9 & 99,9 & 99,9 & 99,9 & 99,9 \\
\hline MLP-382 & $5-5$ & 80,1 & 67,4 & 56,5 & 79,7 & 81,9 & 80,5 & 67,1 & 57,3 & 80,2 & 82,4 & 73,1 & 73,5 \\
\hline MLP-383 & $5-10$ & 99,7 & 99,6 & 99,2 & 99,5 & 99,3 & 99,7 & 99,5 & 99,1 & 99,2 & 99,4 & 99,5 & 99,4 \\
\hline MLP-384 & $5-15$ & 92,8 & 85,7 & 96,9 & 99,8 & 99,2 & 92,1 & 84,3 & 96,9 & 99,6 & 99,3 & 94,9 & 94,5 \\
\hline MLP-385 & $5-20$ & 98,5 & 49,4 & 80,5 & 99,0 & 99,1 & 98,3 & 47,4 & 80,0 & 98,8 & 99,2 & 85,3 & 84,7 \\
\hline MLP-386 & 10 & 99,3 & 94,2 & 62,9 & 72,4 & 46,4 & 99,3 & 93,8 & 63,0 & 72,1 & 46,2 & 75,0 & 74,9 \\
\hline MLP-387 & $10-5$ & 36,3 & 58,3 & 54,0 & 55,5 & 65,6 & 36,9 & 58,3 & 54,3 & 54,3 & 66,1 & 53,9 & 54,0 \\
\hline MLP-388 & $10-10$ & 99,9 & 99,9 & 99,9 & 99,9 & 99,9 & 99,8 & 99,9 & 99,8 & 99,8 & 99,8 & 99,9 & 99,8 \\
\hline MLP-389 & $10-15$ & 74,6 & 68,5 & 70,6 & 79,2 & 73,5 & 74,5 & 68,5 & 71,0 & 79,3 & 72,4 & 73,3 & 73,1 \\
\hline MLP-390 & $10-20$ & 99,8 & 99,6 & 99,9 & 85,8 & 82,0 & 99,7 & 99,6 & 99,8 & 86,3 & 81,4 & 93,4 & 93,4 \\
\hline MLP-391 & 15 & 99,0 & 99,2 & 99,5 & 99,1 & 98,4 & 98,9 & 99,1 & 99,6 & 98,8 & 98,7 & 99,0 & 99,0 \\
\hline MLP-392 & $15-5$ & 99,7 & 39,5 & 67,6 & 76,6 & 81,2 & 99,6 & 38,9 & 67,7 & 75,5 & 80,9 & 72,9 & 72,5 \\
\hline MLP-393 & $15-10$ & 78,4 & 80,2 & 93,4 & 85,0 & 92,2 & 77,5 & 80,1 & 92,8 & 84,8 & 92,3 & 85,8 & 85,5 \\
\hline MLP-394 & $15-15$ & 99,7 & 99,8 & 99,9 & 99,8 & 99,8 & 99,7 & 99,8 & 99,8 & 99,7 & 99,7 & 99,8 & 99,7 \\
\hline MLP-395 & $15-20$ & 99,6 & 99,9 & 99,7 & 99,6 & 99,6 & 99,5 & 99,8 & 99,6 & 99,4 & 99,5 & 99,7 & 99,6 \\
\hline MLP-396 & 20 & 99,3 & 86,3 & 99,3 & 99,4 & 99,9 & 99,3 & 86,3 & 99,3 & 99,4 & 99,8 & 96,8 & 96,8 \\
\hline MLP-397 & $20-5$ & 63,0 & 68,7 & 63,0 & 81,1 & 63,1 & 63,4 & 68,3 & 63,3 & 81,6 & 62,3 & 67,8 & 67,8 \\
\hline MLP-398 & $20-10$ & 99,4 & 99,3 & 99,4 & 99,9 & 99,4 & 99,4 & 99,3 & 99,4 & 99,8 & 99,4 & 99,5 & 99,5 \\
\hline MLP-399 & $20-15$ & 99,2 & 99,3 & 99,3 & 99,4 & 99,6 & 99,2 & 99,2 & 99,3 & 99,1 & 99,6 & 99,4 & 99,3 \\
\hline MLP-400 & $20-20$ & 99,3 & 99,6 & 99,6 & 99,4 & 99,7 & 99,0 & 99,6 & 99,5 & 99,3 & 99,4 & 99,5 & 99,4 \\
\hline
\end{tabular}

Tabela C.21: Resultado do treinamento e validação das topologias especialistas candidatas (12 entradas e uma saída com o esterçamento do veículo) para o sétimo sistema neural (dados com ruídos e sem parede), usando o algoritmo Resilient Propagation.

\begin{tabular}{|c|c|c|c|c|c|c|c|c|c|c|c|c|c|}
\hline \multirow[t]{2}{*}{ Ref. } & \multirow{2}{*}{$\begin{array}{l}\text { Neurônios } \\
\text { Escondidos }\end{array}$} & \multicolumn{5}{|c|}{$\begin{array}{c}\text { Treinamento } \\
\text { MAPE (\% acertos) }\end{array}$} & \multicolumn{5}{|c|}{$\begin{array}{c}\text { Validação } \\
\text { MAPE (\% acertos) }\end{array}$} & \multicolumn{2}{|c|}{$\begin{array}{c}\text { Média Final } \\
\text { MAPE }(\% \text { acertos })\end{array}$} \\
\hline & & C1 & $\mathrm{C} 2$ & C3 & $\mathrm{C} 4$ & C5 & $\mathrm{C} 1$ & $\mathrm{C} 2$ & C3 & $\mathrm{C} 4$ & $\mathrm{C} 5$ & Trein. & Val. \\
\hline MLP-401 & 5 & 99,9 & 99,8 & 99,9 & 99,8 & 99,8 & 99,9 & 99,8 & 99,9 & 99,8 & 99,9 & 99,9 & 99,9 \\
\hline MLP-402 & $5-5$ & 99,8 & 99,9 & 99,9 & 100,0 & 99,9 & 99,8 & 99,9 & 99,9 & 100,0 & 99,9 & 99,9 & 99,9 \\
\hline MLP-403 & $5-10$ & 100,0 & 99,9 & 100,0 & 99,9 & 99,9 & 100,0 & 99,9 & 99,9 & 99,9 & 99,9 & 99,9 & 99,9 \\
\hline MLP-404 & $5-15$ & 99,9 & 99,9 & 100,0 & 99,9 & 99,9 & 99,9 & 99,9 & 99,9 & 99,9 & 99,9 & 99,9 & 99,9 \\
\hline MLP-405 & $5-20$ & 99,9 & 99,8 & 99,8 & 99,9 & 99,9 & 99,9 & 99,8 & 99,8 & 99,9 & 99,9 & 99,9 & 99,9 \\
\hline MLP-406 & 10 & 99,9 & 99,8 & 99,9 & 99,9 & 99,9 & 99,9 & 99,8 & 99,9 & 99,9 & 99,9 & 99,9 & 99,9 \\
\hline MLP-407 & $10-5$ & 99,8 & 99,9 & 99,7 & 99,9 & 99,8 & 99,7 & 99,9 & 99,7 & 99,9 & 99,8 & 99,8 & 99,8 \\
\hline MLP-408 & $10-10$ & 99,9 & 99,9 & 99,9 & 99,9 & 99,9 & 99,9 & 99,9 & 99,8 & 99,9 & 99,9 & 99,9 & 99,9 \\
\hline MLP-409 & $10-15$ & 99,9 & 100,0 & 99,9 & 99,9 & 99,9 & 99,9 & 100,0 & 99,9 & 100,0 & 99,9 & 99,9 & 99,9 \\
\hline MLP-410 & $10-20$ & 100,0 & 100,0 & 100,0 & 100,0 & 99,9 & 100,0 & 100,0 & 100,0 & 100,0 & 99,9 & 100,0 & 100,0 \\
\hline MLP-411 & 15 & 99,8 & 99,9 & 99,9 & 99,8 & 99,9 & 99,8 & 99,9 & 99,9 & 99,9 & 99,9 & 99,9 & 99,9 \\
\hline MLP-412 & $15-5$ & 99,9 & 99,9 & 99,9 & 99,9 & 99,9 & 99,9 & 99,9 & 99,9 & 99,9 & 99,9 & 99,9 & 99,9 \\
\hline MLP-413 & $15-10$ & 99,9 & 99,9 & 99,9 & 99,9 & 99,9 & 99,9 & 99,9 & 99,8 & 99,9 & 99,9 & 99,9 & 99,9 \\
\hline MLP-414 & $15-15$ & 100,0 & 100,0 & 100,0 & 100,0 & 100,0 & 100,0 & 100,0 & 100,0 & 100,0 & 100,0 & 100,0 & 100,0 \\
\hline MLP-415 & $15-20$ & 100,0 & 100,0 & 100,0 & 100,0 & 100,0 & 100,0 & 100,0 & 100,0 & 100,0 & 100,0 & 100,0 & 100,0 \\
\hline MLP-416 & 20 & 99,9 & 99,9 & 99,9 & 99,9 & 99,9 & 99,9 & 99,9 & 99,9 & 99,9 & 99,9 & 99,9 & 99,9 \\
\hline MLP-417 & $20-5$ & 99,9 & 99,8 & 99,8 & 99,8 & 99,9 & 99,9 & 99,8 & 99,8 & 99,9 & 99,9 & 99,9 & 99,9 \\
\hline MLP-418 & $20-10$ & 99,9 & 99,9 & 99,9 & 99,9 & 99,9 & 99,9 & 99,9 & 99,9 & 99,9 & 99,9 & 99,9 & 99,9 \\
\hline MLP-419 & $20-15$ & 100,0 & 99,6 & 100,0 & 99,9 & 99,9 & 100,0 & 99,6 & 100,0 & 100,0 & 99,9 & 99,9 & 99,9 \\
\hline MLP-420 & $20-20$ & 99,9 & 100,0 & 100,0 & 99,9 & 99,9 & 99,9 & 100,0 & 100,0 & 99,9 & 99,9 & 99,9 & 99,9 \\
\hline
\end{tabular}


Tabela C.22: Resultado do treinamento e validação das topologias especialistas candidatas (12 entradas e uma saída com o esterçamento do veículo) para o sétimo sistema neural (dados com ruídos e sem parede), usando o algoritmo Levenberg-Marquardt.

\begin{tabular}{|c|c|c|c|c|c|c|c|c|c|c|c|c|c|}
\hline \multirow[t]{2}{*}{ Ref. } & \multirow{2}{*}{$\begin{array}{l}\text { Neurônios } \\
\text { Escondidos }\end{array}$} & \multicolumn{5}{|c|}{$\begin{array}{c}\text { Treinamento } \\
\text { MAPE }(\% \text { acertos })\end{array}$} & \multicolumn{5}{|c|}{$\begin{array}{c}\text { Validação } \\
\text { MAPE (\% acertos) }\end{array}$} & \multicolumn{2}{|c|}{$\begin{array}{c}\text { Média Final } \\
\text { MAPE ( } \% \text { acertos) }\end{array}$} \\
\hline & & $\mathrm{C} 1$ & $\mathrm{C} 2$ & $\mathrm{C} 3$ & $\mathrm{C} 4$ & $\mathrm{C} 5$ & $\mathrm{C} 1$ & $\mathrm{C} 2$ & C3 & $\mathrm{C} 4$ & C5 & Trein. & Val. \\
\hline MLP-421 & 5 & 100,0 & 100,0 & 100,0 & 100,0 & 100,0 & 100,0 & 100,0 & 100,0 & 100,0 & 100,0 & 100,0 & 100,0 \\
\hline MLP-422 & $5-5$ & 100,0 & 100,0 & 99,8 & 98,7 & 100,0 & 100,0 & 100,0 & 99,4 & 99,3 & 100,0 & 99,7 & 99,7 \\
\hline MLP-423 & $5-10$ & 97,7 & 65,9 & 75,1 & 98,7 & 97,1 & 97,1 & 65,8 & 77,3 & 99,3 & 97,5 & 86,9 & 87,4 \\
\hline MLP-424 & $5-15$ & 100,0 & 100,0 & 83,1 & 99,8 & 100,0 & 100,0 & 100,0 & 84,9 & 99,7 & 100,0 & 96,6 & 96,9 \\
\hline MLP-425 & $5-20$ & 98,9 & 99,3 & 82,9 & 88,9 & 100,0 & 98,6 & 99,2 & 83,5 & 89,4 & 100,0 & 94,0 & 94,1 \\
\hline MLP-426 & 10 & 41,9 & 97,7 & 100,0 & 100,0 & 27,5 & 42,9 & 97,5 & 100,0 & 100,0 & 31,6 & 73,4 & 74,4 \\
\hline MLP-427 & $10-5$ & 100,0 & 100,0 & 100,0 & 100,0 & 100,0 & 100,0 & 100,0 & 100,0 & 100,0 & 100,0 & 100,0 & 100,0 \\
\hline MLP-428 & $10-10$ & 100,0 & 97,7 & 100,0 & 100,0 & 100,0 & 100,0 & 97,5 & 100,0 & 100,0 & 100,0 & 99,5 & 99,5 \\
\hline MLP-429 & $10-15$ & 100,0 & 100,0 & 100,0 & 100,0 & 100,0 & 100,0 & 100,0 & 100,0 & 100,0 & 100,0 & 100,0 & 100,0 \\
\hline MLP-430 & $10-20$ & 100,0 & 100,0 & 100,0 & 100,0 & 100,0 & 100,0 & 100,0 & 100,0 & 100,0 & 100,0 & 100,0 & 100,0 \\
\hline MLP-431 & 15 & 100,0 & 100,0 & 100,0 & 100,0 & 100,0 & 100,0 & 100,0 & 100,0 & 100,0 & 100,0 & 100,0 & 100,0 \\
\hline MLP-432 & $15-5$ & 100,0 & 100,0 & 100,0 & 100,0 & 100,0 & 100,0 & 100,0 & 100,0 & 100,0 & 100,0 & 100,0 & 100,0 \\
\hline MLP-433 & $15-10$ & 100,0 & 100,0 & 100,0 & 100,0 & 100,0 & 100,0 & 100,0 & 100,0 & 100,0 & 100,0 & 100,0 & 100,0 \\
\hline MLP-434 & $15-15$ & 99,9 & 100,0 & 100,0 & 100,0 & 100,0 & 99,9 & 100,0 & 100,0 & 100,0 & 100,0 & 100,0 & 100,0 \\
\hline MLP-435 & $15-20$ & 98,9 & 98,8 & 98,8 & 98,5 & 98,7 & 98,6 & 98,7 & 98,4 & 99,0 & 99,0 & 98,7 & 98,7 \\
\hline MLP-436 & 20 & 100,0 & 100,0 & 100,0 & 100,0 & 100,0 & 100,0 & 100,0 & 100,0 & 100,0 & 100,0 & 100,0 & 100,0 \\
\hline MLP-437 & $20-5$ & 100,0 & 100,0 & 100,0 & 97,4 & 100,0 & 100,0 & 100,0 & 100,0 & 98,6 & 100,0 & 99,5 & 99,7 \\
\hline MLP-438 & $20-10$ & 100,0 & 100,0 & 100,0 & 100,0 & 100,0 & 100,0 & 100,0 & 100,0 & 100,0 & 100,0 & 100,0 & 100,0 \\
\hline MLP-439 & $20-15$ & 100,0 & 100,0 & 100,0 & 100,0 & 100,0 & 100,0 & 100,0 & 100,0 & 100,0 & 100,0 & 100,0 & 100,0 \\
\hline MLP-440 & $20-20$ & 93,5 & 89,2 & 100,0 & 97,2 & 100,0 & 94,0 & 88,3 & 100,0 & 98,6 & 100,0 & 96,0 & 96,2 \\
\hline
\end{tabular}

Tabela C.23: Resultado do treinamento e validação das topologias especialistas candidatas (12 entradas e uma saída com a velocidade do veículo) para o sétimo sistema neural (dados com ruídos e sem parede), usando o algoritmo Resilient Propagation.

\begin{tabular}{|c|c|c|c|c|c|c|c|c|c|c|c|c|c|}
\hline \multirow[t]{2}{*}{ Ref. } & \multirow{2}{*}{$\begin{array}{l}\text { Neurônios } \\
\text { Escondidos }\end{array}$} & \multicolumn{5}{|c|}{$\begin{array}{c}\text { Treinamento } \\
\text { MAPE (\% acertos) }\end{array}$} & \multicolumn{5}{|c|}{$\begin{array}{c}\text { Validação } \\
\text { MAPE (\% acertos) }\end{array}$} & \multicolumn{2}{|c|}{$\begin{array}{c}\text { Média Final } \\
\text { MAPE ( } \% \text { acertos })\end{array}$} \\
\hline & & $\mathrm{C} 1$ & $\mathrm{C} 2$ & $\mathrm{C} 3$ & $\mathrm{C} 4$ & $\mathrm{C} 5$ & $\mathrm{C} 1$ & $\mathrm{C} 2$ & C3 & $\mathrm{C} 4$ & $\mathrm{C} 5$ & Trein. & Val. \\
\hline MLP-441 & 5 & 95,6 & 95,0 & 95,2 & 95,4 & 95,0 & 95,8 & 95,3 & 95,2 & 94,9 & 95,1 & 95,3 & 95,2 \\
\hline MLP-442 & $5-5$ & 94,3 & 95,0 & 96,0 & 95,7 & 95,2 & 94,4 & 95,3 & 96,1 & 95,3 & 95,2 & 95,2 & 95,2 \\
\hline MLP-443 & $5-10$ & 94,8 & 95,2 & 95,2 & 95,3 & 95,3 & 94,9 & 95,6 & 95,2 & 94,9 & 95,3 & 95,2 & 95,2 \\
\hline MLP-444 & $5-15$ & 95,2 & 95,5 & 95,5 & 95,5 & 96,0 & 95,3 & 95,8 & 95,5 & 95,1 & 96,1 & 95,5 & 95,5 \\
\hline MLP-445 & $5-20$ & 95,0 & 95,6 & 95,5 & 95,9 & 95,7 & 95,1 & 95,9 & 95,5 & 95,4 & 95,8 & 95,5 & 95,5 \\
\hline MLP-446 & 10 & 95,6 & 95,4 & 95,9 & 95,7 & 95,6 & 95,6 & 95,6 & 95,9 & 95,3 & 95,7 & 95,6 & 95,6 \\
\hline MLP-447 & $10-5$ & 95,6 & 95,4 & 96,3 & 95,6 & 96,4 & 95,6 & 95,7 & 96,2 & 95,2 & 96,5 & 95,9 & 95,9 \\
\hline MLP-448 & $10-10$ & 95,1 & 95,6 & 95,6 & 95,5 & 96,0 & 95,1 & 95,9 & 95,6 & 95,1 & 96,0 & 95,6 & 95,5 \\
\hline MLP-449 & $10-15$ & 95,9 & 95,8 & 96,0 & 95,6 & 95,7 & 95,9 & 96,1 & 96,0 & 95,2 & 95,8 & 95,8 & 95,8 \\
\hline MLP-450 & $10-20$ & 95,3 & 95,4 & 95,9 & 95,7 & 95,8 & 95,3 & 95,7 & 96,0 & 95,3 & 95,9 & 95,6 & 95,6 \\
\hline MLP-451 & 15 & 95,2 & 95,4 & 95,9 & 95,5 & 96,1 & 95,3 & 95,7 & 95,8 & 95,1 & 96,1 & 95,6 & 95,6 \\
\hline MLP-452 & $15-5$ & 95,4 & 95,4 & 96,1 & 95,7 & 96,3 & 95,5 & 95,8 & 96,1 & 95,3 & 96,4 & 95,8 & 95,8 \\
\hline MLP-453 & $15-10$ & 95,3 & 95,6 & 96,6 & 95,5 & 96,4 & 95,3 & 95,8 & 96,6 & 95,1 & 96,4 & 95,9 & 95,9 \\
\hline MLP-454 & $15-15$ & 95,7 & 95,6 & 96,0 & 95,8 & 95,4 & 95,8 & 95,8 & 96,0 & 95,4 & 95,4 & 95,7 & 95,7 \\
\hline MLP-455 & $15-20$ & 95,3 & 95,5 & 96,1 & 94,8 & 96,4 & 95,4 & 95,8 & 96,1 & 94,4 & 96,4 & 95,6 & 95,6 \\
\hline MLP-456 & 20 & 95,4 & 95,5 & 95,9 & 95,4 & 95,9 & 95,5 & 95,7 & 95,9 & 95,0 & 95,9 & 95,6 & 95,6 \\
\hline MLP-457 & $20-5$ & 95,6 & 95,5 & 95,8 & 95,8 & 96,5 & 95,6 & 95,8 & 95,8 & 95,3 & 96,6 & 95,8 & 95,8 \\
\hline MLP-458 & $20-10$ & 96,1 & 95,5 & 96,2 & 95,7 & 96,5 & 96,3 & 95,8 & 96,2 & 95,3 & 96,6 & 96,0 & 96,0 \\
\hline MLP-459 & $20-15$ & 95,1 & 95,4 & 96,1 & 95,5 & 96,3 & 95,1 & 95,7 & 96,2 & 95,1 & 96,3 & 95,7 & 95,7 \\
\hline MLP-460 & $20-20$ & 95,8 & 95,3 & 96,4 & 95,7 & 82,5 & 95,9 & 95,7 & 96,4 & 95,3 & 82,4 & 93,2 & 93,1 \\
\hline
\end{tabular}


Tabela C.24: Resultado do treinamento e validação das topologias especialistas candidatas (12 entradas e uma saída com a velocidade do veículo) para o sétimo sistema neural (dados com ruídos e sem parede), usando o algoritmo Levenberg-Marquardt.

\begin{tabular}{|c|c|c|c|c|c|c|c|c|c|c|c|c|c|}
\hline \multirow[t]{2}{*}{ Ref. } & \multirow{2}{*}{$\begin{array}{l}\text { Neurônios } \\
\text { Escondidos }\end{array}$} & \multicolumn{5}{|c|}{$\begin{array}{c}\text { Treinamento } \\
\text { MAPE }(\% \text { acertos })\end{array}$} & \multicolumn{5}{|c|}{$\begin{array}{c}\text { Validação } \\
\text { MAPE (\% acertos) }\end{array}$} & \multicolumn{2}{|c|}{$\begin{array}{c}\text { Média Final } \\
\text { MAPE (\% acertos) }\end{array}$} \\
\hline & & $\mathrm{C} 1$ & $\mathrm{C} 2$ & $\mathrm{C} 3$ & $\mathrm{C} 4$ & $\mathrm{C} 5$ & $\mathrm{C} 1$ & $\mathrm{C} 2$ & $\mathrm{C} 3$ & $\mathrm{C} 4$ & $\mathrm{C} 5$ & Trein. & Val. \\
\hline MLP-461 & 5 & 96,9 & 95,6 & 96,7 & 96,5 & 97,0 & 97,0 & 95,8 & 96,8 & 96,0 & 97,1 & 96,5 & 96,5 \\
\hline MLP-462 & $5-5$ & 96,8 & 94,5 & 96,2 & 95,8 & 96,9 & 97,0 & 94,8 & 96,1 & 95,4 & 97,0 & 96,1 & 96,1 \\
\hline MLP-463 & $5-10$ & 95,8 & 95,8 & 96,2 & 92,4 & 96,5 & 95,8 & 96,1 & 96,2 & 91,8 & 96,6 & 95,3 & 95,3 \\
\hline MLP-464 & $5-15$ & 96,6 & 95,6 & 96,7 & 96,5 & 96,6 & 96,8 & 95,7 & 96,6 & 96,0 & 96,6 & 96,4 & 96,3 \\
\hline MLP-465 & $5-20$ & 96,8 & 95,7 & 96,9 & 96,3 & 96,8 & 96,9 & 96,0 & 96,7 & 95,8 & 96,9 & 96,5 & 96,5 \\
\hline MLP-466 & 10 & 96,9 & 95,6 & 96,2 & 95,7 & 97,0 & 96,8 & 95,9 & 96,2 & 95,4 & 97,1 & 96,3 & 96,3 \\
\hline MLP-467 & $10-5$ & 96,8 & 95,5 & 96,4 & 96,1 & 97,1 & 96,9 & 95,7 & 96,4 & 95,8 & 97,2 & 96,4 & 96,4 \\
\hline MLP-468 & $10-10$ & 95,6 & 94,7 & 93,0 & 96,7 & 96,7 & 95,6 & 94,9 & 93,0 & 96,1 & 96,9 & 95,3 & 95,3 \\
\hline MLP-469 & $10-15$ & 94,6 & 95,8 & 96,6 & 96,1 & 97,2 & 94,4 & 95,9 & 96,6 & 95,8 & 97,2 & 96,0 & 96,0 \\
\hline MLP-470 & $10-20$ & 96,2 & 95,9 & 88,3 & 81,4 & 97,0 & 96,4 & 96,1 & 88,2 & 82,4 & 97,1 & 91,8 & 92,0 \\
\hline MLP-471 & 15 & 97,0 & 95,6 & 96,5 & 96,2 & 97,3 & 97,1 & 95,8 & 96,5 & 95,8 & 97,4 & 96,5 & 96,5 \\
\hline MLP-472 & $15-5$ & 97,0 & 96,0 & 96,2 & 95,9 & 97,0 & 97,1 & 96,2 & 96,2 & 95,4 & 97,0 & 96,4 & 96,4 \\
\hline MLP-473 & $15-10$ & 96,5 & 95,9 & 96,2 & 96,3 & 97,0 & 96,6 & 96,1 & 96,2 & 95,9 & 97,1 & 96,4 & 96,4 \\
\hline MLP-474 & $15-15$ & 85,8 & 84,4 & 97,4 & 96,8 & 96,9 & 85,9 & 84,8 & 97,2 & 96,2 & 97,1 & 92,3 & 92,3 \\
\hline MLP-475 & $15-20$ & 97,0 & 95,9 & 96,9 & 96,5 & 95,0 & 97,1 & 95,6 & 96,8 & 96,0 & 94,9 & 96,3 & 96,1 \\
\hline MLP-476 & 20 & 97,1 & 95,7 & 96,5 & 96,6 & 97,2 & 97,2 & 95,8 & 96,5 & 96,1 & 97,3 & 96,6 & 96,6 \\
\hline MLP-477 & $20-5$ & 97,3 & 95,9 & 96,6 & 96,7 & 97,3 & 97,3 & 96,1 & 96,6 & 96,3 & 97,3 & 96,8 & 96,7 \\
\hline MLP-478 & $20-10$ & 96,9 & 96,1 & 96,8 & 96,5 & 96,9 & 97,0 & 96,3 & 96,7 & 96,1 & 97,0 & 96,7 & 96,6 \\
\hline MLP-479 & $20-15$ & 89,1 & 96,6 & 96,4 & 96,3 & 97,1 & 88,9 & 96,7 & 96,2 & 95,8 & 97,1 & 95,1 & 94,9 \\
\hline MLP-480 & $20-20$ & 95,6 & 95,3 & 90,8 & 95,3 & 97,2 & 95,8 & 95,5 & 90,9 & 94,6 & 97,4 & 94,9 & 94,8 \\
\hline
\end{tabular}

Tabela C.25: Resultado do treinamento e validação das topologias especialistas candidatas (12 entradas e 4 saídas com o próximo estado da manobra) para o sétimo sistema neural (dados com ruídos e sem parede), usando o algoritmo Resilient Propagation.

\begin{tabular}{|c|c|c|c|c|c|c|c|c|c|c|c|c|c|}
\hline \multirow[t]{2}{*}{ Ref. } & \multirow{2}{*}{$\begin{array}{l}\text { Neurônios } \\
\text { Escondidos }\end{array}$} & \multicolumn{5}{|c|}{$\begin{array}{c}\text { Treinamento } \\
\text { MAPE (\% acertos) }\end{array}$} & \multicolumn{5}{|c|}{$\begin{array}{c}\text { Validação } \\
\text { MAPE (\% acertos) }\end{array}$} & \multicolumn{2}{|c|}{$\begin{array}{c}\text { Média Final } \\
\text { MAPE (\% acertos) }\end{array}$} \\
\hline & & $\mathrm{C} 1$ & $\mathrm{C} 2$ & C3 & $\mathrm{C} 4$ & C5 & $\mathrm{C} 1$ & $\mathrm{C} 2$ & $\mathrm{C} 3$ & $\mathrm{C} 4$ & C5 & Trein. & Val. \\
\hline MLP-481 & 5 & 98,0 & 98,4 & 97,9 & 98,1 & 98,1 & 98,3 & 98,7 & 97,7 & 97,9 & 98,1 & 98,1 & 98,1 \\
\hline MLP-482 & $5-5$ & 98,4 & 98,2 & 98,3 & 98,4 & 98,0 & 98,5 & 98,4 & 98,1 & 98,2 & 98,1 & 98,3 & 98,3 \\
\hline MLP-483 & $5-10$ & 98,4 & 98,3 & 98,1 & 98,4 & 98,3 & 98,5 & 98,4 & 97,9 & 98,2 & 98,5 & 98,3 & 98,3 \\
\hline MLP-484 & $5-15$ & 98,0 & 98,1 & 98,4 & 98,3 & 97,6 & 98,0 & 98,5 & 98,0 & 98,1 & 97,7 & 98,1 & 98,0 \\
\hline MLP-485 & $5-20$ & 98,1 & 98,3 & 98,6 & 98,5 & 98,8 & 98,2 & 98,5 & 98,5 & 98,3 & 98,9 & 98,5 & 98,5 \\
\hline MLP-486 & 10 & 97,7 & 97,7 & 98,3 & 98,5 & 98,2 & 97,8 & 98,0 & 98,0 & 98,3 & 98,3 & 98,1 & 98,1 \\
\hline MLP-487 & $10-5$ & 98,3 & 98,4 & 98,1 & 98,3 & 98,9 & 98,4 & 98,6 & 97,9 & 98,2 & 99,1 & 98,4 & 98,4 \\
\hline MLP-488 & $10-10$ & 98,5 & 98,3 & 98,5 & 98,7 & 98,4 & 98,6 & 98,5 & 98,3 & 98,5 & 98,5 & 98,5 & 98,5 \\
\hline MLP-489 & $10-15$ & 97,9 & 98,0 & 98,5 & 98,6 & 98,3 & 98,1 & 98,4 & 98,1 & 98,4 & 98,5 & 98,3 & 98,3 \\
\hline MLP-490 & $10-20$ & 97,9 & 98,3 & 98,4 & 98,8 & 97,9 & 98,0 & 98,6 & 98,2 & 98,7 & 98,1 & 98,3 & 98,3 \\
\hline MLP-491 & 15 & 98,3 & 98,2 & 98,6 & 98,6 & 98,2 & 98,3 & 98,4 & 98,3 & 98,5 & 98,3 & 98,4 & 98,4 \\
\hline MLP-492 & $15-5$ & 97,7 & 98,3 & 98,0 & 98,6 & 97,7 & 97,8 & 98,6 & 97,7 & 98,5 & 97,7 & 98,1 & 98,1 \\
\hline MLP-493 & $15-10$ & 98,4 & 98,6 & 98,6 & 98,8 & 98,5 & 98,4 & 98,8 & 98,4 & 98,7 & 98,7 & 98,6 & 98,6 \\
\hline MLP-494 & $15-15$ & 98,0 & 98,6 & 98,4 & 98,8 & 98,7 & 98,1 & 98,8 & 98,2 & 98,8 & 98,8 & 98,5 & 98,5 \\
\hline MLP-495 & $15-20$ & 98,2 & 98,3 & 98,5 & 98,8 & 98,8 & 98,1 & 98,5 & 98,2 & 98,6 & 99,0 & 98,5 & 98,5 \\
\hline MLP-496 & 20 & 98,4 & 98,3 & 98,5 & 98,7 & 98,6 & 98,4 & 98,6 & 98,1 & 98,6 & 98,7 & 98,5 & 98,5 \\
\hline MLP-497 & $20-5$ & 98,2 & 98,0 & 98,4 & 97,8 & 98,4 & 98,2 & 98,2 & 98,0 & 97,6 & 98,5 & 98,2 & 98,1 \\
\hline MLP-498 & $20-10$ & 98,4 & 98,9 & 97,9 & 98,7 & 98,3 & 98,3 & 99,1 & 97,6 & 98,5 & 98,4 & 98,4 & 98,4 \\
\hline MLP-499 & $20-15$ & 98,6 & 98,8 & 98,9 & 98,8 & 98,7 & 98,6 & 98,9 & 98,7 & 98,6 & 98,8 & 98,7 & 98,7 \\
\hline MLP-500 & $20-20$ & 98,7 & 98,3 & 98,3 & 99,0 & 98,5 & 98,6 & 98,5 & 98,0 & 98,8 & 98,6 & 98,5 & 98,5 \\
\hline
\end{tabular}


Tabela C.26: Resultado do treinamento e validação das topologias especialistas candidatas (12 entradas e 4 saídas com o próximo estado da manobra) para o sétimo sistema neural (dados com ruídos e sem parede), usando o algoritmo Levenberg-Marquardt.

\begin{tabular}{|c|c|c|c|c|c|c|c|c|c|c|c|c|c|}
\hline \multirow[t]{2}{*}{ Ref. } & \multirow{2}{*}{$\begin{array}{l}\text { Neurônios } \\
\text { Escondidos }\end{array}$} & \multicolumn{5}{|c|}{$\begin{array}{c}\text { Treinamento } \\
\text { MAPE (\% acertos) }\end{array}$} & \multicolumn{5}{|c|}{$\begin{array}{c}\text { Validação } \\
\text { MAPE (\% acertos) }\end{array}$} & \multicolumn{2}{|c|}{$\begin{array}{c}\text { Média Final } \\
\text { MAPE (\% acertos) }\end{array}$} \\
\hline & & $\mathrm{C} 1$ & $\mathrm{C} 2$ & $\mathrm{C} 3$ & $\mathrm{C} 4$ & C5 & $\mathrm{C} 1$ & $\mathrm{C} 2$ & C3 & $\mathrm{C} 4$ & $\mathrm{C} 5$ & Trein. & Val. \\
\hline MLP-501 & 5 & 99,0 & 81,5 & 93,0 & 81,8 & 81,5 & 99,2 & 81,1 & 93,1 & 81,8 & 81,6 & 87,3 & 87,4 \\
\hline MLP-502 & $5-5$ & 98,8 & 99,4 & 99,3 & 99,5 & 99,4 & 98,7 & 99,4 & 99,1 & 99,4 & 99,4 & 99,3 & 99,2 \\
\hline MLP-503 & $5-10$ & 80,1 & 80,0 & 82,5 & 82,7 & 95,6 & 80,0 & 81,0 & 82,7 & 82,4 & 95,6 & 84,2 & 84,3 \\
\hline MLP-504 & $5-15$ & 99,5 & 85,7 & 98,7 & 99,4 & 98,8 & 99,4 & 85,4 & 98,5 & 99,2 & 99,0 & 96,4 & 96,3 \\
\hline MLP-505 & $5-20$ & 99,5 & 99,4 & 99,5 & 99,4 & 98,9 & 99,4 & 99,4 & 99,2 & 99,3 & 99,0 & 99,3 & 99,3 \\
\hline MLP-506 & 10 & 85,5 & 85,5 & 85,2 & 77,5 & 85,8 & 85,4 & 85,2 & 85,5 & 76,6 & 85,8 & 83,9 & 83,7 \\
\hline MLP-507 & $10-5$ & 78,3 & 65,5 & 83,4 & 75,5 & 84,4 & 78,8 & 66,3 & 83,5 & 75,0 & 84,6 & 77,4 & 77,6 \\
\hline MLP-508 & $10-10$ & 49,3 & 45,5 & 29,5 & 48,1 & 37,7 & 49,8 & 45,9 & 30,1 & 48,0 & 37,8 & 42,0 & 42,3 \\
\hline MLP-509 & $10-15$ & 42,1 & 38,0 & 36,5 & 70,8 & 36,3 & 43,3 & 39,0 & 37,3 & 70,4 & 36,4 & 44,8 & 45,3 \\
\hline MLP-510 & $10-20$ & 99,2 & 99,2 & 99,3 & 98,6 & 99,1 & 99,1 & 99,2 & 98,8 & 98,6 & 99,1 & 99,1 & 99,0 \\
\hline MLP-511 & 15 & 99,4 & 99,3 & 99,4 & 99,4 & 99,1 & 99,3 & 99,3 & 99,0 & 99,3 & 99,2 & 99,3 & 99,2 \\
\hline MLP-512 & $15-5$ & 81,8 & 97,0 & 99,3 & 99,2 & 82,2 & 82,1 & 97,3 & 99,0 & 99,0 & 82,4 & 91,9 & 92,0 \\
\hline MLP-513 & $15-10$ & 99,5 & 85,7 & 91,4 & 85,7 & 99,3 & 99,3 & 85,3 & 91,4 & 85,4 & 99,3 & 92,3 & 92,2 \\
\hline MLP-514 & $15-15$ & 98,8 & 98,6 & 99,4 & 99,5 & 99,3 & 98,7 & 98,8 & 99,1 & 99,4 & 99,3 & 99,1 & 99,1 \\
\hline MLP-515 & $15-20$ & 99,4 & 99,3 & 99,4 & 99,4 & 99,2 & 99,3 & 99,3 & 99,1 & 99,3 & 99,3 & 99,3 & 99,3 \\
\hline MLP-516 & 20 & 99,5 & 99,2 & 99,1 & 99,3 & 99,5 & 99,2 & 99,2 & 98,6 & 99,0 & 99,5 & 99,3 & 99,1 \\
\hline MLP-517 & $20-5$ & 99,1 & 98,9 & 99,3 & 99,2 & 99,3 & 98,7 & 98,7 & 99,4 & 99,1 & 99,3 & 99,2 & 99,1 \\
\hline MLP-518 & $20-10$ & 90,1 & 57,5 & 69,2 & 97,4 & 92,2 & 90,5 & 56,7 & 69,8 & 97,1 & 91,9 & 81,3 & 81,2 \\
\hline MLP-519 & $20-15$ & 64,2 & 58,5 & 67,9 & 83,6 & 70,5 & 66,1 & 58,8 & 68,8 & 83,5 & 71,3 & 68,9 & 69,7 \\
\hline MLP-520 & $20-20$ & 82,7 & 99,5 & 99,4 & 99,0 & 99,1 & 81,9 & 99,3 & 99,4 & 99,0 & 99,2 & 95,9 & 95,8 \\
\hline
\end{tabular}

Tabela C.27: Resultados do Treinamento e validação das topologias especialistas candidatas (12 entradas e uma saída com esterçamento do veículo) para o quinto sistema neural (dados com ruídos e com parede), usando o algoritmo Resilient Propagation.

\begin{tabular}{|c|c|c|c|c|c|c|c|c|c|c|c|c|c|}
\hline \multirow[t]{2}{*}{ Ref. } & \multirow{2}{*}{$\begin{array}{l}\text { Neurônios } \\
\text { Escondidos }\end{array}$} & \multicolumn{5}{|c|}{$\begin{array}{c}\text { Treinamento } \\
\text { MAPE }(\% \text { acertos })\end{array}$} & \multicolumn{5}{|c|}{$\begin{array}{c}\text { Validação } \\
\text { MAPE (\% acertos) }\end{array}$} & \multicolumn{2}{|c|}{$\begin{array}{c}\text { Média Final } \\
\text { MAPE (\% acertos) }\end{array}$} \\
\hline & & $\mathrm{C} 1$ & $\mathrm{C} 2$ & C3 & $\mathrm{C} 4$ & C5 & $\mathrm{C} 1$ & $\mathrm{C} 2$ & C3 & $\mathrm{C} 4$ & C5 & Trein. & Val. \\
\hline MLP-521 & 5 & 99,7 & 99,9 & 99,8 & 99,9 & 99,8 & 99,8 & 99,9 & 99,8 & 99,9 & 99,8 & 99,8 & 99,8 \\
\hline MLP-522 & $5-5$ & 100,0 & 99,9 & 99,9 & 99,9 & 99,9 & 100,0 & 99,9 & 99,9 & 99,9 & 99,9 & 99,9 & 99,9 \\
\hline MLP-523 & $5-10$ & 99,9 & 99,8 & 100,0 & 99,9 & 99,9 & 99,9 & 99,8 & 100,0 & 99,8 & 99,9 & 99,9 & 99,9 \\
\hline MLP-524 & $5-15$ & 99,8 & 100,0 & 99,8 & 99,8 & 99,8 & 99,8 & 100,0 & 99,8 & 99,8 & 99,8 & 99,9 & 99,9 \\
\hline MLP-525 & $5-20$ & 99,9 & 99,9 & 100,0 & 100,0 & 99,8 & 99,9 & 99,9 & 100,0 & 100,0 & 99,8 & 99,9 & 99,9 \\
\hline MLP-526 & 10 & 99,8 & 99,8 & 99,8 & 99,8 & 99,8 & 99,8 & 99,7 & 99,8 & 99,8 & 99,8 & 99,8 & 99,8 \\
\hline MLP-527 & $10-5$ & 99,8 & 99,8 & 99,9 & 99,7 & 99,6 & 99,8 & 99,8 & 99,9 & 99,7 & 99,7 & 99,8 & 99,8 \\
\hline MLP-528 & $10-10$ & 99,8 & 99,8 & 100,0 & 100,0 & 99,8 & 99,8 & 99,8 & 100,0 & 100,0 & 99,8 & 99,9 & 99,9 \\
\hline MLP-529 & $10-15$ & 99,9 & 100,0 & 99,9 & 99,9 & 99,5 & 99,9 & 100,0 & 99,9 & 99,9 & 99,5 & 99,8 & 99,8 \\
\hline MLP-530 & $10-20$ & 100,0 & 99,9 & 100,0 & 100,0 & 100,0 & 100,0 & 100,0 & 100,0 & 100,0 & 100,0 & 100,0 & 100,0 \\
\hline MLP-531 & 15 & 99,9 & 99,9 & 99,9 & 99,9 & 99,9 & 99,9 & 99,9 & 99,9 & 99,9 & 99,9 & 99,9 & 99,9 \\
\hline MLP-532 & $15-5$ & 99,9 & 99,7 & 99,2 & 99,9 & 99,5 & 99,9 & 99,7 & 99,2 & 99,9 & 99,5 & 99,6 & 99,6 \\
\hline MLP-533 & $15-10$ & 99,7 & 99,8 & 99,9 & 99,8 & 99,9 & 99,7 & 99,8 & 99,9 & 99,8 & 99,9 & 99,8 & 99,8 \\
\hline MLP-534 & $15-15$ & 99,9 & 99,9 & 99,9 & 99,9 & 100,0 & 99,9 & 99,9 & 99,9 & 99,9 & 100,0 & 99,9 & 99,9 \\
\hline MLP-535 & $15-20$ & 99,9 & 99,8 & 99,9 & 99,8 & 99,8 & 99,9 & 99,8 & 99,9 & 99,8 & 99,8 & 99,8 & 99,8 \\
\hline MLP-536 & 20 & 99,9 & 99,9 & 99,9 & 99,9 & 99,9 & 99,9 & 99,9 & 99,9 & 99,9 & 99,9 & 99,9 & 99,9 \\
\hline MLP-537 & $20-5$ & 99,8 & 99,8 & 99,8 & 99,7 & 99,7 & 99,8 & 99,8 & 99,8 & 99,7 & 99,7 & 99,8 & 99,8 \\
\hline MLP-538 & $20-10$ & 99,9 & 99,9 & 99,8 & 99,9 & 99,9 & 99,9 & 99,9 & 99,8 & 99,9 & 99,9 & 99,9 & 99,9 \\
\hline MLP-539 & $20-15$ & 99,9 & 100,0 & 99,9 & 100,0 & 99,9 & 99,9 & 100,0 & 99,9 & 100,0 & 99,9 & 99,9 & 99,9 \\
\hline MLP-540 & $20-20$ & 100,0 & 100,0 & 100,0 & 100,0 & 100,0 & 100,0 & 100,0 & 100,0 & 100,0 & 100,0 & 100,0 & 100,0 \\
\hline
\end{tabular}


Tabela C.28: Resultados do Treinamento e validação das topologias especialistas candidatas (12 entradas e uma saída com esterçamento do veículo) para o quinto sistema neural (dados com ruídos e com parede), usando o algoritmo Levenberg-Marquardt.

\begin{tabular}{|c|c|c|c|c|c|c|c|c|c|c|c|c|c|}
\hline \multirow[t]{2}{*}{ Ref. } & \multirow{2}{*}{$\begin{array}{l}\text { Neurônios } \\
\text { Escondidos }\end{array}$} & \multicolumn{5}{|c|}{$\begin{array}{c}\text { Treinamento } \\
\text { MAPE (\% acertos) }\end{array}$} & \multicolumn{5}{|c|}{$\begin{array}{c}\text { Validação } \\
\text { MAPE (\% acertos) }\end{array}$} & \multicolumn{2}{|c|}{$\begin{array}{c}\text { Média Final } \\
\text { MAPE (\% acertos) }\end{array}$} \\
\hline & & $\mathrm{C} 1$ & $\mathrm{C} 2$ & $\mathrm{C} 3$ & $\mathrm{C} 4$ & $\mathrm{C} 5$ & $\mathrm{C} 1$ & $\mathrm{C} 2$ & C3 & $\mathrm{C} 4$ & $\mathrm{C} 5$ & Trein. & Val. \\
\hline MLP-541 & 5 & 100,0 & 97,5 & 100,0 & 100,0 & 95,5 & 100,0 & 97,7 & 100,0 & 100,0 & 94,2 & 98,6 & 98,4 \\
\hline MLP-542 & $5-5$ & 100,0 & 100,0 & 100,0 & 100,0 & 100,0 & 100,0 & 100,0 & 100,0 & 100,0 & 100,0 & 100,0 & 00,0 \\
\hline MLP-543 & $5-10$ & 100,0 & 100,0 & 100,0 & 100,0 & 100,0 & 100,0 & 100,0 & 100,0 & 100,0 & 100,0 & 100,0 & 100,0 \\
\hline MLP-544 & $5-15$ & 100,0 & 100,0 & 100,0 & 100,0 & 100,0 & 100,0 & 100,0 & 100,0 & 100,0 & 100,0 & 100,0 & 100,0 \\
\hline MLP-545 & $5-20$ & 100,0 & 100,0 & 100,0 & 100,0 & 100,0 & 100,0 & 100,0 & 100,0 & 100,0 & 100,0 & 100,0 & 100,0 \\
\hline MLP-546 & 10 & 100,0 & 100,0 & 100,0 & 45,1 & 100,0 & 100,0 & 100,0 & 100,0 & 46,5 & 100,0 & 89,0 & 89,3 \\
\hline MLP-547 & $10-5$ & 91,3 & 100,0 & 100,0 & 97,6 & 100,0 & 90,0 & 100,0 & 100,0 & 97,7 & 100,0 & 97,8 & 97,5 \\
\hline MLP-548 & $10-10$ & 100,0 & 100,0 & 100,0 & 100,0 & 100,0 & 100,0 & 100,0 & 100,0 & 100,0 & 100,0 & 100,0 & 100,0 \\
\hline MLP-549 & $10-15$ & 100,0 & 100,0 & 100,0 & 100,0 & 100,0 & 100,0 & 100,0 & 100,0 & 100,0 & 100,0 & 100,0 & 100,0 \\
\hline MLP-540 & $10-20$ & 100,0 & 100,0 & 100,0 & 100,0 & 100,0 & 100,0 & 100,0 & 100,0 & 100,0 & 100,0 & 100,0 & 100,0 \\
\hline MLP-551 & 15 & 100,0 & 100,0 & 100,0 & 100,0 & 100,0 & 100,0 & 100,0 & 10 & 100,0 & 100,0 & 100,0 & 1000 \\
\hline MLP-552 & 15 & 100,0 & 100,0 & 100,0 & 100,0 & 100,0 & 100,0 & 100,0 & 100,0 & 100,0 & 100,0 & 100,0 & 100,0 \\
\hline MLP-553 & $15-10$ & 100,0 & 100,0 & 100,0 & 100,0 & 100,0 & 100,0 & 100,0 & 100,0 & 100,0 & 100,0 & 100,0 & 100,0 \\
\hline MLP-554 & $15-15$ & 100,0 & 100,0 & 100,0 & 98,8 & 98,8 & 100,0 & 100,0 & 100,0 & 98,7 & 98,6 & 99,5 & 99,5 \\
\hline MLP-555 & $15-20$ & 100,0 & 100,0 & 100,0 & 100,0 & 100,0 & 100,0 & 100,0 & 100,0 & 100,0 & 100,0 & 100,0 & 100,0 \\
\hline MLP-556 & 20 & 100,0 & 100,0 & 100,0 & 100,0 & 100,0 & 100,0 & 100,0 & 100,0 & 100,0 & 100,0 & 100,0 & 100,0 \\
\hline MLP-557 & $20-5$ & 100,0 & 100,0 & 100,0 & 100,0 & 100,0 & 100,0 & 100,0 & 100,0 & 100,0 & 100,0 & 100,0 & 100,0 \\
\hline MLP-558 & $20-10$ & 100,0 & 100,0 & 100,0 & 100,0 & 100,0 & 100,0 & 100,0 & 100,0 & 100,0 & 100,0 & 100,0 & 100,0 \\
\hline MLP-559 & $20-15$ & 96,6 & 88,4 & 62,9 & 22,1 & 91 & 96,8 & 89,8 & 65,9 & 23,5 & 92,0 & 72,4 & 73,6 \\
\hline MLP-550 & $20-20$ & 100,0 & 100,0 & 100,0 & 100,0 & 100,0 & 100,0 & 100,0 & 100,0 & 100,0 & 100,0 & 100,0 & 100,0 \\
\hline
\end{tabular}

Tabela C.29: Resultados do Treinamento e validação das topologias especialistas candidatas (12 entradas e uma saída com a velocidade do veículo) para o quinto sistema neural (dados com ruídos e com parede), usando o algoritmo Resilient Propagation.

\begin{tabular}{|c|c|c|c|c|c|c|c|c|c|c|c|c|c|}
\hline \multirow[t]{2}{*}{ Ref. } & \multirow{2}{*}{$\begin{array}{l}\text { Neurônios } \\
\text { Escondidos }\end{array}$} & \multicolumn{5}{|c|}{$\begin{array}{c}\text { Treinamento } \\
\text { MAPE }(\% \text { acertos })\end{array}$} & \multicolumn{5}{|c|}{$\begin{array}{c}\text { Validação } \\
\text { MAPE (\% acertos) }\end{array}$} & \multicolumn{2}{|c|}{$\begin{array}{c}\text { Média Final } \\
\text { MAPE (\% acertos) }\end{array}$} \\
\hline & & $\mathrm{C} 1$ & $\mathrm{C} 2$ & $\mathrm{C} 3$ & $\mathrm{C} 4$ & C5 & $\mathrm{C} 1$ & $\mathrm{C} 2$ & $\mathrm{C} 3$ & $\mathrm{C} 4$ & C5 & Trein. & Val. \\
\hline MLP-561 & 5 & 96,1 & 96,2 & 95,8 & 96,0 & 96,0 & 96,3 & 95,9 & 95,9 & 95,7 & 96,1 & 96,0 & 96,0 \\
\hline MLP-562 & $5-5$ & 96,0 & 96,0 & 95,6 & 93,2 & 95,8 & 96,3 & 95,6 & 95,7 & 93,1 & 95,9 & 95,3 & 95,3 \\
\hline MLP-563 & $5-10$ & 96,3 & 95,5 & 94,7 & 95,9 & 94,0 & 96,6 & 95,2 & 94,8 & 95,6 & 94,0 & 95,3 & 95,2 \\
\hline MLP-564 & $5-15$ & 96,6 & 96,3 & 95,9 & 95,8 & 96,4 & 96,8 & 96,1 & 96,0 & 95,5 & 96,4 & 96,2 & 96,2 \\
\hline MLP-565 & $5-20$ & 96,4 & 95,8 & 94,9 & 96,6 & 95,6 & 96,6 & 95,6 & 95,0 & 96,3 & 95,6 & 95,8 & 95,8 \\
\hline MLP-566 & 10 & 96,1 & 95,3 & 95,5 & 95,6 & 95,7 & 96,4 & 95,1 & 95,7 & 95,4 & 95,8 & 95,7 & 95,7 \\
\hline MLP-567 & $10-5$ & 96,4 & 96,0 & 94,0 & 95,3 & 95,6 & 96,7 & 95,8 & 94,2 & 95,2 & 95,6 & 95,5 & 95,5 \\
\hline MLP-568 & $10-10$ & 96,2 & 96,3 & 94,7 & 96,4 & 95,5 & 96,5 & 96,0 & 94,9 & 96,1 & 95,6 & 95,8 & 95,8 \\
\hline MLP-569 & $10-15$ & 96,3 & 95,9 & 95,8 & 95,2 & 95,6 & 96,6 & 95,6 & 95,9 & 94,9 & 95,7 & 95,8 & 95,7 \\
\hline MLP-570 & $10-20$ & 96,7 & 96,8 & 95,3 & 96,8 & 95,5 & 97,0 & 96,5 & 95,4 & 96,5 & 95,7 & 96,2 & 96,2 \\
\hline MLP-571 & 15 & 96,1 & 96,3 & 95,8 & 95,6 & 96,0 & 96,3 & 95,9 & 96,0 & 95,4 & 96,1 & 96,0 & 95,9 \\
\hline MLP-572 & $15-5$ & 96,3 & 96,4 & 96,5 & 96,3 & 96,3 & 96,6 & 96,1 & 96,5 & 96,0 & 96,4 & 96,3 & 96,3 \\
\hline MLP-573 & $15-10$ & 96,7 & 96,3 & 95,6 & 96,3 & 96,3 & 97,0 & 96,0 & 95,7 & 96,0 & 96,4 & 96,2 & 96,2 \\
\hline MLP-574 & $15-15$ & 96,4 & 96,0 & 95,5 & 96,0 & 95,9 & 96,6 & 95,7 & 95,7 & 95,8 & 96,0 & 96,0 & 96,0 \\
\hline MLP-575 & $15-20$ & 95,8 & 96,8 & 96,0 & 96,0 & 96,3 & 96,0 & 96,5 & 96,2 & 95,8 & 96,3 & 96,2 & 96,2 \\
\hline MLP-576 & 20 & 96,4 & 96,3 & 95,5 & 95,7 & 95,7 & 96,7 & 96,0 & 95,6 & 95,5 & 95,8 & 95,9 & 95,9 \\
\hline MLP-577 & $20-5$ & 96,6 & 96,5 & 95,7 & 96,1 & 96,6 & 96,8 & 96,2 & 95,8 & 95,9 & 96,6 & 96,3 & 96,3 \\
\hline MLP-578 & $20-10$ & 96,3 & 95,9 & 95,5 & 96,1 & 95,8 & 96,6 & 95,5 & 95,7 & 95,8 & 95,9 & 95,9 & 95,9 \\
\hline MLP-579 & $20-15$ & 96,4 & 95,9 & 95,7 & 96,3 & 96,3 & 96,6 & 95,5 & 95,8 & 96,0 & 96,3 & 96,1 & 96,1 \\
\hline MLP-580 & $20-20$ & 96,2 & 96,2 & 95,9 & 96,6 & 96,1 & 96,4 & 95,9 & 96,1 & 96,3 & 96,2 & 96,2 & 96,2 \\
\hline
\end{tabular}


Tabela C.30: Resultados do Treinamento e validação das topologias especialistas candidatas (12 entradas e uma saída com a velocidade do veículo) para o quinto sistema neural (dados com ruídos e com parede), usando o algoritmo Levenberg-Marquardt.

\begin{tabular}{|c|c|c|c|c|c|c|c|c|c|c|c|c|c|}
\hline \multirow[t]{2}{*}{ Ref. } & \multirow{2}{*}{$\begin{array}{l}\text { Neurônios } \\
\text { Escondidos }\end{array}$} & \multicolumn{5}{|c|}{$\begin{array}{c}\text { Treinamento } \\
\text { MAPE (\% acertos) }\end{array}$} & \multicolumn{5}{|c|}{$\begin{array}{c}\text { Validação } \\
\text { MAPE (\% acertos) }\end{array}$} & \multicolumn{2}{|c|}{$\begin{array}{c}\text { Média Final } \\
\text { MAPE (\% acertos) }\end{array}$} \\
\hline & & $\mathrm{C} 1$ & $\mathrm{C} 2$ & $\mathrm{C} 3$ & $\mathrm{C} 4$ & C5 & $\mathrm{C} 1$ & $\mathrm{C} 2$ & $\mathrm{C} 3$ & $\mathrm{C} 4$ & C5 & Trein. & Val. \\
\hline MLP-581 & 5 & 96,8 & 96,7 & 97,0 & 96,8 & 95,8 & 97,1 & 96,4 & 97,0 & 96,5 & 95,6 & 96,6 & 96,5 \\
\hline MLP-582 & $5-5$ & 96,8 & 96,2 & 97,2 & 97,0 & 95,9 & 97,0 & 95,9 & 97,2 & 96,7 & 95,9 & 96,6 & 96,6 \\
\hline MLP-583 & $5-10$ & 97,2 & 94,6 & 97,4 & 90,0 & 95,0 & 97,4 & 94,4 & 97,3 & 90,0 & 95,1 & 94,9 & 94,8 \\
\hline MLP-584 & $5-15$ & 97,1 & 97,0 & 96,3 & 97,0 & 96,4 & 97,3 & 96,8 & 96,3 & 96,7 & 96,4 & 96,8 & 96,7 \\
\hline MLP-585 & $5-20$ & 96,3 & 97,1 & 96,9 & 96,5 & 95,9 & 96,5 & 96,8 & 96,9 & 96,2 & 95,9 & 96,5 & 96,5 \\
\hline MLP-586 & 10 & 96,1 & 96,1 & 97,2 & 96,9 & 95,6 & 96,3 & 96,1 & 97,1 & 96,6 & 95,5 & 96,4 & 96,3 \\
\hline MLP-587 & $10-5$ & 96,9 & 96,7 & 97,0 & 96,8 & 96,1 & 97,1 & 96,5 & 97,0 & 96,6 & 96,0 & 96,7 & 96,6 \\
\hline MLP-588 & $10-10$ & 95,4 & 97,2 & 96,4 & 96,0 & 96,2 & 95,5 & 97,1 & 96,4 & 95,8 & 96,2 & 96,2 & 96,2 \\
\hline MLP-589 & 15 & 97,0 & 97,1 & 97,1 & 96,8 & 96,4 & 97,1 & 96,9 & 97,1 & 96,6 & 96,4 & 96,9 & 96,8 \\
\hline MLP-590 & $10-20$ & 96,8 & 97,0 & 96,5 & 97,0 & 95,9 & 97,0 & 96,7 & 96,6 & 96,8 & 95,9 & 96,6 & 96,6 \\
\hline MLP-591 & 15 & 85,3 & 96,5 & 91,3 & 96,6 & 95,5 & 85,6 & 96,1 & 91,4 & 96,4 & 95,5 & 93,1 & 93,0 \\
\hline MLP-592 & $15-5$ & 44,5 & 89,4 & 45,5 & 93,0 & 90,2 & 43,1 & 88,9 & 45,1 & 92,7 & 90,7 & 72,5 & 72,1 \\
\hline MLP-593 & $15-10$ & 96,4 & 97,3 & 96,8 & 97,1 & 95,9 & 96,6 & 97,0 & 96,8 & 96,9 & 96,0 & 96,7 & 96,7 \\
\hline MLP-594 & & 97,1 & 97,2 & 97,5 & 96,8 & 96,2 & 97,3 & 97,0 & 97,4 & 96,6 & 96,3 & 97,0 & 96,9 \\
\hline MLP-595 & $15-20$ & 97,0 & 97,2 & 97,2 & 96,8 & 96,2 & 97,2 & 96,9 & 97,2 & 96,6 & 96,3 & 96,9 & 96,8 \\
\hline MLP-596 & 20 & 55,5 & 97,0 & 97,0 & 96,8 & 96,3 & 56,8 & 96,8 & 96,9 & 96,6 & 96,3 & 88,5 & 88,7 \\
\hline MLP-597 & $20-5$ & 96,7 & 96,8 & 97,3 & 97,0 & 96,4 & 96,9 & 96,5 & 97,2 & 96,7 & 96,5 & 96,8 & 96,7 \\
\hline MLP-598 & $20-10$ & 96,7 & 97,4 & 96,9 & 97,1 & 96,9 & 97,0 & 97,2 & 96,9 & 96,8 & 96,8 & 97,0 & 97,0 \\
\hline MLP-599 & $20-15$ & 90,8 & 97,0 & 64,9 & 96,7 & 95,9 & 90,7 & 96,6 & 65,2 & 96,4 & 95,7 & 89,1 & 88,9 \\
\hline MLP-600 & $20-20$ & 96,1 & 96,9 & 97,4 & 96,9 & 96,2 & 96,3 & 96,5 & 97,3 & 96,7 & 96,1 & 96,7 & 96,6 \\
\hline
\end{tabular}

Tabela C.31: Resultados do Treinamento e validação das topologias especialistas candidatas (12 entradas e três saídas com os próximos estados da manobra) para o quinto sistema neural (dados com ruídos e com parede), usando o algoritmo Resilient Propagation.

\begin{tabular}{|c|c|c|c|c|c|c|c|c|c|c|c|c|c|}
\hline \multirow[t]{2}{*}{ Ref. } & \multirow{2}{*}{$\begin{array}{l}\text { Neurônios } \\
\text { Escondidos }\end{array}$} & \multicolumn{5}{|c|}{$\begin{array}{c}\text { Treinamento } \\
\text { MAPE ( } \% \text { acertos })\end{array}$} & \multicolumn{5}{|c|}{$\begin{array}{c}\text { Validação } \\
\text { MAPE (\% acertos) }\end{array}$} & \multicolumn{2}{|c|}{$\begin{array}{c}\text { Média Final } \\
\text { MAPE (\% acertos) }\end{array}$} \\
\hline & & $\mathrm{C} 1$ & $\mathrm{C} 2$ & $\mathrm{C} 3$ & $\mathrm{C} 4$ & $\mathrm{C} 5$ & $\mathrm{C} 1$ & $\mathrm{C} 2$ & $\mathrm{C} 3$ & $\mathrm{C} 4$ & $\mathrm{C} 5$ & Trein. & Val. \\
\hline MLP-601 & 5 & 98,1 & 98,5 & 98,5 & 98,6 & 98,6 & 98,1 & 98,5 & 98,6 & 98,5 & 98,6 & 98,5 & 98,5 \\
\hline MLP-602 & $5-5$ & 98,1 & 98,2 & 98,4 & 98,5 & 97,9 & 98,2 & 98,3 & 98,4 & 98,3 & 98,0 & 98,2 & 98,2 \\
\hline MLP-603 & $5-10$ & 98,1 & 98,6 & 98,5 & 98,6 & 98,6 & 98,2 & 98,6 & 98,5 & 98,4 & 98,6 & 98,5 & 98,5 \\
\hline MLP-604 & $5-15$ & 98,1 & 98,3 & 98,2 & 98,3 & 98,1 & 98,1 & 98,4 & 98,3 & 98,1 & 98,2 & 98,2 & 98,2 \\
\hline MLP-605 & $5-20$ & 98,5 & 98,3 & 98,6 & 98,5 & 98,3 & 98,5 & 98,3 & 98,7 & 98,4 & 98,4 & 98,4 & 98,4 \\
\hline MLP-606 & 10 & 97,9 & 98,7 & 98,4 & 98,6 & 98,7 & 98,0 & 98,6 & 98,5 & 98,5 & 98,7 & 98,5 & 98,5 \\
\hline MLP-607 & $10-5$ & 98,4 & 98,6 & 98,5 & 98,6 & 98,4 & 98,4 & 98,6 & 98,5 & 98,4 & 98,5 & 98,5 & 98,5 \\
\hline MLP-608 & $10-10$ & 98,2 & 98,7 & 98,7 & 98,8 & 98,5 & 98,3 & 98,7 & 98,8 & 98,6 & 98,5 & 98,6 & 98,6 \\
\hline MLP-609 & $10-15$ & 98,4 & 98,2 & 98,0 & 98,2 & 98,6 & 98,5 & 98,2 & 98,0 & 98,0 & 98,6 & 98,3 & 98,3 \\
\hline MLP-610 & $10-20$ & 98,2 & 98,4 & 98,1 & 98,4 & 98,4 & 98,2 & 98,4 & 98,1 & 98,2 & 98,4 & 98,3 & 98,3 \\
\hline MLP-611 & 15 & 98,5 & 98,4 & 98,4 & 98,6 & 98,4 & 98,5 & 98,4 & 98,5 & 98,5 & 98,4 & 98,5 & 98,5 \\
\hline MLP-612 & $15-5$ & 98,3 & 97,8 & 98,3 & 98,4 & 98,9 & 98,4 & 97,9 & 98,4 & 98,2 & 98,9 & 98,4 & 98,4 \\
\hline MLP-613 & $15-10$ & 98,4 & 98,2 & 98,4 & 98,4 & 98,7 & 98,4 & 98,2 & 98,5 & 98,2 & 98,7 & 98,4 & 98,4 \\
\hline MLP-614 & $15-15$ & 98,2 & 98,2 & 98,6 & 98,5 & 98,3 & 98,2 & 98,2 & 98,7 & 98,3 & 98,4 & 98,4 & 98,3 \\
\hline MLP-615 & $15-20$ & 98,3 & 98,5 & 98,7 & 98,5 & 98,7 & 98,3 & 98,5 & 98,7 & 98,3 & 98,7 & 98,5 & 98,5 \\
\hline MLP-616 & 20 & 98,1 & 98,4 & 98,7 & 98,6 & 98,8 & 98,1 & 98,3 & 98,7 & 98,4 & 98,9 & 98,5 & 98,5 \\
\hline MLP-617 & $20-5$ & 98,0 & 98,1 & 97,9 & 99,0 & 98,0 & 98,0 & 98,1 & 98,0 & 98,9 & 98,1 & 98,2 & 98,2 \\
\hline MLP-618 & $20-10$ & 98,1 & 98,7 & 98,6 & 98,9 & 98,9 & 98,1 & 98,7 & 98,7 & 98,8 & 99,0 & 98,7 & 98,6 \\
\hline MLP-619 & $20-15$ & 98,7 & 98,5 & 98,6 & 98,3 & 98,4 & 98,6 & 98,5 & 98,7 & 98,2 & 98,5 & 98,5 & 98,5 \\
\hline MLP-620 & $20-20$ & 98,0 & 98,1 & 98,7 & 98,8 & 98,7 & 98,0 & 98,1 & 98,8 & 98,6 & 98,7 & 98,5 & 98,4 \\
\hline
\end{tabular}


Tabela C.32: Resultados do Treinamento e validação das topologias especialistas candidatas (12 entradas e três saídas com os próximos estados da manobra) para o quinto sistema neural (dados com ruídos e com parede), usando o algoritmo Levenberg-Marquardt.

\begin{tabular}{|c|c|c|c|c|c|c|c|c|c|c|c|c|c|}
\hline \multirow[t]{2}{*}{ Ref. } & \multirow{2}{*}{$\begin{array}{l}\text { Neurônios } \\
\text { Escondidos }\end{array}$} & \multicolumn{5}{|c|}{$\begin{array}{c}\text { Treinamento } \\
\text { MAPE (\% acertos) }\end{array}$} & \multicolumn{5}{|c|}{$\begin{array}{c}\text { Validação } \\
\text { MAPE (\% acertos) }\end{array}$} & \multicolumn{2}{|c|}{$\begin{array}{c}\text { Média Final } \\
\text { MAPE }(\% \text { acertos })\end{array}$} \\
\hline & & $\mathrm{C} 1$ & $\mathrm{C} 2$ & $\mathrm{C} 3$ & $\mathrm{C} 4$ & $\mathrm{C} 5$ & $\mathrm{C} 1$ & $\mathrm{C} 2$ & $\mathrm{C} 3$ & $\mathrm{C} 4$ & C5 & Trein. & Val. \\
\hline MLP-621 & 5 & 98,3 & 98,6 & 98,8 & 99,3 & 99,6 & 98,2 & 98,6 & 98,8 & 99,3 & 99,5 & 98,9 & 98,9 \\
\hline MLP-622 & $5-5$ & 98,8 & 98,6 & 97,7 & 93,7 & 98,5 & 98,6 & 98,6 & 97,8 & 93,6 & 98,6 & 97,5 & 97,4 \\
\hline MLP-623 & $5-10$ & 99,6 & 99,3 & 99,6 & 99,1 & 97,9 & 99,5 & 99,3 & 99,5 & 99,0 & 97,8 & 99,1 & 99,0 \\
\hline MLP-624 & $5-15$ & 68,0 & 81,0 & 81,1 & 80,9 & 80,9 & 67,8 & 81,7 & 80,6 & 80,6 & 80,5 & 78,4 & 78,3 \\
\hline MLP-625 & $5-20$ & 98,9 & 99,1 & 99,0 & 99,1 & 99,1 & 98,7 & 99,1 & 99,0 & 99,0 & 99,0 & 99,0 & 99,0 \\
\hline MLP-626 & 10 & 99,3 & 99,3 & 99,5 & 99,1 & 99,5 & 99,2 & 99,3 & 99,5 & 98,9 & 99,4 & 99,4 & 99,3 \\
\hline MLP-627 & $10-5$ & 98,8 & 99,6 & 99,2 & 99,5 & 98,8 & 98,7 & 99,5 & 99,2 & 99,5 & 98,8 & 99,2 & 99,1 \\
\hline MLP-628 & $10-10$ & 99,4 & 99,5 & 99,5 & 99,4 & 99,4 & 99,2 & 99,4 & 99,5 & 99,3 & 99,4 & 99,4 & 99,3 \\
\hline MLP-629 & $10-15$ & 83,9 & 98,9 & 99,2 & 99,1 & 99,2 & 83,5 & 98,9 & 99,1 & 98,7 & 99,0 & 96,0 & 95,8 \\
\hline MLP-630 & $10-20$ & 99,6 & 99,4 & 99,5 & 99,5 & 99,6 & 99,4 & 99,3 & 99,5 & 99,4 & 99,5 & 99,5 & 99,4 \\
\hline MLP-631 & 15 & 99,4 & 99,4 & 99,4 & 99,4 & 99,6 & 99,2 & 99,3 & 99,4 & 99,2 & 99,5 & 99,4 & 99,3 \\
\hline MLP-632 & $15-5$ & 45,6 & 51,5 & 49,1 & 21,2 & 30,8 & 45,5 & 51,2 & 48,6 & 22,1 & 30,9 & 39,7 & 39,7 \\
\hline MLP-633 & $15-10$ & 70,5 & 80,1 & 67,7 & 86,1 & 67,7 & 70,2 & 80,8 & 67,6 & 86,4 & 67,3 & 74,4 & 74,5 \\
\hline MLP-634 & $15-15$ & 99,4 & 99,4 & 99,6 & 99,5 & 99,5 & 99,3 & 99,3 & 99,5 & 99,4 & 99,4 & 99,5 & 99,4 \\
\hline MLP-635 & $15-20$ & 97,8 & 98,5 & 89,9 & 98,9 & 82,3 & 97,3 & 98,3 & 90,3 & 98,3 & 82,1 & 93,5 & 93,2 \\
\hline MLP-636 & 20 & 95,1 & 99,2 & 80,3 & 99,1 & 95,4 & 95,4 & 99,0 & 79,9 & 98,8 & 95,2 & 93,8 & 93,7 \\
\hline MLP-637 & $20-5$ & 98,9 & 99,3 & 99,3 & 99,6 & 99,4 & 98,8 & 99,2 & 99,4 & 99,4 & 99,3 & 99,3 & 99,2 \\
\hline MLP-638 & $20-10$ & 99,1 & 60,5 & 99,1 & 98,6 & 98,6 & 99,0 & 60,7 & 98,9 & 98,3 & 98,6 & 91,2 & 91,1 \\
\hline MLP-639 & $20-15$ & 86,9 & 95,2 & 80,5 & 86,6 & 76,0 & 86,7 & 95,2 & 80,7 & 85,9 & 76,4 & 85,1 & 85,0 \\
\hline MLP-640 & $20-20$ & 99,7 & 99,4 & 99,3 & 99,5 & 99,5 & 99,3 & 99,3 & 99,1 & 99,4 & 99,3 & 99,5 & 99,3 \\
\hline
\end{tabular}

